UNIVERSIDADE DE SÃO PAULO

Instituto de Química de São Carlos

\title{
ELETRÓLITOS SÓLIDOS POLIMÉRICOS À BASE DE POLISSACARÍDEOS: SÍNTESE E CARACTERIZAÇÃO
}

Anelise Maria Regiani

Tese apresentada ao Instituto de Química de São Carlos, da Universidade de São Paulo para obtenção do título de Doutor em Ciências na área de Físico-química

Orientador: Profa. Dra. Agnieszka Joanna Pawlicka Maule

São Carlos

2000 

Pouca ciência afasta de Deus.

Muita, a Ele reconduz.

Louis Pasteur 
Que a Profa. Dra. Agnieszka Pawlicka encontre aqui a expressão do meu agradecimento pela confiança em meu trabalho e paciência em orientar-me.

Ao Prof. Dr. Aprigio Curvelo agradeço as significativas observações e sugestões.

Exprimo meu reconhecimento ao Prof. Dr. Alessandro Gandini por me receber em seu grupo de pesquisa. Sua competência científica e seus conselhos foram um porto seguro na realização deste trabalho.

Agradeço ao Prof. Dr. Jean-François Le Nest na amabilidade, constante disponibilidade e pelos numerosos conselhos e encorajamento.

Ao Prof. Dr. José Pedro Donoso e ao colega de doutorado Caio Eduardo Tambelli meu obrigado pela realização e discussão dos estudos de ressonância magnética nuclear.

Devo também agradecer ao Prof. Dr. Alain Dufresne pela sua colaboração nas análises de DMTA.

Não poderia esquecer do assessor FAPESP pelos valiosos comentários e sugestões; muito obrigada.

Meu profundo agradecimento aos colegas do grupo de físico-química orgânica pela prazerosa convivência.

Também agradeço às amigas Sandrine Waigfang, Vanessa Durrieu, Hélène Bernard e aos colegas do Laboratoire des Materiaux Polymères da EFPG (Grenoble) pelos bons momentos na França.

Agradeço a ajuda preciosa das Irmãs Filles de Marie (Michele, Ivone, Marthe, M. Madeleine et M. Ferriole) pela estada tão agradável em sua casa.

Aos meus amigos italianos Davide, Guido, Andrea e Claudia: gracie per $i$ momenti divertiti.

Meu obrigado à mia cara Elisa Zeno (la mia picolla sorella) e i suoi genitori. Non dimenticheró mai la cortesia che ho trovato a casa sua. 
Aos amigos do Mosteiro de São Bento em Brasília, em especial D. Mauro, D. Justino e D. Guilherme, pela amizade, atenção, paciência e conselhos.

Muito obrigada ao Pe. Antônio Heggendorn pela infinita paciência.

Muito mais que obrigada às minhas queridas amigas Ana Paula Joaquim e Ana Paula M. Camargo por todos estes anos de convivência e troca de experiências.

Aos meus pais, Claudari e Liliam, que com seu amor e dedicação me levam a alcançar tão belos horizontes. Não existem palavras para exprimir todo o meu agradecimento.

Ao Mozamô Rogério por me dar seu coração.

À FAPESP pelo apoio financeiro e à UNION CARBIDE do Brasil pelas amostras de hidroxietil celulose.

Enfim, agradeço à todos que de alguma forma colaboraram para a realização deste trabalho. 
S UMÁRIO

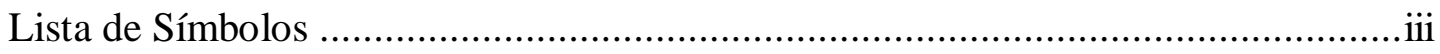

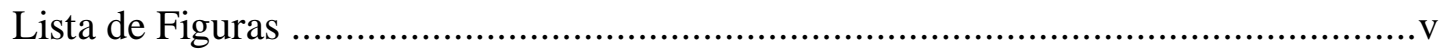

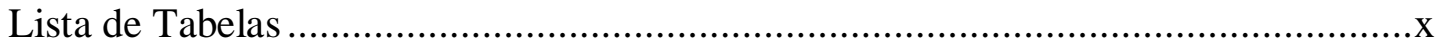

Resumo

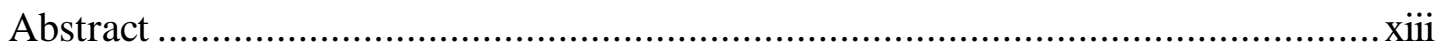

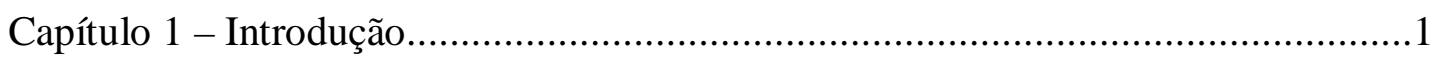

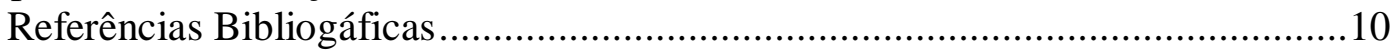

Capítulo 2 - Filmes de polissacarídeos enxertados com poliéteres.............................15

2.1 - Caracterização dos polissacarídeos ...........................................................15

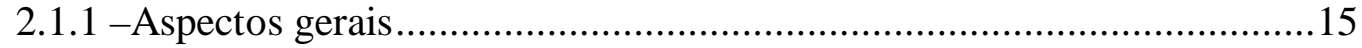

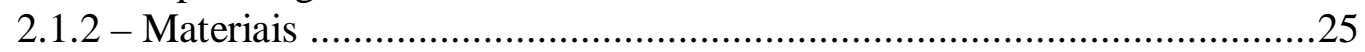

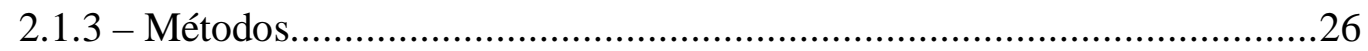

2.1.3.1 - Análise de difração de raios-X ......................................................26

2.1.3.2 - Análise por espectroscopia no infravermelho ................................26

2.1.3.3 - Análise por espectroscopia de ressonância magnética nuclear .......27

2.1.3.3.1 - Ressonância magnética nuclear de próton ................................22

2.1.3.3.2 - Ressonância magnética nuclear de carbono ...............................28

2.1.3.4 - Determinação de massa molar por técnica viscosimétrica...............29

2.1.3.5 - Análises Térmicas ........................................................................31

2.1.3.5.1 - Calorimetria Diferencial Exploratória (DSC) ………………....32

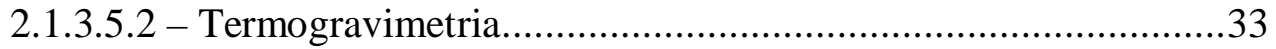

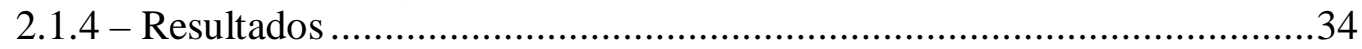

2.1.4.1 - Determinação dos parâmetros estruturais de hidroxietil celulose ...40

2.1.4.2 - Determinação dos parâmetros estruturais de hidroxipropil celulose

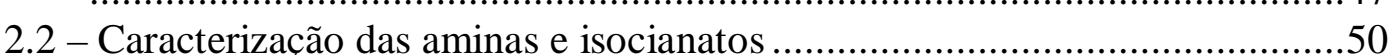

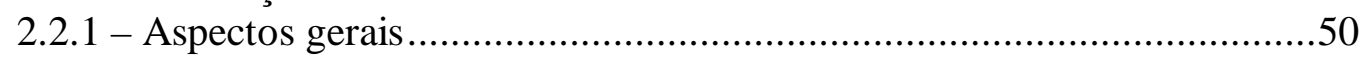

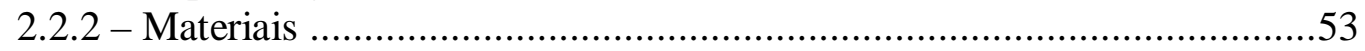

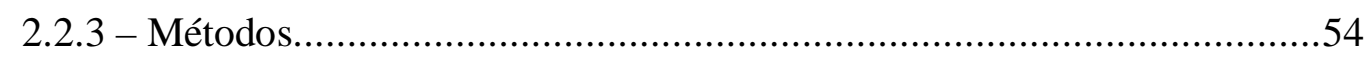

2.2.3.1 - Prurificação dos solventes e dos reagentes …………………….....54

2.2.3.2 - Caracterização das aminas ..........................................................54

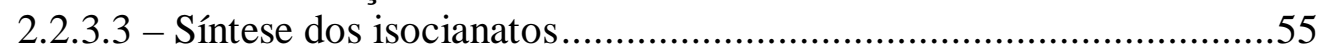

2.2.3.4 - Caracterização dos isocianatos ....................................................57

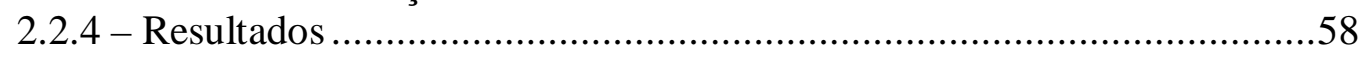

2.2.4.1 - Caracterização das aminas ............................................................58 
2.2.4.2 - Síntese e caracterização dos isocianatos.......................................60 60

2.3 - Síntese dos filmes de polissacarídeos enxertados com poliéteres ................63 63

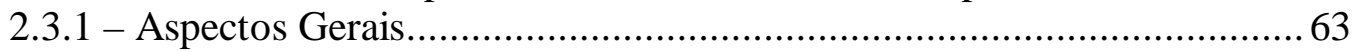

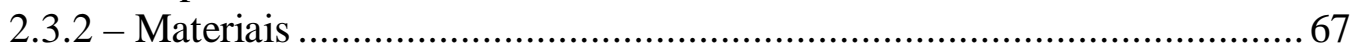

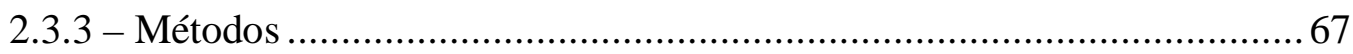

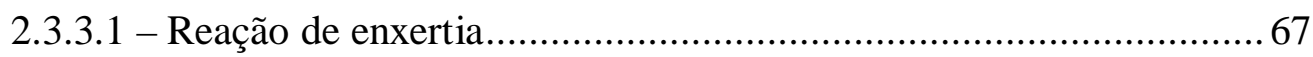

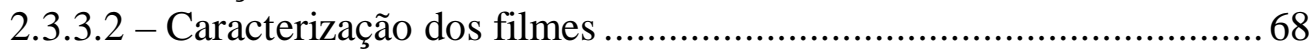

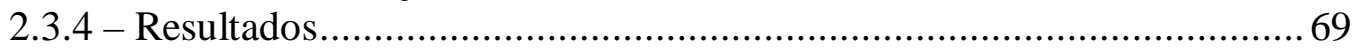

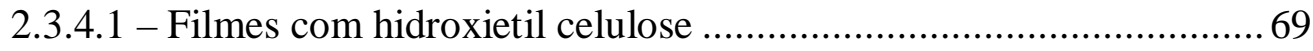

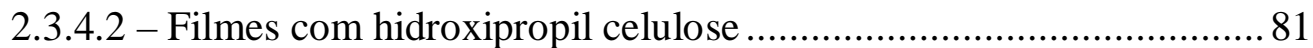

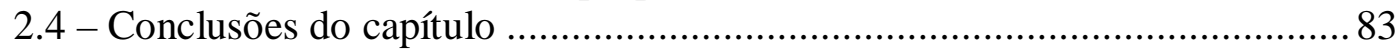

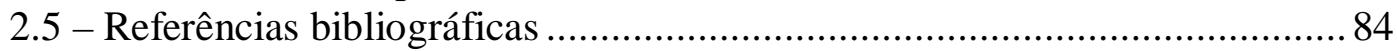

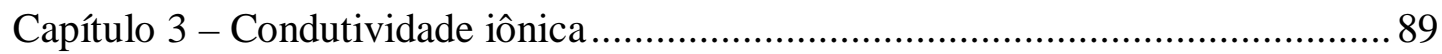

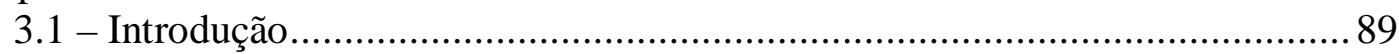

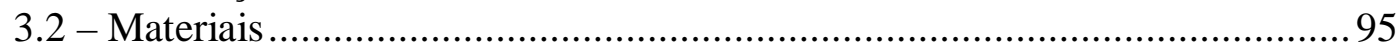

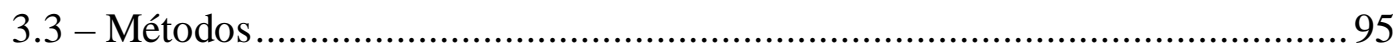

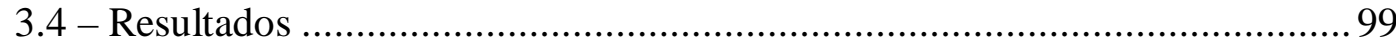

3.4.1 - Eletrólitos sólidos poliméricos à base de hidroxietil celulose enxertada

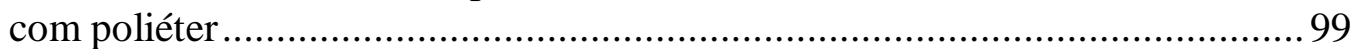

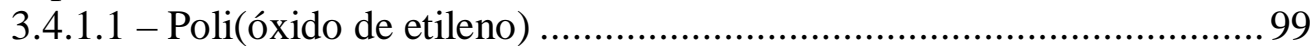

3.4.1.2 - Poli(óxido de propileno) ............................................................ 106

3.4.2 - Eletrólitos sólidos poliméricos à base de hidroxipropil celulose

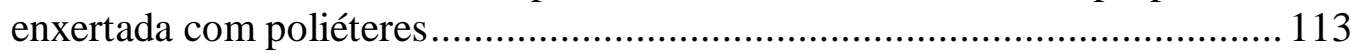

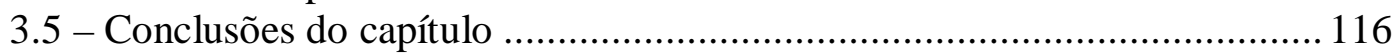

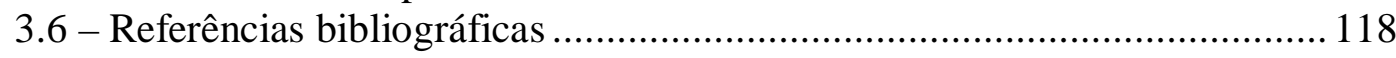

Capítulo 4 - Ensaios com isocianatos comerciais.............................................. 121

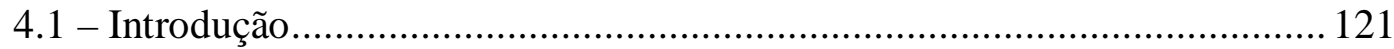

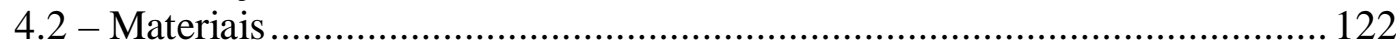

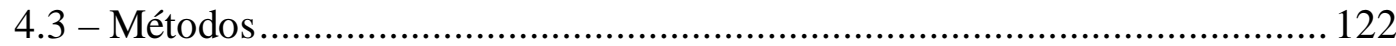

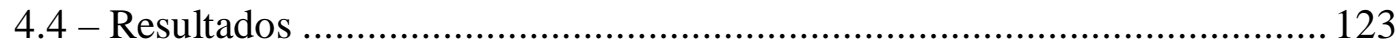

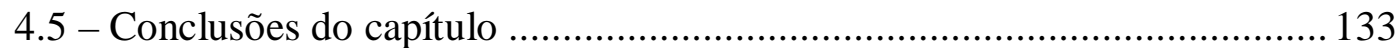

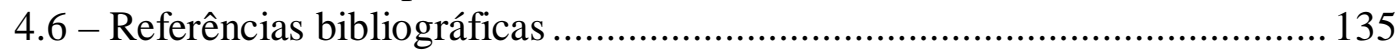

Capítulo 5 - Estudos de Ressonância Magnética Nuclear..................................... 137

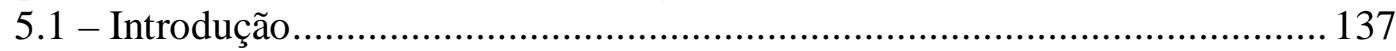

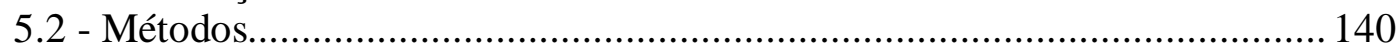

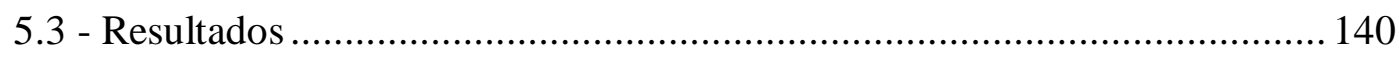

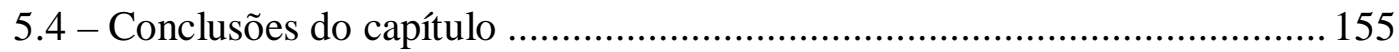

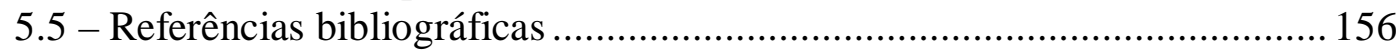

Capítulo 6 - Conclusões e perspectivas.................................................................. 159 
$\mathcal{L I S T \mathcal { D E }} \mathcal{S} I \mathcal{M B O} L O S$

$\tau_{\mathrm{c}} \quad$ tempo de correlação

$1 / \mathrm{T}_{1} \quad$ taxa de relaxação

DMTAanálise termodinâmico-mecânica

DP grau de polimerização

DPOE diisocianato de poli (óxido de etileno)

DPOP diisocianato de poli (óxido de propileno)

DS grau de substituição

DSC calorimetria diferencial exploratória

HDI hexametileno diisocianato

HEC hidroxietil celulose

HPC hidroxipropil celulose

MPOP monoisocianato de poli (óxido de propileno)

MS grau de substituição molar

PhNCO fenil isocianato

POE poli(óxido de etileno)

$\mathrm{Tg}$ temperatura de transição vítrea

TG termogravimetria

VTF equação de Vogel-Tamman-Fulcher

WLF equação de Williams-Landel-Ferry 


\section{LIS TA $\mathcal{D E}$ FI GURAS}

Figura 1. 1: Esquema de bateria de lítio

Figura 1. 2: Modos de solvatação dos cátions $\left(\mathrm{Li}^{+}\right)$pelos átomos de oxigênio de uma cadeia polimérica: (a) solvatação por uma única cadeia; (b) solvatação por duas cadeias

Figura 2. 1: Estrutura da celulose a partir da $\beta$-D-glicopiranose destacando a unidade básica repetitiva (celobiose) e extremidades redutora e não redutora......

Figura 2. 2: Representação das ligações hidrogênio presentes na estrutura cristalina da celulose. A) ligações hidrogênio intermolecular e B) ligação hidrogênio intramolecular

Figura 2. 3: Principais planos cristalinos da cela unitária da celulose I ...................20

Figura 2. 4: Difratograma de raios- $\mathrm{X}$ de vários tipos de celulose ${ }^{8}$..........................20

Figura 2. 5: Modelo de estrutura de hidroxietil celulose .......................................23

Figura 2. 6: Modelo de estrutura para hidroxipropil celulose .................................24

Figura 2. 7: Comparação esquemática das técnicas de TG e DSC ...........................34

Figura 2. 8: Difratogramas de raios-X das várias amostras comerciais de hidroxietil celulose

Figura 2. 9: Sobreposição de espectros no infravermelho de celulose microcristalina AVICEL, hidroxietil celulose (QP09H) e hidroxipropil celulose (Aldrich43,500-7)

Figura 2. 10: Curvas de análise térmica (DSC e TG) para amostra QP15MH de hidroxietil celulose; fluxo de nitrogênio

Figura 2. 11: Curvas de análise térmica (DSC e TG) para amostra de hidroxipropil celulose (Aldrich 19,188-4); fluxo de nitrogênio

Figura 2. 12: Espectro de ${ }^{1} \mathrm{H}-\mathrm{RMN}$ de hidroxietil celulose QP09H hidrolisada em $\mathrm{HCl}$......

Figura 2. 13: Espectro de ${ }^{13} \mathrm{C}-\mathrm{RMN}$ de HEC QP09H em DMSO $d_{6}$ e deslocamentos químicos 
Figura 2. 14: Gráfico de grau de substituição (DS) versus grau de substituição molar (MS) para amostras de hidroxietil celulose; (a): obtido para as amostras analisadas; (b): hipotético para a síntese do polissacarídeo

Figura 2. 15: Espectro de ${ }^{1} \mathrm{H}-\mathrm{RMN}$ de hidroxipropil celulose (Aldrich - 19,188-4) em clorofórmio deuterado; A: área relativa aos hidrogênios do grupo $\mathrm{CH}_{3}$ do substituinte; B: área relativa aos hidrogênios do anel de anidroglicose e dos grupos $\mathrm{CH}_{2}$ e $\mathrm{CH}$ da substituição

Figura 2. 16: Espectro de ressonância magnética nuclear de carbono de hidroxipropil celulose (Aldrich 19,188-4); (a) pico dos hidrogênios metílicos terminais na cadeia de substituinte; (b) pico dos hidrogênios metílicos internos ao substituinte

Figura 2. 17: Esquema de síntese de isocianato a partir de amina e fosgênio ...........50

Figura 2. 18: Esquema de síntese de isocianato a partir de amina e trifosgênio........52

Figura 2. 19: Esquema de reação de isocianato com álcool para formação de uretana

Figura 2. 20: Aparato usado para a síntese dos isocianatos 56

Figura 2. 21: Estruturas das aminas comerciais utilizadas como precursoras dos isocianatos; A: O,O'-(2-aminopropil) polipropilenoglicol (JEFFAMINE D400); B: O,O'-(2-aminopropil) polietilenoglicol (JEFFAMINE ED600); C: O-(2aminopropil)-O'-(2-metoxietil) polipropilenoglicol (JEFFAMINE M600) ......58

Figura 2. 22: Espectros no infravermelho das aminas comerciais utilizadas 59

Figura 2. 23: Espectro no infravermelho de diisocianato de poli(óxido de etileno) (DPOE1) sintetizado a partir de JEFFAMINE ED600 (banda de absorção em $2250 \mathrm{~cm}^{-1}$ é característica de grupo NCO)

Figura 2. 24: Representação esquemática do catalisador dibutil-dilaurato de estanho

Figura 2. 25: Representação do mecanismo de catálise na graftização de poliálcool com isocianatos

Figura 2. 26: Esquema simplificado da estrutura de rede de hidroxietil celulose entrecruzada com diisocianato de poli(óxido de etileno)

Figura 2. 27: Espectro no infravermelho de hidroxietil celulose (QP4400) enxertada com diisocianato de poli(óxido de etileno) (DPOE1) ...................................70

Figura 2. 28: Difratograma de raios-X de rede de hidroxietil celulose (QP4400) enxertada com diisocianato de poli(óxido de etileno) (DPOE1).....

Figura 2. 29: Análise de calorimetria exploratória diferencial de rede de hidroxietil celulose (QP4400) enxertada com diisocianato de poli(óxido de etileno) (DPOE1).

Figura 2. 30: Dependência do inverso de Tg em função da concentração de $\mathrm{LiClO}_{4}$ (PEO 1050, 2100 e 3800 foram entrecruzados com Desmodur R) ${ }^{35,43}$

Figura 2. 31: Variação do inverso de $\mathrm{Tg}$ em função da concentração de $\mathrm{LiClO}_{4}$; 40D $=[\mathrm{NCO}] /[\mathrm{OH}]=0,4 ; 60 \mathrm{D}=[\mathrm{NCO}] /[\mathrm{OH}]=0,6 ; 50 \mathrm{D}+25 \mathrm{M}=[\mathrm{NCO}]_{\mathrm{DPOE}} /[\mathrm{OH}]$ $=0,5$ 
Figura 2. 32: Curvas de análise termodinâmico-mecânicas para filmes de hidroxietil celulose enxertada com poliéter e dopados com $\mathrm{LiClO}_{4}$.

Figura 2. 33: Difratogramas de raios-X de filmes de HPC 19,189-2 entrecruzadas com diisocianato de poli(óxido de propileno) (DPOP) com e sem sal de lítio ..82

Figura 3. 1: Transferência de dipolo promovida pelos movimentos dos segmentos poliméricos; (1) dissociação de quadrupolos; (2) dissociação de dipolos; (3) deslocamento iônico.....

Figura 3. 2: Cela de medida utilizada nos experimentos de determinação de condutividade dos ESP: (1) contato do eletrodo superior; (2) tubo em aço inox, dentro do qual se encontra o termopar; (3) tampa com rosca; (4) junta para vedação; (5) junta em vidro; (6) contato do eletrodo inferior; (7) conjunto do porta amostras (no detalhe); (8) eletrodo superior em inox; (9) amostra; (10) eletrodo inferior; (11) junta; (12) guia do porta amostras (em teflon); (13) capa metálica; (14) solda vidro-metal; (15) conjunto em vidro pyrex; (16) mola de compensação; (17) termopar.

Figura 3. 3: Representação da voltagem e corrente sinusoidais, a uma dada freqüência, associada a uma cela eletroquímica; $v=$ voltagem, $i=$ corrente, $\theta=$ ângulo de fase entre voltagem e corrente

Figura 3. 4: Representação da impedância, $Z$, de uma cela eletroquímica no diagrama vetorial. $Z$ ' e $Z$ " são respectivamente as correspondentes real e imaginária da impedância complexa $Z^{*}=Z^{\prime}-j Z^{\prime}$.

Figura 3. 5: Curvas log-log de condutividade iônica $(\sigma)$ em função de concentração de $\mathrm{LiClO}_{4}$ para vários eletrólitos sólidos poliméricos (referências 10 e 11)....100

Figura 3. 6: Diagramas de logaritmo de condutividade em função do inverso de temperatura para eletrólitos sólidos poliméricos com matriz de hidroxietil celulose entrecruzada com poli(óxido de etileno)

Figura 3. 7: Estudo da influência de MS da hidroxietil celulose e da razão

$[\mathrm{NCO}] /[\mathrm{OH}]$ nos valores de logaritmo de condutividade a $60^{\circ} \mathrm{C}$ para os eletrólitos sólidos poliméricos sintetizados com DPOE2.

Figura 3. 8: Diagramas de logaritmo de condutividade em função do inverso de temperatura para filmes de hidroxietil celulose entrecruzada com poli(óxido de propileno) a várias razões de entrecruzamento.

Figura 3. 9: Estudo da influência de MS da hidroxietil celulose e da razão

$[\mathrm{NCO}] /[\mathrm{OH}]$ nos valores de logaritmo de condutividade a $60^{\circ} \mathrm{C}$ para os eletrólitos sólidos poliméricos sintetizados com DPOP2

Figura 3. 10: Diagramas de logaritmo de condutividade em função do inverso da temperatura para filmes de hidroxietil celulose enxertada com monoisocianato de poli(óxido de propileno) a várias razões de enxertia

Figura 3. 11: Estudo da influência de MS da hidroxietil celulose e da razão $[\mathrm{NCO}] /[\mathrm{OH}]$ nos valores de logaritmo de condutividade a $60^{\circ} \mathrm{C}$ para os eletrólitos sólidos poliméricos sintetizados com MPOP1 
Figura 3. 12: Diagrama do tipo Arrhenius para os eletrólitos sólidos poliméricos com matriz de hidroxipropil celulose enxertada com poliéteres.

Figura 4. 1 : Modelo de estrutura do hexametileno diisocianato (HDI).................. 124

Figura 4. 2: Espectro no infravermelho de hexametileno diisocianato (HDI)......... 124

Figura 4. 3: Modelo de estrutura de fenil isocianato............................................ 125

Figura 4. 4: Espectro no infravermelho de fenil isocianato

Figura 4. 5: Curva de calorimetria diferencial exploratória de redes de hidroxietil celulose (HEC) graftizadas com hexametileno diisocianato (HDI) ...

Figura 4. 6: Curva de calorimetria diferencial exploratória de redes de hidroxietil celulose (HEC) graftizadas com fenil isocianato ( $\mathrm{PhNCO}$ ).

Figura 4. 7: Difratograma de raios-X de hidroxietil celulose QP300H graftizada com hexametileno diisocianato

Figura 4. 8: Difratograma de raios-X de hidroxietil celulose QP300H graftizada com fenil isocianato.

Figura 4. 9: Espectro no ultravioleta de redes de hidroxietil celulose graftizadas com fenil isocianato.

Figura 4. 10: Espectro no infravermelho de hidroxietil celulose grafitizada com hexametileno diisocianato

Figura 4. 11: Diagrama do tipo Arrhenius para condutividade das amostras de hidroxietil celulose QP300H e QP15MH derivatizadas com fenilisocianato .. 133

Figura 5. 1: Dependência da largura de linha de ${ }^{1} \mathrm{H}-\mathrm{RMN}$ com a temperatura para filmes de HECQP300H/DPOE (O) e HECQP300H/DPOE/LiClO 4

Figura 5. 2: Dependência da taxa de relaxação de próton, $1 / T_{1}$, com a temperatura dos filmes HEC QP300H/DPOE (O); HECQP300H/DPOP $(\Delta)$

Figura 5. 3: Dependência com a temperatura da taxa de relaxação spin-rede, $1 / T_{1}$, de eletrólitos sólidos poliméricos com matriz de hidroxietil celulose entrecruzada com diisocianato de poli(óxido de etileno) dopados com $\mathrm{LiClO}_{4}$ 146

Figura 5. 4: Espectro de ${ }^{7} \mathrm{Li}-\mathrm{RMN}$ de amostra HEC/QP30MH/DPOE/LiClO 4 obtida a partir da transformada de Fourrier do sinal FID a 183K. (a) Espectro de ${ }^{7} \mathrm{Li}$ RMN (b) Espectro de ${ }^{7} \mathrm{Li}-\left\{{ }^{1} \mathrm{H}\right\}$ desacoplado 149

Figura 5. 5: Dependência com a temperatura de taxa de relaxação spin-rede de ${ }^{7} \mathrm{Li}$ para os filmes de HEC QP300H, QP4400, QP30MH entrecruzados com DPOE e dopados com $\mathrm{LiClO}_{4}$ 
Figura 5. 6: Dependência com a temperatura dos tempos de correlação de ${ }^{7} \mathrm{Li}$ e ${ }^{1} \mathrm{H}$ calculados a partir dos parâmetros de mobilidade obtidos em experimentos de $\mathrm{RMN}$, assumindo comportamento Arrhenius para $\tau_{c}$. As linhas cheias correspondem aos eletrólitos sólidos poliméricos com matriz de hidroxietil celulose entrecruzada com poli(óxido de etileno): (1) QP4400; (2) QP30MH; (3) QP300H. As curvas tracejadas correspondem aos dados da literatura: (4) $\mathrm{PPO}_{6} \mathrm{LiBF}_{4}$; (5) $\mathrm{PEO}_{8} \mathrm{LiClO}_{4}$; (6) $\mathrm{PEG}_{10} \mathrm{LiCF}_{3} \mathrm{SO}_{3}$; (7) $\mathrm{PPG}_{8} \mathrm{LiCF}_{3} \mathrm{SO}_{3}{ }^{14}$; (8) $\mathrm{PPO}_{8} \mathrm{LiClO}_{4}{ }^{23}$ 


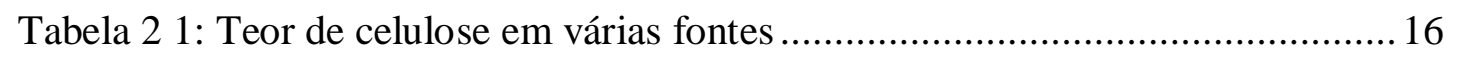

Tabela 2. 2: Principais derivados de celulose ........................................................ 22

Tabela 2. 3: Solubilidade da hidroxietil celulose em vários solventes...................... 24

Tabela 2. 4: Valores de grau de substituição molar de amostras de hidroxietil

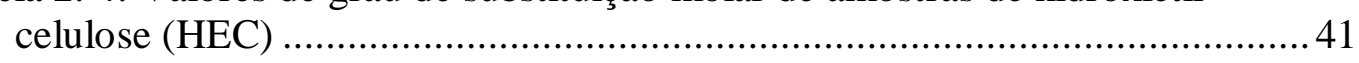

Tabela 2. 5: Deslocamentos químicos em ${ }^{13} \mathrm{C}$-RMN para $\beta$-D-glicose, celulose e alguns derivados do tipo éter................................................................ 43

Tabela 2. 6: Resultados de caracterização de HEC através de técnicas de espectroscopia de ressonância magnética nuclear ........................................ 45

Tabela 2. 7: Resultados de viscosimetria de amostras de HEC em solução aquosa .. 46

Tabela 2. 8: Valores dos parâmetros estruturais determinados para as amostras de

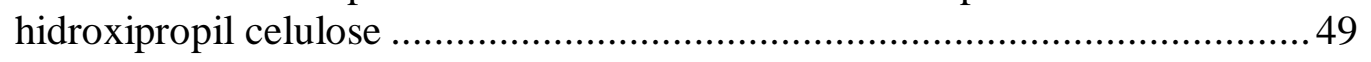

Tabela 2. 9: Massas molares e principais bandas de absorção no infravermelho

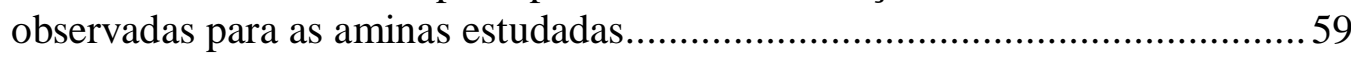

Tabela 2. 10: Deslocamentos químicos de carbono e hidrogênio em experimento de RMN das aminas precursoras dos isocianatos ...........................................6 60

Tabela 2. 11: Teores de função NCO nos isocianatos sintetizados e porcentagem de

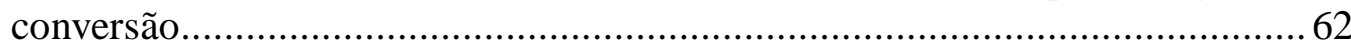

Tabela 2. 12: Valores de Tg para os filmes obtidos de hidroxietil celulose enxertada

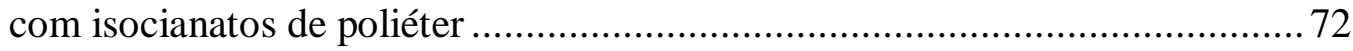

Tabela 2. 13: Teor de extrativos nos filmes de hidroxietil celulose enxertadas com diisocianato de poli(óxido de etileno) - DPOE1 e diisocianato de poli(óxido de

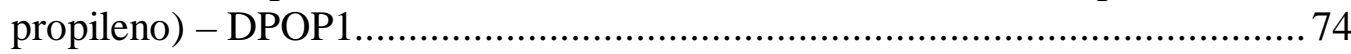

Tabela 2. 14: Concentração de sal dos filmes de hidroxietil celulose dopados com

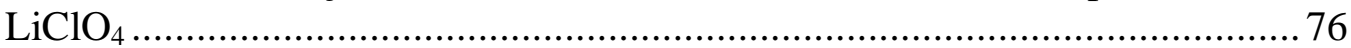

Tabela 2. 15: Valores de temperatura de transição vítrea para os filmes de hidroxietil

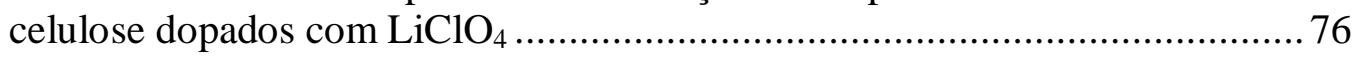

Tabela 2. 16: Valores de temperatura de transição vítrea para filmes de hidroxipropil celulose enxertada com poliéter .......................................................... 82 
Tabela 2. 17: Valores de concentração de $\mathrm{LiClO}_{4}$ e temperatura de transição vítrea para filmes de hidroxipropil celulose enxertados com poliéter.

Tabela 3. 1: Parâmetros obtidos a partir do ajuste VTF e WLF dos resultados experimentais de condutividade para filmes de HEC/DPOE2 dopados com $\mathrm{LiClO}_{4}$

Tabela 3. 2: Parâmetros obtidos a partir do ajuste VTF e WLF dos resultados experimentais de condutividade para filmes de HEC/DPOP2 dopados com $\mathrm{LiClO}_{4}$

Tabela 3. 3: Parâmetros obtidos a partir do ajuste VTF e WLF dos resultados experimentais de condutividade para filmes de HEC/MPOP1 dopados com $\mathrm{LiClO}_{4}$

Tabela 3. 4: Resultados do ajuste VTF e constantes WLF para filmes de hidroxipropil celulose enxertados com poliéter

Tabela 4. 1: Principais bandas de absorção no infravermelho observadas para o hexametileno diisocianato (HDI)

Tabela 4. 2: Deslocamentos químicos dos hidrogênios no espectro de ressonância magnética nuclear do hexametileno diisocianato (HDI)

Tabela 4. 3: Principais bandas de absorção observadas no espectro no infravermelho de fenil isocianato

Tabela 4. 4: Valores de temperatura de transição vítrea (Tg) de filmes de hidroxietil celulose (HEC) graftizada com isocianatos comerciais (hexametileno diisocianato - HDI- e fenil isocianato - PhNCO)

Tabela 4. 5: Resultados do ajuste VTF e constantes WLF para filmes de hidroxietil celulose entrecruzados com fenilisocianato e dopados com $\mathrm{LiClO}_{4}$

Tabela 5. 1: Parâmetros obtidos a partir de experimentos de RMN de ${ }^{1} \mathrm{H} \mathrm{e}{ }^{7} \mathrm{Li}$ dos eletrólitos sólidos poliméricos com matriz de hidroxietil celulose graftizada com diisocianato de poli(óxido de etileno) e dopadas com $\mathrm{LiClO}_{4} . \Delta H_{\text {res }}$ é a largura de linha residual de ${ }^{7} \mathrm{Li}$ após o desacoplamento de próton; $T_{\max }$ é a temperatura no máximo de taxa de relaxação e $E_{a}$ é a energia de ativação para o movimento responsável pela relaxação 
A síntese e a caracterização de um novo tipo de eletrólito sólido polimérico são descritas neste trabalho. Os materiais preparados consistiram de filmes de hidroxietil celulose ou hidroxipropil celulose entrecruzadas com diisocianatos de poli(óxido de etileno) e poli(óxido de propileno) ou enxertadas com monoisocianato de poli(óxido de propileno). Todos estes isocianatos foram sintetizados a partir das respectivas aminas comerciais. Filmes de hidroxietil celulose entrecruzada com hexametileno diisocianato ou enxertados com fenil isocianato também foram estudados. Como técnicas de caracterização foram utilizadas espectroscopia no infravermelho, no ultravioleta e de ressonância magnética nuclear, análises térmicas e difração de raios-X. Os filmes dopados com $\mathrm{LiClO}_{4}$ foram caracterizados utilizando-se as mesmas técnicas e a condutividade foi determinada através do método de impedância complexa. Os resultados foram da ordem de $10^{-5} \mathrm{Scm}^{-1}$ a $60^{\circ} \mathrm{C}$. Este valor permitiu concluir que as cadeias de derivado de celulose parecem não influenciar no fenômeno de condução; aparentemente este encontra-se mais relacionado ao tipo de isocianato utilizado na formação do filme. Os resultados de condutividade e de mobilidade de cadeia polimérica indicam que os sistemas aqui estudados podem ser aplicados como eletrólitos sólidos poliméricos. Os filmes com isocianatos comerciais, no entanto não apresentaram resultado de condução interessante. 
The synthesis and characterization of new types of solid polymer electrolytes based on hydroxyethyl and hydroxypropyl cellulose grafted with different polyethers were investigated. The synthesis is based on the reaction between the cellulose derivative and mono and difunctional isocyanates prepared from amines of polyethylene oxide and polypropylene oxide. It were also synthesized films of hydroxyethyl cellulose grafted with hexamethylene diisocyanate and phenylisocyanate. These materials were characterized through techniques of infrared, ultraviolet and nuclear magnetic ressonance spectroscopies, thermal analysis and $\mathrm{X}$ ray diffraction. The films of polysaccharide and polyether that contained $\mathrm{LiClO}_{4}$ showed conductivity values of the order of $10^{-5} \mathrm{Scm}^{-1}$ at $60^{\circ} \mathrm{C}$. The value of this parameter seems to be independent of the cellulose derivative parameters and it is better related to the type of isocyanate grafted on the polysaccharide chain. The conductivity and chain mobility results show that the systems studied here can be applied as solid polymer electrolytes. The materials synthesized using commercial isocyanates as grafting reactant did not show interesting conductivity response. 


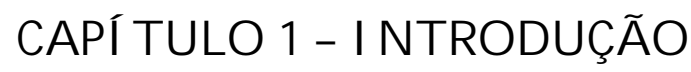

No final do século XIX Thomas Edison declara": "Um dispositivo de armazenamento de energia, uma bateria, é um caça níqueis, uma sensação, uma maneira de enganar o público promovida pela indústria. É uma coisa peculiar que apela para a imaginação - algo mais perfeito não poderia ser desejado... mas tão logo alguém comece a trabalhar nisto, ficará latente a sua capacidade de mentir. Cientificamente o armazenamento de energia é possível, mas comercialmente o mais absoluto fracasso que se pode imaginar."

Apesar do pessimismo do famoso inventor do século XIX (autor de 1093 patentes), o mercado de baterias no século XX explodiu em um negócio mutibilionário $^{1}$. E ainda, um crescimento maior do setor está previsto para o próximo século. Pesquisadores têm se esmerado na investigação de novos dispositivos, recarregáveis ou não, de longa duração, menores, mais leves, mais seguros e mais baratos. A demanda de mercado é intensa: o número de telefones celulares e computadores portáteis comercializados tem aumentado vertiginosamente. E também, com o atual consenso ecológico veículos elétricos têm sido vistos com alternativa promissora para o controle da poluição urbana. Em todos estes casos, qual usuário não gostaria de ter acoplada ao seu equipamento uma bateria que permitisse a sua utilização durante horas intermináveis? 
Uma bateria é selecionada comercialmente pelo seu tempo de vida e custo por kWh de descarga. Dentre as baterias comerciais a de chumbo ácido dificilmente alcança $35 \mathrm{Wh} / \mathrm{kg}$ e a de níquel/cádmio ${ }^{2}$ tem densidade de energia entre 45 e 50 $\mathrm{Wh} / \mathrm{kg}$; além destes materiais possuírem características diferentes, estes valores podem ser considerados insuficientes em determinadas aplicações. Mais recentemente, baterias de níquel/hidreto metálico, baseadas em eletrólitos líquidos, têm sido comercializadas e alcançam $70 \mathrm{Wh} / \mathrm{kg}^{2}$. De acordo com o diretor de marketing da Benchmarq Microeletronics ${ }^{1}$, foram industrializadas em 1997 1,5 bilhões de baterias de níquel/cádmio, 500 milhões de níquel/hidreto metálico e 200 milhões de baterias de lítio. Esta última tem o mercado aparentemente mais promissor devido à sua alta energia específica que pode chegar à $125 \mathrm{Wh} / \mathrm{kg}^{1,2}$.

Utilizada em sistemas recarregáveis ou não, as baterias baseadas em líto operam em voltagem mais alta e fornecem mais eletricidade que outras baterias de mesmo tamanho e peso. Estas características são dadas pela baixa densidade do lítio $\left(0,51 \mathrm{~g} / \mathrm{cm}^{3}\right)$ e alto potencial padrão de redução $\left(-3,01 \mathrm{~V} \text { a } 25^{\circ} \mathrm{C}\right)^{1}$. A figura 1.1 representa esquematicamente uma bateria de lítio ${ }^{2}$ composta por um ânodo de carbono e lítio metálico, cátodo formado por eletrodo constituído geralmente de óxido de vanádio ou manganês e um eletrólito que é uma solução contendo sal de lítio dissolvido em solvente orgânico ou em matriz polimérica.

Durante a descarga da cela, o lítio é oxidado no ânodo segundo a equação redox: $\mathrm{Li}^{0} \rightarrow \mathrm{Li}^{+}+1 \mathrm{e}$; enquanto que os cátions $\mathrm{Li}^{+}$depositam-se no cátodo. $\mathrm{A}$ reação inversa ocorre durante o recarregamento da bateria. Devido à alta reatividade do lítio metálico, muitos fabricantes não produzem baterias de alta densidade de carga com eletrólitos líquidos ou na forma de gel. Como alternativa podem ser utilizados eletrólitos sólidos poliméricos ou cerâmicas do tipo ORMOCER ou 
ORMOLYTES ${ }^{3}$. A utilização de eletrólitos sólidos poliméricos é favorecida porque a flexibilidade dos filmes confere melhor contato com os eletrodos durante a operação da bateria $^{2,4}$.

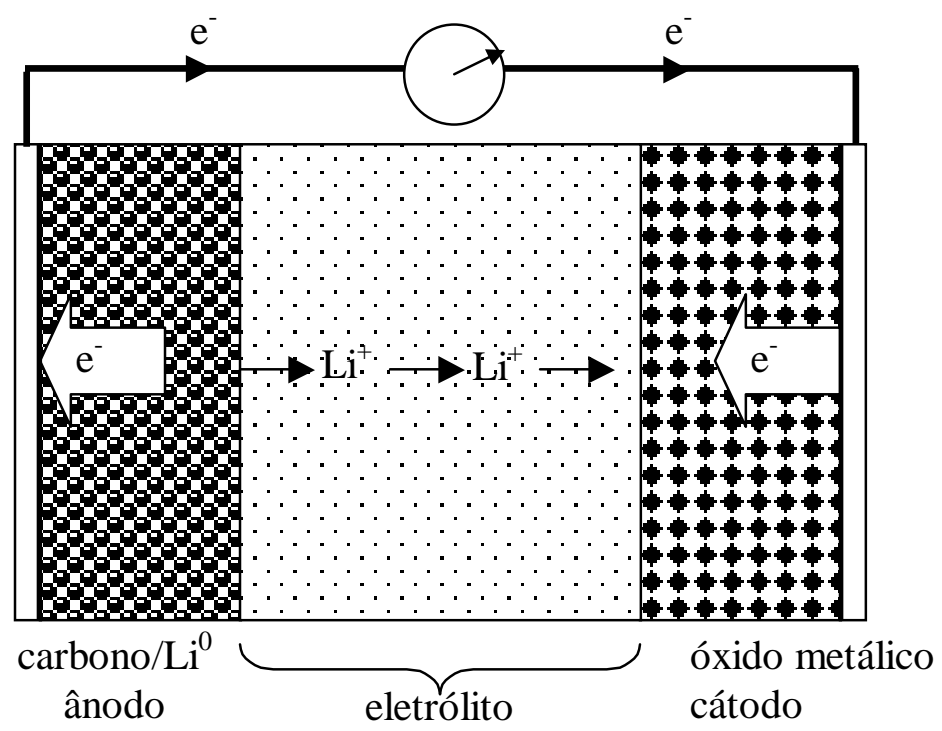

Figura 1. 1: Esquema de bateria de lítio

Os primeiros materiais utilizados para a substituição dos eletrólitos líquidos foram os géis poliméricos, ou seja, materiais poliméricos com grande quantidade de plasticizante adicionada à sua estrutura ${ }^{5}$. Estes sistemas mostraram bom desempenho relacionado à alta mobilidade iônica e alta concentração de transportadores de carga. Entretanto, não possuem estabilidade química e eletroquímica adequada. Nos últimos anos as pesquisas têm como objetivo o desenvolvimento de eletrólitos sólidos poliméricos, ou seja, materiais que consistem em um sal dissolvido em uma matriz polimérica de alta massa molar. Este tipo de eletrólito deve possuir como características: estabilidade em contato com os eletrodos de lítio ou outros materiais oxidantes, resistência (a fim de conservar as propriedades de adesão e manter os 
contatos elétricos durante a operação), disponibilidade e fabricação em processos tecnológicos de baixo custo ${ }^{4}$.

A propriedade mais comum reportada para eletrólitos sólidos poliméricos é a condutividade iônica como função da temperatura ${ }^{6,7}$. Em uma primeira etapa, os cátions $\mathrm{Li}^{+}$, formados na dissociação do sal, coordenam-se com as espécies capazes de solvatá-los ${ }^{7}$. Polímeros que contém átomos doadores de elétrons, como o oxigênio, aparecem como os melhores candidatos, pois solvatam adequadamente as espécies responsáveis pela condução. A figura 1.2 mostra esquematicamente as interações doador/aceptor (solvatação) dos íons $\mathrm{Li}^{+}$pelos segmentos de cadeia polimérica que contem átomos de oxigênio.

(a)

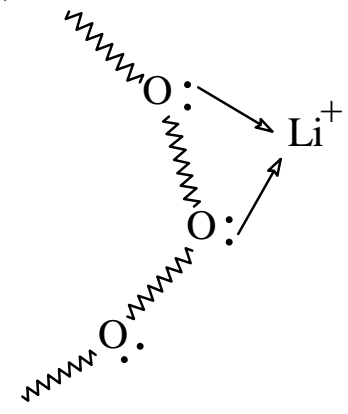

(b)

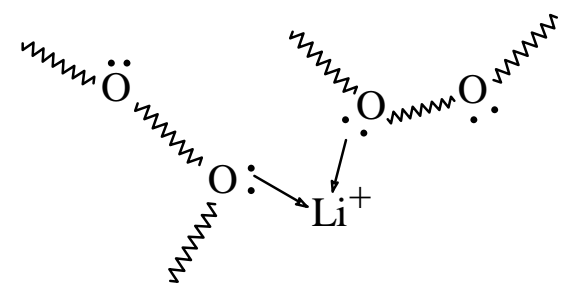

Figura 1. 2: Modos de solvatação dos cátions $\left(\mathrm{Li}^{+}\right)$pelos átomos de oxigênio de uma cadeia polimérica: (a) solvatação por uma única cadeia; (b) solvatação por duas cadeias

Bruce et $\mathrm{al}^{8}$ através de estudos sobre a estrutura cristalina de complexos poli(óxido de etileno)/sal $\left(\mathrm{LiCF}_{3} \mathrm{SO}_{3}, \mathrm{NaClO}_{4}, \mathrm{KSCN}, \mathrm{NH}_{4} \mathrm{SCN}\right)$ observaram que as cadeias do poliéter adotam conformação helicoidal com os íons $\mathrm{Li}^{+}$coordenados por três oxigênios do polímero e dois contra-íons, apresentando configuração geométrica de bipirâmide trigonal. $\mathrm{O}$ número médio de oxigênios a uma distância $r$ do cátion decresce com o aumento da concentração de sal, enquanto que o número médio de 
contra-íons na mesma distância aumenta. Esta tendência reflete a competição entre os oxigênios da molécula e ânions para a coordenação do cátion. A preferência pela não dissociação do sal a altas concentrações é devido à diferença de tamanho entre o segmento polimérico e o contra-íon. A configuração mais favorável é a coordenação de um cátion com vários oxigênios de uma única cadeia. A probabilidade de duas cadeias diferentes coordenarem o mesmo cátion é maior para baixas concentrações de sal devido à maior flexibilidade da cadeia ao redor de seus átomos de oxigênio. Mesmo em sistemas muito diluídos o número de cadeias coordenadas em um único cátion nunca excede a três ${ }^{9}$.

Nos casos mais simples, o transporte iônico em eletrólitos sólidos poliméricos pode ser tratado como partículas difundindo na matriz polimérica através da sua transferência entre os sítios de solvatação ${ }^{10}$. Este processo de migração encontra-se associado à movimentação das cadeias poliméricas ${ }^{9,11,12}$. Desta forma, a condutividade iônica depende de uma série de parâmetros que influenciam a mobilidade das cadeias. Dentre eles encontram-se a massa molar do polímero, funcionalização dos grupos terminais, grau de cristalinidade, concentração do sal e tamanho das espécies iônicas e parâmetros externos como temperatura e pressão ${ }^{9}$. Vários modelos matemáticos podem ser aplicados a fim de quantificar a mobilidade iônica em função da temperatura e efeitos de agregação do sal; são eles, a teoria do volume livre, da entropia configuracional, e percolação dinâmica de ligações. A condutividade pode ser equacionada através das equações de Vogel-TammanFulcher (VTF) e Williams-Landel-Ferry (WLF) ${ }^{7}$.

Pode-se imaginar então que, quanto maior o número de espécies transportadoras de cargas maior a condutividade. Entretanto, a condutividade iônica não pode ser explicada somente pela quantidade de cátions introduzida na matriz. A 
associação iônica a altas concentrações de sal é um fator determinante no transporte de $\operatorname{cargas}^{7}$. Desta forma, a condutividade aumenta com a inserção de sal no eletrólito até um valor limite, após este máximo ocorre a diminuição da condutividade com o aumento da concentração de sal, pois ocorre a associação iônica e aumento da viscosidade e da temperatura de transição vítrea $(\mathrm{Tg})$ do sistema ${ }^{13}$.

Sircar e colaboradores ${ }^{14}$ correlacionaram a transição de fases (cristalina e amorfa), observadas por técnicas de DSC e TG, com o comportamento iônico dos complexos polímero/sal no sistema $\mathrm{PEO} / \mathrm{LiBF}_{4}$. Foi observado que, com a introdução do sal na matriz polimérica a condutividade aumenta rapidamente devido ao aumento do número de espécies responsáveis pela condução. Entretanto, a altas concentrações de sal a viscosidade do sistema aumenta e a mobilidade iônica diminui. Este decréscimo é devido não somente à redução da mobilidade dos íons mas também à formação de pares iônicos neutros (sal livre) o que faz diminuir o número de espécies transportadoras de cargas ligadas ao polímero, com conseqüente redução da condutividade. Foi também demonstrado que esta aumenta com o aumento de temperatura, não só devido à diminuição da cristalinidade, mas como conseqüência da dissociação do sal livre. Esta correlação entre a condução iônica e as propriedades viscoelásticas e temperatura do sistema foi também observada por Magistris e Singh ${ }^{15}$.

Assim como um líquido, o poli(óxido de etileno) (POE) dissolve uma grande variedade de sais inorgânicos ${ }^{15,16}$. Esta propriedade e outras como boa condutividade, propriedades mecânicas adequadas, compatibilidade com eletrodos de lítio e de óxidos metálicos e facilidade de processamento na forma de filme ${ }^{14}$ fizeram com que eletrólitos sólidos poliméricos baseados em POE fossem muito estudados. Entretanto esta macromolécula possui algumas características que limitam o seu 
desempenho ${ }^{15,17,18}$. POE puro é um polímero linear com alta cristalinidade à temperatura ambiente. A parte cristalina corresponde a $70-84 \%$ do material e o restante refere-se à parte amorfa entre os cristais $^{15}$, cuja transição vítrea, para POE com massa molar próxima a $1000 \mathrm{~g} / \mathrm{mol}$, ocorre em temperaturas próximas a $-60^{\circ} \mathrm{C}$. A presença de regiões cristalinas dificulta a condutividade e pode ser diminuída com a adição de sais de lítio onde o contra-íon é um grupo volumoso ${ }^{9,19}$. A temperatura de fusão desta parte cristalina é em torno de $65^{\circ} \mathrm{C}$; esta transição de fases pode perturbar o fenômeno de condução e tem como conseqüência valores pequenos de condutividade na temperatura ambiente. Outro problema é o envelhecimento do material, o que resulta na sua curta durabilidade.

Uma maneira de resolver estes problemas é o entrecruzamento das cadeias poliméricas com o objetivo de minimizar a organização local ${ }^{17,18}$. Inicialmente estas modificações foram realizadas através da reação entre poli(óxido de etileno) triol e um diisocianato de $\mathrm{POE}^{20,21}$. Os pontos de entrecruzamento caracterizam-se pela presença de ligações do tipo uretana, sendo obtido um material completamente desordenado e sem modificação da natureza química do POE. Estes materiais foram extensivamente estudados, sendo determinados parâmetros importantes como a influência do tipo e quantidade de sal nas propriedades das redes de poliéter $^{22,23}$, transporte catiônico ${ }^{24}$, condutividade iônica ${ }^{25}$ e mecanismo de condução ${ }^{26}$.

Estes sistemas entrecruzados possuem como principal característica a estabilidade mecânica na temperatura de operação. Foram estudados então outros sistemas à base de $\mathrm{POE}$ como os policondensados de poli(óxido de etileno) com 3cloro-2-clorometil-1-propeno $^{27,28}$. Estes sistemas apresentaram alta estabilidade dimensional e alta condutividade à temperatura ambiente $\left(2 \times 10^{-5} \mathrm{Scm}^{-1}\right)$. A influência da massa molar de POE na condutividade dos eletrólitos entrecruzados 
com 4,4',4"'-metilidine-tris(fenil isocianato) (Desmodur R) foi estudado por Carvalho et $\mathrm{al}^{29}$. Foram obtidos valores de condutividade a $30^{\circ} \mathrm{C}$ iguais a $7 \times 10^{-5} \mathrm{Scm}^{-1}$ a uma razão $\mathrm{O} / \mathrm{Li}=43$ para poli(óxido de etileno) com massa molar igual a $2000 \mathrm{~g} / \mathrm{mol}$. Observou-se que o comportamento da condutividade segue modelo WLF, ou seja, ocorre com participação dos movimentos moleculares, quando a massa molar do poliéter é maior que $1000 \mathrm{~g} / \mathrm{mol}$. Para redes à base de $\mathrm{POE}_{600}$ foi observado comportamento do tipo Arrhenius para a condução.

Outra possibilidade de melhoramento das propriedades do POE, bem como de sua condutividade, é a introdução de cargas durante a formação dos filmes. Kim et $a l^{30}$ reporta a inserção de 29 tipos diferentes de cargas (por exemplo, $\mathrm{Al}_{2} \mathrm{O}_{3}, \mathrm{Fe}_{2} \mathrm{O}_{3}$ e sílica, entre outros) à eletrólitos à base de $\mathrm{POE}_{16} \mathrm{LiClO}_{4}$. Em temperatura alta não é observada variação de condutividade, mas à baixas temperaturas maiores ou menores valores são obtidos dependendo do material adicionado. Relacionou-se este efeito às modificações morfológicas dos filmes.

Novos materiais onde se combina as propriedades de unidades de óxido de etileno e outros polímeros estão sendo estudados, entre eles eletrólitos baseados em oligo(óxido de etileno) entrecruzado com poli(metacrilato de metila) ${ }^{31}$. Foram obtidos valores de condutividade da ordem de $10^{-4} \mathrm{Scm}^{-1}$ à temperatura ambiente e utilizando-se perclorato de magnésio como sal. Outra alternativa de material consiste em polímeros em blocos, por exemplo, os sistemas contendo óxido de etileno e óxido de metileno-oligo(óxido de etileno) ${ }^{32}$, ou poli(tetrametileno glicol-co-etileno glicol) reforçado por condensação com hexametildiisocianato ${ }^{33}$. Valores de condutividade em torno de $10^{-6} \mathrm{Scm}^{-1}$ foram obtidos em temperatura igual a $23^{\circ} \mathrm{C}$. Também encontra-se estudos com híbridos de poliamida e poli(óxido de etileno) com ou sem adição de $\mathrm{SiO}_{2}$ como carga ${ }^{34,35}$. Foram também estudadas as propriedades como 
eletrólitos sólidos poliméricos de blendas de poli(óxido de etileno) e polisiloxanas ${ }^{36} \mathrm{e}$ copolímeros de óxido de etileno e epiclorohidrina ${ }^{37}$. Todos estes estudos consistem em caracterizar as propriedades mecânicas e térmicas do novo material. É também analisada a condutividade e seu comportamento em função da temperatura e da variação do tipo e concentração de sal utilizado.

Uma vez atingido o objetivo de síntese de redes estáveis e com alta condutividade, torna-se interessante o estudo de uma nova propriedade: a formação de filmes finos. Alguns polissacarídeos são conhecidos pela sua capacidade filmógena e boas propriedades mecânicas. Um exemplo é a utilização de acetato de celulose como matriz para polianilina, com obtenção de filmes finos, transparentes e flexíveis para a condução eletrônica ${ }^{38}$. Foram também preparados eletrólitos sólidos poliméricos a partir de hidroxietil celulose ${ }^{39}$ e quitosana ${ }^{40}$ entrecruzadas com poli(óxido de etileno). Foram obtidos filmes com boas propriedades mecânicas e condutividade da ordem de $10^{-4} \mathrm{Scm}^{-1}$ a $60^{\circ} \mathrm{C}$ para filmes com hidroxietil celulose e $10^{-5} \mathrm{Scm}^{-1}$ para filmes com quitosana na mesma temperatura. Estes resultados são bastante satisfatórios e mostram a potencial aplicação de polissacarídeos nestes sistemas.

O entendimento da contribuição do polissacarídeo e de seus parâmetros estruturais no fenômeno de condutividade neste tipo de sistema é importante para o desenvolvimento de novos materiais. Neste contexto o presente trabalho tem como objetivo o estudo sistemático das características de filmes de hidroxietil e hidroxipropil celulose enxertadas ou entrecruzadas com poli(óxido de etileno) ou poli(óxido de propileno). Os procedimentos experimentais adotados e os resultados obtidos serão discutidos nos capítulos a seguir. 
Referências Bibliogáficas

${ }^{1}$ JACOBY, M. Taking charge of the $21^{\text {st }}$ century: enormous growth in personal electronics, other applications drives researchers to develop a wide range of power solutions. Science and Technology, p. 37-43, 1998.

${ }^{2}$ SANCHEZ, J. Y.; ALLOIN, F.; BENRABAH, D.; ROUX, C. Polymers for electrochemical devices. Macromolecular Symposium, v. 114, p.85-95, 1997.

${ }^{3}$ DAHMOUCHE, K.; DE SOUZA, P. H.; BONAGAMBA, T. J.; PANEPPUCCI, H.; JUDEINSTEIN, P.; PULCINELLI, S. H.; DANTILLI, C. V. Investigation of new ion conducting ormolytes silica-polypropyleneglycol. Journal of the Electrochemical Society, v. 103, n. 1, p. 6-12, 1996.

${ }^{4}$ APPETECCHI, G. B.; DAUTZENBERG, G.; SCROSATI, B. A new class of advanced polymer electrolytes and their relevance in plastic-like, rechargeable lithium batteries. Journal of the Electrochemical Society, v. 103, n. 1, p. 6-12, 1996.

${ }^{5}$ FAUTEAUX, D.; MASSUCO, A.; McLIN, M.; VAN BUREN, M.; SHI, J. Lithium polymer electrolyte rechargeable battery. Electrochimica Acta, v. 40, n. 13-14, p. 2185-2190, 1995.

${ }^{6}$ LONERGAN. M. C.; SHRIVER, D. F.; RATNER, M. A. Polymer electrolytes: the importance of ion-ion interactions in diffusion dominated behaviour. Electrochimica Acta, v. 40, n. 13-14, p. 2041-2048, 1995.

${ }^{7}$ ALBINSSON, I.; MELLANDER, B. E.; STEVENS, J. R. Ion association effects and ionic conductivity in polymer electrolytes. Solid State Ionics, v. 60, p. 63-66, 1993.

${ }^{8}$ BRUCE, P. G.; CAMPBELL, S. A.; LightFOOT, P.; MEHTA, M. A. Polymer electrolytes: structure and electrode process. Solid State Ionics, v. 78, p. 191-198, 1995.

${ }^{9}$ NEYERTZ, S.; BROWN, D. Local structure and mobility of ions in polymer electrolytes: a molecular dynamic simulation study of the amorphous $\mathrm{PEO}_{\mathrm{x}} \mathrm{NaI}$ system. Journal of Chemical Physics, v. 104, n. 10, p. 3797-3809, 1996.

${ }^{10}$ VINCENT, C. A. Ion transport in polymer electrolytes. Electrochimica Acta, v. 40, n. 13-14, p. 2035-2040, 1995.

${ }^{11}$ CHADWICK, A. V.; HANMER, P.; COPPOLA, L.; RANIERI, G.; TERENZI, M. Ionic environment and trnasport in polymer electrolytes. Solid State Ionics, v. 72, p. 147-151, 1994. 
${ }^{12} \mathrm{XU}, \mathrm{G}$. The effects of chain segment motion on ionic diffusion in solid polymer electrolytes. Solid State Ionics, v. 50, p. 345-347, 1992.

${ }^{13}$ WARD, I. M.; BODEN, N.; CRUICKSHANK, J.; LENG, S. A. NMR studies of ionic mobility and molecular mobility in polymer electrolytes.

Electrochimica Acta, v. 40, n. 13-14, p. 2071-2076, 1995.

${ }^{14}$ SIRCAR, A. K.; WEISSMAN, P. T.; KUMAR, B.; MARSH, R. A. Evaluation of doped polyethylene oxide as solid electrolyte. Thermochimica Acta, v. 226, p. 281-299, 1983.

${ }^{15}$ MAGISTIS, A.; SINGH, K. PEO-based polymer electrolytes. Polymer International, v. 28, p. 277-280, 1992.

${ }^{16}$ BRUCE, P.G. Structure and electrochemistry of polymer electrolytes. Electrochimica Acta, v. 40, n. 13-14, p. 2077-2086, 1995.

${ }^{17}$ LeNEST, J. F.; GANDINI, A.; CHERADAME, H. Crosslinked polyethers as media for ionic conduction. British Polymer Journal, v. 20, p. 253-268, 1988.

${ }^{18}$ LeNEST, J. F.; GANIDINI, A.; SCHOENENBERGER, C. Elastomeric polymer electrolytes based on crosslinked polyethers: state of the art. Trends in Polymer Science, v. 2, n. 12, p. 432-437, 1994.

${ }^{19}$ ROBITAILLE, C. D.; FAUTEUX, D. Phase diagrams and conductivity characterization of some PEO-LiX electrolytes. Composite Polymer Membranes. v. 133, n. 2, p. 315-325, 1986.

${ }^{20}$ LeNEST, J. -F.; CALLENS, S.; GANDINI, A.; ARMAND, M. A new polymer network for ionic conduction. Electrochimica Acta, v. 37, n. 9, p. 1585-1588, 1992.

${ }^{21}$ CALLENS, S.; LeNEST, J. -F.; GANDINI, A.; ARMAND, M. A novel solid polymer electrolyte: synthesis and characterization. Polymer Bulletin, v. 25, p. 443-450, 1991.

${ }^{22}$ LeNEST, J. -F.; GANDINI, A.; CHERADAME, H. COHEN-ADDAD, J. -P. Influence of $\mathrm{LiClO}_{4}$ on the properties of polyether networks: specific volume and glass transition temperature. Macromolecules, v. 21, p. 1117-1120, 1988.

${ }^{23}$ LeNEST, J. F.; GANDINI, A. Electrolytes for solid-state bateries: glass transition temperature of polyether networks with and without alkali metal salts. Polymer Bulletin, v. 21, p. 347-351, 1989.

${ }^{24}$ LeNEST, J. F.; GANDINI, A.; CHERADAME, H.; COHEN-ADDAD, J. -P. Cationic transport features of ionomeric polymer networks. Polymer Communications, v. 28, p. 302-305, 1987. 
${ }^{25}$ LeNEST, J. F.; GANDINI, A. Crosslinked polyether electrolytes with alkali-metal salts for solid-state batteries: relationship between structure and ionic conductivity. in: INTERNATIONAL SYMPOSIUM ON POLYMER ELECTROLYTES, 2., Siena, 1989. Proceedings. Londres, Elsevier, 1989. p. $129-141$.

${ }^{26}$ LeNEST, J. F.; CHERADAME, H.; GANDINI, A. A mechanism of ionic conduction in cross-linked polyethers. Solid State Ionics, v. 28, p. 1032-1037, 1988.

${ }^{27}$ ALLOIN, F.; SANCHEZ, J. Y.; ARMAND, M. New solvating cross-linked polyether for lithium batteries. Journal of Power Sources, v. 54, p. 34-39, 1995.

${ }^{28}$ OLLIVRIN, X.; FARIN, N.; ALLOIN, F.; LeNEST, J. -F.; SANCHEZ, J. -Y. Physical properties of amorphous polyether networks. Electrochimica Acta, v. 43, n. 10-11, p. 1257-1262, 1998.

${ }^{29}$ CARVALHO, L. M.; GUÉGAN, P.; CHERADAME, H.; GOMES, A. S. Variation of the mesh size of PEO-based networks filled with TFSILi: from na Arrhenius to WLF type conductivity behavior. European Polymer Journal, v. 36, p. 401-409, 2000.

${ }^{30}$ KIM, Y. W.; LEE, W. CHOI, B. K. Relation between glass transition temperature and melting of PEO-salt complexes. Electrochimica Acta, v. 45, p. 1472-1477, 2000.

${ }^{31}$ MORITA, M.; ARAKI, F.; KASHIWAMURA, K.; YOSHIMOTO, N.; ISHIKAWA, M. Ionic structure and condutance behavior of plasticized polymeric electrolytes containing multivalent cations. Electrochimica Acta, v. 45, p. 1335-1340, 2000.

${ }^{32}$ WILSON, D. J.; NICHOLAS, C. V.; MOBBS, R. H.; BOOTH, C.; GILES, J. R. Synthesis of block copolymers based on oxyethylene chains and their use as polymer electrolytes. British Polymer Journal, v. 22, p. 129-135, 1990.

${ }^{33}$ FURTADO, C. A.; GOULART SILVA, G.; MACHADO, J. C.; PIMENTA, M. A.; SILVA, R. A. Study of correlations between microstructure and conductivity in a thermoplastic polyurethane electrolyte. Journal of Physical Chemistry B, v. 103, p. 7102-7110, 1999.

${ }^{34}$ ZOPPI, R. A.; FONSECA, C. M. N. P.; De PAOLI, M. A.; NUNES, S. P. Solid electrolytes based on poly(amide 6-b-ethylene oxide). Solid State Ionics, v. 91, p. 123-130, 1996.

${ }^{35}$ ZOPPI, R. A.; DE CASTRO, C. R.; YOSHIDA, I. V. P.; NUNES, S. P. Hybrids of $\mathrm{SiO}_{2}$ and poly(amide 6-b-ethylene oxide). Polymer Papers, v. 18, n. 23, p. 5705-5712, 1997. 
${ }^{36}$ SHIBATA, M.; KOBAYASHI, T.; YOSOMIYA, R.; SEKI, M. Polymer electrolytes based on blends of poly(ether urethane) and polysiloxanes. European Polymer Journal, v. 36, p. 485-490, 2000.

${ }^{37}$ GAZOTTI, W. A.; SPINACÉ, M. A. S.; GIROTTO, E. M.; DE PAOLI, M. A. Polymer electrolytes based on ethylene oxide-epichlorohydrin copolymers. Solid State Ionics, v. 130, n. 3-4, p. 281-291, 2000.

${ }^{38}$ PRON, A.; NICOLAU, Y.; NECHTSCHEN, M. Flexible, highly transparent, and conductive polyaniline-cellulose acetate composite films. Journal of Applied Polymer Science, v. 63, p. 971-977, 1997.

${ }^{39}$ SCHOENENBERGER, C.; LeNEST, J. F.; GANDINI, A. Polymer electrolytes based on modified polysaccharides. 2. Polyether-modified cellulosics. Electrochimica Acta, v. 40, n. 13-14, p. 2281-2284, 1995.

${ }^{40}$ VELAZQUEZ-MORALES, P.; LeNEST, J. F.; GANDINI, A. Polymer electrolytes dirived from chitosan/polyether networks. Electrochimica Acta, v. 43, n. 10-11, p. 1275-1279, 1998. 


\section{CAPÍTULO $2-\mathcal{F I L M E S ~ D E ~ P O L I S S A C A R I ́ ~ D E O S ~}$ ENXERTADOS COM POLIÉTERES}

2.1 - Caracterização dos polissacarídeos

$2.1 .1-\mathcal{A s p e c t o s}$ gerais

A celulose é o polímero natural mais abundante. A química de polímeros teve início com a sua caracterização, entretanto o interesse no seu estudo diminuiu com o advento da química do petróleo. A conscientização do homem na preservação do meio ambiente leva à busca de materiais ecológicos e de novas fontes de matériaprima renováveis, promovendo então uma nova abordagem da utilização da biomassa vegetal.

As fibras vegetais constituem a principal fonte de celulose, sendo anualmente produzidas bilhões de toneladas desta macromolécula por fotossíntese. Em média, $40 \%$ do total de carbono existente em uma planta encontra-se na estrutura da celulose $^{1}$, sendo a quantidade desta dependente das características morfológicas de cada espécie ${ }^{2,3}$. 
Entretanto, a celulose não é encontrada apenas em organismos vegetais. Ela também é produzida por alguns organismos marinhos como o Tunicin da classe Tunicata $^{2}$. Estudos recentes sobre a produção de celulose por bactérias, especialmente Acetobacter xylinum, ajudam na elucidação do mecanismo de formação de fibrilas ${ }^{4}$. A tabela $2.1^{1}$ apresenta o teor de celulose encontrado em fontes diversificadas.

Tabela 2 1: Teor de celulose em várias fontes

\begin{tabular}{cc}
\hline Material & Celulose (\%) \\
\hline Algodão & $95-99$ \\
Rami & $80-90$ \\
Bambu & $40-50$ \\
Madeira & $40-50$ \\
Casca de árvores & $20-30$ \\
Musgos & $25-30$ \\
Bactérias & $20-30$ \\
\hline
\end{tabular}

$\mathrm{Na}$ madeira, a celulose encontra-se associada a polioses e a lignina, sendo esta uma macromolécula formada por um sistema aromático composto de unidades de fenilpropano. As polioses, também denominadas hemiceluloses, são macromoléculas consideradas amorfas e em sua composição podem aparecer condensadas, em proporções variadas, as unidades de açúcar $\beta$-D-xilose, $\beta$-Dmanose, $\beta$-D-glicose, $\alpha$-L-arabinose, $\alpha$-D-galactose, ácido $\beta$-D-glicurônico e ácido $\alpha-\mathrm{D}-4, \mathrm{O}-\mathrm{metilglicurônico}{ }^{1,5}$.

De acordo com a espécie, a madeira contem entre 40 e $50 \%$ de celulose, 15 e $35 \%$ de lignina e 25 e $40 \%$ de hemiceluloses. A separação da celulose dos demais componentes da madeira pode ser realizada por tratamento químico intenso, denominado polpação. Polpas com diferentes características podem ser obtidas pela variação do agente químico de polpação e condições de temperatura e pressão. 
Dependendo da aplicação, necessita-se polpa com maior pureza, o que é obtido através de um processo químico adicional, o branqueamento. Polpa de madeira altamente purificada apresenta entre 95 e $99 \%$ de celulose ${ }^{1}$.

As propriedades físico-químicas e mecânicas da celulose estão relacionadas com a sua constituição química. Este polissacarídeo é formado por unidades de $\beta$-Dglicopiranose unidas por ligações glicosídicas do tipo $\beta-(1 \rightarrow 4)$. A unidade repetitiva é a celobiose ou anidro glicose sindiotática (figura 2.1). Os grupos terminais são diferentes quanto à reatividade; o grupo $\mathrm{C}_{1}-\mathrm{OH}$ é derivado da formação do anel através de ligação hemiacetal intramolecular. Por esta razão, este grupo possui propriedades redutoras, enquanto que, o grupo $\mathrm{C}_{4}-\mathrm{OH}$ é um grupo alcoólico, portanto, não redutor ${ }^{1}$. Os anéis de glicose adotam conformação mais estável na forma de cadeira com os grupos hidroxila na posição equatorial; a formação de ligações de hidrogênio entre átomos adjacentes de oxigênio e hidrogênio forçam o arranjo linear da macromolécula ${ }^{2,3}$.
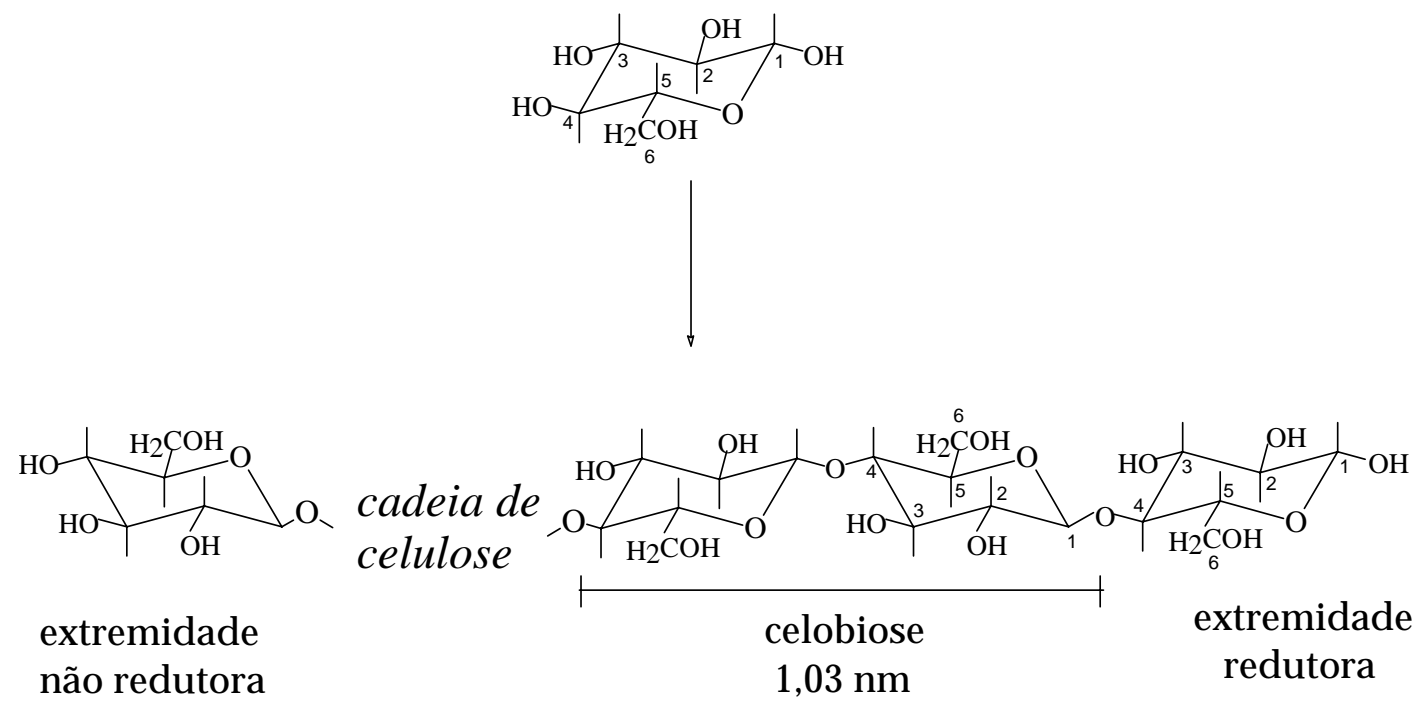

Figura 2. 1: Estrutura da celulose a partir da $\beta$-D-glicopiranose destacando a unidade básica repetitiva (celobiose) e extremidades redutora e não redutora. 
O grau de polimerização (DP) da celulose é o número de moléculas de $\beta$-Dglicopiranose que formam a cadeia. Como cada unidade repetitiva tem massa molar igual a 162 g/mol, DP x 162 leva à massa molar da celulose. No entanto este é um valor médio porque a fibra de celulose consiste em uma mistura de macromoléculas de vários tamanhos. Valores de grau de polimerização da celulose encontam-se na faixa de 1.000 a $15.000^{5}$, o que corresponde a massas molares de 162.000 a 2.430.000 g/mol. Este parâmetro contribui fundamentalmente para as propriedades físico-químicas do material celulósico, quer como fibra, como filme ou em qualquer outra forma. A origem e a degradação da amostra, bem como o método empregado para determinação do DP têm influência marcante sobre o valor obtido.

As cadeias de celulose formam ligações de hidrogênio intramoleculares (entre grupos hidroxila da mesma molécula) e intermoleculares (entre grupos hidroxila de cadeias adjacentes) como representado na figura 2.2. O primeiro tipo de interação é responsável pela rigidez da cadeia e o segundo, pela formação da fibra vegetal, ou seja, as cadeias de celulose se agregam formando as microfibrilas, que, por sua vez, agregam-se formando as fibrilas que se ordenam para formar as sucessivas paredes celulares da fibra ${ }^{6}$. As fibras são constituídas de regiões ordenadas tridimensionalmente (cristalitos) que se alternam a regiões amorfas (completamente desordenadas). A relação entre regiões ordenadas e desordenadas varia consideravelmente conforme a origem da celulose ${ }^{5}$.

Os cristalitos da celulose possuem várias formas polimórficas. Estas dependem das condições em que as regiões cristalinas foram formadas. Por exemplo, a celulose I é obtida somente como produto da biossíntese. Uma vez mercerizada, solubilizada ou regenerada, ocorre a transformação irreversível à celulose II porque 
esta estrutura espacial permite a formação de maior número de ligações hidrogênio, resultando numa estrutura termodinamicamente mais estável ${ }^{7}$. Os principais planos

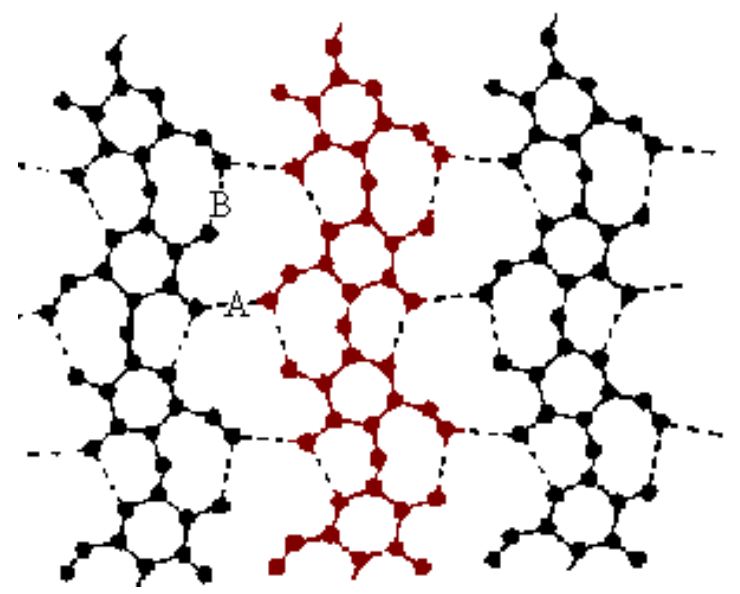

Figura 2. 2: Representação das ligações hidrogênio presentes na estrutura cristalina da celulose. A) ligações hidrogênio intermolecular e B) ligação hidrogênio intramolecular

cristalinos para celulose I são mostrados na figura 2.3 e correspondem às difrações próximas aos seguintes ângulos de Bragg $(2 \theta)^{1}$ (figura 2.4): $23^{\circ}$ (plano 002), $21^{\circ}$ (plano 021), $17^{\circ}$ (plano 101$), 15^{\circ}(101)$ e $35^{\circ}(040)$. Para a celulose II as difrações em ângulos de Bragg iguais a $23^{\circ}$ (plano 002) e $20^{\circ}$ (plano 10 $\overline{1}$ ) têm intensidades semelhantes. Espera-se também, para a celulose II, o aparecimento de difração próximo a $2 \theta=15^{\circ}$ decorrente do plano cristalino 101 , entretanto esta identificação pode ser dificultada pela difração difusa da parte amorfa.

As modificações dos cristalitos com a derivatização da celulose foi discutida por alguns autores ${ }^{8,9,10}$ sendo demonstrada a ocorrência de perturbação na estrutura levando à perda de cristalinidade da amostra. Nos difratogramas de raios-X para celulose e seus derivados no estado predominantemente amorfo observa-se a presença de uma única banda alargada centrada a ângulo de Bragg próximo a $20^{\circ}$, como mostrado na figura 2.4 . 


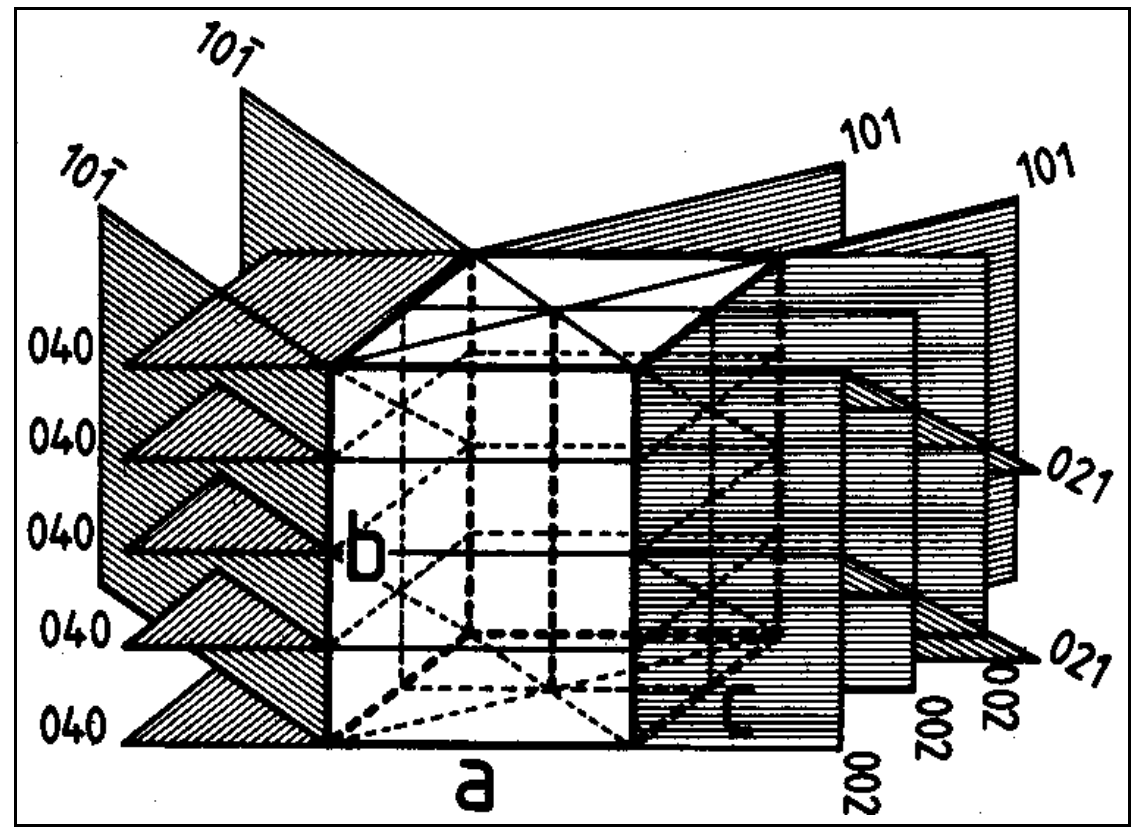

Figura 2. 3: Principais planos cristalinos da cela unitária da celulose I

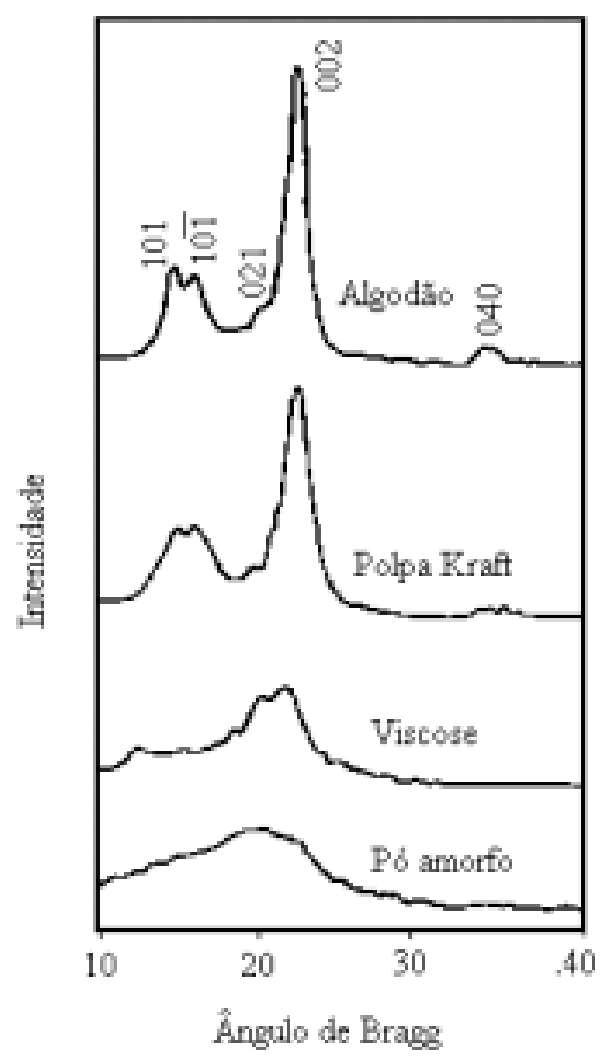

Figura 2. 4: Difratograma de raios- $X$ de vários tipos de celulose ${ }^{8}$ 
A reatividade da celulose é governada tanto pelos grupos funcionais presentes em sua estrutura química, quanto pelas interações físicas entre as cadeias. A presença de regiões amorfas e cristalina na fibra da celulose determina a acessibilidade dos agentes químicos aos grupos reativos. As propriedades dos derivados de celulose variam com o grau de substituição (DS) e a distribuição dos substituintes na cadeia. Estes parâmetros estão diretamente relacionados à acessibilidade do reagente aos grupos funcionais da macromolécula. Se as fibras estão presentes em um meio que favoreça o intumescimento, as reações de derivatização se limitarão às suas superfícies. A solubilização permite o acesso das espécies reativas a todos os grupos funcionais, aumentando a substituição e distribuindo-a homogeneamente. Cada unidade de glicose presente na estrutura da celulose tem três grupos hidroxila reativos, cujas reatividades diferem de acordo com o ambiente eletrônico no qual ela se encontra. Dados de ressonância magnética nuclear $(\mathrm{RMN})^{11}$ indicam a maior reatividade da hidroxila primária $(\mathrm{OH}-6)$ frente às reações de esterificação. A hidroxila ligada ao carbono secundário C2 é mais reativa que a ligada ao carbono C3 porque esta se encontra envolvida em ligações hidrogênio intramoleculares. Os grupos hidroxila da celulose podem ser esterificados ou eterificados. A tabela $2.2^{1}$ relaciona dos derivados de celulose mais conhecidos.

Os derivados de celulose escolhidos para estudo foram a hidroxietil celulose (HEC) (figura 2.5) e a hidroxipropil celulose (HPC) (figura 2.6). A HEC é um polímero não iônico solúvel em água que apresenta a capacidade de espessar, suspender, aglutinar, emulsificar, formar películas, estabilizar, dispersar, reter água e atuar como protetor coloidal ${ }^{12}$. Na síntese desta macromolécula, a celulose reage com hidróxido de sódio obtendo-se a álcali celulose, reagindo a seguir com o óxido de etileno com produção do éter. Nesta reação os átomos de hidrogênio dos grupos 
hidroxila da celulose são substiuídos por grupos hidroxietil, os quais conferem solubilidade em água. Na figura 2.5 é mostrada a estrutura da HEC.

Tabela 2. 2: Principais derivados de celulose

\begin{tabular}{|c|c|c|}
\hline Tipo & Reagente & Substituinte \\
\hline \multicolumn{3}{|l|}{ Ésteres } \\
\hline nitrato & $\mathrm{HNO}_{3}$ & $\mathrm{R}-\mathrm{ONO}_{2}$ \\
\hline \multirow[t]{2}{*}{ sulfato } & $\mathrm{H}_{2} \mathrm{SO}_{4}$ & $\mathrm{R}-\mathrm{OSO}_{3} \mathrm{H}$ \\
\hline & & $\mathrm{R}-\mathrm{OSO}_{3} \mathrm{Na}$ \\
\hline fosfato & $\mathrm{H}_{3} \mathrm{PO}_{4}$ & $\mathrm{R}-\mathrm{OPO}_{3} \mathrm{H}_{2}$ \\
\hline formiato & $\mathrm{HCOOH}$ & R-OCHO \\
\hline acetato & $\left(\mathrm{CH}_{3} \mathrm{CO}\right)_{2} \mathrm{O}$ & $\mathrm{R}-\mathrm{OCOCH}_{3}$ \\
\hline propionato & $\left(\mathrm{C}_{2} \mathrm{H}_{5} \mathrm{CO}\right)_{2} \mathrm{O}$ & $\mathrm{R}-\mathrm{OCOC}_{2} \mathrm{H}_{5}$ \\
\hline butirato & $\left(\mathrm{C}_{3} \mathrm{H}_{7} \mathrm{CO}\right)_{2} \mathrm{O}$ & $\mathrm{R}-\mathrm{OCOC}_{3} \mathrm{H}_{7}$ \\
\hline aceto-acetato & $\mathrm{C}_{4} \mathrm{H}_{4} \mathrm{O}_{2}$ & $\mathrm{R}-\mathrm{OCOCH}_{2} \mathrm{COCH}_{3}$ \\
\hline $\begin{array}{c}\text { sucinatos de alquila ftalatos } \\
\text { de alquila }\end{array}$ & $\begin{array}{c}\mathrm{R}^{\prime} \mathrm{OCOCH} \mathrm{CH}_{2} \mathrm{COOH}+ \\
\left(\mathrm{ClCH}_{2} \mathrm{CO}\right)_{2} \mathrm{O}\end{array}$ & R-OCOCH${ }_{2} \mathrm{CH}_{2} \mathrm{COOR}^{\prime}$ \\
\hline p-toluenossulfonato & $\mathrm{CH}_{3} \mathrm{C}_{6} \mathrm{H}_{4} \mathrm{SO}_{2} \mathrm{Cl}$ & $\mathrm{R}-\mathrm{OSO}_{2} \mathrm{C}_{6} \mathrm{H}_{4} \mathrm{CH}_{3}$ \\
\hline feniluretano & $\mathrm{C}_{6} \mathrm{H}_{5} \mathrm{NCO}$ & $\mathrm{R}-\mathrm{OCONHC}{ }_{6} \mathrm{H}_{5}$ \\
\hline \multicolumn{3}{|l|}{ Xantatos } \\
\hline ditiocarbonato & $\mathrm{CS}_{2}+\mathrm{NaOH}$ & $\mathrm{R}-\mathrm{OCS}_{2} \mathrm{Na}$ \\
\hline tiocarbonato & $\mathrm{COS}+\mathrm{NaOH}$ & R-OCOSNa \\
\hline \multicolumn{3}{|l|}{ Éteres } \\
\hline metil & $\mathrm{CH}_{3} \mathrm{Cl}$ & $\mathrm{R}-\mathrm{O}-\mathrm{CH}_{3}$ \\
\hline etil & $\mathrm{C}_{2} \mathrm{H}_{5} \mathrm{Cl}$ & $\mathrm{R}-\mathrm{OC}_{2} \mathrm{H}_{5}$ \\
\hline propil & $\mathrm{C}_{3} \mathrm{H}_{7} \mathrm{Cl}$ & $\mathrm{R}-\mathrm{OC}_{3} \mathrm{H}_{7}$ \\
\hline butil & $\mathrm{C}_{4} \mathrm{H}_{9} \mathrm{Br}$ & $\mathrm{R}-\mathrm{OC}_{4} \mathrm{H}_{9}$ \\
\hline amil & $\mathrm{C}_{5} \mathrm{H}_{11} \mathrm{Br}$ & $\mathrm{R}-\mathrm{OC}_{5} \mathrm{H}_{11}$ \\
\hline 2-hidroxietil & $\mathrm{C}_{2} \mathrm{H}_{4} \mathrm{O}, \mathrm{ClCH}_{2} \mathrm{CH}_{2} \mathrm{OH}$ & $\mathrm{R}-\mathrm{OCH}_{2} \mathrm{CH}_{2} \mathrm{OH}$ \\
\hline carboximetil & $\mathrm{ClCH}_{2} \mathrm{COONa}$ & $\mathrm{R}-\mathrm{OCH}_{2} \mathrm{COONa}$ \\
\hline sulfoetil & $\mathrm{ClCH}_{2} \mathrm{CH}_{2} \mathrm{SO}_{3} \mathrm{Na}$ & $\mathrm{R}-\mathrm{OCH}_{2} \mathrm{CH}_{2} \mathrm{SO}_{3} \mathrm{Na}$ \\
\hline alil & $\mathrm{CH}_{2}=\mathrm{CHCH}_{2} \mathrm{Br}$ & $\mathrm{R}-\mathrm{OCH}_{2} \mathrm{CH}=\mathrm{CH}_{2}$ \\
\hline cianoetil & $\mathrm{CH}_{2}=\mathrm{CHCN}$ & $\mathrm{R}-\mathrm{OCH}_{2} \mathrm{CH}_{2} \mathrm{CN}$ \\
\hline benzil & $\mathrm{C}_{6} \mathrm{H}_{5} \mathrm{CH}_{3} \mathrm{Cl}$ & $\mathrm{R}-\mathrm{OCH}_{2} \mathrm{C}_{6} \mathrm{H}_{5}$ \\
\hline tritil & $\left(\mathrm{C}_{6} \mathrm{H}_{5}\right)_{3} \mathrm{CCl}$ & $\mathrm{R}-\mathrm{OC}\left(\mathrm{C}_{6} \mathrm{H}_{5}\right)_{3}$ \\
\hline
\end{tabular}

A forma pela qual o óxido de etileno é adicionado à celulose pode ser descrita através de dois termos: grau de substituição (DS) e grau de substituição molar (MS). O grau de substituição representa o número de grupos hidroxila da cadeia celulósica que reagiram com o óxido de etileno. A substituição molar é definida como o número 
médio de moléculas de óxido de etileno que reagiram em cada unidade de anidroglicose (figura 2.5). Outro parâmetro é $n$, que representa o número de unidades repetitivas de óxido de etileno por substituinte que podem ser adicionados enquanto o óxido de etileno estiver disponível; esta reação pode, portanto, continuar, teoricamente, sem limite.

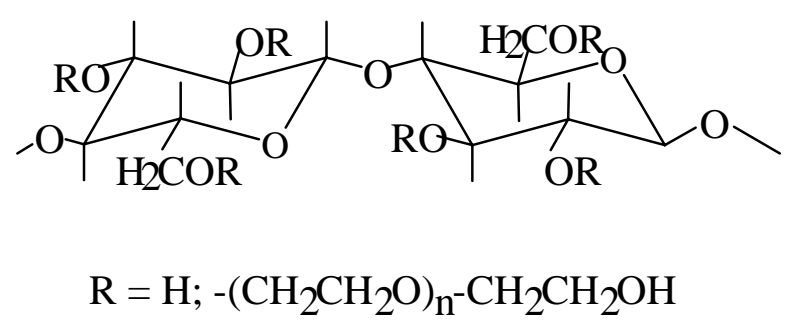

Figura 2. 5: Modelo de estrutura de hidroxietil celulose

A hidroxietil celulose, derivado de celulose solúvel em água, é insolúvel na maioria dos solventes orgânicos como indicado na tabela $2.3^{12}$.

A HPC é um éter de celulose com estrutura semelhante à da HEC (figura 2.6). A síntese comercial também é realizada de modo análogo ao outro polissacarídeo utilizando-se como reagente o óxido de propileno. Os mesmos parâmetros estruturais são definidos para este polímero cuja solubilidade em solventes orgânicos é maior que para a HEC. Por exemplo, além dos solventes utilizados para a HEC, a HPC é solúvel em tetracloreto de carbono, clorofórmio, diclorometano, metanol e etanol, entre outros. 


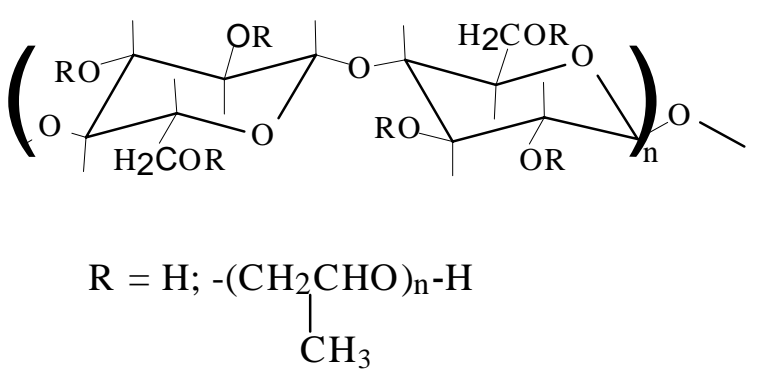

Figura 2. 6: Modelo de estrutura para hidroxipropil celulose

Tabela 2. 3: Solubilidade da hidroxietil celulose em vários solventes

\begin{tabular}{|c|c|c|c|}
\hline Solventes & Solubilidade & Solvente & Solubilidade \\
\hline \multicolumn{2}{|l|}{ Hidrocarbonetos } & \multicolumn{2}{|l|}{ Ácidos } \\
\hline Xileno & I & Ácido acético & $\mathrm{P}$ \\
\hline Benzeno & I & Ácido fórmico & $\mathrm{S}$ \\
\hline Petrolene & I & \multicolumn{2}{|l|}{ Ésteres } \\
\hline Querosene & I & \multirow{2}{*}{$\begin{array}{l}\text { Acetato de amila } \\
\text { primário } \\
\text { Acetato de etila }\end{array}$} & I \\
\hline \multicolumn{2}{|l|}{ Hidrocarbonetos } & & I \\
\hline Clorobenzeno & $\mathrm{I}$ & \multicolumn{2}{|l|}{ Aminas } \\
\hline \multicolumn{2}{|l|}{$\begin{array}{l}\text { Tetracloreto de carbono; } \\
\text { clorofórmio; } \\
\text { diclorometano }\end{array}$} & Etileno diamina & $\mathrm{S}$ \\
\hline Tricloro etileno & $\mathrm{I}$ & Piridina & I \\
\hline Dicloro etileno & I & Dietileno triamina & $S$ \\
\hline Cloreto de metileno & $\mathrm{I}$ & \multicolumn{2}{|l|}{ Éteres } \\
\hline \multicolumn{2}{|l|}{ Álcoois, Glicóis } & \multicolumn{2}{|l|}{ Éter isopropílico } \\
\hline \multirow{3}{*}{$\begin{array}{l}\text { Butanol } \\
\text { Etanol }(95 \%) \\
\text { Metil CELLOSOLVE }\end{array}$} & I & \multirow{2}{*}{$\begin{array}{l}\text { Éter etílico } \\
\text { 1,4-Dioxano }\end{array}$} & \multirow{2}{*}{$\begin{array}{l}\mathrm{I} \\
\mathrm{I}\end{array}$} \\
\hline & I & & \\
\hline & I & \multicolumn{2}{|l|}{ Óleos } \\
\hline Metanol & I & Óleo mineral & I \\
\hline Carbitol solvente & I & $\begin{array}{l}\text { Óleo de caroço de } \\
\text { algodão }\end{array}$ & I \\
\hline \multicolumn{2}{|l|}{ Aldeídos } & \multirow{2}{*}{$\begin{array}{l}\text { Óleo animal } \\
\text { Óleo de linhaça }\end{array}$} & $\mathrm{I}$ \\
\hline \multirow{2}{*}{$\begin{array}{l}\text { Butiraldeído } \\
\text { Formalina }\end{array}$} & $\begin{array}{l}P \\
S\end{array}$ & & $\mathrm{I}$ \\
\hline & $S$ & \multicolumn{2}{|l|}{ Outros } \\
\hline \multicolumn{2}{|l|}{ Cetonas } & \multicolumn{2}{|l|}{ Dimetil formamida } \\
\hline \multirow{3}{*}{$\begin{array}{l}\text { Acetona } \\
\text { Dietil cetona }\end{array}$} & I & Dimetil acetamida & $S$ \\
\hline & I & Dimetil sulfóxido & $S$ \\
\hline & & Fenol & $\mathrm{S}$ \\
\hline
\end{tabular}




\subsection{2-Materiais}

A hidroxietil celulose (HEC) foi gentilmente cedida pela empresa UNION CARBIDE PRODUTOS QUÍMICOS LTDA. Foram estudadas sete amostras de HEC classificadas pelo fornecedor segundo suas viscosidades em solução aquosa à concentração de 2\%. Estas amostras são QP09H, QP300H, QP4400, QP15MH, QP30MH, QP52MH e QP100MH. Para a sua caracterização foram utilizados como solventes água MILLI-Q para viscosimetria e dimetilsulfóxido deuterado (DMSO $d_{6}$, Aldrich) para experimentos de ${ }^{13} \mathrm{C}-\mathrm{RMN}$ e ácido clorídrico ( $\mathrm{HCl}$, Synth) para ${ }^{1} \mathrm{H}$ RMN. Os experimentos de infravermelho foram realizados com pastilhas de amostra em $\mathrm{KBr}$ (Riedel-de-Haën). A HEC e todos os solventes e reagentes foram utilizados como recebidos.

As amostras de hidroxipropil (HPC) celulose utilizadas foram adquiridas da Aldrich sendo identificadas pelo número de catálogo: 43,500-7 (80000g/mol); 19,188-4 (100000 g/mol); 19,189-2 (370000g/mol). As massas molares indicadas foram fornecidas no catálogo. Para a caracterização destas amostras foram utilizados como solventes clorofórmio deuterado $\left(\mathrm{CDCl}_{3}\right.$, Aldrich) ${ }^{1} \mathrm{H}-\mathrm{RMN}$ e água MILLI-Q para ${ }^{13} \mathrm{C}$-RMN. Os experimentos de infravermelho foram realizados com pastilhas de amostra em $\mathrm{KBr}$ (Riedel-de-Haën). A HPC e os solventes foram utilizados como recebidos. 
2.1.3-Métodos

2.1.3.1-Análise de difração de raios $-\mathcal{X}$

A técnica de difração de raios-X é usada na investigação da estrutura fina do material. No princípio era usada apenas para a determinação da estrutura cristalina. Com o desenvolvimento da técnica, hoje é usada para vários fins como análises químicas, medidas de tamanho de partículas e determinações de orientações de cristais $^{13}$. Raios-X, radiação eletromagnética de comprimento de onda entre 0,5 e 2,5 Å, são produzidos quando elétrons com alta velocidade colidem com uma placa de metal liberando este tipo de radiação em todas as direções. Ao incidirem sobre os planos cristlográficos da amostra serão difratados com determinado ângulo, que é definido pela forma e tamanho da cela cristalográfica do composto. A intensidade indicada no gráfico de intensidade versus ângulo de Bragg é a soma das intensidades relativas de todos os raios difratados na mesma direção ${ }^{13}$.

A cristalinidade das amostras de hidroxietil celulose utilizadas foram observadas através de medidas de difração de raios-X realizadas em Difratômetro Universal de Raios-X URD-6, CARL ZEISS JENA, a potência $\mu=40$ kV/20 mA e $\lambda(\mathrm{CuK} \alpha)=1540 \AA$.

2.1.3.2 - Análise por espectroscopia no infravermelho

Uma molécula pode absorver energia proveniente de radiação eletromagnética, sofrendo vários tipos de excitação como a eletrônica, rotacional, mudança de spin e deformação de ligação, entre outras. A espectroscopia no 
infravermelho refere-se à radiação de excitação a números de onda entre 4000 e 600 $\mathrm{cm}^{-1}$. A diferença de intensidade entre o feixe de referência e a do feixe transmitido mede a quantidade de radiação absorvida. Os números de onda de absorção relativos aos modos de vibração dependem da força da ligação química entre dois átomos, e a intensidade de absorção da diferença de momento dipolar nesta mesma ligação. Desta forma, é possível caracterizar a função química a qual pertence o composto ${ }^{14}$.

As análises das amostras de HEC e HPC foram realizadas em aparelho BOMEM modelo MB-102. Utilizaram-se pastilhas de $\mathrm{KBr}$ na proporção 150:1 KBr/amostra, preparadas após secagem em sistema do tipo Abderhalden, sob refluxo com metanol durante 24 horas.

\subsubsection{3 - Análise por espectroscopia de ressonância magnétic a nucle ar}

A espectroscopia de ressonância magnética nuclear é uma técnica amplamente usada para o estudo da estrutura molecular dos compostos. Baseia-se na alteração do número quântico spin em função de um campo magnético externo. A excitação do núcleo, ou a sua oscilação de uma orientação para outra, é detectada como uma voltagem induzida, resultando da absorção de energia do campo de radiofrequiência ${ }^{15}$. A área sob um "pico" depende do número total de núcleos que estão oscilando. De acordo com o ambiente químico dos núcleos excitados a intensidade do campo magnético para a excitação sofre um deslocamento. Pode também ocorrer um desdobramento do "pico de oscilação", o que é devido ao acoplamento de vários núcleos, ou seja, acoplamento de spin. Dentre os núcleos paramagnéticos, com número quântico spin igual a n/2, os mais utilizados para estudo de estruturas moleculares são os de ${ }^{1} \mathrm{H}$ e ${ }^{13} \mathrm{C}$. 


\subsubsection{1 - Ressonância magnética nuclear de próton}

Os espectros de ${ }^{1} \mathrm{H}-\mathrm{RMN}$ foram obtidos em espectrômetro BRUCKER AC200 $(200,132 \mathrm{MHz})$ a $34,5^{\circ} \mathrm{C}$ em tubo de $5 \mathrm{~mm}$ de diâmetro. As intensidades dos picos foram determinadas por integração.

HEC: : Eles foram obtidos a partir de HEC hidrolisada ${ }^{16}$. Preparou-se uma solução $20 \%$ de polissacarídeo em ácido clorídrico concentrado. A dispersão foi agitada e submetida à temperatura de $50^{\circ} \mathrm{C}$ durante 2 horas. Em seguida a solução foi filtrada diretamente no tubo de análise. Na ausência de solvente deuterado, foi utilizado como referência interna o pico relativo ao hidrogênio do ácido clorídrico a 8,2 ppm.

HPC: As amostras foram dissolvidas em clorofórmio deuterado $\left(\mathrm{CDCl}_{3}\right)$ à concentração de 5g/dL. O ângulo de análise foi de $90^{\circ}$ com largura de pulso de $19 \mu \mathrm{s}^{17}$

\subsubsection{2 - Ressonância magnética nuclear de carbono}

Os espectros de ${ }^{13} \mathrm{C}-\mathrm{RMN}$ foram obtidos em espectrômetro BRUCKER $\operatorname{AC50}(50,32 \mathrm{MHz})$ a $75^{\circ} \mathrm{C}$ em tubo de $10 \mathrm{~mm}$ de diâmetro.

HEC: Foi utilizada concentração de $200 \mathrm{mg} / \mathrm{mL}$ em DMSO- $d_{6}{ }^{18}$.

HPC: O ângulo de análise e tempo de repetição de pulso foram $45^{\circ}$ e $3 \mathrm{~s}$ respectivamente, sendo acumulados cerca de 5000 scans $^{17}$. A concentração das soluções foram $10 \mathrm{~g} / \mathrm{dL}$ para HPC com menor massa molar e 3,8g/dL para HPC com maior massa molar. 


\subsubsection{4 - Determinação de massa molar por técnica viscosimétrica}

A viscosidade de soluções poliméricas é basicamente uma medida do volume hidrodinâmico (tamanho ou extensão no espaço) do polímero em solução ${ }^{19}$, estando empiricamente relacionada à massa molar de polímeros lineares. A simplicidade desta técnica permite sua ampla utilização na caracterização de macromoléculas. A medida de viscosidade de soluções poliméricas é resultado da comparação entre o tempo de escoamento do solvente num capilar calibrado $\left(t_{0}\right)$ e o da solução a determinada concentração $\left(t_{s}\right)$. A partir destas medidas físicas são definidos vários parâmetros:

- Viscosidade relativa $\left(\eta_{\text {rel }}\right)$; parâmetro adimensional:

$$
\eta_{r e l}=\frac{t_{s}}{t_{0}}
$$

- Viscosidade específica $\left(\eta_{\mathrm{sp}}\right)$; parâmetro adimensional:

$$
\eta_{s p}=\eta_{\text {rel }}-1
$$

- Viscosidade reduzida ( $\left.\eta_{\text {red }}\right)$; tem como dimensão o inverso da concentração:

$$
\eta_{\text {red }}=\frac{\eta_{s p}}{C}
$$

- Viscosidade intínseca ([ๆ]); tem como dimensão o inverso da concentração: 


$$
\left.[\eta]=\lim _{C \rightarrow 0} \mid \eta_{s p} / C\right\rfloor
$$

A viscosidade intrínseca é independente da concentração, entretanto depende do solvente utilizado para a realização das medidas. Este parâmetro reflete as propriedades da macromolécula individual, ou seja, reflete as propriedades de uma única molécula em solução. A medida de viscosidade intrínseca é feita pela extrapolação do gráfico de viscosidade reduzida versus concentração à diluição infinita. Esta extrapolação é realizada com base na equação de Huggins,

$$
\eta_{\text {red }}=[\eta]+k[\eta]^{2} C
$$

onde k é uma constante característica do polímero e de sua massa molar.

A dependência da viscosidade intrínseca com a massa molar é dada pela expressão geral (equação de Staudinger) ${ }^{19,20}$

$$
[\eta]=K M^{a}
$$

onde a constante $a$ está relacionada ao volume hidrodinâmico do polímero em solução como descrito na teoria de Flory e Fox ${ }^{19,20}$. Para soluções aquosas de HEC a relação entre o parâmetro viscosimétrico aqui discutido e a massa molar do polímero é dada por (unidade de $\left.\mathrm{dL} \cdot \mathrm{g}^{-1}\right)^{20}$

$$
[\eta]=1,1 \cdot 10^{-2} \bar{M}^{0,87}
$$


As massas molares das HEC utilizadas foram determinadas através de medidas de viscosidade de soluções do polissacarídeo a várias concentrações. As soluções de HEC foram preparadas por dissolução de amostras de polissacarídeo em água destilada e deionizada (MILLI-Q) com agitação por uma noite, a temperatura ambiente. Foram preparadas soluções iniciais a concentrações definidas, que foram diluídas no próprio capilar por adição de solvente e homogeneizadas por borbulhamento de ar. As medidas de viscosidade foram realizadas em viscosímetro capilar do tipo Ubbelohde submerso em banho termostático a $25^{\circ} \mathrm{C}$.

\subsubsection{5 - Análises Térmic as}

Métodos térmicos de análise de polímeros auxiliam na obtenção de informação sobre a estabilidade térmica, tempo de vida, transição de fases e efeitos decorrentes da incorporação de aditivos na estrutura polimérica ${ }^{21}$. Dentre as técnicas de análise térmica encontram-se: análise térmica diferencial (DTA), análise termomecânica (TMA), análise dinâmico-mecânica (DMA), calorimetria diferencial exploratória (DSC) e termogravimetria (TG), sendo estas duas últimas discutidas a seguir.

Antes é importante esclarecer o que é temperatura de transição vítrea (Tg). A transição vítrea é definida como a passagem do material do estado vítreo, sólido no qual os únicos movimentos observados são as vibrações das ligações químicas, para um estado onde o polímero apresenta-se borrachoso, onde são observados movimentos rotacionais de ligações e segmentos da cadeia ${ }^{22}$. Como qualquer outra 
transição física esta também é consequiência de um aumento da temperatura do sistema.

A rotação dos segmentos da cadeia polimérica ao redor de uma ligação é influenciada pela flexibilidade da macromolécula. A presença de substituintes volumosos, grupos polares e reticulação afetam a $\mathrm{Tg}$ elevando a temperatura onde esta transição ocorre ${ }^{21,22}$.

\subsubsection{1 - Calorimetria Diferencial Exploratória (DSC)}

A técnica de análise por calorimetria diferencial exploratória tem como objetivo registrar temperaturas de transição através da comparação de temperaturas da amostra e de uma referência que é totalmente inerte dentro da faixa de temperatura ensaiada. Observando como esta diferença de temperatura varia com o aquecimento a uma taxa constante é possível registrar as transições importantes como a temperatura de transição vítrea e a temperatura de início de degradação; estas resultam em picos endotérmicos ou exotérmicos no gráfico de quantidade de calor versus temperatura ${ }^{22}$. Análises posteriores são feitas com base na quantificação do calor envolvido nestas transições.

Para a obtenção das curvas de DSC de HEC utilizou-se um aparelho DSC 2910 - Differencial Scanning Calorimeter - TA Instruments e para HPC sistema SHIMADZU DSC-50. As corridas foram realizadas a uma taxa de aquecimento de $10^{\circ} \mathrm{C} / \mathrm{min}$ numa faixa de temperatura de 0 a $500^{\circ} \mathrm{C}$ sob atmosfera de nitrogênio (fluxo de 20mL/min); colocando-se a amostra em panela de alumínio. 


\subsubsection{2 - Termogravimetria}

A análise termogravimétrica permite observar a perda de massa da amostra em função da temperatura. Nem todas as transições da amostra resultam em perda de massa, como fusão, cristalização, e transição vítrea, mas fenômenos como dessorção, absorção, sublimação e decomposição podem ser observados. Esta técnica é utilizada para caracterizar a estabilidade térmica de polímeros a várias condições experimentais. As curvas de TG são gráficos de porcentagem de perda de massa versus temperatura. A interpretação dos dados é facilitada com o auxílio de outra como o DSC. A figura 2.7 ilustra esquematicamente a relação entre TG e DSC para alguns processos físico-químicos ${ }^{22}$.

As análises foram realizadas em aparelho SHIMADZU TGA-50 no intervalo de temperatura de 20 a $900^{\circ} \mathrm{C}$ a taxa de aquecimento de $10^{\circ} \mathrm{C} / \mathrm{min}$ e fluxo de nitrogênio de $20 \mathrm{~mL} / \mathrm{min}$, colocando-se a amostra em panela de platina. 


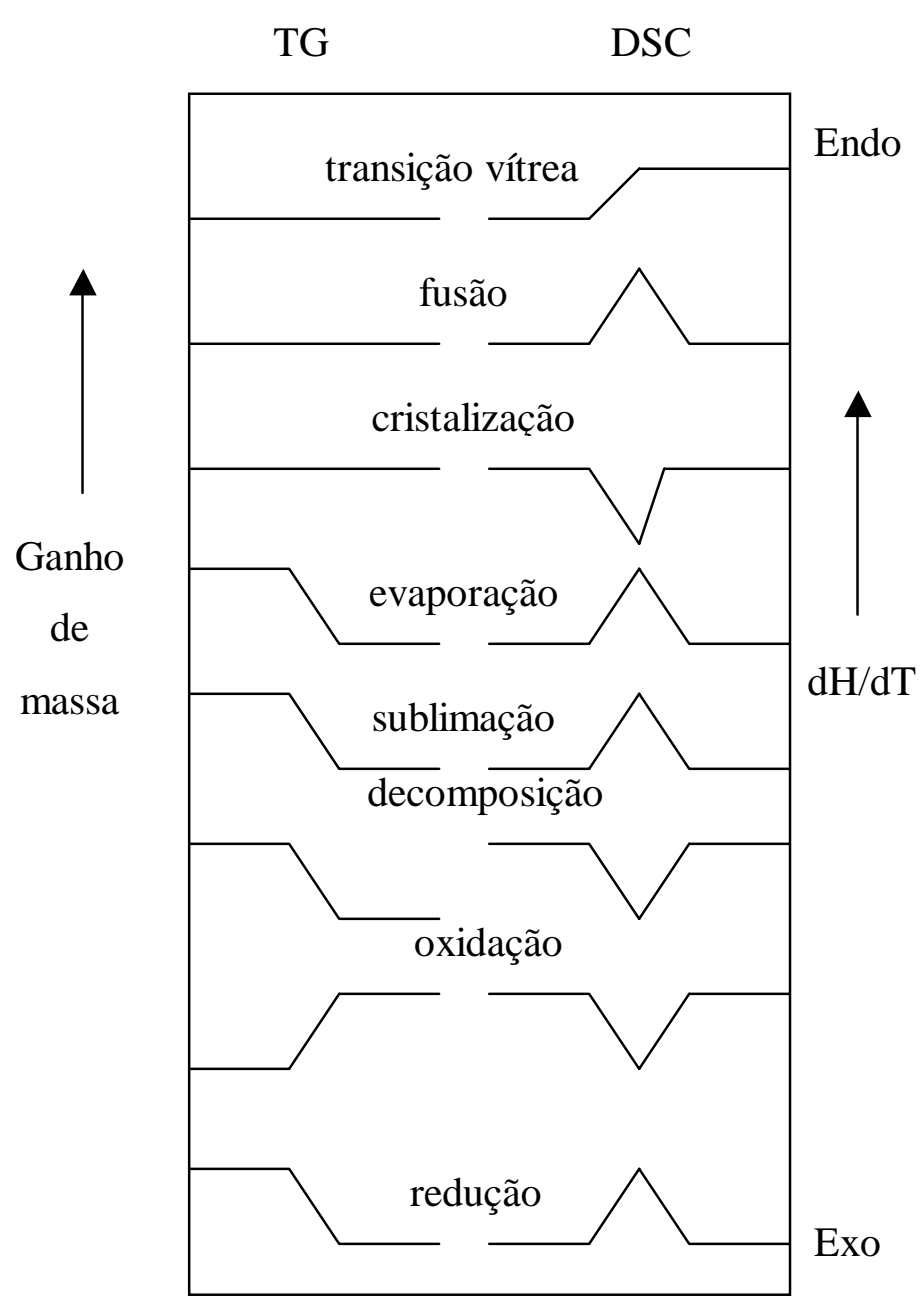

Figura 2. 7: Comparação esquemática das técnicas de TG e DSC

\subsection{4-Resultados}

Com a finalidade de observar a eventual presença de arranjos cristalinos nas amostras de polissacarído, estas foram submetidas a análises de raios-X. Como descrito anteriormente, a celulose microcristalina apresenta difratograma de raios-X bastante característico (figura 2.4). Quando a celulose é derivatizada ocorre um 
desarranjo das regiões cristalinas presentes na estrutura, pois a introdução de substituintes diminui a probabilidade de arranjo de uma cadeia sobre a outra para a formação de ligações hidrogênio intermoleculares. Desta forma, os derivados de celulose são, geralmente, amorfos ${ }^{7-9}$. A figura 2.8 apresenta os difratogramas de raios-X para a amostra QP15MH de hidroxietil celulose e hidroxipropil celulose amostra 19,189-2. Pode ser observado para a amostra de HEC banda residual larga centrada a ângulo de Bragg igual a $22^{\circ}$ indicando a existência de regiões cristalinas. Esta única banda é decorrente do principal plano cristlográfico da celulose e o seu alargamento indica a diminuição da cristalinidade da HEC. Não foi observada a presença de nenhum outro pico cristalino caracterizando, portanto, a predominância do estado amorfo das amostras. Os difratogramas de raios-X para todas as amostras de HEC são bastante semelhantes.

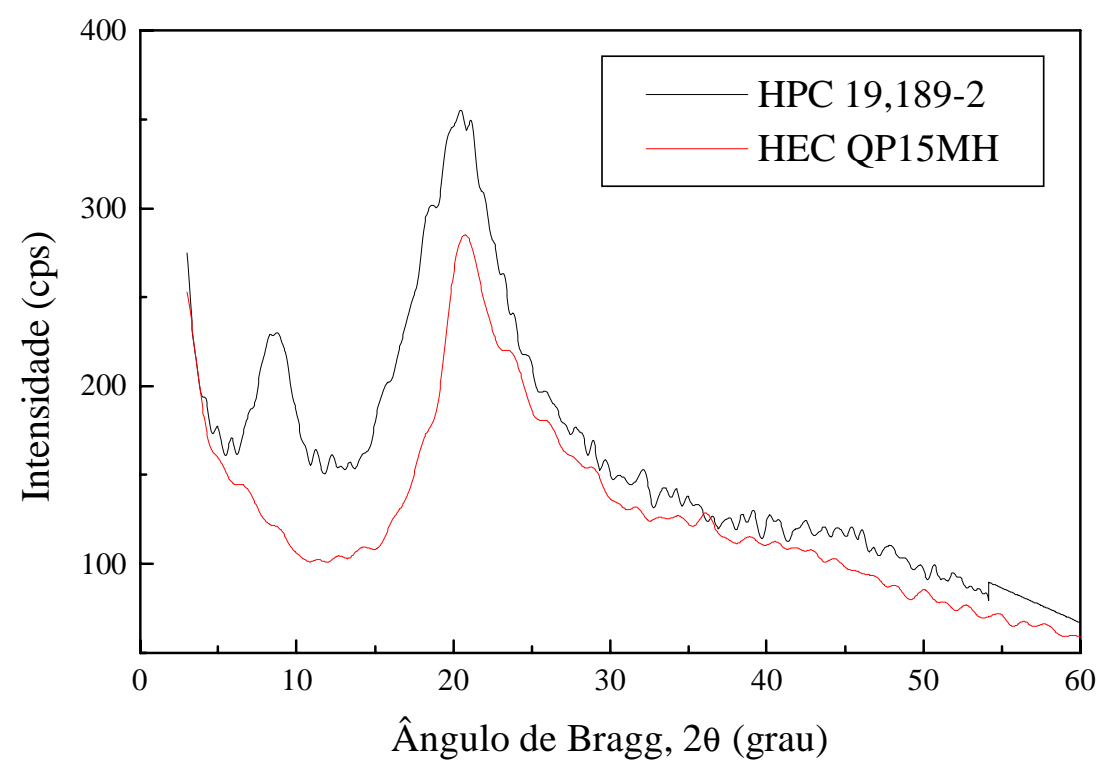

Figura 2. 8: Difratogramas de raios-X das várias amostras comerciais de hidroxietil celulose 
Para as amostras de HPC, representadas na figura 2.8 pelo difratograma da amostra 19,189-2, observa-se duas bandas: a primeira próxima a ângulo de Bragg igual a $10^{\circ}$ e a segunda em ângulo de Bragg em torno de $22^{\circ}$. A presença destas duas bandas sugere que as amostras de HPC são mais cristalinas que as de HEC.

A análise por espectroscopia no infravermelho permite observar e classificar algumas bandas relativas a vibrações características dos grupos funcionais presentes na estrutura de celulose e derivados. Na figura 2.9 é apresentada a sobreposição dos espectros obtidos para HEC e HPC comparando-os com o de celulose microcristalina AVICEL ${ }^{10}$.

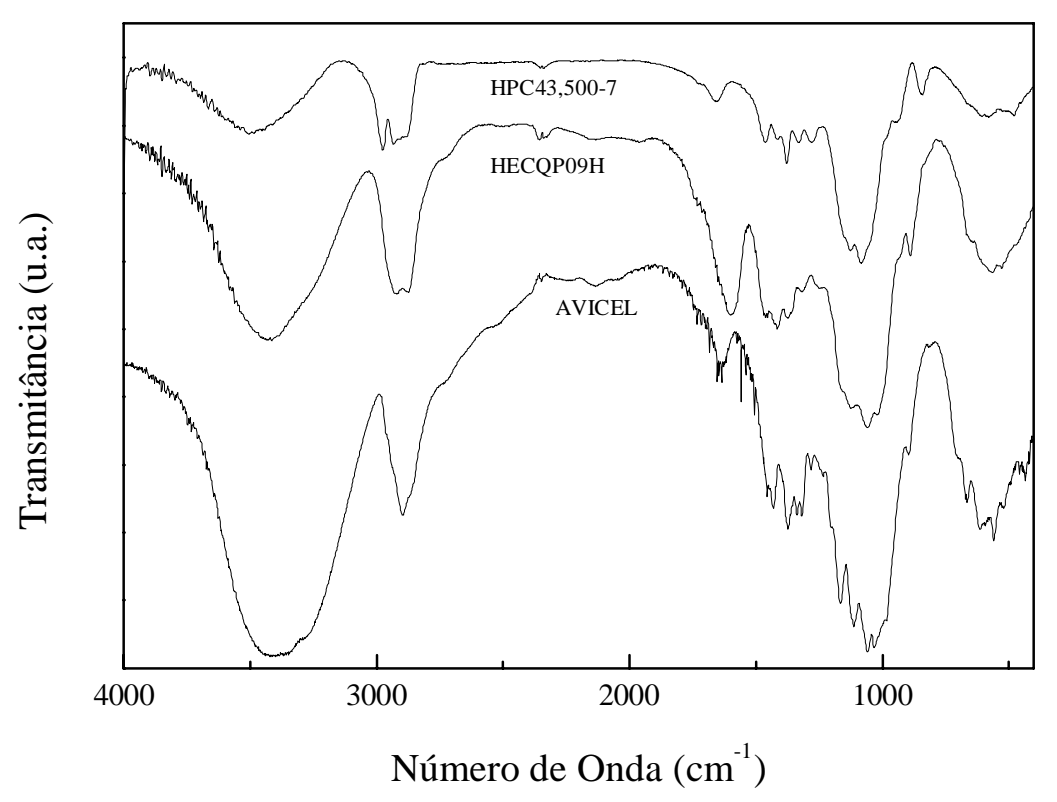

Figura 2. 9: Sobreposição de espectros no infravermelho de celulose microcristalina AVICEL, hidroxietil celulose (QP09H) e hidroxipropil celulose (Aldrich-43,500-7)

A principal banda de grande intensidade resulta do estiramento da ligação entre oxigênio e hidrogênio na região de 3650 a $3000 \mathrm{~cm}^{-1}$, que devido à presença de ligações de hidrogênio apresenta-se larga. Outra banda presente no espectro de álcoois é a relativa ao estiramento de ligação entre carbono e oxigênio próxima a 
$1000 \mathrm{~cm}^{-1}$. Outras bandas relativas à deformação angular da hidroxila de álcoois primários e secundários aparecem na região de $1600 \mathrm{~cm}^{-1}$, entretanto estas bandas não contribuem muito para a caracterização do composto por espectroscopia no infravermelho $^{14}$. As ligações do tipo éter presentes na cadeia celulósica apresentam banda de grande intensidade na região de 1100 a $1170 \mathrm{~cm}^{-1}$.

Outras bandas que auxiliam na caracterização são as relativas às vibrações das ligações entre carbono e hidrogênio. A banda de estiramento assimétrico desta ligação para o grupo metileno $\left(\mathrm{CH}_{2}\right)$ encontra-se próxima a $2900 \mathrm{~cm}^{-1}$. As bandas de deformação angular desta ligação aparecem na região de 1300 a $1400 \mathrm{~cm}^{-1}$.

A HEC apresenta no grupo substituinte ligações do tipo éter e grupo hidroxila terminal. A figura 2.9 apresenta espectro no infravermelho típico de HEC, amostra QP09H. Podem ser observadas as mesmas bandas de absorção que no espectro da celulose (as funções químicas presentes nas duas macromoléculas são as mesmas), porém mais bem definidas, porque as cadeias de substituinte são bem menos rígidas que a de celulose, favorecendo os movimentos de rotação e vibração das ligações.

A figura 2.9 também apresenta o espectro no infravermelho de HPC, amostra Aldrich-43,500-7. Este polissacarídeo também apresenta as mesmas funções químicas da celulose. Pode ser observado o desdobramento da banda a $2900 \mathrm{~cm}^{-1}$ devido à presença de vários grupos $\mathrm{CH}_{3}$ na estrutura da HPC. Comparando as bandas de $\mathrm{OH}$ e C-O-C para os polissacaídeos observamos maior intensidade de absorção da banda a $1110 \mathrm{~cm}^{-1}$ para as amostras de derivado de celulose. Este aumento reflete a introdução de ligações do tipo éter na reação de derivatização.

Na figura 2.10 são apresentadas as curvas de análise térmica de HEC amostra QP15MH. Devido a grande semelhança entre as curvas para as várias amostras foi escolhido e será discutido apenas um gráfico. Observamos na curva de TG perda de 
9,6\% em massa da temperatura ambiente até aproximadamente $100^{\circ} \mathrm{C}$. Relaciona-se esta perda à umidade existente na amostra, uma vez que o polissacarídeo em questão é bastante higroscópico. Pode ser observado pico endotérmico na curva de DSC para o mesmo intervalo de temperatura.

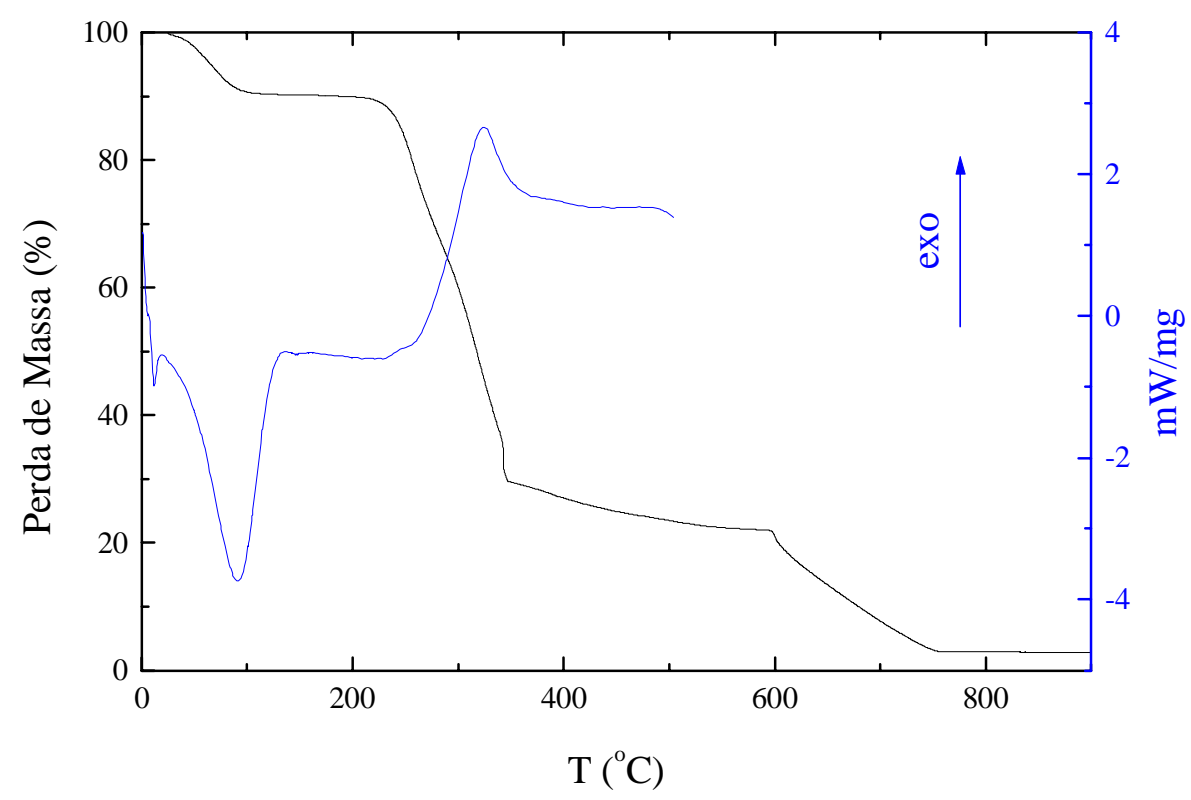

Figura 2. 10: Curvas de análise térmica (DSC e TG) para amostra QP15MH de hidroxietil celulose; fluxo de nitrogênio

Continuando a análise da curva de DSC, observamos pico exotérmico, com associada perda de massa, a temperatura próxima a $320^{\circ} \mathrm{C}$. É descrito na literatura ${ }^{23}$ a presença desta transição para este derivado de celulose. Ela é conseqüente da degradação térmica deste derivado de celulose. Kaloustian et al ${ }^{23,24}$ demonstraram que, quando a análise é feita sob fluxo de oxigênio a celulose e a HEC apresentam pico exotérmico de degradação. Sob fluxo de nitrogênio, este fenômeno para a celulose corresponde a pico endotérmico, indicando que a degradação ocorre seguindo um processo de oxidação. Já a hidroxietil celulose continua a apresentar pico exotérmico mesmo sob fluxo de nitrogênio. Portanto este polissacarídeo não 
sofre degradação térmica por oxidação. Observamos através do diagrama de TG que esta degradação não ocorre em uma única etapa, mas em três. A primeira no intervalo de temperatura de 200 a $350^{\circ} \mathrm{C}$ com perda de $61 \%$ de massa, a segunda de 350 a $600^{\circ} \mathrm{C}$ com $7 \%$ de perda e a última etapa de degradação (onde poderia ser observado um outro pico exotérmico ${ }^{23,24}$ ) de 600 a $750^{\circ} \mathrm{C}$ com perda de $19 \%$ em massa. O teor de cinzas para esta amostra de HEC é igual a 3,4\%. Resultados semelhantes foram obtidos para as outras amostras estudadas.

As curvas de análise térmica para uma das amostras de HPC são apresentadas na figura 2.11. Na análise de TG observa-se a perda de massa de aproximadamente $4 \%$ no intervalo de temperatura de ambiente até próximo a $100^{\circ} \mathrm{C}$. Este fenômeno é acompanhado de pico endotérmico na curva de DSC e está relacionado com a umidade presente na amostra.

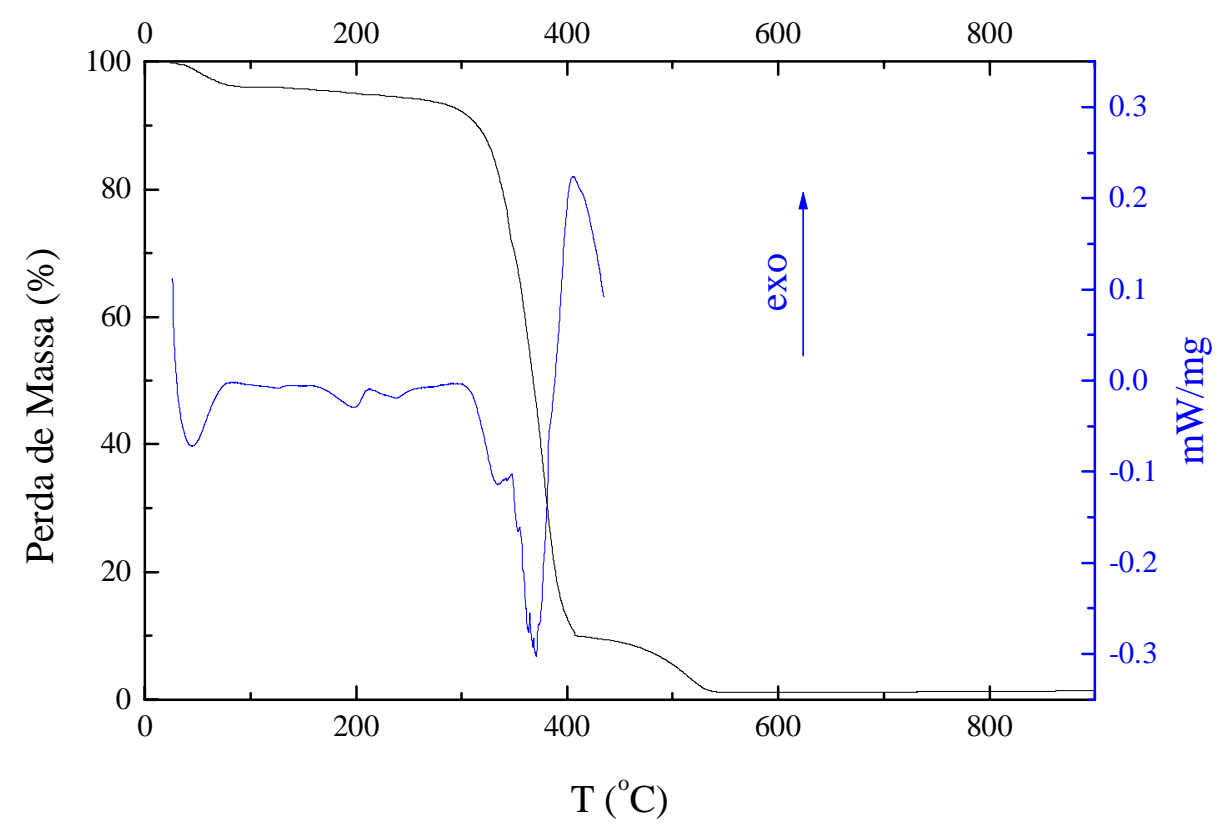

Figura 2. 11: Curvas de análise térmica (DSC e TG) para amostra de hidroxipropil celulose (Aldrich 19,188-4); fluxo de nitrogênio 
Outros dois picos endotérmicos são observados no intervalo de 300 a $400^{\circ} \mathrm{C}$ acompanhado de perda de massa de $86 \%$. Foi demonstrado que estes picos estão associados à decomposição térmica da HPC. É descrito na literatura ${ }^{23,24}$ que, sob fluxo de ar a decomposição térmica encontra-se associada a pico exotérmico indicando a ocorrência deste processo via mecanismo de oxidação, diferente da hidroxietil celulose. Uma última transição na curva de TG corresponde ao intervalo de temperatura de 400 a $550^{\circ} \mathrm{C}$ com perda de $8,5 \%$ em massa; o teor de cinzas da amostra é, portanto, igual a 1,5\%. Podemos inferir através das curvas de análise térmica que os mecanismos de degradação térmica para os dois polissacarídeos estudados (HEC e HPC) são diferentes.

\subsubsection{1-Determinação dos parâmetros estruturais de fidroxietilcelulose}

Os valores de grau de substituição molar (MS) das amostras de HEC foram obtidos dos correspondentes espectros de ${ }^{1} \mathrm{H}-\mathrm{RMN}$ (figura 2.12). Para determinar o MS por esta técnica espectroscópica, é necessária a hidrólise preliminar do derivado de celulose em ácido clorídrico concentrado ( $36 \%)$. Este procedimento leva à despolimerização da macromolécula e resulta em melhor definição das regiões espectrais a serem analisadas ${ }^{16}$. Podemos identificar na figura 2.12 duas regiões. A região $B(3,5$ a 4,4 ppm) representa a contribuição de 6 hidrogênios do anel de anidroglicose e 4 hidrogênios do grupo substituinte hidroxietil. A área $A$ (entre 4,3 e 5,8 ppm) representa a intensidade do átomo de hidrogênio ligado ao carbono 1 (figura 2.13) do anel de anidroglicose. A presença de vários deslocamentos químicos nesta região é devido à diferenciação do ambiente eletrônico relativo ao átomo na mesma posição nos derivados de celulose que são formados durante a hidrólise ${ }^{16}$. 
Desta forma, o grau de substituição molar pode ser calculado para as várias amostras de HEC segundo a expressão $8^{16}$, sendo os resultados obtidos apresentados na tabela 2.4 .

$$
M S=\frac{B-6 A}{4 A}
$$

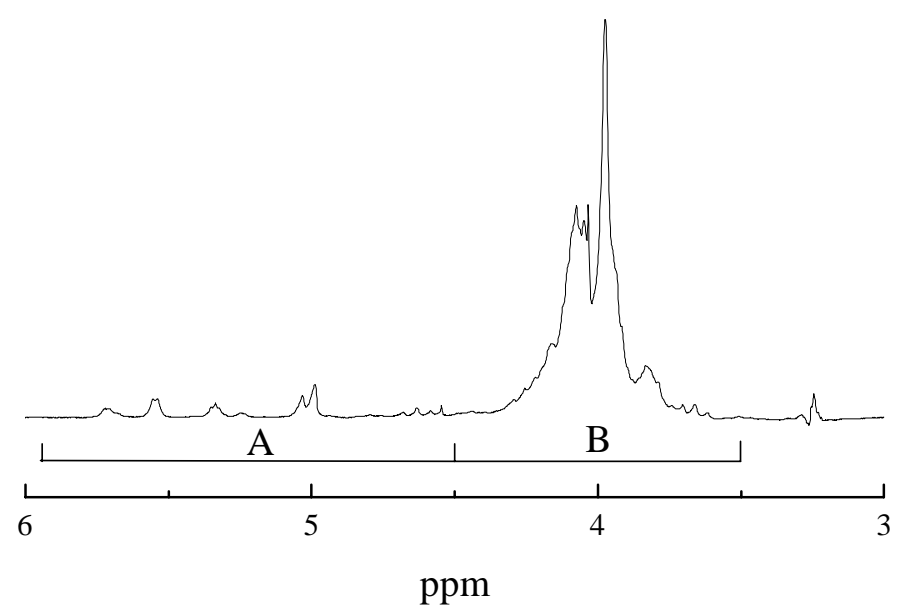

Figura 2. 12: Espectro de ${ }^{1} \mathrm{H}-\mathrm{RMN}$ de hidroxietil celulose QP09H hidrolisada em $\mathrm{HCl}$

Tabela 2. 4: Valores de grau de substituição molar de amostras de hidroxietil celulose (HEC)

\begin{tabular}{cc}
\hline HEC & MS \\
\hline QP09H & 1,22 \\
QP300H & 0,58 \\
QP4400 & 1,35 \\
QP15MH & 1,72 \\
QP30MH & 0,91 \\
QP52MH & 2,19 \\
QP100MH & 1,98 \\
\hline
\end{tabular}

A figura 2.13 apresenta o espectro de ${ }^{13} \mathrm{C}-\mathrm{RMN}$ de $\mathrm{HEC}$ QP09H e deslocamentos químicos relativos aos carbonos dos anéis de anidroglicose e das 
substituições. Os deslocamentos químicos apresentados foram atribuídos segundo a literatura existente ${ }^{18,25,26}$.

\begin{tabular}{|c|c|c|c|c|}
\hline & $\mathbf{N}^{0} \mathbf{C}$ & (PPM) & $\mathbf{N}^{\mathbf{0}} \mathbf{C}$ & (PPM) \\
\hline & 1 & 102.3 & 6 & $\begin{array}{l}70,0(\mathrm{R}=\mathrm{H}) \\
60,4(\mathrm{R} \neq \mathrm{H})\end{array}$ \\
\hline & 2 & $\begin{array}{l}79,6(\mathrm{R} \neq \mathrm{H}) \\
74,5(\mathrm{R}=\mathrm{H})\end{array}$ & 7 & 69,7 \\
\hline \multirow{3}{*}{$\mathrm{R}=\mathrm{H} ;-\left(\mathrm{CH}_{7}^{2} \underset{7}{\mathrm{CH}_{2} \mathrm{O}}\right)_{\mathrm{n}}-\underset{8}{\mathrm{CH}_{2}} \underset{9}{\mathrm{CH}_{2}} \mathrm{OH}$} & 3 & $\begin{array}{l}81,8(\mathrm{R} \neq \mathrm{H}) \\
79,6(\mathrm{R}=\mathrm{H})\end{array}$ & 8 & 72,0 \\
\hline & 4 & 81,8 & \multirow[t]{2}{*}{9} & \multirow[t]{2}{*}{60,0} \\
\hline & 5 & 73,7 & & \\
\hline
\end{tabular}

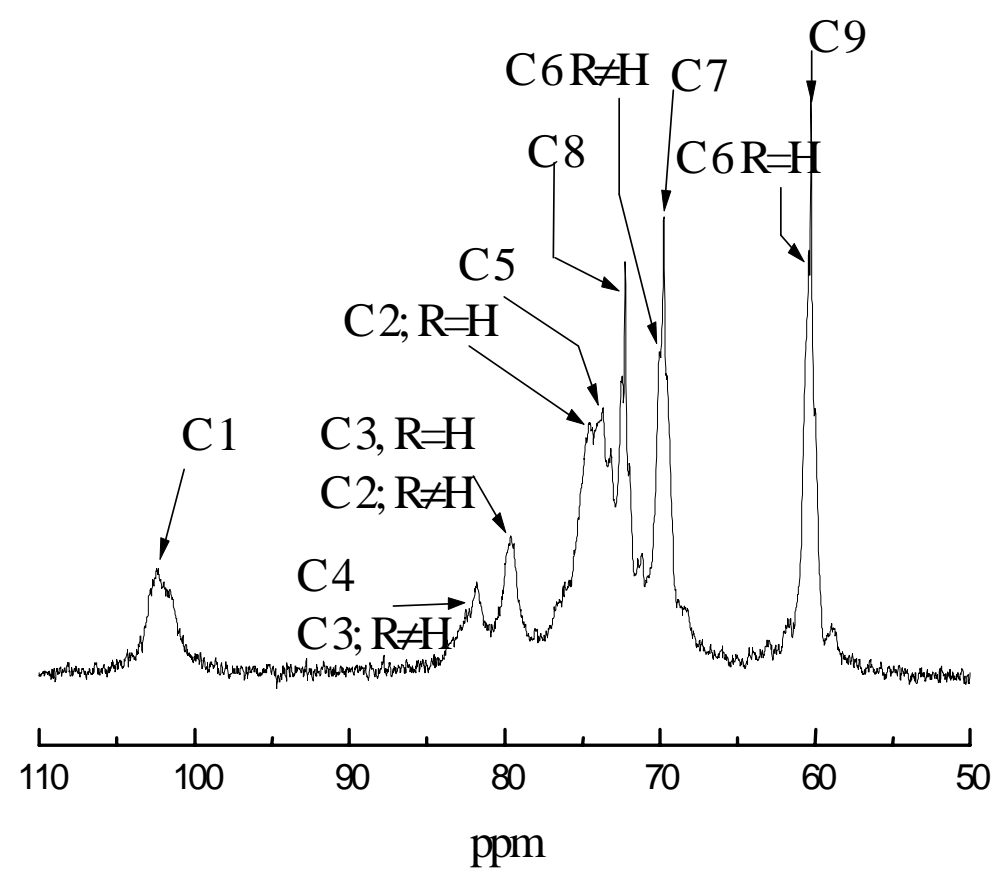

Figura 2. 13: Espectro de ${ }^{13} \mathrm{C}-\mathrm{RMN}$ de HEC QP09H em DMSO $d_{6}$ e deslocamentos químicos

Na tabela 2.5 são apresentados os valores para os deslocamentos químicos de $\beta$-D-glicose, celulose e alguns derivados do tipo éter. Pode ser observado que a formação da ligação glicosídica entre os anéis de anidroglicose resulta em deslocamento do pico do carbono 1, tornando-o mais desblindado. Também pode ser observada mudança do deslocamento químico dos carbonos substituídos (carbonos 2, 
3 e 6) para campo menos blindado. Os deslocamentos químicos assinalados para os carbonos da substituição (figura 2.13) foram atribuídos segundo literatura existente para poli(óxido de etileno) ${ }^{18}$. Segundo estes estudos, o tamanho da cadeia do substituinte não afeta os valores de deslocamento químico

Tabela 2. 5: Deslocamentos químicos em ${ }^{13} \mathrm{C}-\mathrm{RMN}$ para $\beta$-D-glicose, celulose e alguns derivados do tipo éter

\begin{tabular}{ccccccc}
\hline Amostra & \multicolumn{5}{c}{ Deslocamentos químicos (PPM) } \\
\cline { 1 - 3 } & C1 & C2 & C3 & C4 & C5 & C6 \\
\hline B-D-glicose & 96,5 & 74,8 & 76,4 & 70,3 & 76,6 & 61,5 \\
6-O-(2-hidroxietil)- $\beta$-D-glicose & 97,2 & 75,2 & 76,7 & 70,4 & 75,9 & 70,5 \\
celulose & 103,5 & 74,6 & 75,7 & 79,8 & 76,4 & 61,3 \\
Tri-O-etilcelulose & 103,0 & 82,1 & 82,6 & 77,4 & 75,3 & 68,8 \\
HEC & 102,3 & 79,6 & 81,8 & 81,8 & 79,6 & 70,0 \\
\hline
\end{tabular}

DeMember e colaboradores ${ }^{18}$ mostraram que é possível a determinação de DS pela observação do espectro de ${ }^{13} \mathrm{C}-\mathrm{RMN}$ aplicando-se as seguintes relações:

$$
p=[C 7] /[C 9]
$$

isto é, a razão do número de átomos de carbono na unidade repetitiva da cadeia de substituinte (C7 e C9); esta razão é usada para o cálculo de DS:

$$
D S=\frac{M S}{p / 2+1}
$$

Outra relação interessante é a razão entre o número total de átomos de carbono C9 e o número de átomos de carbono ligados a grupos alcoólicos primários: 


$$
q=[C 9] /[C 9]+[C 6, R=H]
$$

Esta relação auxilia no cálculo de número de carbonos na posição 6 não substituídos, e o número de carbonos secundários (C2 e C3) não substituídos:

$$
\begin{gathered}
{[C 6, R=H]=\frac{D S(1-q)}{q}} \\
{[C 2, R=H]+[C 3, R=H]=3-D S-[C 6, R=H]}
\end{gathered}
$$

Os valores obtidos para estes parâmetros estão apresentados na tabela 2.6. Analisando esta e a figura 2.14, observa-se que os valores de DS apresentam uma boa relação linear com os respectivos valores de MS. Esta linearidade (no intervalo estudado) é conseqüência do método industrial de obtenção da HEC, o qual consiste em uma primeira etapa de ativação da celulose por hidróxido de sódio e posterior adição do óxido de etileno ${ }^{12}$. Vale a pena ressaltar, que esta dependência linear é limitada, já que poderiam ser substituidos no máximo três grupos $\mathrm{OH}$ presentes na unidade de anidroglicose, levando ao valor de DS $=3$. Entretanto o valor de MS poderia ser infinito por causa dos grupos $\mathrm{OH}$ dos substituintes serem livres para reações posteriores com óxido de etileno ${ }^{27}$. 
Tabela 2. 6: Resultados de caracterização de HEC através de técnicas de espectroscopia de ressonância magnética nuclear

\begin{tabular}{ccccc}
\hline HEC & MS & DS & {$[\mathbf{C 6}, \mathbf{R}=\mathbf{H}]$} & {$[\mathbf{C 2}, \mathbf{R}=\mathbf{H}]+[\mathbf{C 3}, \mathbf{R}=\mathbf{H}]$} \\
\hline QP09H & 1,22 & 0,75 & 0,69 & 1,56 \\
QP300H & 0,58 & 0,34 & 0,33 & 2,33 \\
QP4400 & 1,35 & 0,88 & 0,45 & 1,67 \\
QP15MH & 1,72 & 1,01 & 0,97 & 1,02 \\
QP30MH & 0,91 & 0,54 & 0,46 & 2,00 \\
QP52MH & 2,19 & 1,30 & 0,94 & 0,76 \\
QP100MH & 1,98 & 1,19 & 1,42 & 0,40 \\
\hline
\end{tabular}

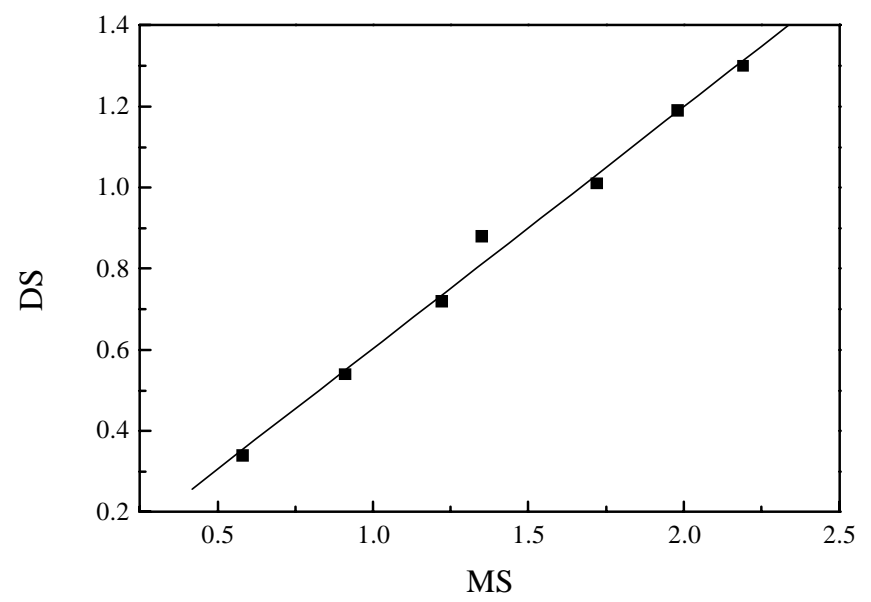

(a)

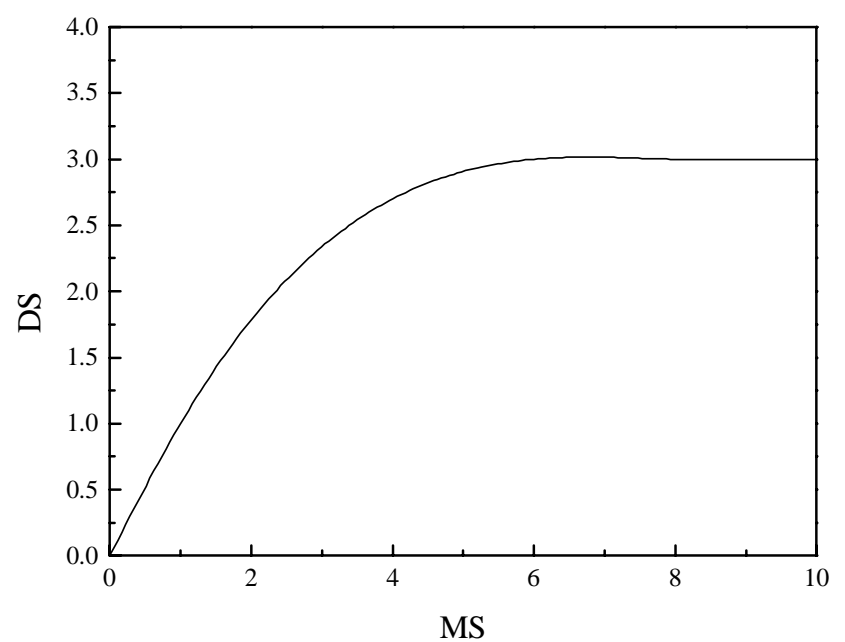

(b)

Figura 2. 14: Gráfico de grau de substituição (DS) versus grau de substituição molar (MS) para amostras de hidroxietil celulose; (a): obtido para as amostras analisadas;

(b): hipotético para a síntese do polissacarídeo 
Brown e colaboradores ${ }^{20}$ mostraram a possibilidade de determinação da massa molar de hidroxietil celulose através de técnicas viscosimétricas, por solubilização deste polímero em água e cadoxen. Em solução aquosa, este derivado de celulose comporta-se como uma cadeia rígida e estendida, enquanto que em cadoxen exibe propriedades de polímero flexível. A equação de Staudinger para soluções aquosas de HEC, que relaciona a viscosidade intrínseca à massa molar, é dada pela expressão 7 apresentada aqui novamente:

$$
[\eta]=1,1 \cdot 10^{-2} \bar{M}^{0,87}
$$

As viscosidades intrínseca das várias amostras de HEC estudadas, obtidas através da extrapolação do gráfico de viscosidade intrínseca versus concentração ao limite de diluição infinita, são apresentadas na tabela 2.7. Pode ser observado que a constante de Huggins $\left(k^{\prime}\right)$ não se encontra apenas relacionada à massa molar e à temperatura do sistema, mas também ao poder de hidratação da molécula pelo solvente. Este, assim como a viscosidade intrínseca, é um parâmetro característico a cada polímero ${ }^{20}$.

Tabela 2. 7: Resultados de viscosimetria de amostras de HEC em solução aquosa

\begin{tabular}{cccc}
\hline HEC & $\left.[\eta] \mathbf{~ d L . g ~}^{-\mathbf{1}}\right)$ & $\mathbf{k}^{\boldsymbol{\prime}}$ & DP \\
\hline QP09H & 1,386 & 0,636 & 259 \\
QP300H & 3,913 & 0,747 & 854 \\
QP4400 & 7,619 & 0,803 & 1835 \\
QP15MH & 9,762 & 0,637 & 2447 \\
QP30MH & 9,855 & 0,687 & 2474 \\
QP52MH & 11,85 & 0,796 & 3058 \\
QP100MH & 13,92 & 0,635 & 3680 \\
\hline
\end{tabular}


Os valores de DP obtidos, ainda que elevados para algumas amostras, concordam com os dados da literatura ${ }^{20}$ e, como esperado, não mostram qualquer relação com os valores de DS e MS, indicando que o tamanho da cadeia de celulose não afeta o rendimento da reação de oxietilação nem a distribuição dos grupos substituintes $^{27}$.

2.1.4.2 - Determinação dos parâmetros estruturais de fidroxipropil celulose

Com o auxílio da técnica de RMN podemos calcular os parâmetros estruturais (MS e DS) das amostras de hidroxipropil celulose estudadas. Para determinação de $\mathrm{MS}^{28}$ dissolveu-se a HPC em clorofórmio deuterado, sendo obtido o espectro apresentado na figura 2.15. O pico em campo mais desblindado (A, 0,5 a 1,5 ppm) corresponde à ressonância dos prótons metilênicos da substituição. Os picos alargados entre 2 e 5,5 ppm (região B na figura 2.15) resultam dos hidrogênios do anel de anidroglicose e dos grupos $\mathrm{CH}_{2}$ e $\mathrm{CH}$ presentes na substituição. Desta forma, o cálculo de MS é expresso pela equação 14 .

$$
M S=\frac{10 A}{3(B-A)}
$$




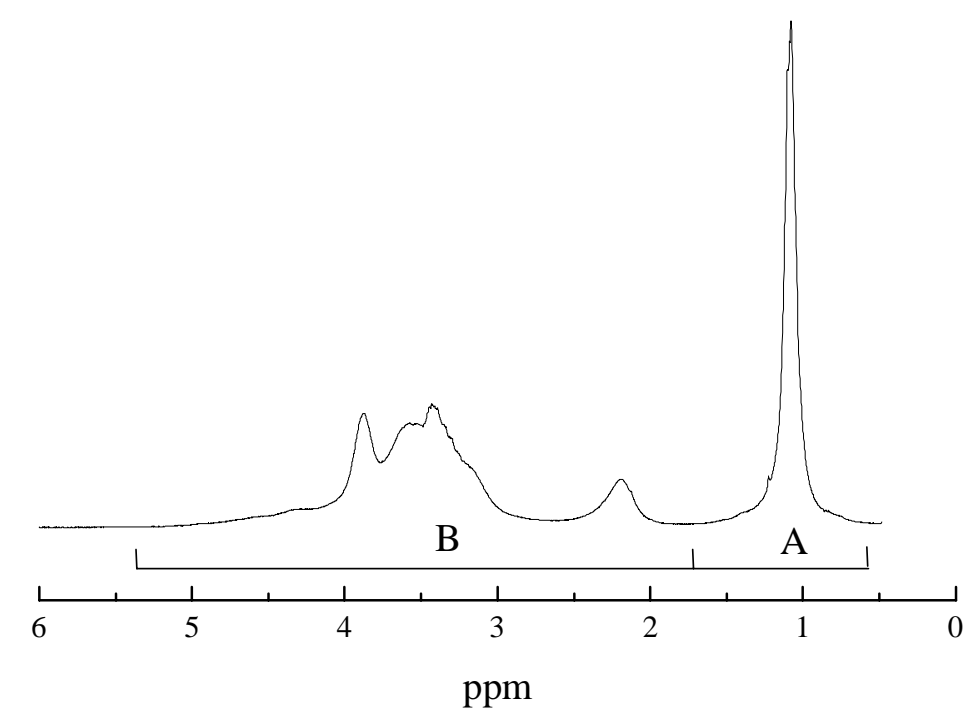

Figura 2. 15: Espectro de ${ }^{1} \mathrm{H}-\mathrm{RMN}$ de hidroxipropil celulose (Aldrich - 19,188-4) em clorofórmio deuterado; A: área relativa aos hidrogênios do grupo $\mathrm{CH}_{3}$ do substituinte; B: área relativa aos hidrogênios do anel de anidroglicose e dos grupos $\mathrm{CH}_{2}$ e $\mathrm{CH}$ da substituição

O valor de grau de substitução (DS) pode ser calculado a partir do espectro obtido no experimento de ${ }^{13} \mathrm{C}-\mathrm{RMN}$ (figura 2.16). Os deslocamentos químicos dos carbonos presentes no anel de anidroglicose da HPC podem ser identificados a partir da comparação dos espectros aqui obtidos com os de HEC. Sabendo que $(b)$ representa a área do pico de ressonância dos hidrogênios metílicos internos à cadeia de substituinte e $(a)$ a dos hidrogênios metílicos terminais ${ }^{17}$, podemos obter a razão $\mathrm{R}=$ número de $\mathrm{CH}_{3}$ internos/número de $\mathrm{CH}_{3}$ terminais. Desta forma o cálculo de DS fica simplificado a $\mathrm{DS}=\mathrm{MS} /(1+\mathrm{R})$. A precisão das medidas de DS e MS é questionável, pois a incerteza na medida de cada integral é multiplicada no cálculo matemático. Entretanto, a grande vantagem destes experimentos é a rapidez na medida. Na tabela 2.8 são apresentados os valores de DS e MS obtidos para as amostras de HPC estudadas. 


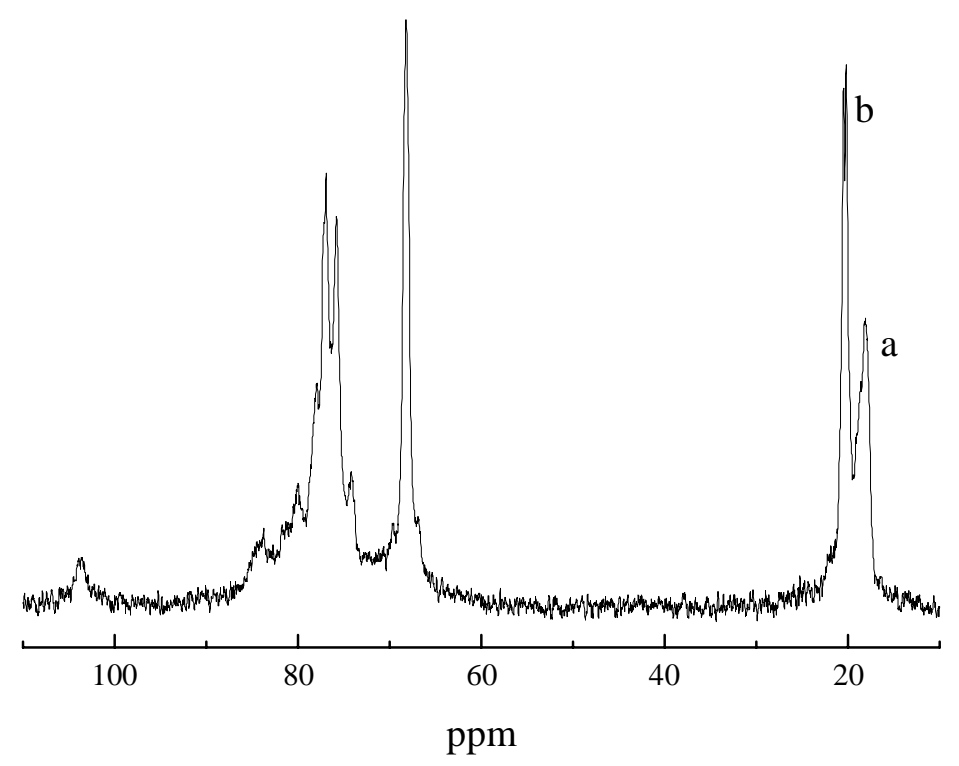

Figura 2. 16: Espectro de ressonância magnética nuclear de carbono de hidroxipropil celulose (Aldrich 19,188-4); (a) pico dos hidrogênios metílicos terminais na cadeia de substituinte; (b) pico dos hidrogênios metílicos internos ao substituinte

Tabela 2. 8: Valores dos parâmetros estruturais determinados para as amostras de hidroxipropil celulose

\begin{tabular}{cccc}
\hline HPC & $\begin{array}{c}\text { Mw (g/mol - } \\
\text { catálogo) }\end{array}$ & MS & DS \\
\hline $43,500-7$ & 80000 & 5,60 & 3,0 \\
$19,188-4$ & 100000 & 5,46 & 2,4 \\
$19,189-2$ & 370000 & 4,25 & 1,2 \\
\hline
\end{tabular}

Analisando os valores de DS e MS apresentados na tabela 2.8 podemos observar que também para a HPC o valor de DS é limitado a 3 e o valor de MS varia conforme a disponibilidade de óxido de propileno no meio reacional durante a síntese do derivado de celulose. Observamos também que as amostras de HPC apresentam valores de MS bem maiores que as de HEC. 
2.2 - Caracterização das aminas e isocianatos

\subsection{1-Aspectos gerais}

A síntese dos filmes de polissacarídeos enxertados com poliéteres baseia-se na conhecida reação entre álcoois e isocianatos com formação de poliuretanas ${ }^{15}$. No entanto, os isocianatos de poli(óxido de etileno) e poli(óxido de propileno) desejados não eram disponíveis comercialmente. Já podem ser encontrados alguns isocianatos de poliéter com variadas massas molares, no entanto o valor comercial é muito elevado. Desta forma a síntese dos isocianatos desejados a partir das correspondentes aminas comerciais foi a alternativa escolhida.

Existem mais de 25 métodos de preparação de isocianatos ${ }^{29}$. A primeira síntese foi realizada em 1849 na decomposição simultânea do sulfato de dialquila e cianeto de potássio ${ }^{15}$. Com o advento das poliuretanas vários estudos foram realizados buscando novos métodos de preparação, sendo o mais importante o de fosgenação de aminas ${ }^{29}$, como mostrado na figura 2.17 .

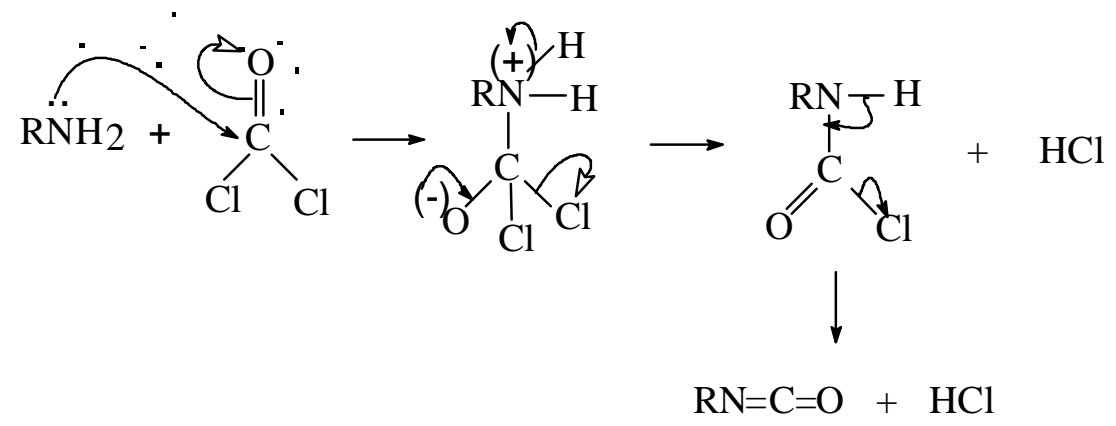

Figura 2. 17: Esquema de síntese de isocianato a partir de amina e fosgênio 
O uso de fosgênio como reagente é arriscado pois este produto químico é um gás altamente tóxico. Triclorometil cloroformato (difosgênio) foi utilizado como substituto sendo obtidos resultados satisfatórios, mas por ser um líquido seu armazenamento e transporte são dificultados ${ }^{30}$. Um interessante subtituto para este reagente é o bis(triclorometil) carbonato ou trifosgênio, um sólido com ponto de fusão igual a $80^{\circ} \mathrm{C}$ e ponto de ebulição igual a $260^{\circ} \mathrm{C}$ fácil de ser transportado e $\operatorname{armazenado}^{30,31}$. A reatividade do trifosgênio com compostos nitrogenados é a análoga ao do fosgênio, e os produtos de reação são isocianatos, uréias e compostos carbonilados $^{31}$. O esquema de síntese de isocianatos a partir de aminas primárias é apresentado na figura 2.18. É reportado que quantidades estequiométricas são suficientes $^{32}$, no entanto o excesso de trifosgênio assegura que uréias de alta massa molar sejam formadas a partir do excesso de amina. A presença de trietilamina para remoção de $\mathrm{HCl}$ é imprescindível para a formação do produto desejado ${ }^{31,32}$. Devido à sensibilidade das funções isocianato à presença de água, a síntese deve ser efetuada em meio anidro, pois traços deste solvente levam à formação de uréia. 


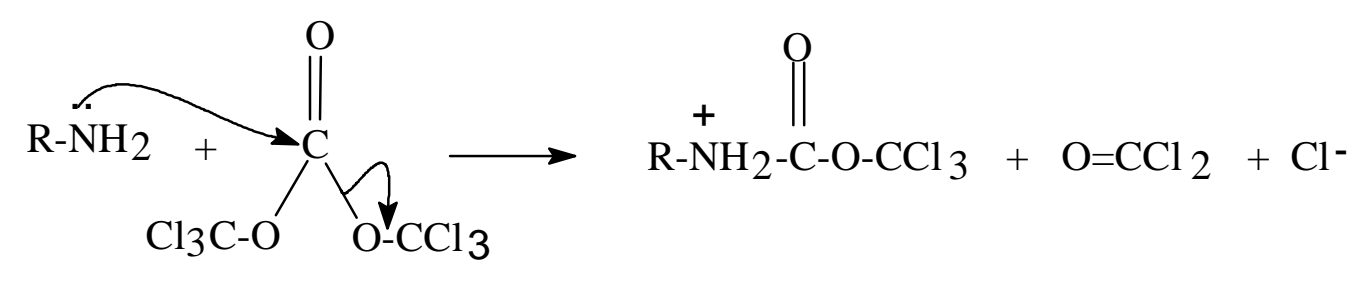<smiles></smiles>

$\stackrel{\mathrm{Et} 3 \mathrm{~N}}{\longrightarrow} \mathrm{R}-\mathrm{N}=\mathrm{C}=\mathrm{O}+2 \mathrm{Et} 3 \mathrm{NH}^{+} \mathrm{Cl}^{-}+2 \mathrm{O}=\mathrm{CCl} 2$

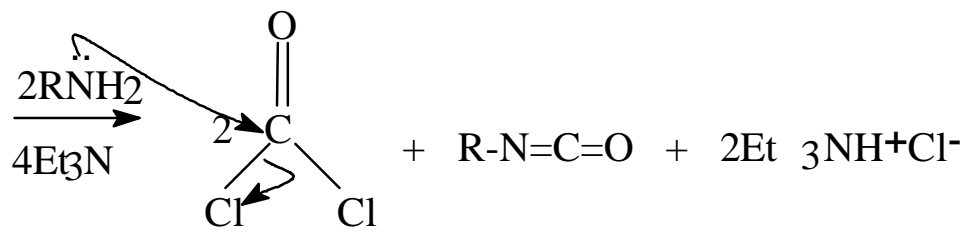

$\longrightarrow \quad 3 \mathrm{R}-\mathrm{N}=\mathrm{C}=\mathrm{O}+6 \mathrm{Et} 3 \mathrm{NH}^{+} \mathrm{Cl}^{-}$

Figura 2. 18: Esquema de síntese de isocianato a partir de amina e trifosgênio

A ligação $\mathrm{N}=\mathrm{C}=\mathrm{O}$ dos isocianatos é altamente polarizada, o que torna o carbono da carbonila suscetível ao ataque de nucleófilos. A reação mais importante, e a ser utilizada, é a adição de álcoois com formação de carbamatos (uretanas) representada na figura 2.19. Os isocianatos também reagem com ácidos carboxílicos, aminas e água, formando respectivamente amidas, uréias e ácido carbâmico ${ }^{15,30}$. Este último é instável e se decompõe em dióxido de carbono e na amina correspondente. A altas temperaturas os isocianatos podem também reagir com grupos $\mathrm{NH}$ de uretanas, uréias ou amidas ${ }^{15,30}$. Algumas reações podem levar à ramificação e/ou entrecruzamento das cadeias de uretana com formação de alofanatos e biuréias. 
Outras reações de entrecruzamento a altas temperaturas são as de formação de dímeros, em isocianatos aromáticos, e trímeros em isocianatos alifáticos. Estes compostos são termicamente estáveis.

$$
\left[\mathrm{R}-\ddot{\mathrm{N}}=\mathrm{C}=\ddot{\mathrm{O}} \rightleftharpoons \mathrm{R}-\ddot{\mathrm{N}}=\stackrel{(+)}{\mathrm{C}}-\ddot{\mathrm{O}}:^{(-)} \rightleftharpoons \mathrm{R}-\stackrel{\ddot{\mathrm{N}}^{-}}{=} \stackrel{(+)}{\mathrm{C}}=\ddot{\mathrm{O}}\right]
$$

Figura 2. 19: Esquema de reação de isocianato com álcool para formação de uretana

\section{$2.2 .2-$ Materiais}

Para a realização dos experimentos foram utilizados os seguintes produtos químicos: dicloro-metano (Merk), tetra-hidro-furano, THF, (Merk), trietilamina (Merk), trifosgênio (Aldrich), O,O'-bis(2-aminopropil) polietilenoglicol (JEFFAMINE ED600 - Fluka), O,O'-bis(2-aminopropil) polipropilenoglicol (JEFFAMINE D400 - Fluka), O-(2-aminopropil)-O'-(2-metoxietil) polipropilenoglicol (JEFFAMINE M600 - Fluka), ortoformiato de etila (Sigma), tolueno (Nuclear), isopropanol (Synth), di-n-butilamina (Nuclear), ácido clorídrico (Synth), hidróxido de potássio, $\mathrm{KOH}$, (Synth), hidróxido de sódio, $\mathrm{NaOH}$, (Mallinckrod), cloreto de cálcio anidro, $\mathrm{CaCl}_{2}$ (Nuclear), sulfato de cobre, $\mathrm{CuSO}_{4}$ (Reagen), dimetilsulfóxido deuterado (Aldrich) e brometo de potássio, KBr (Riedelde-Haën). 


\section{$2.2 .3-$ Métodos}

\subsubsection{1-Prurificação dos solventes e dos reagentes}

$\mathrm{O}$ diclorometano foi destilado sobre $\mathrm{KOH}$ seguido de secagem com $\mathrm{NaOH}$ e $\mathrm{CaCl}_{2}$ anidro ${ }^{33}$. THF foi destilado sobre $\mathrm{CuSO}_{4}$ seguido de destilação sobre $\mathrm{KOH}^{33}$. Estes dois solventes foram, após purificação, armazenados com peneiras moleculares e sob atmosfera de nitrogênio seco. A trietilamina foi seca e destilada sobre $\mathrm{KOH}$ e também armazenada com peneiras moleculares e sob atmosfera de nitrogênio seco ${ }^{34}$. As aminas foram secas por agitação com ortoformiato de etila (5\% em massa) durante aproximadamente 6 horas e depois aquecidas a $40^{\circ} \mathrm{C}$ sob vácuo para evaporar o ortoformiato de etila que não reagiu e os produtos de sua reação com a água $^{34}$. O trifosgênio foi utilizado como adquirido.

\subsubsection{2 - Caracterização das aminas}

Os espectros de infravermelho das aminas foram registrados a partir de filmes líquidos sobre pastilhas de $\mathrm{KBr}$, utilizando-se aparelho BOMEM modelo MB-102.

As análises de RMN foram realizadas em espectrômetro BRUCKER AC200 (200MHz para hidrogênio e 50MHz para carbono) a temperatura ambiente em tubos de $5 \mathrm{~mm}$ de diâmetro utilizando-se como solvente DMSO- $d_{6}{ }^{35}$.

As massas molares foram obtidas segundo método titulométrico ${ }^{36}$ com o seguinte procedimento: aproximadamente $1,0 \mathrm{~g}$ de amina foi dissolvido em tolueno. A solução permaneceu em agitação durante 15 minutos. Logo após, foram adicionados $100 \mathrm{~mL}$ de isopropanol e 4 a 6 gotas de azul de bromofenol. A solução 
foi titulada com ácido clorídrico $0,1 \mathrm{~N}$ até ponto de viragem do indicador. A massa molar da amina foi calculada segundo a equação

$$
M M=\frac{2 m(g)}{N_{\text {ácido }} V_{\text {ăcido }}(m L)}
$$

2.2.3.3 - Sintese dos isocianatos

O sistema mostrado na figura 2.20 foi utilizado na síntese dos isocianato mono e di funcionais ${ }^{32,34}$. O aparato constitui-se de um balão reacional de 3 bocas sendo conectados dois funis de adição e um condensador de refluxo; a agitação do meio reacional é magnética. A entrada de nitrogênio no sistema localiza-se na extremidade superior de um dos funis de adição. À saída do condensador de refluxo encontravam-se três trapes contendo, na seqüência, papel de filtro umedecido com solução de p-dimetilaminobenzaldeído em tetracloreto de carbono, solução de hidróxido de sódio e água. Estes foram utilizados para neutralizar $\mathrm{HCl}$ gasoso e trifosgênio, ou seus produtos de degradação, que possam, eventualmente desprenderse da solução ${ }^{34}$. Antes do início da reação deixou-se o sistema desaerando com nitrogênio seco durante aproximadamente 10 minutos.

Para a síntese de diisocianato dissolveu-se $16 \mathrm{~g}$ de trifosgênio em $50 \mathrm{~mL}$ de diclorometano no balão. A temperatura do sistema foi mantida a $0^{\circ} \mathrm{C}$ através de banho de gelo. $35 \mathrm{~g}$ de diamina foram dissolvidos em $100 \mathrm{~mL}$ de diclorometano e a solução foi transferida para o funil de adição. Esta foi adicionada gota a gota ao meio reacional. Depois, uma solução de $40 \mathrm{~mL}$ de trietilamina em $50 \mathrm{~mL}$ de diclorometano foi adicionada da mesma maneira. Durante as duas adições o sistema foi mantido a 
$0^{\circ} \mathrm{C}$, sob fluxo de nitrogênio seco. Ao final da adição da trietilamina cessou-se o fluxo de nitrogênio e o sistema foi aquecido até $40^{\circ} \mathrm{C}$ e mantido em refluxo durante duas horas. Após este período passou-se novamente nitrogênio seco pelo sistema que foi fechado e colocado em refrigerador por duas horas para precipitar o cloridrato de trietilamina. Esta substância foi filtrada em funil de placa sinterizada. O diclorometano foi evaporado sob pressão reduzida. Foram adicionados $20 \mathrm{~mL}$ de THF e deixou-se o produto da reação no refrigerador por uma noite para precipitar resíduos de cloridrato de trietilamina que foi novamente filtrado. O THF foi evaporado sob pressão reduzida. O diisocianato obtido foi transferido para um frasco apropriado para armazenamento, desaerado com nitrogênio e guardado em refrigerador.

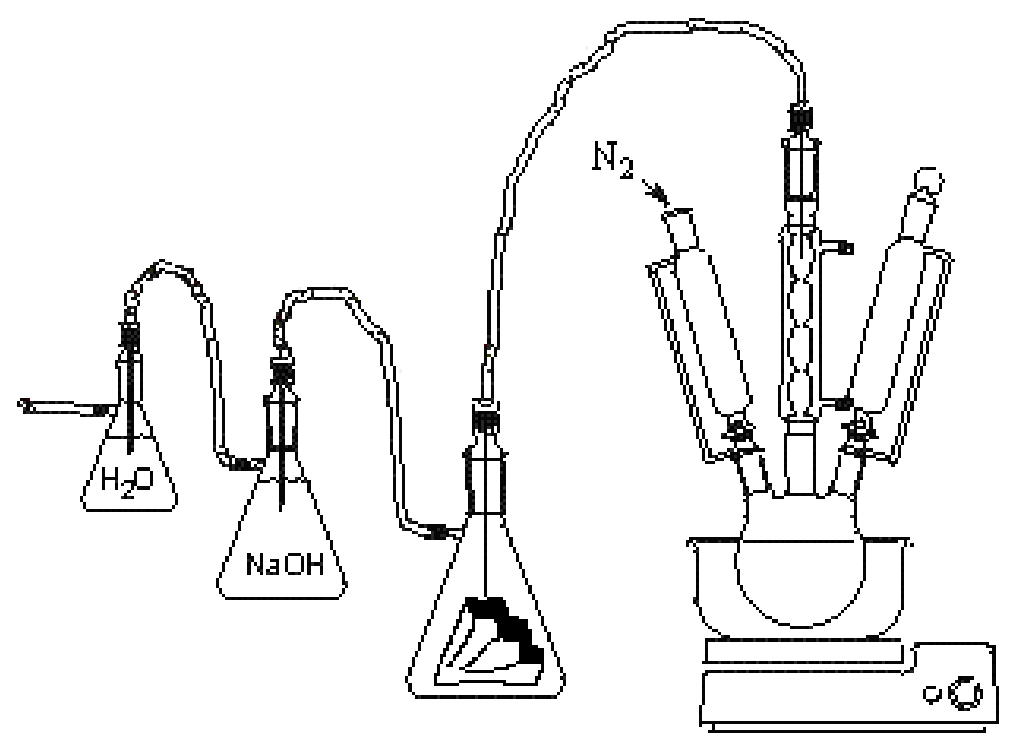

Figura 2. 20: Aparato usado para a síntese dos isocianatos 


\subsubsection{4 - Caracterização dos isocianatos}

As análises de infravermelho e RMN foram realizadas de modo análogo às das aminas precursoras. A dosagem de funções isocianato foi realizada segundo norma $\mathrm{ASTM}^{36}$. Aproximadamente $1,0 \mathrm{~g}$ de isocianato foi dissolvido em $25 \mathrm{~mL}$ de tolueno. A solução foi submetida à agitação até dissolução completa do isocianato, sendo então adicionado $25 \mathrm{~mL}$ de solução $0,1 \mathrm{~N}$ de di-n-butilamina em tolueno e continuando agitação por mais 15 minutos. Após este período foram adicionados $100 \mathrm{~mL}$ de isopropanol e gotas de azul de bromofenol. A solução foi então titulada com ácido clorídrico $0,1 \mathrm{~N}$ até ponto de viragem do indicador. $\mathrm{O}$ cálculo da dosagem de funções isocianato é baseado na reação deste com aminas com formação de uréias: $\mathrm{RN}=\mathrm{C}=\mathrm{O}+\mathrm{R}^{\prime} \mathrm{NH}_{2} \rightarrow \mathrm{RNHCONHR}$. O excesso de amina é neutralizado com ácido padronizado tornando simples o cálculo:

$$
N C O \%=\frac{[(B-V) x N x 0,042]}{m(g)} \times 100
$$

onde $B$ é o volume de ácido gasto na titulação do branco (solução que contém apenas di-n-butilamina $0,1 \mathrm{~N}$, tolueno e isopropanol), $V$ é o volume de ácido gasto na titulação da solução de isocianato e $N$ é a normalidade do ácido. 
$2.2 .4-$ Resultados

\subsubsection{1-Caracterização das aminas}

As estruturas das aminas precursoras dos isocianatos são apresentadas na figura 2.21. É interessante observar que estas estruturas possuem grupos funcionais fáceis de serem observados através de espectroscopia no infravermelho (figura 2.22). As principais bandas de absorção são apresentadas na tabela 2.9, bem como as massas molares determinadas através de técnicas viscosimétricas. Na tabela 2.10 encontram-se os valores dos deslocamentos químicos dos picos de ressonância de hidrogênio e carbono atribuídos de acordo com a literatura ${ }^{34,35}$. A numeração corresponde à utilizada na figura 2.21 .<smiles>CC(N)COCCC(C)C(=O)CC(C)N</smiles>

$A$<smiles>CC(N)COCCCOCC(C)OCC(C)N</smiles>

$B$<smiles>COCCC(=O)OCC(C)N</smiles>

C

Figura 2. 21: Estruturas das aminas comerciais utilizadas como precursoras dos isocianatos; A: O,O'-(2-aminopropil) polipropilenoglicol (JEFFAMINE D400); B:

O,O'-(2-aminopropil) polietilenoglicol (JEFFAMINE ED600); C: O-(2aminopropil)-O'-(2-metoxietil) polipropilenoglicol (JEFFAMINE M600) 
Tabela 2. 9: Massas molares e principais bandas de absorção no infravermelho observadas para as aminas estudadas

\begin{tabular}{|c|c|}
\hline Amina & MM (g/mol) \\
\hline JEFFAMINE D400 & 450 \\
\hline JEFFAMINE ED600 & 660 \\
\hline JEFFAMINE M600 & 600 \\
\hline Número de onda $\left(\mathrm{cm}^{-1}\right)$ & Ligação \\
\hline 3430 & $\begin{array}{l}\text { Deformação axial simétrica e assimétrica de ligação } \mathrm{NH} \\
\text { (observe que esta banda é mais larga para as diaminas e } \\
\text { quase não aparece na amina monofuncional devido à } \\
\text { concentração de grupos } \mathrm{NH}_{2} \text { na estrutura ser muito pequena) }\end{array}$ \\
\hline$\sim 2860$ & $\begin{array}{l}\text { Deformação axial de } \mathrm{CH}, \mathrm{CH}_{2} \text { e } \mathrm{CH}_{3} \text { alifáticos } \\
\text { (observar que esta banda é mais intensa nas aminas de } \\
\text { poli(óxido de propileno) }\end{array}$ \\
\hline $1640-1590$ & Deformação angular simétrica de ligação NH \\
\hline 1450 & $\begin{array}{l}\text { Deformação angular simétrica de ligação } \mathrm{CH} \text { de grupo } \\
\text { metileno }\end{array}$ \\
\hline 1350 & Deformação angular simétrica de ligação $\mathrm{CH}$ de grupo metila \\
\hline 1300 e 1245 & Deformação axial de ligação $\mathrm{CN}$ \\
\hline 1105 & Deformação axial assimétrica de ligação COC \\
\hline$\sim 945$ e $\sim 850$ & Deformação angular simétrica fora do plano de ligação $\mathrm{CH}$ \\
\hline
\end{tabular}

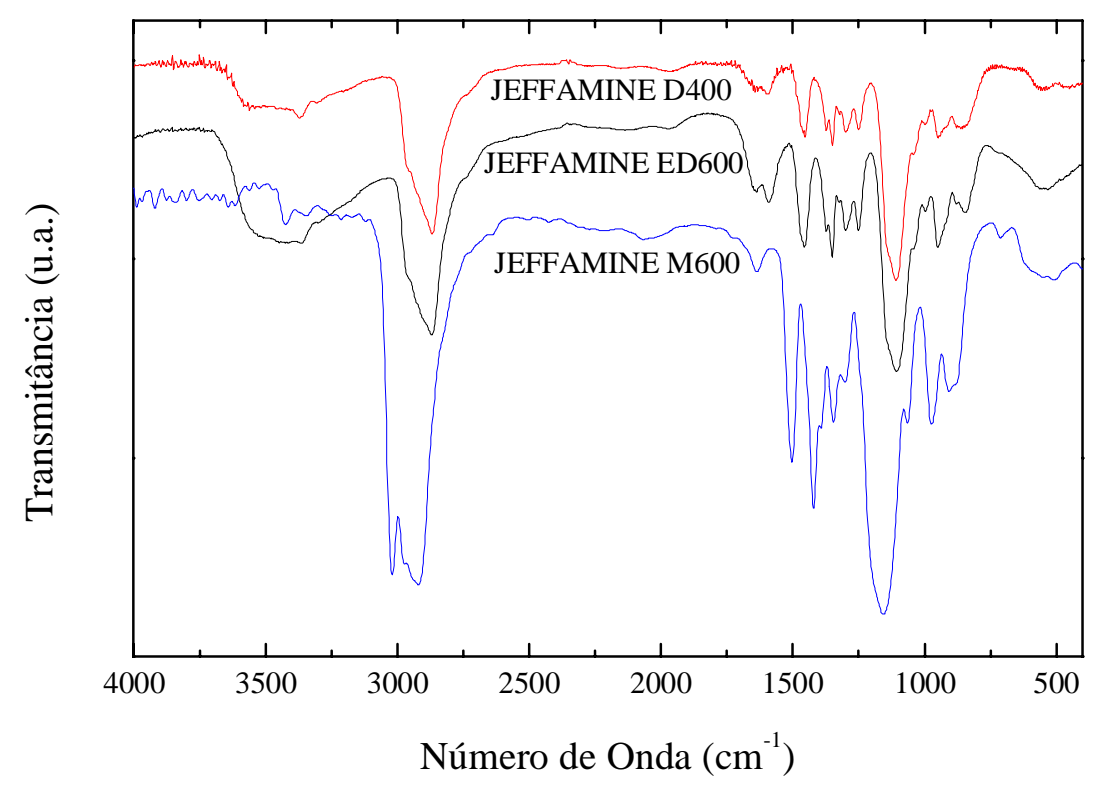

Figura 2. 22: Espectros no infravermelho das aminas comerciais utilizadas 
Tabela 2. 10: Deslocamentos químicos de carbono e hidrogênio em experimento de RMN das aminas precursoras dos isocianatos

\begin{tabular}{|c|c|c|c|}
\hline \multicolumn{4}{|c|}{ JEFFAMINE D400 } \\
\hline Hidrogênio & $\begin{array}{l}\text { Deslocamento } \\
\text { químico (ppm) }\end{array}$ & Carbono & $\begin{array}{l}\text { Deslocamento } \\
\text { químico (ppm) }\end{array}$ \\
\hline 1 & $2,83(2 \mathrm{H}$, multiplete $)$ & 1 & $46,1(2 \mathrm{C})$ \\
\hline 2 & $0,89(6 \mathrm{H}$, multiplete $)$ & 2 & $20,3(2 \mathrm{C})$ \\
\hline 3,4 e 6 & $\begin{array}{l}3,00-3,80 \\
(22 \mathrm{H}, \text { multiplete })\end{array}$ & 3 & 76,0 e $78,2(2 \mathrm{C})$ \\
\hline 5 & $1,05(18 \mathrm{H}$, dublete $)$ & 4 & $72,3(6 C)$ \\
\hline \multirow[t]{2}{*}{$\mathrm{NH}_{2}$} & $1,36(4 \mathrm{H}$, alargado $)$ & 5 & $17,1(6 \mathrm{C})$ \\
\hline & & 6 & $74,1(6 C)$ \\
\hline \multicolumn{4}{|c|}{ JEFFAMINE ED600 } \\
\hline Hidrogênio & $\begin{array}{l}\text { Deslocamento } \\
\text { químico (ppm) }\end{array}$ & Carbono & $\begin{array}{l}\text { Deslocamento } \\
\text { químico (ppm) }\end{array}$ \\
\hline 1 & $2,87(2 \mathrm{H}$, multiplete $)$ & 1 & $46,3(2 \mathrm{C})$ \\
\hline 2 & $0,87(6 \mathrm{H}$, dublete $)$ & 2 & $19,2(2 \mathrm{C})$ \\
\hline $3,6,7$ & $\begin{array}{l}3,50 \\
(56 \mathrm{H}, \text { multiplete })\end{array}$ & 3 & $\begin{array}{l}77,6 \text { e } 75,6(1 \mathrm{C} \text { e } \\
1 \mathrm{C})\end{array}$ \\
\hline 4 & $3,10(2 \mathrm{H}$, multiplete $)$ & 4 e 6 & $74,4(4 C)$ \\
\hline 5 & $1,02(6 \mathrm{H}$, dublete $)$ & 5 & $17,1(2 \mathrm{C})$ \\
\hline $\mathrm{NH}_{2}$ & $1,37(4 \mathrm{H}$, alargado $)$ & 7 & $69,9(20 \mathrm{C})$ \\
\hline \multicolumn{4}{|c|}{ JEFFAMINE M600 } \\
\hline Hidrogênio & $\begin{array}{l}\text { Deslocamento } \\
\text { químico (ppm) }\end{array}$ & Carbono & $\begin{array}{l}\text { Deslocamento } \\
\text { químico (ppm) }\end{array}$ \\
\hline 1 & $3,14(1 \mathrm{H}$, multiplete $)$ & 1 & $46,2(1 \mathrm{C})$ \\
\hline 2 & $1,00(3 \mathrm{H}$, dublete $)$ & 2 & $19,2(1 \mathrm{C})$ \\
\hline $3,4,6,7$ e 8 & $\begin{array}{l}3,40 \text { a } 3,80 \\
(30 \mathrm{H}, \text { multiplete })\end{array}$ & 3 & 75,7 a $77,6(1 \mathrm{C})$ \\
\hline 5 & $1,13(24 \mathrm{H}$, dublete $)$ & 4 & $72,6(8 C)$ \\
\hline 9 & $3,37(3 \mathrm{H}$, singlete $)$ & 5 & $16,9(8 C)$ \\
\hline \multirow[t]{4}{*}{$\mathrm{NH}_{2}$} & $1,38(2 \mathrm{H}$, alargado $)$ & 6 & $74,7(8 \mathrm{C})$ \\
\hline & & 7 & $71,5(1 \mathrm{C})$ \\
\hline & & 8 & $70,2(1 \mathrm{C})$ \\
\hline & & 9 & $58,5(1 \mathrm{C})$ \\
\hline
\end{tabular}

\subsubsection{2 - Sintese e caracterização dos isocianatos}

O sucesso na síntese de isocianato a partir de amina comercial é calculado com base na expectativa de conversão dos grupos $\mathrm{NH}_{2}$ presentes no polímero de partida em grupos NCO. Aparentemente a reação de conversão é simples, contudo 
baixos rendimentos foram obtidos em várias sínteses. Em princípio imaginou-se que as condições experimentais não eram apropriadas; então o sistema de síntese foi aprimorado e a secagem dos solventes e reativos foi realizada com maior cuidado. Contudo, o rendimento da reação continuou muito abaixo do desejado. A única explicação para este resultado seria a perda de reatividade do trifosgênio.

Uma busca bibliográfica revelou a existência de uma publicação sobre a reatividade e estabilidade do bis(triclorometil) carbonato $^{31}$. A troca de informações com o autor do artigo apresentou-se como solução ao fato deste não trazer esclarecimentos sobre o problema aqui abordado. Livius Cotarca alega que, a probabilidade de perda de reatividade com o tempo deste reagente nas condições de armazenamento e manipulação utilizadas são remotas. Entretanto, o trabalho experimental leva a conclusões no sentido contrário, pois com reagente recém adquirido foi possível obter isocianatos com taxa de conversão satisfatória. Conforme este reagente foi "envelhecendo" a taxa de conversão foi diminuindo, sendo obtidos valores próximos a $3 \%$. Considera-se portanto, que a perda de reatividade do trifosgênio com o tempo é um bom objeto de estudo mas está fora do escopo deste trabalho. Os teores de NCO obtidos para os isocianatos sintetizados são apresentados na tabela 2.11. Foi também observado que, após sintetizado o isocianato não é estável por tempo indeterminado, ou seja, a \% de NCO diminui com o decorrer do tempo mesmo com o produto sendo armazenado sob atmosfera de nitrogênio e em refrigerador.

Os espectros no infravermelho dos isocianatos obtidos contém a forte absorção em $2250 \mathrm{~cm}^{-1}$ característica de NCO (figura 2.23). Os espectros de ressonância magnética nuclear de carbono dos produtos da síntese apresentam pico típico do grupo funcional em deslocamento químico igual a $125 \mathrm{ppm}$. As demais 
bandas no FTIR e picos no espectro de RMN são os mesmos já mencionados para as aminas precursoras (tabela 2.9 e 2.10 respectivamente).

Tabela 2. 11: Teores de função NCO nos isocianatos sintetizados e porcentagem de conversão

\begin{tabular}{|c|c|c|}
\hline Isocianato & $\% \mathrm{NCO}$ & \%Conversão \\
\hline $\begin{array}{l}\text { Diisocianato de poli(óxido de etileno) - DPOE1 } \\
\text { (a partir de JEFFAMINE ED600) }\end{array}$ & 8,4 & 61,3 \\
\hline DPOE2 & 9,1 & 66,0 \\
\hline $\begin{array}{l}\text { Diisocianato de poli(óxido de propileno) - DPOP1 } \\
\text { (a partir de JEFFAMINE D400) }\end{array}$ & 11,6 & 66,7 \\
\hline DPOP2 & 12,3 & 70,0 \\
\hline $\begin{array}{l}\text { Monoisocianato de poli(óxido de propileno) - MPOP1 } \\
\text { (a partir de JEFFAMINE M600) }\end{array}$ & 6,2 & 92,0 \\
\hline MPOP2 & 6,6 & 99,0 \\
\hline
\end{tabular}

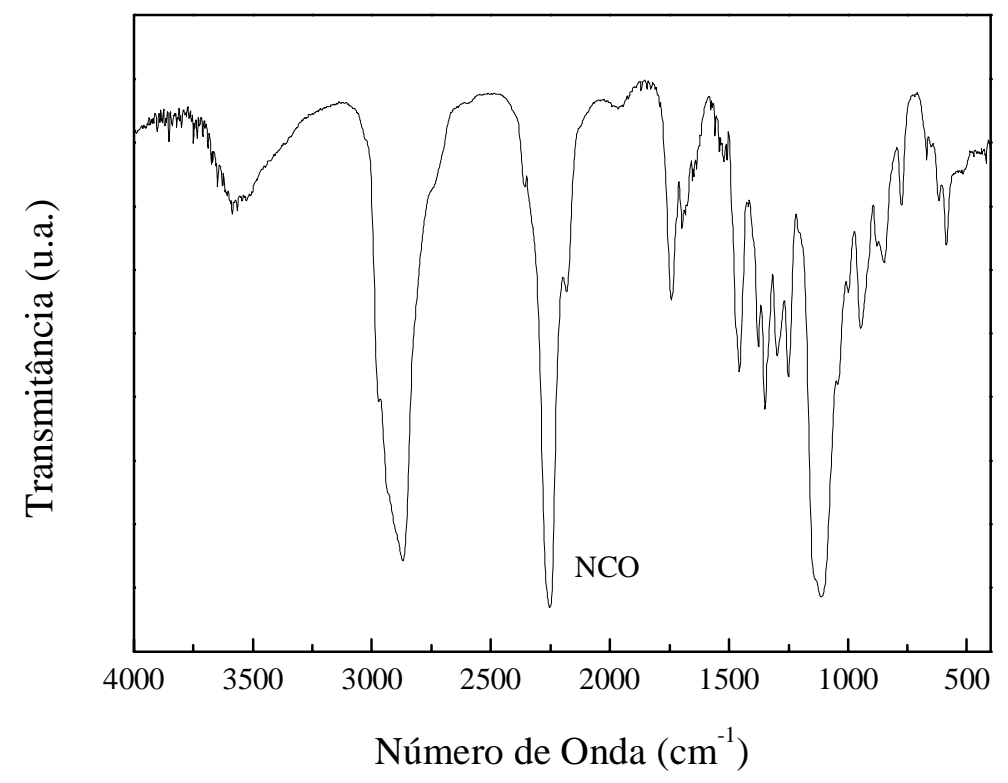

Figura 2. 23: Espectro no infravermelho de diisocianato de poli(óxido de etileno) (DPOE1) sintetizado a partir de JEFFAMINE ED600 (banda de absorção em 2250 $\mathrm{cm}^{-1}$ é característica de grupo $\mathrm{NCO}$ ) 
2.3 - Sintese dos filmes de polissacarideos enxertados com poliéteres

2.3.1-Aspectos Gerais

Poliuretanas são macromoléculas que apresentam em sua estrutura o grupo funcional carbamato e outros como o grupo éster, éter e amida. A denominação poliuretana é derivada do composto carbamato de etila, conhecido como uretana.

Ao lado dos isocianatos, compostos contendo funções hidroxila na molécula são componentes fundamentais na formação de poliuretanas, agindo como nucleófilos $^{34}$. O efeito estérico e indutivo do álcool utilizado é um dos fatores determinantes da cinética da reação. Desta forma, a reatividade dos álcoois é dada por: $\mathrm{OH}_{\text {prim }}>\mathrm{OH}_{\mathrm{sec}}>\mathrm{OH}_{\text {terc. }}$ Estudos cinéticos ${ }^{29}$ da reação entre poliéteres-polióis e diisocianato de tolueno indicam que a reatividade do álcool independe do comprimento da cadeia e do número de grupos funcionais $\mathrm{OH}$ presentes na estrutura, obedecendo, porém a seqüência de reatividade já mencionada.

Devido à baixa velocidade de reação as poliuretanas são industrialmente obtidas com a adição de catalisador ao meio reacional ${ }^{37}$. A utilização deste altera sensivelmente a reatividade do isocianato e evita reações secundárias prejudiciais à qualidade do produto final ${ }^{34}$. Os catalisadores mais utilizados são os de amina terciária e os de sais metálicos, notoriamente sais de estanho, como o dibutildilaurato de estanho, representado na figura $2.24^{29}$.

O mecanismo de catálise passa pela formação de complexos ternários entre o álcool, o isocianato e o catalisador, como mostrado no esquema da figura 2.25 a seguir $^{29,37}$. 


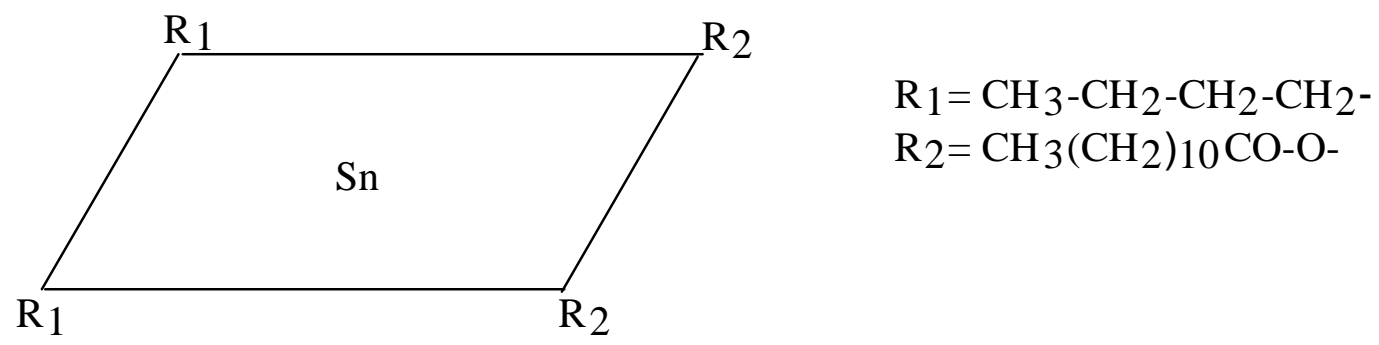

Figura 2. 24: Representação esquemática do catalisador dibutil-dilaurato de estanho<smiles>C[N+](C)(C)[N+](C)(C)C</smiles>
$\stackrel{\text { rápido }}{\rightleftharpoons}$

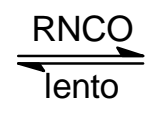<smiles>[R]N=C1O[13C](C)(C)O[Ge]([R])(C)O1</smiles><smiles>C=C=C</smiles><smiles>[R][NH2+]C(O)O[W](C)(C)C</smiles><smiles>[In]=C=[I-]</smiles><smiles>[R]NC(O)=[W](C)(C)C</smiles>

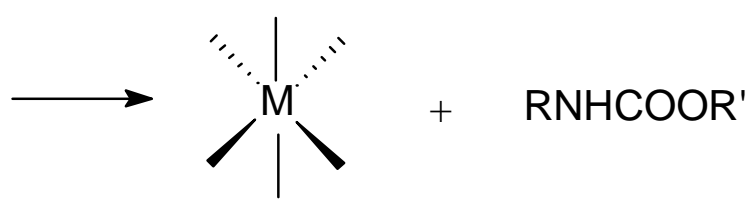

Figura 2. 25: Representação do mecanismo de catálise na graftização de poliálcool com isocianatos 
Os polióis mais simples são os glicóis; reagentes de baixas massas molares levando, após reação com isocianatos, a segmentos rígidos de polímeros, fato devido à alta concentração de grupos uretanas ${ }^{34}$. Atualmente, a preparação de poliuretanas é baseada em polióis de massa molar mais alta, sendo as principais classes os poliéteres e poliésteres ${ }^{34,35}$. Alguns estudos reportam a modificação química de polióis com isocianatos a fim de se obter polímeros com melhores propriedades. Hsieh $e t ~ a l^{38}$ reportam a modificação de membranas de acetato de celulose com diisocianato de 4,4'-difenil metano na presença de traços de dibutil-dilaurato de estanho. Os resultados indicaram melhoramento das propriedades mecânicas e de rejeição de sal. A modificação de celulose com fenil isocianatos é descrita por Ellzey et $a l^{39}$. Esta reação é realizada em meio heterogêneo utilizando-se dimetilsulfóxido (DMSO) como meio de suspensão e di-n-butil diacetato de estanho como catalisador. Os autores destacam a necessidade de atmosfera e solventes secos para reprodutibilidade dos resultados. A modificação superficial de fibras de celulose com o objetivo de se utilizar o produto como compósito é reportada por Trejo-O'-Reilly et $a l^{40}$. Foram utilizados isocianatos e anidridos, sendo a modificação das propriedades estudada através de técnicas de infravermelho, microscopia de transmissão eletrônica, difração de raios-X, análise elementar e espectroscopia fotoeletrônica.

A derivatização de poli(óxido de etileno) com isocianatos é reportada em vários $\operatorname{artigos}^{41,42,43}$. É descrito o estudo sistemático destes eletrólitos ${ }^{43}$ sendo estabelecida uma relação entre a estrutura da rede e suas propriedades, tais como $\mathrm{Tg}$, comportamento dinâmico-mecânico, condutividade iônica e estabilidade eletroquímica, entre outras. A reação de modificação de derivados de celulose com isocianatos também é reportada na literautra ${ }^{44,45,46}$. Toffey e Galsser ${ }^{44}$ estudarama cinética de reação entre HPC e MDI (metileno diisocianato polimérico) e 
determinaram as características das poliuretanas sintetizadas ao variar a concentração de entrecruzamento (NCO/OH). Schoenenberger $e t a l^{45}$ e Moralez et al ${ }^{46}$ estudaram a possível aplicação de hidroxietil celulose e quitosana entrecruzadas com poli(óxido de etileno) como eletrólitos sólidos poliméricos. No presente trabalho, cinco diferentes amostras de hidroxietil celulose e três de hidroxipropil celulose foram entrecruzadas com diisocianatos de poli(óxido de etileno) e poli(óxido de propileno) ou enxertadas com isocianato de poli(óxido de propileno). As relações utilizadas foram de 0,4; 0,6 e 0,8 funções NCO para cada função $\mathrm{OH}$ do derivado de celulose, obtendo-se estruturas tridimensionais como a apresentada na figura 2.26 para o uso de hidroxietil celulose entrecruzada com DPOE.

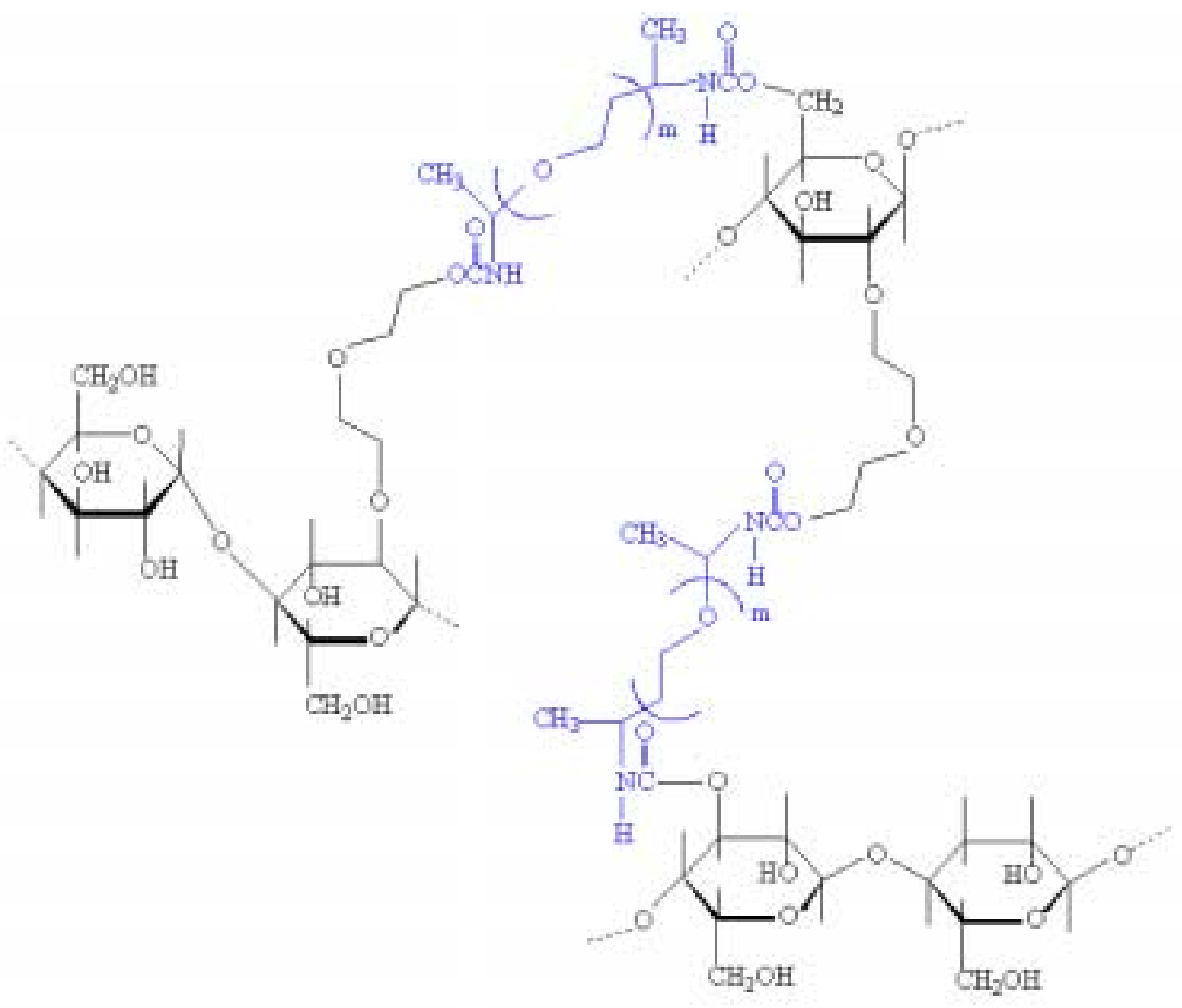

Figura 2. 26: Esquema simplificado da estrutura de rede de hidroxietil celulose entrecruzada com diisocianato de poli(óxido de etileno) 
2.3.2-Materiais

Foram utilizados na síntese das redes: N,N-dimetilacetamida (DMAc) (Aldrich), que foi previamente seca por destilação sobre hidreto de cálcio $\left(\mathrm{CaH}_{2}\right.$, Aldrich), o catalisador dibutil-dilaurato de estanho (Aldrich) e para as redes dopadas com sal, o perclorato de lítio $\left(\mathrm{LiClO}_{4}\right.$, Aldrich). Para determinação do teor de extrativos foi utilizado tetracloreto de carbono $\left(\mathrm{CCl}_{4}\right.$; Aldrich) como solvente.

$2.3 .3-\mathcal{M e ́}$ todos

2.3.3.1-Reação de enxertia

As reações de graftização foram realizadas a temperatura ambiente dentro de câmara seca sob atmosfera de nitrogênio. As amostras de polissacarídeo (HEC e HPC) foram secas sob vácuo a temperatura ambiente. Misturou-se uma solução de polissacarídeo e uma solução de isocianato em DMAc na presença do catalisador dibutil-dilaurato de estanho. O filme foi moldado em placa de teflon e, 48 horas após sua formação, foi seco em estufa a $40^{\circ} \mathrm{C}^{27}$. A concentração de síntese (CS) é definida por:

$$
C S=\frac{m_{N C O}+m_{p s s}}{m_{N C O}+m_{H E C}+m_{D M A c}}
$$


onde, $\mathrm{m}_{\mathrm{NCO}}$ é a massa de isocianato utilizada, $\mathrm{m}_{\mathrm{pss}}$, a massa de polissacarídeo e mDMAc, a massa do solvente.

A fim de se evitar o fenômeno de sinérese, caracterizado pela expulsão de solvente no momento da gelificação e pela formação de microbolhas, deseja-se que a velocidade de formação do gel seja inferior à velocidade de inchamento máximo da rede $^{35}$. Considerando este fenômeno e a viscosidade da solução de polissacarídeo, estudou-se as redes preparadas a CS igual a 0,1 para amostras de HEC com grau de polimerização (DP) mais baixos; e CS igual a 0,05 para amostras de HEC com DP mais $\operatorname{altos}^{35}$ e HPC. Para a síntese dos filmes dopados com sal, o $\mathrm{LiClO}_{4}$ foi introduzido juntamente com o isocianato durante a reação de enxertia.

\subsubsection{2-Caracterização dos filmes}

Os filmes foram submetidos à análise no infravermelho (FTIR) em aparelho Perkin-Elmer no Laboratório de Macromoléculas da École Française de Papeterie et des Industries Graphiques (INPG - Grenoble - França).

As análises de difração de raios-X foi realizada em Difratômetro Universal de Raios-X URD-6, Carl Zeiss Jena, a potência de $\mu=40 \mathrm{kV} / 20 \mathrm{~mA}$ e irradiação CuK $\alpha$ $\operatorname{com} \lambda=1.540 \AA$.

Para a determinação da temperatura de transição vítrea dos filmes (Tg) através de calorimetria diferencial exploratória, DSC (SHIMADZU DSC-50), foram realizadas duas corridas no intervalo de temperatura de -100 a $200^{\circ} \mathrm{C}$ sob fluxo de nitrogênio $(20 \mathrm{~mL} / \mathrm{min})$. A primeira corrida foi realizada a uma taxa de aquecimento de $20^{\circ} \mathrm{C} / \mathrm{min}$ e a segunda, utilizada na determinação de $\mathrm{Tg}$, a $10^{\circ} \mathrm{C} / \mathrm{min}$. A determinação das redes dopadas com sal foram realizadas em aparelho SETARAM 
DSC92 (EFPG/INPG - Grenoble - França) no intervalo de temperatura de -100 a $100^{\circ} \mathrm{C}$.

As substâncias solúveis (extrativos) contidas nos filmes foram removidas através de extração em sistema soxhlet durante tempo aproximado de 6 horas utilizando-se tetracloreto de carbono como solvente.

$2.3 .4-$ Resultados

2.3.4.1-Filmes com fidroxie til celulose

A análise dos espectros no infravermelho de HEC entrecruzada ou enxertada com poliéter (representado na figura 2.27 para HEC QP4400/DPOE1 ) permite avaliar a ocorrência de reação. A banda relativa à carbonila das funções uretana pode ser observada em $1720 \mathrm{~cm}^{-1}$; o pequeno ombro presente em $1650 \mathrm{~cm}^{-1}$ é devido à carbonila de uréia, proveniente do isocianato sintetizado, já que este não foi submetido a nenhum procedimento de purificação. 


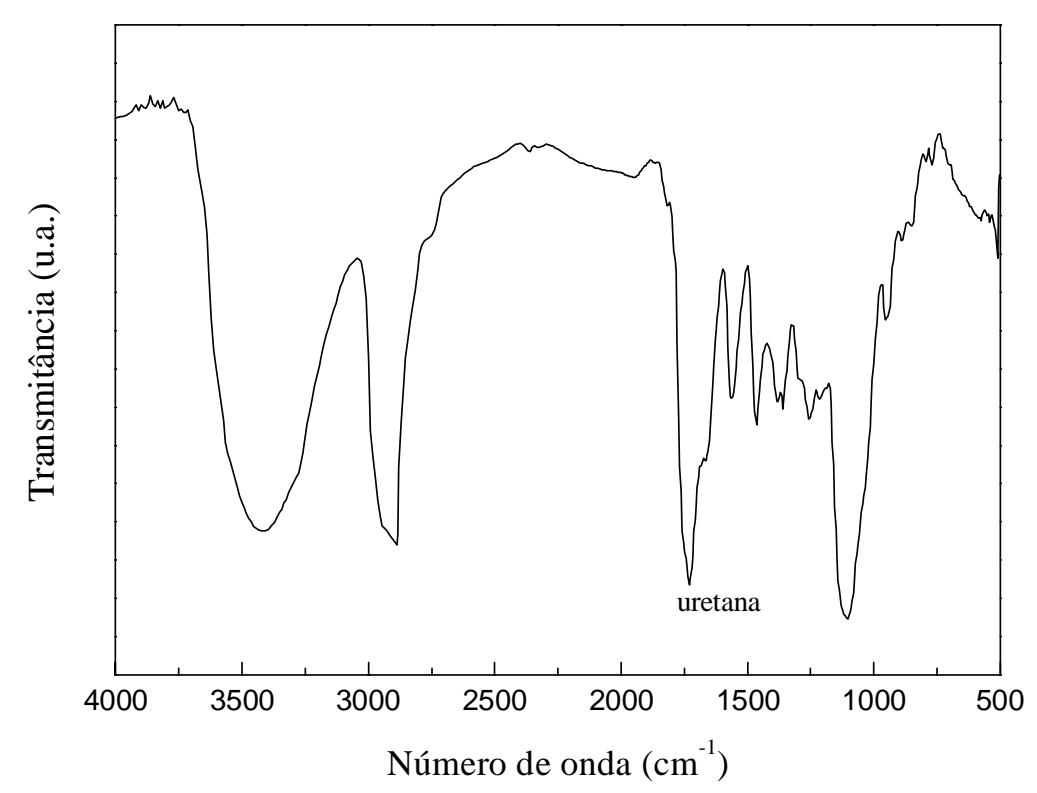

Figura 2. 27: Espectro no infravermelho de hidroxietil celulose (QP4400) enxertada com diisocianato de poli(óxido de etileno) (DPOE1)

Para avaliar a influência dos parâmetros estruturais da HEC (MS, DS e DP) sobre as características das redes sem sal, submeteu-se amostras deste polissacarídeo a reações de entrecruzamento com a mesma proporção de diisocianato. Foram realizadas reações com monoisocianato na mesma estequiometria com o objetivo de comparar estes resultados com os obtidos a partir de filmes onde não ocorre o entrecruzamento. Nas reações com isocianato monofuncional ocorre apenas a enxertia de cadeias de poliéter na matriz de polissacarídeo.

Foram obtidos filmes finos, transparentes e bastante flexíveis cuja predominância do estado amorfo é observada através dos experimentos de raios-X (figura 2.28) onde encontra-se apenas uma banda larga de difração centrada em ângulo de Bragg próximo a $20^{\circ}$. 


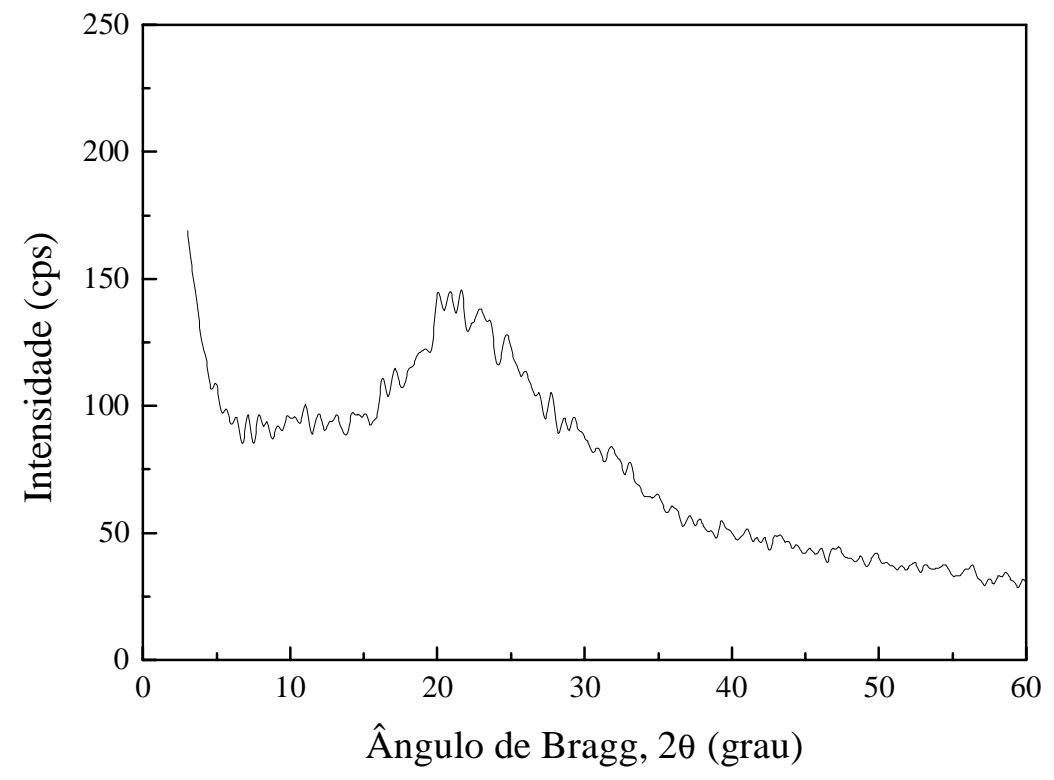

Figura 2. 28: Difratograma de raios-X de rede de hidroxietil celulose (QP4400) enxertada com diisocianato de poli(óxido de etileno) (DPOE1)

As curvas de DSC para todos os filmes preparados apresentam comportamento similar, sendo bem representada pela curva da figura 2.29 , onde se pode observar claramente a mudança de linha de base, ocorrência típica do fenômeno de transição vítrea. Nestas curvas não foram detectadas outras transições indicando o caráter amorfo destas redes. 


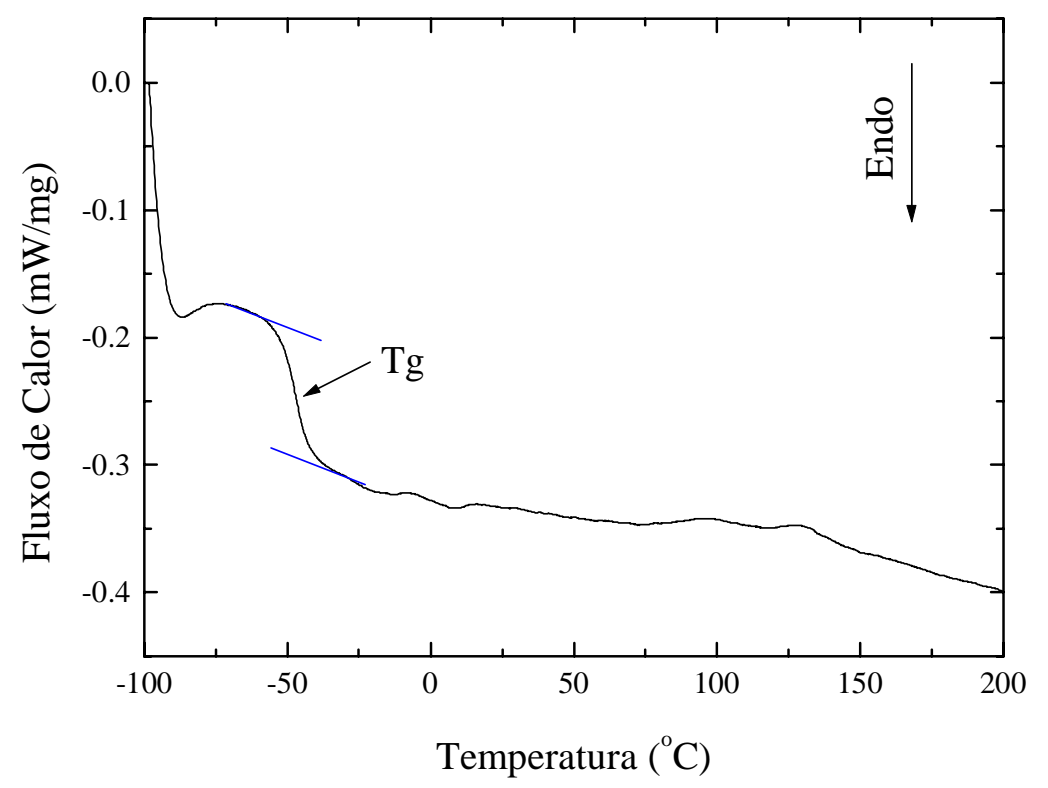

Figura 2. 29: Análise de calorimetria exploratória diferencial de rede de hidroxietil celulose (QP4400) enxertada com diisocianato de poli(óxido de etileno) (DPOE1)

Os valores de temperatura de transição vítrea para os vários filmes obtidos são apresentados na tabela 2.12. A Tg é consequiência da enxertia do poliéter na matriz de polissacarídeo e da correspondente reticulação uma vez que esta transição não pode ser detectada para aminas ou isocianatos, porque estes são líquidos. Também a Tg não é observada para HEC. Como os valores de Tg são constantes para cada tipo de poliéter enxertado no polissacarídeo infere-se que os parâmetros estruturais da HEC não influenciam na transição vítrea.

Tabela 2. 12: Valores de Tg para os filmes obtidos de hidroxietil celulose enxertada com isocianatos de poliéter

\begin{tabular}{lccc}
\hline \multicolumn{1}{c}{ Amostra } & \multicolumn{3}{c}{ Tg $\left({ }^{\mathbf{0}}\right)$} \\
\cline { 2 - 4 } & DPOE1 & DPOP1 & MPOP2 \\
\hline QP09H & -54 & -36 & -74 \\
QP300H & -47 & -35 & -70 \\
QP4400 & -48 & -35 & -77 \\
QP15MH & -52 & -33 & -75 \\
QP30MH & -52 & -34 & -67 \\
\hline
\end{tabular}


São observados valores em torno de $-50^{\circ} \mathrm{C}$ para entrecruzamento de HEC com diisocianato de poli(óxido de etileno), $-35^{\circ} \mathrm{C}$ para diisocianato de poli(óxido de propileno) e a transição ocorre em torno de $-73^{\circ} \mathrm{C}$ para monoisocianato de poli(óxido de propileno). O efeito da reticulação pode ser constatado ao comparar os valores de Tg das redes entrecruzadas, sintetizadas com isocianato difuncional (DPOP), e daquelas onde há apenas enxertia (rede de HEC com monoisocianato - MPOP). O efeito da reticulação é o aumento da $\mathrm{Tg}$ em cerca de $38^{\circ}$. O efeito da estrutura do isocianato pode ser observado comparando-se os resultados das redes obtidas a partir da reação da HEC com os diisocianatos (DPOE e DPOP). A estrutura mais ramificada, contendo grupo lateral metila, do poli(óxido de propileno) provoca um aumento de aproximadamente $15^{\circ}$ na temperatura de transição vítrea dos filmes em relação às amostras de HEC entrecruzadas com poli(óxido de etileno). Esta diferença é resultado do menor grau de liberdade rotacional das unidades de poli(óxido de propileno) frente às de poli(óxido de etileno) e já foi observada em redes preparadas a partir de oligoéteres e poliisocianatos simples ${ }^{43}$. Em todos os casos os valores para a transição vítrea dos filmes sintetizados estão em temperaturas muito abaixo da ambiente. Este é um fator importante do ponto de vista de transporte iônico (e portanto de condutividade) que depende da mobilidade dos segmentos das cadeias de poliéter.

Para avaliar a formação de estrutura tridimensional os filmes obtidos foram submetidos à extração de substâncias solúveis em $\mathrm{CCl}_{4}$. Na tabela 2.13 são apresentados os teores de extrativos dos filmes sintetizados a partir de HEC e DPOE1 e DPOP1. 
Tabela 2. 13: Teor de extrativos nos filmes de hidroxietil celulose enxertadas com diisocianato de poli(óxido de etileno) - DPOE1 e diisocianato de poli(óxido de propileno) - DPOP1

\begin{tabular}{cc}
\hline Amostra & \% Extrativos \\
\hline DPOE1 & 71 \\
\hline QP09H & 67 \\
QP300H & 61 \\
QP4400 & 64 \\
QP15MH & 78 \\
QP30MH & \\
\hline DPOP1 & 65 \\
QP09H & 77 \\
QP300H & 60 \\
QP4400 & 56 \\
QP15MH & 59 \\
QP30MH & \\
\hline
\end{tabular}

Os sistemas aqui estudados apresentaram alto teor de extrativos o que permite fazer algumas inferências: (i) como a reação de conversão de amina em isocianato não é completa, apenas uma parte dos grupos $\mathrm{NH}_{2}$ são convertidos em $\mathrm{NCO}$ (ver tabela 2.11), algumas cadeias do diisocianato podem ser monofuncionais. A conseqüência deste fato na reação entre o derivado de celulose e o isocianato é a não formação de rede, mas apenas enxertia levando a um aumento de solubilidade das cadeias de polissacarídeo substituídas com o poliéter. (ii) a reação entre HEC e isocianato é incompleta em razão da formação de micelas ou de agregados no meio reacional. Portanto, a parte solúvel corresponde ao poliéter que não foi incorporado ao polissacarídeo. (iii) Ocorrência de dímeros e trímeros no diisocianto em quantidades expressivas. (iv) Presença de oligômeros de baixa massa molar na amina precursora e na hidroxietil celulose, lembrando que o polissacarídeo e a amina não foram previamente purificados para a remoção destas moléculas. Considerando todos estes fatores optou-se pela síntese das redes dopadas sem a remoção dos extrativos, pois os filmes obtidos apresentam temperatura de transição vítrea adequada para a aplicação em eletrólitos sólidos poliméricos. Os filmes enxertados com poli(óxido de 
etileno) apresentam $\mathrm{Tg}$ em torno de $-23^{\circ} \mathrm{C}$ após a extração e a temperatura de transição vítrea é de difícil detecção para as amostras enxertadas com poli(óxido de propileno) e após a extração.

Para o estudo sistemático das propriedades das redes com sal foram escolhidas três amostras de HEC e três razões $[\mathrm{NCO}] /[\mathrm{OH}]$ distintas. A escolha da hidroxietil celulose foi feita com base nos valores de grau de substituição molar (MS) e a razão de entrecruzamento encontra-se na faixa de 0,4 a 0,8 . O cálculo da concentração de sal foi feito seguindo a relação $n \mathrm{O} / n \mathrm{Li}=12$; onde $n \mathrm{O}$ representa o número de moles de oxigênio presente no filme $\left(n \mathrm{O}_{\mathrm{HEC}}+n \mathrm{O}_{\text {poliéter }}\right)$ e $n \mathrm{Li}$ o número de moles de lítio introduzido. Esta concentração foi escolhida em observação a um trabalho preliminar ${ }^{45}$, no entanto existem outras maneiras de ser calculada. Uma delas é considerar apenas o número de moles de oxigênio do poliéter para cálculo da razão $n \mathrm{O} / n \mathrm{Li}$; e outra é em termos de mol de cátions lítio por volume ( $\left.\mathrm{em}^{\mathrm{dm}}{ }^{3}\right)$ do poliéter. As concentrações de sal para os vários filmes dopados sintetizados são apresentadas na tabela 2.14 .

A caracterização das redes dopadas é feita com base na determinação da temperatura de transição vítrea (tabela 2.15). Em termos gerais pode ser observado que os valores de $\mathrm{Tg}$ obtidos para os filmes contendo sal são maiores quando comparados aos valores dos filmes sem sal. Esta diferença é de cerca de $17^{\circ}$ para redes com DPOE, $30^{\circ}$ para DPOP e em torno de $33^{\circ}$ para MPOP. Este aumento de Tg é decorrente do entrecruzamento iônico promovido pelos cátions $\mathrm{Li}^{+}$quando solvatados pelos oxigênios presentes na estrutura do filme. Esta diferença é mais pronunciada para redes com poli(óxido de propileno) mostrando que a diminuição dos graus de liberdade dos filmes com a introdução de sal é mais acentuada para este poliéter. 
Tabela 2. 14: Concentração de sal dos filmes de hidroxietil celulose dopados com $\mathrm{LiClO}_{4}$

\begin{tabular}{|c|c|c|c|c|c|c|c|c|c|c|}
\hline \multirow[t]{3}{*}{ NCO } & \multirow{3}{*}{$\frac{N C O}{O H}$} & \multicolumn{3}{|c|}{ QP09H } & & \multicolumn{2}{|c|}{ QP4400 } & \multicolumn{3}{|c|}{ QP30MH } \\
\hline & & \multicolumn{9}{|c|}{ Concentração de sal } \\
\hline & & $\mathbf{A}^{*}$ & $\mathbf{B} * *$ & C**** & $\mathbf{A}$ & $\mathbf{B}$ & $\mathbf{C}$ & $\mathbf{A}$ & $\mathbf{B}$ & $\mathbf{C}$ \\
\hline \multirow[t]{3}{*}{ DPOE2 } & 0,4 & 12 & 6,8 & 3,0 & 12,6 & 7,3 & 2,9 & 12 & 7,3 & 2,8 \\
\hline & 0,6 & 14 & 9,7 & 2,1 & 12 & 7,8 & 2,6 & 12 & 8,2 & 2,5 \\
\hline & 0,8 & 14 & 10,2 & 2,0 & 12,5 & 9,1 & 2,3 & 12 & 9,1 & 2,3 \\
\hline \multirow[t]{3}{*}{ DPOP2 } & 0,4 & 12,4 & 6,8 & 2,7 & 13,4 & 7,3 & 2,8 & 12,9 & 7,3 & 2,6 \\
\hline & 0,6 & 12 & 7,8 & 2,4 & 12,8 & 8,3 & 2,3 & 12,6 & 8,3 & 2,3 \\
\hline & 0,8 & 12,5 & 8,9 & 2,1 & 12,3 & 8,7 & 2,1 & 13,1 & 9,5 & 2,0 \\
\hline \multirow[t]{3}{*}{ MPOP1 } & 0,4 & 12 & 8,1 & 2,0 & 12,8 & 8,6 & 1,9 & 12,6 & 8,7 & 1,8 \\
\hline & 0,6 & 12 & 9,1 & 1,8 & 12,5 & 9,4 & 1,7 & 12,6 & 9,7 & 1,7 \\
\hline & 0,8 & 11,7 & 9,4 & 1,7 & 12,2 & 9,8 & 1,6 & 12,4 & 10,1 & 1,6 \\
\hline
\end{tabular}

$* \mathrm{~A}=n \mathrm{O} / n \mathrm{Li}\left(n \mathrm{O}_{\mathrm{HEC}}+n \mathrm{O}_{\text {poliéter }}\right) ; * * \mathrm{~B}=n \mathrm{O} / n \mathrm{Li}\left(n \mathrm{O}_{\text {poliéter }}\right) ; * * * \mathrm{C}=\mathrm{mol} \mathrm{Li}^{+} / \mathrm{dm}^{3}$ poliéter

Tabela 2. 15: Valores de temperatura de transição vítrea para os filmes de hidroxietil celulose dopados com $\mathrm{LiClO}_{4}$

\begin{tabular}{ccccc}
\cline { 3 - 5 } Isocianato & NCO/OH & DPOE2 & Tg $\left({ }^{\mathbf{0}} \mathbf{C}\right)$ & \\
\hline QP09H & 0,4 & -32 & -6 & MPOP1 \\
& 0,6 & -34 & -10 & -29 \\
& 0,8 & -33 & -4 & -36 \\
\hline QP4400 & 0,4 & -34 & -9 & -35 \\
& 0,6 & -31 & -3 & -34 \\
& 0,8 & -35 & -5 & -41 \\
QP30MH & 0,4 & -31 & -3 & -46 \\
& 0,6 & -32 & -3 & -51 \\
& 0,8 & -34 & -6 & -47 \\
\hline
\end{tabular}

Os filmes preparados a partir do entrecruzamento de HEC com DPOE apresentam valores de $\operatorname{Tg}\left(\mathrm{em}\right.$ torno de $\left.-33^{\circ} \mathrm{C}\right)$ que são aparentemente "insensíveis" à HEC utilizada, à razão molar NCO/OH e à correspondente concentração de sal. Foi previamente observado que, na ausência de $\mathrm{LiClO}_{4}$, a temperatura de transição vítrea destas estruturas diminui com o aumento da porcentagem de isocianato ao limite de $-50^{\circ} \mathrm{C}$, tornando-se independente do grau de reticulação suplementar ${ }^{35}$. Com a 
introdução de sal, a transição vítrea do material acontece a temperaturas mais elevadas cuja causa já foi discutida anteriormente.

Foi demonstrado que, para redes de poli(óxido de etilneo) entrecruzadas com 4,4',4"'-metino-trisfenilisocianato (Desmodur $\mathrm{R})^{43}$ e poli(óxido de etileno)-triol ${ }^{35}$ entrecruzado com diisocianato de poli(óxido de etileno), o aumento da concentração de sal leva a um aumento da $\mathrm{Tg}$. Na figura 2.30 são apresentados as curvas do inverso de Tg em função da concentração de sal para estes sistemas. Observa-se que, neste intervalo de concentração de sal, a dependência linear de $1 / \mathrm{Tg}$ frente à concentração de $\mathrm{LiClO}_{4}$.

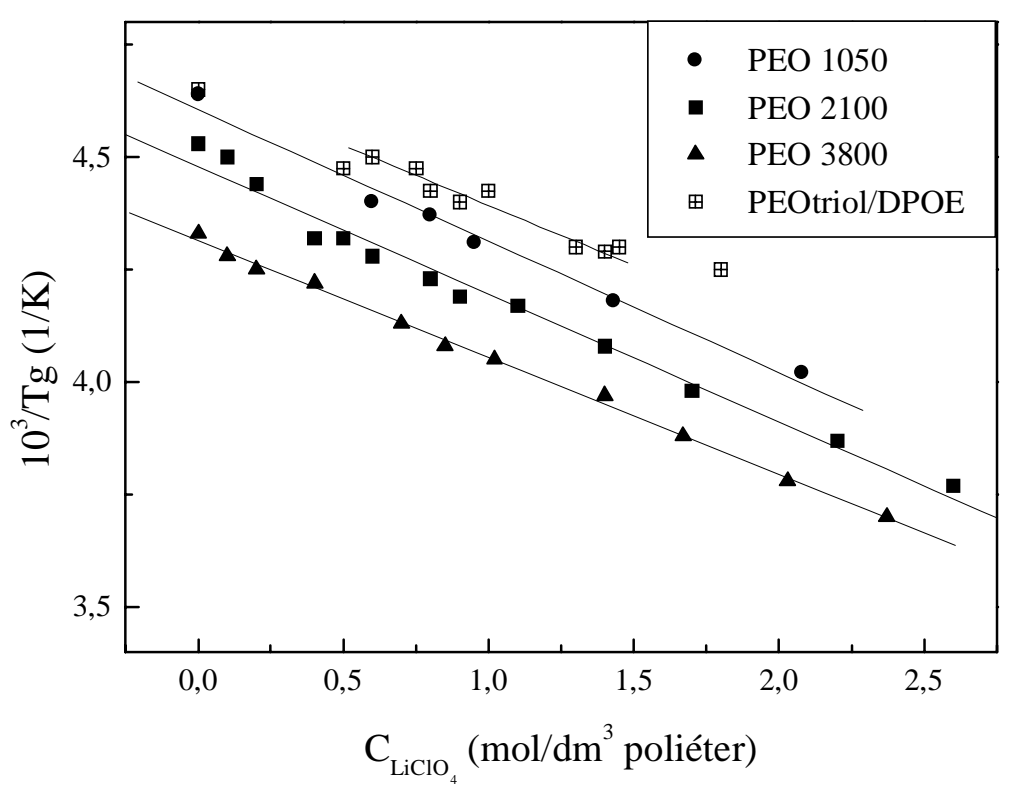

Figura 2. 30: Dependência do inverso de Tg em função da concentração de $\mathrm{LiClO}_{4}$ (PEO 1050, 2100 e 3800 foram entrecruzados com Desmodur R) ${ }^{35,43}$

O mesmo tipo de estudo foi feito com HEC (DP $=300$ e MS $=2)^{45}$ e quitosana $^{46}$ entrecruzadas com diisocianato de poli(óxido de etileno) de massa molar $600 \mathrm{~g} / \mathrm{mol}$. Os dados da literatura apresentados na figura 2.31 correspondem aos pontos e aos ajustes lineares representados pelas linhas cheias. Nestes ajustes foram 
obtidos coeficientes angulares iguais aos descritos para o poli(oxido de etileno) ${ }^{43}$ permitindo concluir que os cátions coordenam-se preferencialmente às cadeias de poli(óxido de etileno) frente às de polissacarídeo utilizadas como matriz. Uma análise mais profunda destes dados da literatura mostra a obtenção de decaimento exponencial de $1 / \mathrm{Tg}$ com a introdução de sal (linhas pontilhadas na figura 2.31) para filmes de hidroxietil celulose e quitosana contendo apenas um tipo de isocianato. $\mathrm{Ou}$ seja, a Tg aumenta com o acréscimo do sal devido ao aumento do entrecruzamento iônico promovido pelos cátions $\mathrm{Li}^{+}$até um limite de concentração, igual a

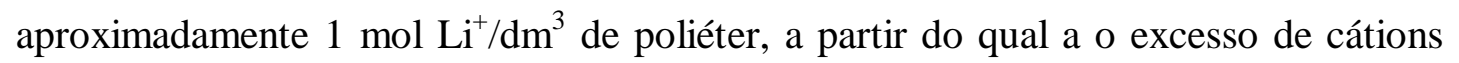
não é solvatado e portanto, não participa deste tipo de entrecruzamento. O mesmo tipo de comportamento é esperado para as outras redes já mencionadas, pois a solubilidade de um sal nestes sistemas não pode chegar a infinito. Entretanto, este limite de concentração deve ocorrer a valores muito mais elevados que para as redes de polissacarídeo derivatizado com DPOE.

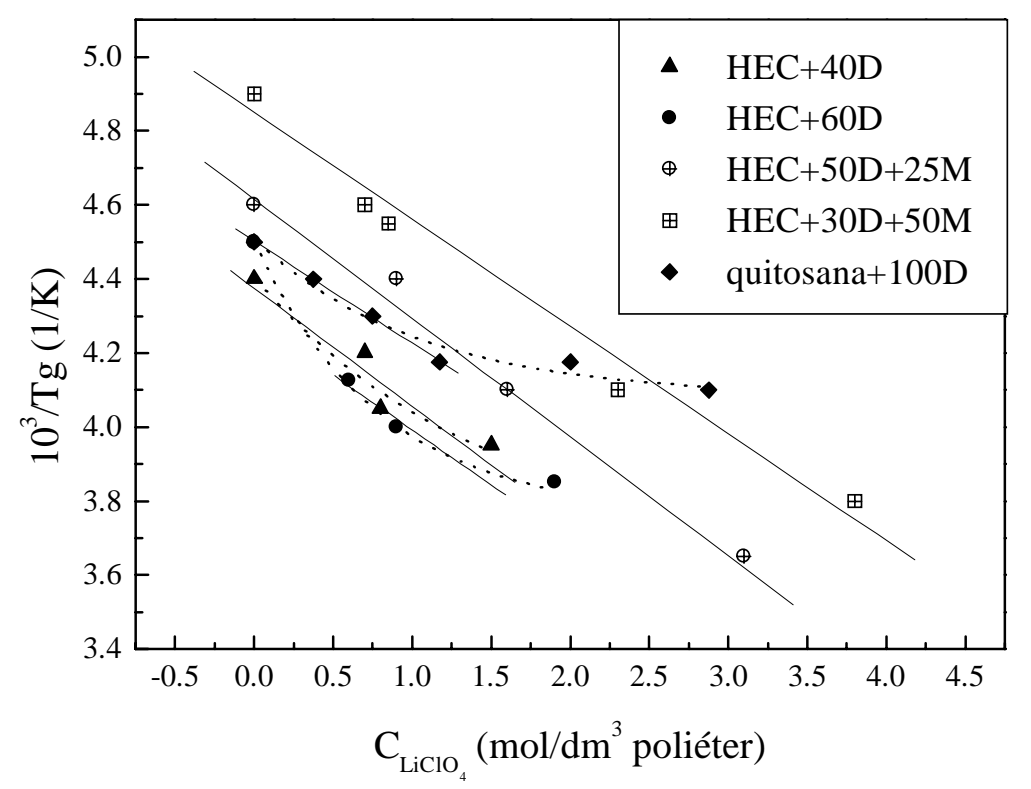

Figura 2. 31: Variação do inverso de $\mathrm{Tg}$ em função da concentração de $\mathrm{LiClO}_{4} ; 40 \mathrm{D}$ $=[\mathrm{NCO}] /[\mathrm{OH}]=0,4 ; 60 \mathrm{D}=[\mathrm{NCO}] /[\mathrm{OH}]=0,6 ; 50 \mathrm{D}+25 \mathrm{M}=[\mathrm{NCO}]_{\mathrm{DPOE}} /[\mathrm{OH}]=0,5$ 
e $[\mathrm{NCO}]_{\mathrm{MPOP}} /[\mathrm{OH}]=0,25 ; 30 \mathrm{D}+50 \mathrm{M}=[\mathrm{NCO}]_{\mathrm{DPOE}} /[\mathrm{OH}]=0,3$ e $[\mathrm{NCO}]_{\mathrm{MPOP}} /[\mathrm{OH}]=$ 0,$5 ; 100 \mathrm{D}=[\mathrm{NCO}] /[\mathrm{OH}]=1 ;$ As linhas cheias correspondem aos dados da literatura ${ }^{35,45,46}$ e as pontilhadas à análise discutida neste trabalho.

Nos dados da literatura para $\mathrm{HEC}^{45}$, conforme o $\mathrm{LiClO}_{4}$ é adicionado à rede, a temperatura de transição vítrea aumenta até o limite de aproximadamente $-23^{\circ} \mathrm{C}$ para redes com $[\mathrm{NCO}] /[\mathrm{OH}]=0,6 \mathrm{e}-16^{\circ} \mathrm{C}$ para redes com $[\mathrm{NCO}] /[\mathrm{OH}]=0,4$. Os filmes sintetizados no trabalho aqui apresentado, comparados com os dados da literatura ${ }^{45}$, possuem concentração de sal acima do limite de saturação, no entanto apresentam valores de $\mathrm{Tg}$ menores. Na literatura, o sal foi adicionado através da imersão do filme em solução salina em acetonitrila. Ou seja, todo material não entrecruzado foi solubilizado e extraído dos filmes (menos de 5\%). Os resultados apresentados neste trabalho foram obtidos a partir de filmes sem extração prévia das substâncias solúveis. Estas podem estar contribuindo para a obtenção de valores de Tg mais baixos acima do ponto de saturação de sal.

O aumento de Tg com a adição de sal foi também observado para os filmes preparados com DPOP que apresentaram $\mathrm{Tg}$ em torno de $-5^{\circ} \mathrm{C}$. É interessante observar que os valores obtidos para estes filmes encontram-se a temperaturas 20 graus mais altas que as obtidas para redes baseadas em DPOE, como o observado para as mesmas estruturas sem $\mathrm{LiClO}_{4}$. Os materiais preparados com MPOP apresentaram uma larga faixa de $\mathrm{Tg}$ sem nenhuma tendência aparente em ralação à concentração de sal ou composição do filme. Conclui-se que as variações observadas nos valores obtidos são decorrentes do erro experimental em se determinar este parâmetro, que possui um valor médio de $-40^{\circ} \mathrm{C}$. Este é menor que os valores obtidos para os materiais entrecruzados, em concordância com o aumento do grau de 
liberdade das cadeias de poli(óxido de propileno) que, nos filmes com MPOP, possuem uma extremidade livre.

Alguns dos filmes dopados tiveram as suas características visco-elásticas observadas através de análise termodinâmico-mecânica (DMTA) utilizando-se aparelho RHEOMETRICS SOLID ANALYSER RSA II (CERMAV - Grenoble França). As medidas foram realizadas a frequiência de $1 \mathrm{~Hz}$ no intervalo de temperatura de -100 a $200^{\circ} \mathrm{C}$. Na figura 2.32 encontram-se representados os diagramas da variação do módulo dinâmico de conservação (E') em função da temperatura para as amostras analisadas. Podem ser observados nas curvas apresentadas quatro domínios: primeiro, um platô $\left(\mathrm{de}-100^{\circ} \mathrm{C}\right.$ a aproximadamente $30^{\circ} \mathrm{C}$ para amostras com DPOE e de $-100^{\circ} \mathrm{C}$ a próximo de $5^{\circ} \mathrm{C}$ para amostras com DPOP) correspondente ao estado vítreo, onde os segmentos poliméricos são rígidos e portanto não apresentam movimento. Conforme há um aumento na temperatura observa-se a zona de transição vítrea, e a seguir um platô viscoelástico. A transição vítrea reflete o aumento dos movimentos moleculares com a temperatura. A temperatura em que esta transição ocorre está em concordância com a obtida para os mesmos materiais utilizando-se técnica de DSC. A segunda zona de transição (começando a temperatura em torno de $70^{\circ} \mathrm{C}$ para amostra QP30MH/DPOE e próximo a $120^{\circ} \mathrm{C}$ para as demais), também seguida de um platô viscoelástico, pode ser correspondente à dissociação do entrecruzamento iônico promovido pela presença dos cátions $\mathrm{Li}^{+}$41,47. 


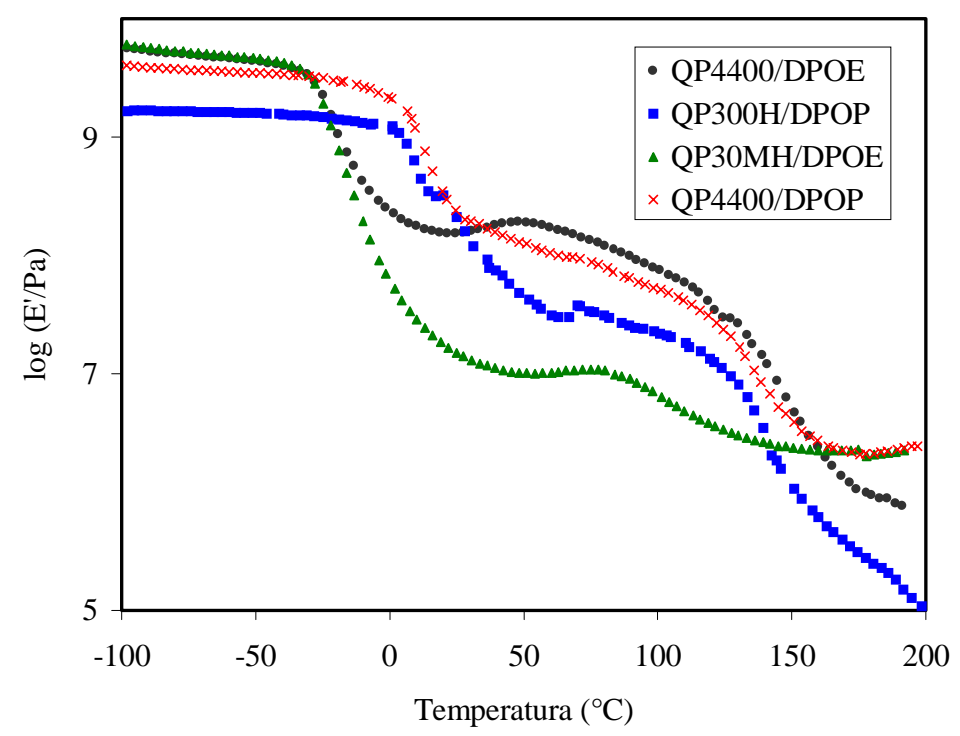

Figura 2. 32: Curvas de análise termodinâmico-mecânicas para filmes de hidroxietil celulose enxertada com poliéter e dopados com $\mathrm{LiClO}_{4}$

\subsubsection{2-Filmes com hidroxipropil celulose}

Foram elaborados filmes utilizando-se três amostras de HPC que foram enxertadas com os três tipos de isocianato a concentração de entrecruzamento ou enxertia $(\mathrm{NCO} / \mathrm{OH}=0,6)$ a fim de avaliar a influência da cadeia de polissacarídeo nas propriedades da rede. Foram obtidos filmes flexíveis e transparentes com caráter predominantemente amorfo exemplificado pelo difratograma de raios- $\mathrm{X}$ de amostra de HPC 19,189-2 entrecruzada com DPOP2 (figura 2.33). Os filmes foram também caracterizados através da determinação de Tg (tabela 2.16).

Aparentemente o comportamento da $\mathrm{Tg}$ nestes sistemas é parecido com o observado para as amostras contendo HEC (os valores de temperatura de transição vítrea são bastante parecidos para os dois tipos de polissacarídeo): em termos gerais Tg é menor para filmes com monoisocianato e maior quando se utiliza o isocianato difuncional de poli(óxido de propileno). Também é notado que os valores de Tg para 
HPC com maior massa molar entrecruzada e com DPOE e DPOP são maiores que para as outras duas amostras de HEC sugerindo uma possível dependência de $\mathrm{Tg}$ com a massa molar.

Tabela 2. 16: Valores de temperatura de transição vítrea para filmes de hidroxipropil celulose enxertada com poliéter

\begin{tabular}{lcc}
\hline \multicolumn{1}{c}{ HPC } & Isocianato & Tg $\left.\mathbf{~}^{\mathbf{0}} \mathbf{C}\right)$ \\
\hline $19188-4$ & DPOE2 & -50 \\
$(\mathrm{MS}=5,45 ; \mathrm{DS}=2,4 ;$ & DPOP2 & -40 \\
$\mathrm{MM}=100000 \mathrm{~g} / \mathrm{mol})$ & MPOP1 & -75 \\
\hline $19189-2$ & DPOE2 & -58 \\
$(\mathrm{MS}=4,25 ; \mathrm{DS}=1,2 ;$ & DPOP2 & -66 \\
$\mathrm{MM}=370000 \mathrm{~g} / \mathrm{mol})$ & MPOP1 & -68 \\
\hline $43500-7$ & DPOE2 & -48 \\
$(\mathrm{MS}=5,60 ; \mathrm{DS}=3 ;$ & DPOP2 & -33 \\
$\mathrm{MM}=80000 \mathrm{~g} / \mathrm{mol})$ & MPOP1 & -63 \\
\hline
\end{tabular}

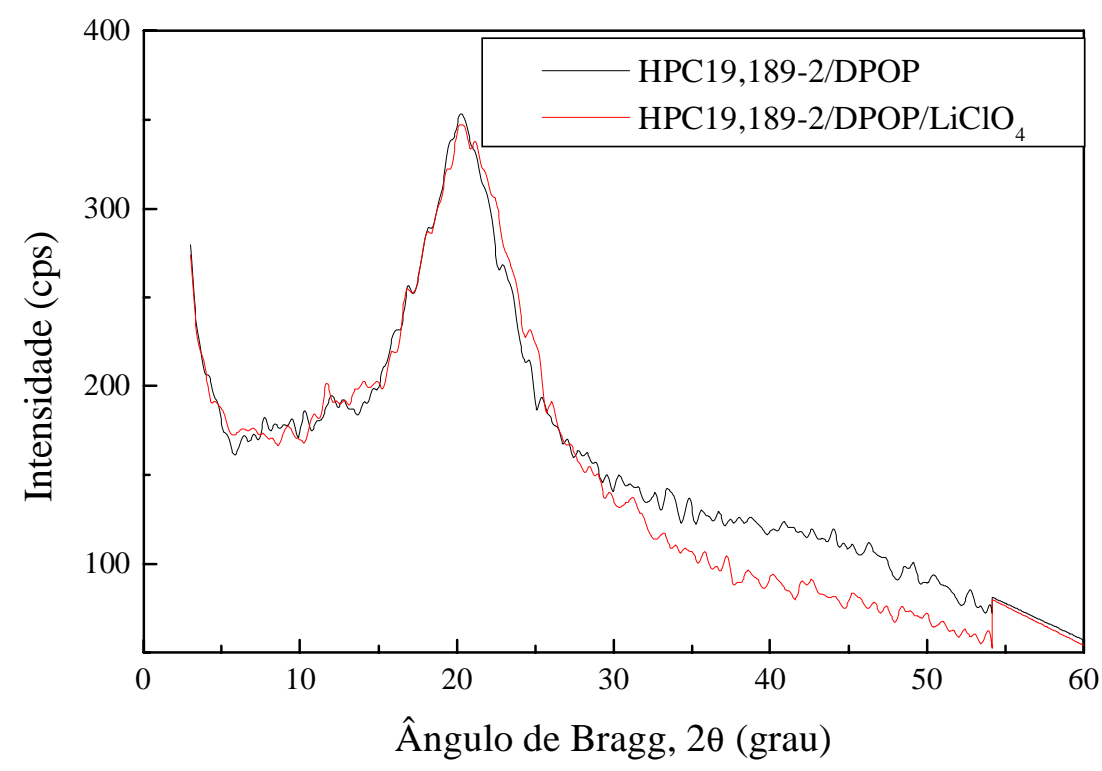

Figura 2. 33: Difratogramas de raios-X de filmes de HPC 19,189-2 entrecruzadas com diisocianato de poli(óxido de propileno) (DPOP) com e sem sal de lítio

Foram também sintetizados filmes de HPC enxertados e dopados com $\mathrm{LiClO}_{4}$ (percebe-se o caráter amorfo destes filmes através do difratograma de raios- $\mathrm{X}$ da amostra HPC 19,189-2 dopada com $\mathrm{LiClO}_{4}$, figura 2.33). Os valores de concentração 
de sal e temperatura de transição vítrea para estes sistemas são apresentados na tabela 2.17. Os valores de $\mathrm{Tg}$ obtidos para estes filmes são da mesma magnitude dos correspondentes sintetizados com HEC, levando a acreditar que a estrutura do polissacarídeo utilizado para síntese do eletrólito sólido polimérico não influencia a mobilidade dos sistemas (propriedade que pode ser analisada através da temperatura de transição vítrea).

Tabela 2. 17: Valores de concentração de $\mathrm{LiClO}_{4}$ e temperatura de transição vítrea para filmes de hidroxipropil celulose enxertados com poliéter

\begin{tabular}{|c|c|c|c|c|c|}
\hline \multirow[t]{2}{*}{ HPC } & \multirow[t]{2}{*}{ Isocianato } & \multicolumn{3}{|c|}{ Concentração de sal } & \multirow[t]{2}{*}{$\operatorname{Tg}\left({ }^{\circ} \mathrm{C}\right)$} \\
\hline & & $\begin{array}{l}n \mathrm{O} / n \mathrm{Li} \\
\left(n \mathrm{O}_{\mathrm{HPC}}+n \mathrm{O}_{\text {poliéter }}\right)\end{array}$ & $\begin{array}{l}n \mathrm{O} / n \mathrm{Li} \\
\left(n \mathrm{O}_{\text {poliéter }}\right)\end{array}$ & $\begin{array}{l}\text { mol } \mathrm{Li}^{+} / \mathrm{dm}^{3} \\
\text { poliéter }\end{array}$ & \\
\hline \multirow[t]{3}{*}{ 19188-4 } & DPOE2 & 12 & 6,0 & 3,6 & -23 \\
\hline & DPOP2 & 12 & 4,7 & 4,3 & -3 \\
\hline & MPOP1 & 12 & 7,8 & 2,3 & -51 \\
\hline \multirow[t]{3}{*}{ 19189-2 } & DPOE2 & 12 & 6,3 & 3,9 & -27 \\
\hline & DPOP2 & 12 & 4,9 & 4,6 & -5 \\
\hline & MPOP1 & 12 & 8,2 & 2,2 & -34 \\
\hline \multirow[t]{3}{*}{$43500-7$} & DPOE2 & 12 & 6,0 & 3,6 & -15 \\
\hline & DPOP2 & 12 & 4,7 & 4,2 & -21 \\
\hline & MPOP1 & 12 & 7,8 & 2,2 & não detectado \\
\hline
\end{tabular}

\section{4 - Conclusões do capitulo}

Neste capítulo foi apresentada a síntese de filmes de polissacaídeos enxertados com poliéteres. A reação de enxertia foi confirmada com a análise de espectros no infravermelho onde a banda a $1740 \mathrm{~cm}^{-1}$ confirma a obtenção de ligação uretana. As amostras em forma de filme antes da dopagem com sal apresentaram a temperatura de transição vítrea muito abaixo da temperatura ambiente. Observou-se que a Tg é função do tipo de poliéter inserido na matriz de polissacarídeo e não dos parâmetros estruturais ou do tipo do derivado de celulose utilizado. A introdução de 
sal leva ao aumento da $\mathrm{Tg}$ como resultado do entrecruzamento iônico promovido pela solvatação dos cátions $\mathrm{Li}^{+}$pelo oxigênios presentes na estrutura do filme. Este tipo de entrecruzamento também é sugerido pela análise termodinâmico-mecânica onde se observa duas transições do módulo visco-elástico. A primeira coincide com a transição vítrea obtendo-se resultados coerentes com os experimentos de calorimetria diferencial exploratória e a segunda transição pode estar associada com o entrecruzamento iônico. A temperatura de transição vítrea das redes contendo sal indicam que elas podem ser utilizadas como eletrólitos sólidos poliméricos.

2.5 - Referências bibliográficas

${ }^{1}$ FENGEL, D; WEGENER, G. Wood: chemistry, ultrastructure, reactions. New York, Walter de Gruyter, 1989. p. 66-105.

${ }^{2}$ DAVID, H.; HON, S. Cellulose: A random walk along its historical path. Cellulose, v. 1, p. 1-25, 1994.

${ }^{3}$ EMSLEY, A. M.; STEVENS, G. C. Kinetics and mechanisms of the lowtemperature degradation of cellulose. Cellulose, v. 1, p. 26-56, 1994.

${ }^{4}$ NEVELL, T. P.; ZERONIAN, S. H. Cellulose chemistry and its applications. London, Unwim Brothers of Working, 1985. p. 15-83, 138-201.

${ }^{5}$ INSTITUTO DE PESQUISAS TECNOLÓGICAS. Celulose e papel: tecnologia de fabricação de pasta celulósica. São Paulo, IPT, 1981. p. 46-67.

${ }^{6}$ SJÖSTROM, E. Wood chemistry: fundamentals and applications. New York, Academic Press, 1981. 223p.

${ }^{7}$ YOUNG, R. A.; ROWELL, R. M., eds. Cellulose: structure, modification and hydrolisis. New York, John Wiley, 1986. p. 3-50.

${ }^{8}$ BUSCHLE-DILLER, G.; ZERONIAN, S. H. Enhancing the reactivity and strenght of cotton fibers. Journal of Applied Polymer Science, v. 45, p. 967-979, 1992.

${ }^{9}$ SASSI, J. F.; CHANZY,H. Ultrastructural aspect of the acetylation of cellulose.

Cellulose, v. 2, p. 111-127, 1995. 
${ }^{10}$ REGIANI, Anelise Maria. Síntese de ésteres de celulose em meio homogêneo. São Carlos, 1997. 75p. Dissertação (Mestrado) - Instituto de Química de São Carlos, Universidade de São Paulo.

${ }^{11}$ SAMARANAYAKE, G.; GLASSER, W. G. Cellulose derivatives with low DS I. A novel acylation system. Carbohydrate Polymers, v. 22, p. 1-7, 1993.

${ }^{12}$ UNION CARBIDE PRODUTOS QUÍMICOS LTDA. Cellozise, hidroxietil celulose HEC. São Paulo, 1981.

${ }^{13}$ CULLITY, B. D. Elements of X-ray diffraction. Reading, Addison-Wesley, 1978. 555p.

${ }^{14}$ SILVERSTEIN, R. M.; BASSLER, G.C. Spectrometric identification of organic compounds. 5.ed. New York, John Wiley, 1974. p. 91-261.

${ }^{15}$ ALLINGER, N. L. et al. Química Orgânica. Trad. de Ricardo Bicca de Alencastro. 2.ed. Rio de Janeiro, Guanabara Dois, 1978. 961p.

${ }^{16}$ CLEMETT, C. J. Determination of the molar substitution of cellulose ethers using proton magnetic ressonance. Analytical Chemistry, v.45, n.1, p. 186-188, 1973.

${ }^{17}$ KIMURA, K. SHIGEMURA, T.; KUBO, M.; MARU, Y. ${ }^{13} \mathrm{C}$ NMR study of O(2-hydroxypropyl)cellulose. Makromoleculare Chemie, v. 136, p. 61-70, 1985.

${ }^{18}$ DeMEMBER, J. R.; TAYLOR, L. D.; TRUMMER, S.; RUBIN, L. E.; CHIKLIS, C. K. Carbon-13 NMR of hydroxyethylcellulose: an accurate method for structural determination. Journal of Applied Polymer Science, v. 21, p. 621-627, 1977.

${ }^{19}$ BILLMEYER, F. W. Textbook of polymer science. 3.ed. New York, John Wiley, 1984. p. 208-213.

${ }^{20}$ BROWN, W.; HENLEY,O.; ÖHMAN, J. Studies on Cellulose Derivatives, Part II: the influence of solvent and temperature on the configurational and hydrodynamic behavior of hydroxyethylcellulose in dilute solution.

Makromoleculare Chemie, v. 64, p. 49-67, 1963.

${ }^{21}$ CROMPTON, T. R. Analysis of polymers: an introduction. Oxford, Pergamon Press, 1989. p. 208-221.

${ }^{22}$ HATAKEYAMA, T; QUINN, F. X. Thermal analysis: fundamentals and applications to polymer science. New York, John Wiley, 1994. 158p. 
${ }^{23}$ KALOUSTIAN, J.; PAULI, A. M.; PASTOR, J. Analyse thermique de la cellulose et de quelques derives etherifies et esterifies. Journal of Thermal Analysis, v. 48, p. 791-804, 1997.

${ }^{24}$ KALOUSTIAN, J.; PAULI, A. M.; PASTOR, J. Caracterisation par analyse thermique de la lignine, de la cellulose et de quelques uns des derives etherifies. Journal of Thermal Analysis, v. 46, p. 91-104, 1996.

${ }^{25}$ PARFONDRY, A.; PERLIN, A. S. ${ }^{13}$ C-NMR spectroscopy of cellulose ethers. Carbohydrate Research, v. 57, p. 39-49, 1977.

${ }^{26}$ NEHLS, I.; WAGENKNECHT, W.; PHILIPP, B.; STSCHERBINA, D. Characterization of cellulose and cellulose derivatives in solution by hight resolution ${ }^{13} \mathrm{C}$-NMR spectroscopy. Progress in Polymer Science, v. 19, p. 29-78, 1994.

${ }^{27}$ REGIANI, A. M.; PAWLICKA, A.; CURVELO, A. A. S.; GANDINI, A.; LeNEST, J. F. Hidroxietil celulose enxertada com poliéteres. Polímeros: ciência e tecnologia, v.9, n.3, p. 45-50, 1999.

${ }^{28}$ HO, F. F.-L.; KOHLER, R. R.; WARD, G. A. Determination of molar substitutuion and degree of substitution of hydroxypropyl cellulose by nuclear magnetic ressonance spectrometry. Analytical Chemistry, v.44, n.1, p. 178$181,1972$.

${ }^{29}$ OZAKI, S. Recent advances in isocyanate chemistry. Chemical Reviews, v. 72, n.5, p. 326-496, 1972.

${ }^{30}$ ECKERT, H.; FORSTER, B. Triphosgene, a crystalline phosgene substitute. Angewandte Chemie, v.26, n.9, p. 894-895, 1987.

${ }^{31}$ COTARCA, L.; DELOGU, P.; NARDELLI, A.; ŠUNJIC, V. Bis(trichloromethyl) carbonate in organic synthesis. Synthesis, n.5, p. 553-576, 1996.

${ }^{32}$ LeNEST, J. F.; CALLENS, S.; GANDINI, A.; ARMAND, M. A new polymer network for ionic conduction. Electrochimica Acta, v.37, n.9, p. 1585-1588, 1992.

${ }^{33}$ PERrin, D. D.; ARMAREGO, W. L. F.; PERRIN, D. R. Purification of laboratory chemicals. 2.ed. New York, Pergamon Press, 1980. 568p.

${ }^{34}$ MONTANARI, Suzelei. Processo de deslignificação organossolve: efeito da concentração de catalisador e do tempo de reação; utilização de ligninas na preparação de uretanas e poliuretanas. São Carlos, 1994. 169p. Tese (Doutorado) - Instituto de Química de São Carlos, Universidade de São Paulo. 
${ }^{35}$ SCHOENENBERGER, Catherine. Synthèse et caracterisation d'electrolytes solides polymères. Grenoble, 1992. 128p. Tese (Doutorado) - Ecole Française de Papeterie et des Industries Graphique, Institut National Polytechnique de Grenoble.

${ }^{36}$ AMERICAN SOCIETY FOR TESTING AND MATERIALS. Standard test method for isocyanate groups in urethane materials prepolymers. (D 2572-87). Philadelphia, ASTM, 1987. v. 06.03, p. 377-378.

${ }^{37}$ FRISCH, K. C.; REGGEN, S. L. Catalyst in isocyanate reactions. Advances in Urethane Science and Tecnology, v. 1, p. 1-30, 1971.

${ }^{38}$ HSIEH, K. H.; LIN, B. Y.; CHIU, W. Y. Studies on diisocyanate - Modified cellulose acetate membranes. Desalination, n.71, p. 97-105, 1989.

${ }^{39}$ ELLZEY, S. E.; MACK, C. H. Reaction of arylisocyanates with cotton cellulose. Part I: Variables in the reaction using phenylisocyanate. Textile Research Journal, p. 1023-1029, 1962.

${ }^{40}$ TREJO-O'REILLY, J. A.; CAVAILLE, J. Y.; GANDINI, A. The surface chemical modification of cellulosic fibres in view of their use in composite materials. Cellulose, v. 4, p. 305-320, 1997.

${ }^{41}$ LeNEST, J. F.; GANDINI, A. Electrolytes for solid-state batteries: glass transition temperature of polyether networks with and without alkali metal salts. Polymer Bulletin, v. 21, p. 347-351, 1989.

${ }^{42}$ CALLENS, S.; LeNEST, J.F.; GANDINI, A.; ARMAND, M. A novel solid polymer electrolyte: synthesis and characterization. Polymer Bulletin, v. 25, p. 443-450, 1991.

${ }^{43}$ LeNEST, J. F.; GANDINI, A.; CHERADAME, H. Crosslinked polyether as media for ionic conduction. British Polymer Journal, v. 20, p. 253-268, 1988.

44 TOFFEY, A.; GASSER, W. G. Cure and characterization of polyurethanes with lignin and cellulose derivatives. Holzforchung, v. 51, p. 71-78, 1997.

${ }^{45}$ SCHOENENBERGER, C.; LeNEST, J. -F.; GANDINI, A. Polymer electrolytes based on modified polysaccharides. 2. polyether modified cellulosics. Electrochimica Acta, v. 40, n.13/14, p. 2281-2284, 1995.

${ }^{46}$ MORALEZ, P. V.; LeNEST, J. F.; GANDINI, A. Polymer electrolytes derived from chitosan/polyether networks. Electrochimica Acta, v.43, n.10/11, p. 1275-1279, 1998. 
${ }^{47}$ LeNEST, Jean-François. Etude fondamentale des relations entre la structure de réseaux macromoleculaires et leur proprieté de conduction ionique.

Grenoble, 1985. 284p. Tese (Doutorado) - Ecole Française de Papeterie et des Industries Graphiques, Institut National Polytechnique de Grenoble. 


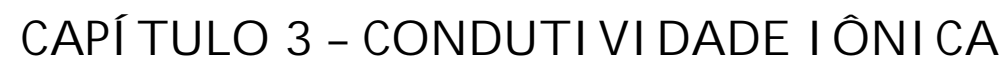

$3.1-$ Introdução

Um eletrólito sólido polimérico (ESP) pode ser visualizado como uma matriz macromolecular do tipo poliéter na qual é dissolvido um sal como $\mathrm{MCF}_{3} \mathrm{SO}_{3}$ ou $\mathrm{MClO}_{4}$ (onde $\left.\mathrm{M}=\mathrm{Li}, \mathrm{Na}, \mathrm{K}\right)^{1}$. A cadeia polimérica contém geralmente unidades de óxido de etileno ou óxido de propileno. A existência de átomos de oxigênio na estrutura da macromolécula propicia a dissociação do sal e a solvatação dos cátions. A condução iônica corresponde, portanto, ao transporte de íons através do material. Neste caso, que o deslocamento dos cátions é favorecido pela movimentação dos segmentos poliméricos. A caracterização eletroquímica destes materiais consiste geralmente em determinar a condutividade do eletrólito em função da temperatura, identificar as espécies carregadas que contribuem na condução e cálculo do número de transporte, isto é, a proporção de corrente carregada por cada espécie em função da temperatura.

A interpretação dos resultados experimentais é complexa e existem vários métodos e modelos teóricos para a interpretação ${ }^{2,3}$. Estas dificuldades resultam principalmente do fato dos sistemas não serem homogêneos. Na realidade estes 
sistemas apresentam regiões amorfas e cristalinas, pode haver gradiente de concentração de sal que pode não estar completamente dissociado ${ }^{1}$. Podem também ocorrer separações de fases e presença de impurezas, incluindo a do solvente residual. Nos ESP, a condutividade pode ser influenciada por uma série de parâmetros, dentre eles a massa molecular do polímero, assim como seus grupos terminais, concentração de sal adicionado, tamanho dos cátions, a valência dos mesmos, história térmica e também fatores externos como temperatura e pressão ${ }^{1}$.

Em termos gerais a condutividade iônica da espécie $i$ na temperatura $T, \sigma_{i}(T)$, pode ser expressa segundo a equação 18

$$
\sigma_{i}(T)=\sum_{i} n_{i} q_{i} u_{i}(T)
$$

onde $n_{i}$ é o número de espécies transportadoras de carga, $q_{i}$ a carga destas partículas e $u_{i}(T)$ a sua mobilidade na temperatura $T$. Dentre as espécies responsáveis pela condução encontram-se os cátions, os ânions e agregados carregados.

Qualquer que seja o transportador de carga ou o meio no qual esteja inserido, o seu deslocamento pode acontecer de duas maneiras ${ }^{4}$ : (i) as espécies responsáveis pela condução estão inseridas em uma matriz imóvel, isto é, estas espécies "saltam” de um sítio de solvatação à outro; (ii) o transporte é feito com o auxílio dos movimentos da cadeia polimérica da matriz onde o sal é dissolvido. Para cada um destes mecanismos a variação de condutividade em função da temperatura segue lei diferente. No primeiro caso trata-se do modelo de Arrhenius (equação 19)

$$
\sigma(T)=A \exp \left[-\frac{\Delta E}{R T}\right]
$$


onde $A$ é o fator pré-exponencial, $\Delta E$ a pseudo-energia de ativação e $R$ a constante dos gases ideais. Portanto, $\sigma$ é função linear de 1/T. Quando há o auxílio da cadeia polimérica a condutividade obedece lei do tipo

$$
\sigma(T)=\frac{A}{T^{1 / 2}} \exp \left[-\frac{\Delta E}{\left(T-T_{0}\right)}\right]
$$

onde $T_{0}$ tem valor característico ao condutor iônico e é denominado temperatura ideal de transição vítrea. A partir do gráfico de lno versus $1 /\left(T-T_{0}\right)$ determina-se os parâmetros $A$ e $\Delta E$ a partir dos coeficientes linear e angular da reta obtida.

A equação do tipo Vogel-Tamman-Fulcher, VTF, (20) foi originalmente proposta para descrever a viscosidade de líquidos super resfriados ${ }^{5,6}$. As adaptações ao modelo foram feitas a fim de relacionar a viscosidade (e portanto o coeficiente de difusão) e a condutividade. Elas baseiam-se em duas considerações ${ }^{3,6}$. A primeira assume que os movimentos moleculares em um líquido não são termicamente ativados, mas ocorrem como resultado da redistribuição do "volume livre" no sistema. Desta forma, $T_{0}$ é a temperatura na qual o volume livre desaparece, ou seja, quando cessam os movimentos translacionais. $T_{0}$ é normalmente expressa como $T_{0}=$ $T g-50[K]^{6}$. Segundo esta consideração, as partículas dissolvidas na matriz tem taxa de difusão igual a dos segmentos poliméricos, movendo-se livremente (sem energia de ativação) enquanto houver volume livre disponível.

A segunda consideração baseia-se no modelo de entropia configuracional, onde o transporte é visualizado como consequiência dos rearranjos cooperativos entre 
as cadeias ${ }^{3}$. Se os íons estiverem fortemente associados ao polímero, os movimentos iônicos podem ser correlacionados aos dos segmentos poliméricos.

Outra equação equivalente é a proposta por Williams-Landel-Ferry (WLF) baseada nas observações empíricas dos tempos de relaxação poliméricos e nas variações entálpicas do processo de difusão. A equação WLF geral para a condutividade é dada por ${ }^{7}$ :

$$
\log \left(\frac{\sigma_{T}}{\sigma_{T g}}\right)=-\frac{f_{i}^{*}}{f_{p}^{*}} \log \left(a_{T}\right)-\frac{E_{i}+\frac{W}{2 \varepsilon}}{2,3 R}\left(\frac{1}{T}-\frac{1}{T_{g}}\right)
$$

onde $f^{*}{ }_{i}$ é a fração de volume livre mínimo necessário para o deslocamento da espécie $i, f^{*}$ é a fração de volume livre crítico necessário para a movimentação das cadeias poliméricas, $E_{i}$ é a energia de ativação da espécie $i, W$ é a entalpia de dissociação do sal e $\log \left(a_{T}\right)$ é fator de deslocamento dinâmico WLF. A temperaturas geralmente entre $\mathrm{Tg}$ e $\mathrm{Tg}+100 \mathrm{~K}$, onde a condutividade segue o comportamento de volume livre ${ }^{8,8}$, a expressão 21 reduz-se à:

$$
\log \left(\frac{\sigma_{T}}{\sigma_{T g}}\right)=-\log \left(a_{T}\right)=\frac{C_{1}(T-T g)}{\left(C_{2}+T-T g\right)}
$$

onde $C_{1}$ e $C_{2}$ são constantes ditas universais e apresentam os valores típicos 17,4 e 52K respectivamente e na temperatura de transição vítrea.

A observação das curvas experimentais de $\log \sigma$ em função do inverso da temperatura permite avaliar a forma com que as espécies migram na matriz 
polimérica. Geralmente os eletrólitos sólidos apresentam os seguintes padrões de comportamento:

(a) Comportamento VTF em todo intervalo de temperatura estudado;

(b) Comportamento do tipo Arrhenius a baixas temperaturas e VTF a altas;

(c) Comportamento do tipo Arrhenius em todo intervalo de temperatura;

(d) Comportamento VTF a temperaturas ligeiramente superiores à Tg e Arrhenius para temperaturas mais elevadas;

$\mathrm{Na}$ verdade todos os modelos teóricos têm suas limitações decorrentes da heterogeneidade dos sistemas de eletrólitos sólidos poliméricos. Alguns fatores que afetam a condução são as propriedades térmicas do polímero, bem como a sua cristalinidade, a incompleta dissolução do sal e a formação de pares-iônicos. Também é importante lembrar que os modelos propostos para a interpretação da condutividade são baseados nos estudos de movimentação das cadeias poliméricas e não na migração de espécies carregadas. A difusão iônica pode ser correlacionada aos movimentos moleculares observando as devidas limitações ${ }^{6}$.

A forma pela qual os movimentos dos segmentos macromoleculares auxiliam na condução foi proposta para eletrólitos sólidos a base de poli(óxido de etileno) por LeNest $^{7}$. Este modelo pode ser representado esquematicamente como na figura 3.1. O equilíbrio (1) caracteriza a dissociação de quadrupolos (formados pela solvatação dos cátions pelos oxigênios da estrutura do poliéter) em dipolos. Em temperaturas superiores a $30^{\circ} \mathrm{C}$ o equilíbrio encontra-se deslocado na direção de formação de dipolos. O equilíbrio (2) representa a dissociação dos dipolos (etapa fundamental para a condução). As reações (3) caracterizam o mecanismo de deslocamento iônico correlacionados com os movimentos das cadeias. Os movimentos dos segmentos 
poliméricos permitem a migração de um cátion através da formação de um intermidiário de configuração triplete.
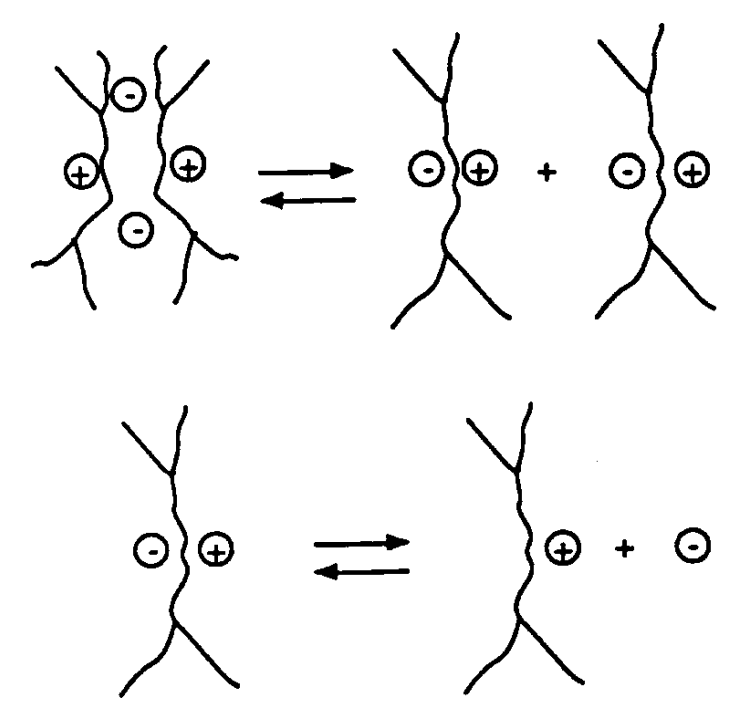

(2)
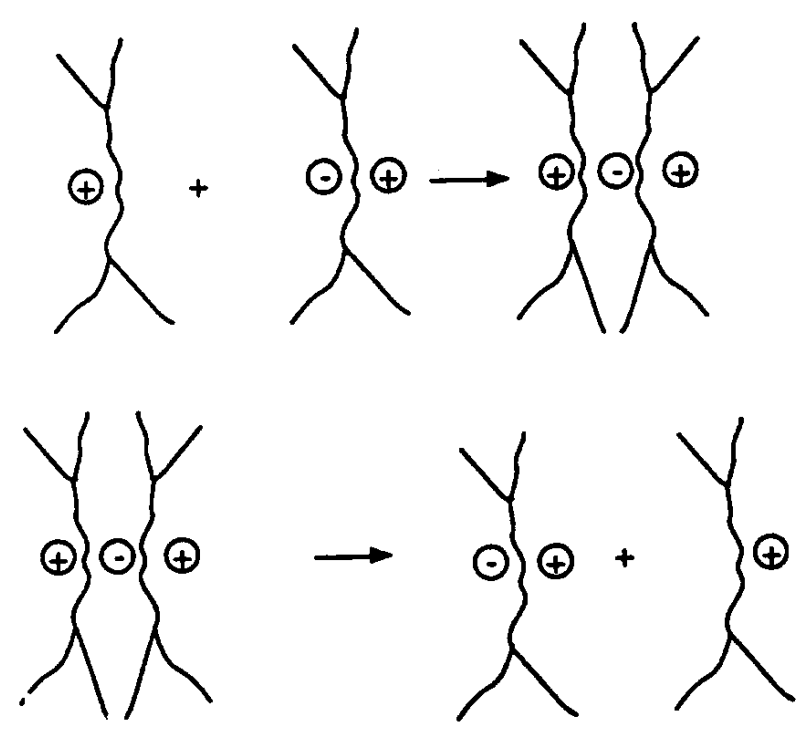

(3)

Figura 3. 1: Transferência de dipolo promovida pelos movimentos dos segmentos poliméricos; (1) dissociação de quadrupolos; (2) dissociação de dipolos; (3) deslocamento iônico 


\section{2-Materiais}

Foram medidas as condutividades em função da temperatura para os vários filmes de hidroxietil celulose e hidroxipropil celulose enxertados e dopados com sal de lítio sintetizados conforme descrito na seção 2.3.3.1.

\section{$3.3-$ Métodos}

O sistema utilizado para a determinação da condutividade está representado na figura 3.2. As amostras de superfície e espessura variável são prensadas entre dois eletrodos de aço (8 e 10) inoxidável polidos e contidos numa guia de porta-amostras de teflon (12). Este é colocado ao fundo de uma cela de medida. Os contatos elétricos são o fundo metálico da cela (6) e barra de aço inoxidável posicionada sobre o eletrodo superior (1). A cela foi concebida de tal forma a permitir a prensagem da amostra sob vácuo. Uma sonda de platina (17) em contado com o eletrodo superior permite a leitura direta da temperatura do sistema. O aquecimento da cela (da temperatura ambiente até $110^{\circ} \mathrm{C}$ ) é realizado com o auxílio de um forno BÜCHI TO50. O diagrama de impedância é obtido em potenciostato SCHLUMBERGER 1272 acoplado a um microcomputador, num intervalo de freqüência de $1 \mathrm{~Hz}$ a 10 MHz. As medidas foram realizadas sob vácuo, para evitar a influência da umidade, em voltagem constante e igual a $0,5 \mathrm{~V}$. Todos os experimentos foram realizados (no laboratório de materiais poliméricos na EFPG - INPG, Grenoble - França) com amostras previamente secas sob vácuo a $60^{\circ} \mathrm{C}$ por duas horas. 

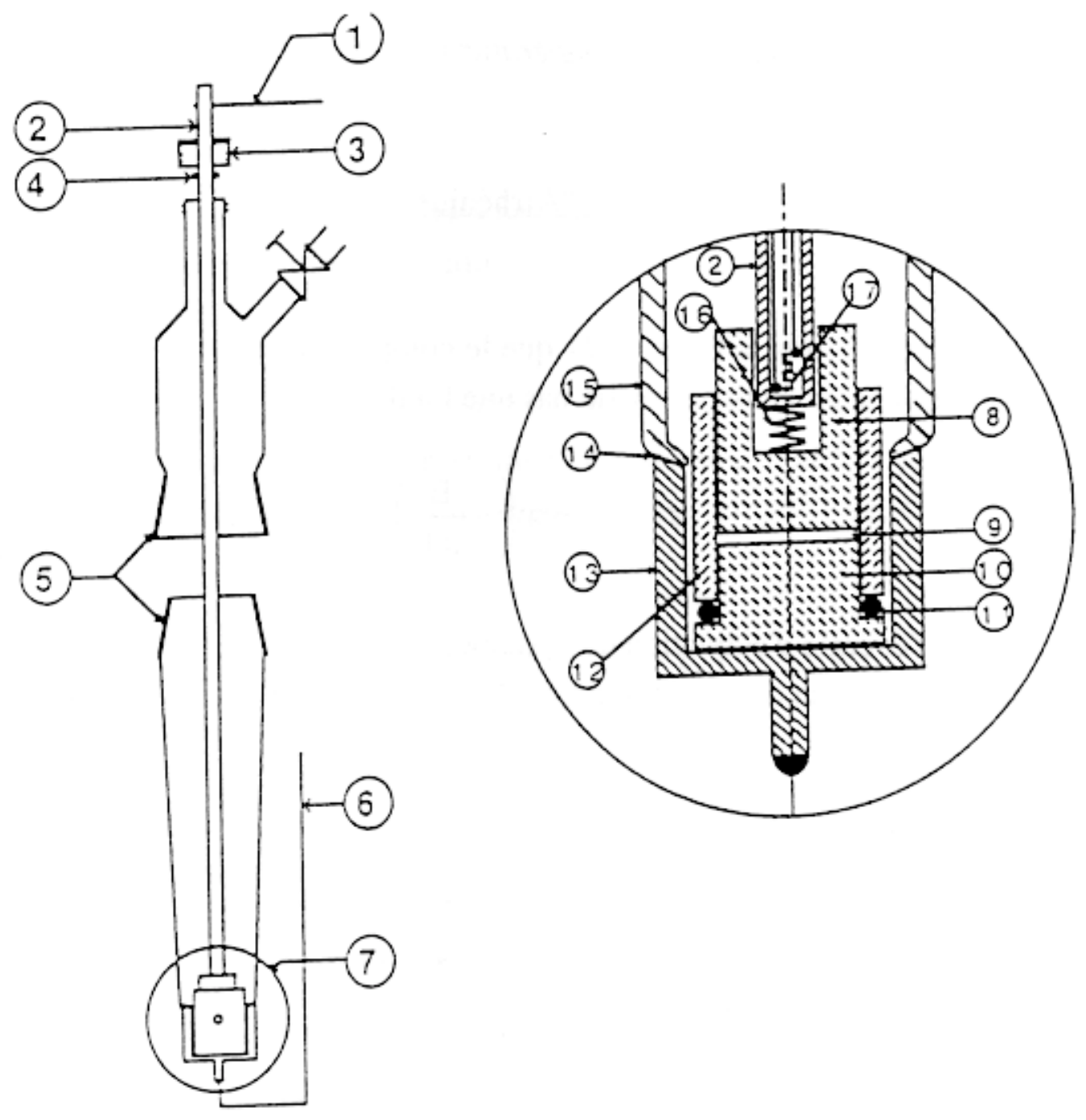

Figura 3. 2: Cela de medida utilizada nos experimentos de determinação de condutividade dos ESP: (1) contato do eletrodo superior; (2) tubo em aço inox, dentro do qual se encontra o termopar; (3) tampa com rosca; (4) junta para vedação; (5) junta em vidro; (6) contato do eletrodo inferior; (7) conjunto do porta amostras (no detalhe); (8) eletrodo superior em inox; (9) amostra; (10) eletrodo inferior; (11) junta; (12) guia do porta amostras (em teflon); (13) capa metálica; (14) solda vidrometal; (15) conjunto em vidro pyrex; (16) mola de compensação; (17) termopar

As medidas de condutividade foram analisadas segundo o método de impedância complexa. Este consiste em medir a impedância do eletrólito, presente entre dois eletrodos, em uma ampla escala de freqüências. A vantagem deste método em relação aos realizados em corrente contínua é a não polarização do eletrólito. 
Durante o procedimento experimental, aplica-se voltagem sinusoidal ( $V=V_{0} \operatorname{sen}(\omega t)$; onde $V_{0}$ é a mplitude máxima e $\omega$ a freqüência) à cela e determinase a corrente sinusoidal obtida como resultado desta perturbação $\left(I=I_{0} \operatorname{sen}(\omega t+\theta)\right.$, onde $\theta$ é a diferença de fase entre a perturbação e a resposta); ver figura $3.3^{9}$. O fator de proporção entre $v$ e $i$ representa a impedância, $Z$, da cela. Um programa de computador permite calcular o valor da impedância da cela de medida a partir dos dados obtidos.

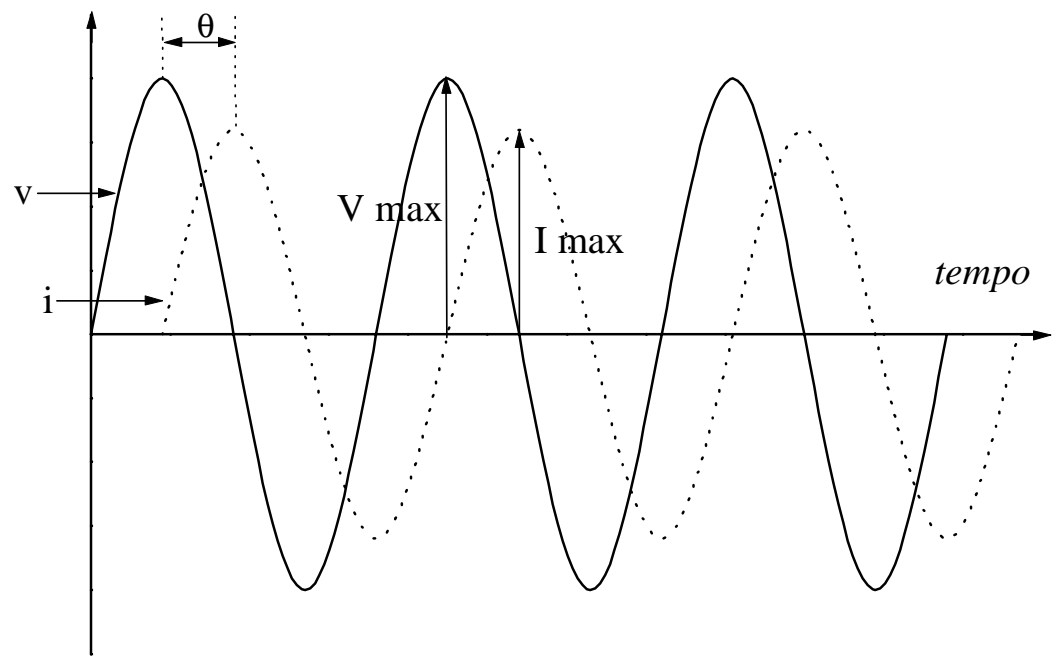

Figura 3. 3: Representação da voltagem e corrente sinusoidais, a uma dada freqüência, associada a uma cela eletroquímica; $v=$ voltagem, $i=$ corrente, $\theta=$ ângulo de fase entre voltagem e corrente

A análise no plano complexo da impedância em função da freqüência permite determinar o circuito elétrico equivalente ao eletrólito e seus parâmetros característicos. A representação mais utilizada é a de um circuito em paralelo resistência/capacitor ${ }^{9}$. Desta forma, a impedância complexa pode ser descrita pela forma geral: 


$$
Z(\omega)=Z^{\prime}(\omega)-j Z^{\prime \prime}(\omega)
$$

A representação gráfica da variação de $Z^{\prime \prime}$ em função de $Z^{\prime}$ é um semicírculo centrado sobre o eixo real. A resistência ôhmica do material $(R)$ é dada pela interseção da curva neste eixo (figura 3.4). A condutividade é então calculada segundo a equação 23.

$$
\sigma=\ell /(R \cdot s)
$$

onde $\ell$ é a espessura do filme e $s$ a área superficial.

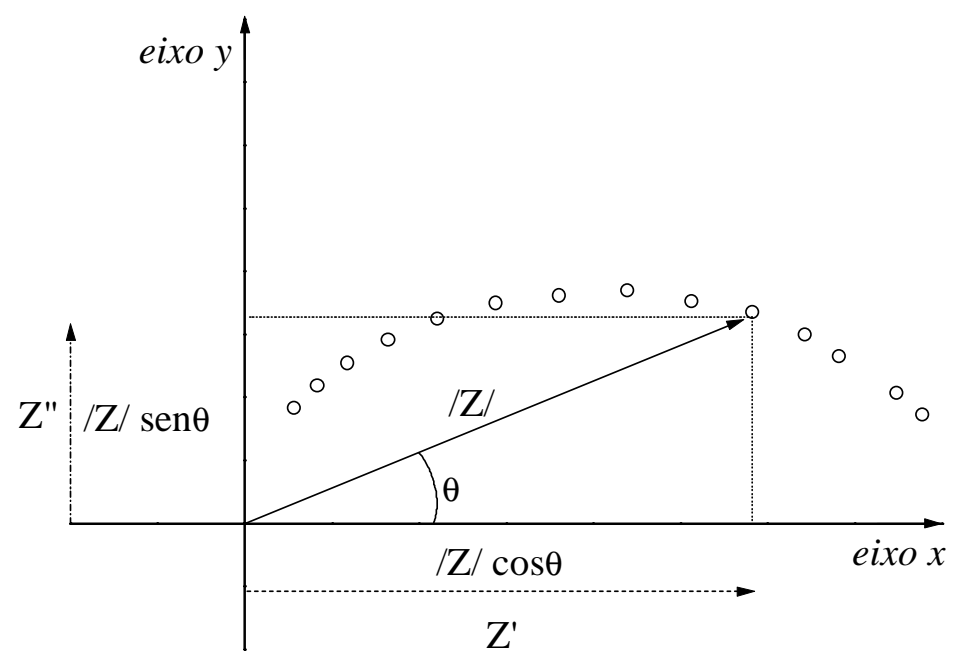

Figura 3. 4: Representação da impedância, $Z$, de uma cela eletroquímica no diagrama vetorial. $Z$ ' e $Z$ ” são respectivamente as correspondentes real e imaginária da impedância complexa $Z^{*}=Z^{\prime}-j Z^{\prime}$. 
$3.4-$ Resultados

3.4.1 - Eletrólitos sólidos poliméricos à base de fidroxietil celulose enxertada com poliéter

3.4.1.1-Poli(óxido de etile no)

O poli(óxido de etileno) é sem dúvida a melhor matriz para a síntese de eletrólitos sólidos poliméricos e suas propriedades nestes sistemas têm sido extensivamente estudadas $^{7,8}$. As modificações estruturais e a inserção de outros tipos de moléculas têm como finalidade melhorar as propriedades mecânicas e resolver alguns problemas relacionados às características estruturais do poliéter. Todos os inúmeros estudos realizados mostram que a condutividade em um sistema polimérico é função da concentração e da mobilidade das espécies carregadas. Um aumento da concentração de sal nestes sistemas leva a um aumento de $\mathrm{Tg}$ enquanto que a condutividade deve aumentar com a abundânica dos transportadores de carga até um determinado máximo. Para melhor estudar estes efeitos correlacionou-se os valores de condutividade à concentração de sal em sistemas com a mesma mobilidade, ou seja, onde (T-Tg) é uma constante ${ }^{10,11}$ (figura. 3.5). Pode-se observar em diagramas deste tipo a linearidade da curva até uma concentração crítica de sal e a ocorrência de mínimos de condutividade a concentrações específicas de sal. A dependência linear de logaritmo de condutividade em função de logaritmo de concentração de sal indica que o sal está totalmente dissociado na estrutura da rede de poliéter ${ }^{12}$ e o coeficiente angular igual a 1 permite concluir que, no caso de redes com perclorato de lítio, 
abaixo da concentração crítica, o $\mathrm{Li}^{+}$encontra-se solvatado com formação de quadrupolos. As discontinuidades observadas estão realacionadas com valores específicos para a relação $\mathrm{O} / \mathrm{Li}$; por exemplo, para PEO com massa molar 1050 g/mol o máximo ocorre quando há um $\mathrm{Li}^{+}$por cadeia, isto é, a molécula de poli(óxido de etileno) estaria dividida em duas partes de 12 unidades de óxido de etileno. Para PEO com massa molar $2100 \mathrm{~g} / \mathrm{mol}$, ocorre a divisão da cadeia polímerica em três segmentos de oito unidades de óxido de etileno. Este fato leva a acreditar na formação de estrutura muito ordenada ${ }^{10}$.

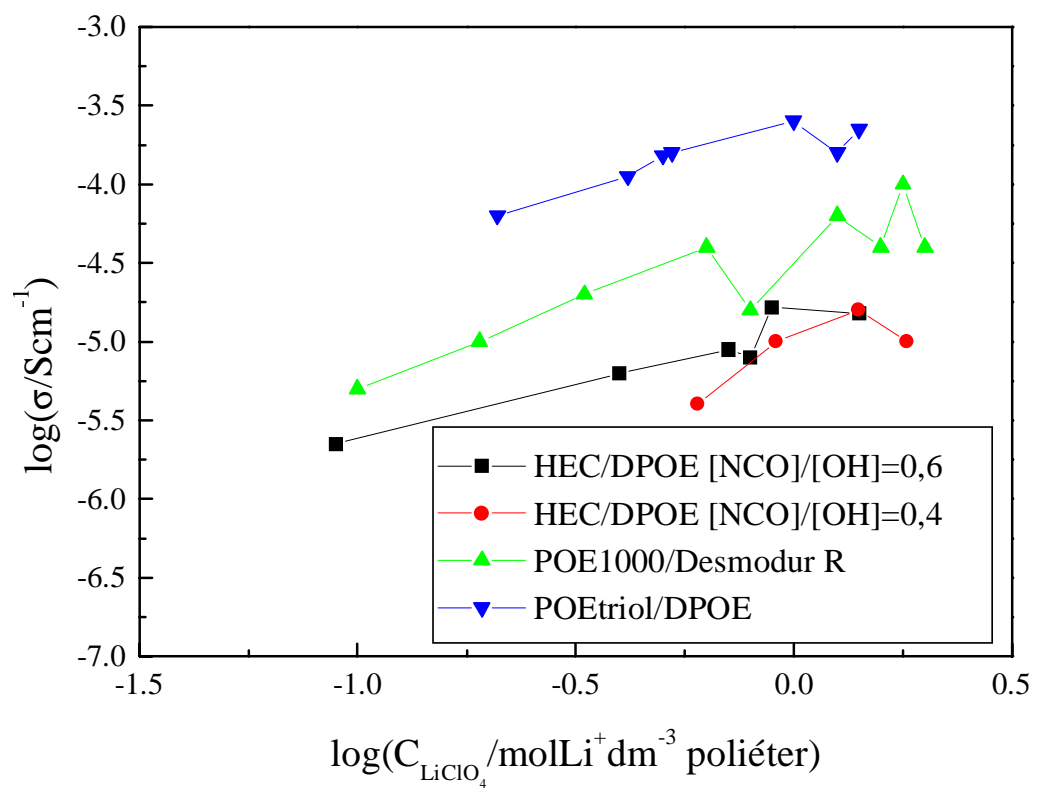

Figura 3. 5: Curvas log-log de condutividade iônica $(\sigma)$ em função de concentração de $\mathrm{LiClO}_{4}$ para vários eletrólitos sólidos poliméricos (referências 10 e 11)

Quando é utilizada matriz de polissacarídeo entrecruzado com poli(óxido de etileno) observa-se que o logaritmo da condutividade, em função do logaritmo da concentração de sal, passa por um único máximo, a partir do qual, a condutividade diminui com a adição de sal. A ocorrência de um único máximo neste tipo de curva 
também foi reportado por Gazotti et $a l^{13}$ para copolímeros de óxido de etileno/epicloroidrina com razão O/Li igual a aproximadamente 29. Este máximo é

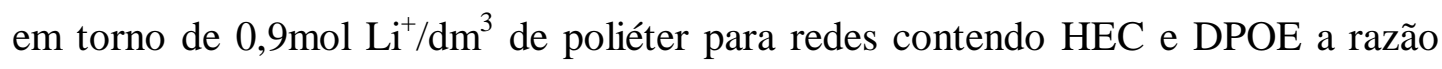

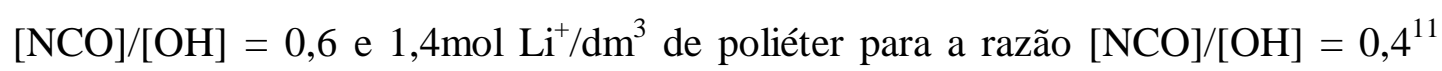
(figura 3.5). A diminuição de condutividade torna-se conseqüência da formação de pares iônicos e agregados cuja ocorrência foi demonstrada através do gráfico de 1/Tg versus concentração de sal (figuras 2.30 e 2.31). A presença destas estruturas causa dificuldade no entendimento da condução. A movimentação dos pares iônicos pode levar à difusão de massa, mas não à difusão de cargas o que resulta na diminuição de condutividade $^{12}$. Como os valores de concentração de sal nos filmes sintetizados para este estudo são maiores que este valor máximo (ver tabela 2.14) são esperados resultados de condutividade menores que os apresentados na literatura.

$\mathrm{Na}$ figura 3.6 podem ser observados os resultados de condutividade em função do inverso de temperatura para filmes de hidroxietil celulose entrecruzada com poli(óxido de etileno) e dopados com $\mathrm{LiClO}_{4}$. Os pontos representam os resultados experimentais e a linha, o ajuste através da equação VTF. 


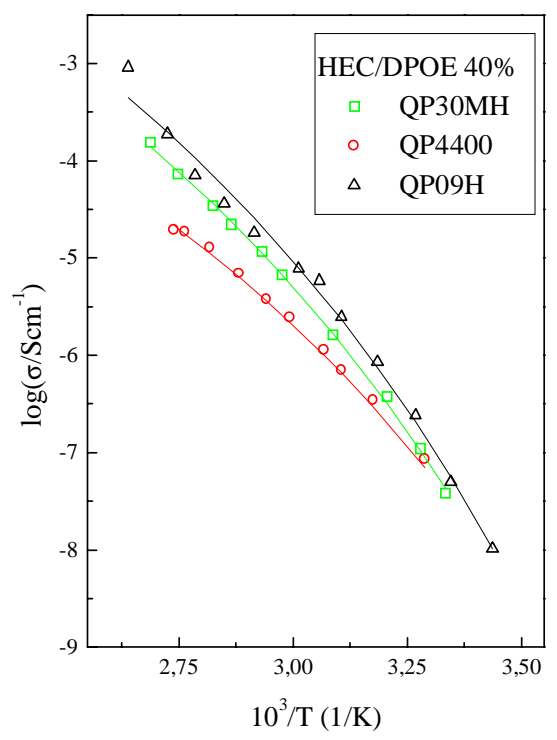

(a)

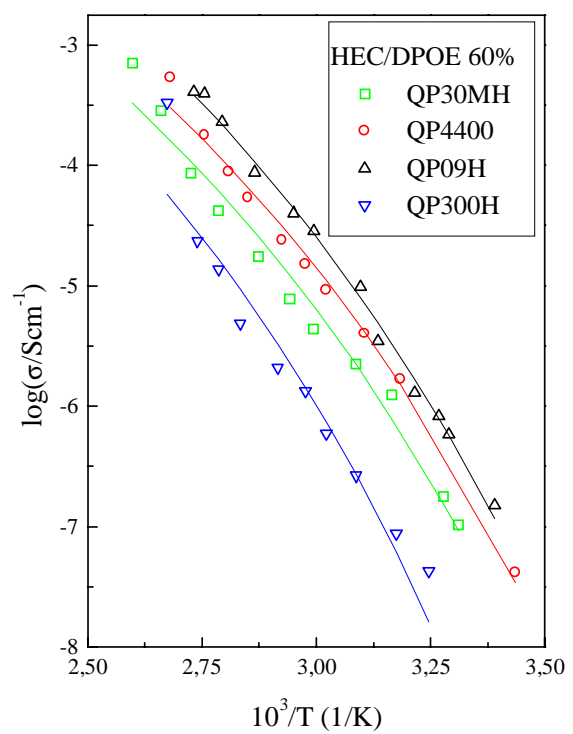

(b)

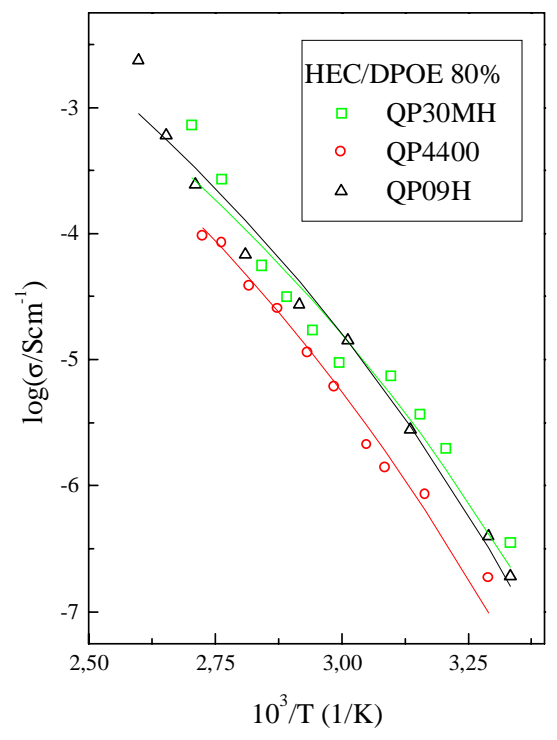

(c)

Figura 3. 6: Diagramas de logaritmo de condutividade em função do inverso de temperatura para eletrólitos sólidos poliméricos com matriz de hidroxietil celulose entrecruzada com poli(óxido de etileno) 
Pode ser observado nas curvas da figura 3.6 boa concordância entre os resultados experimentais e o ajuste pela equação VTF indicando que a condutividade iônica nestes sistemas está associadas aos movimentos das cadeias poliméricas. $\mathrm{Na}$ tabela 3.1 são apresentados os parâmetros obtidos a partir da equação VTF e as constantes WLF obtidos através da equação 22.

Tabela 3. 1: Parâmetros obtidos a partir do ajuste VTF e WLF dos resultados experimentais de condutividade para filmes de HEC/DPOE2 dopados com $\mathrm{LiClO}_{4}$

\begin{tabular}{cccccc}
\hline \multicolumn{2}{c}{ Eletrólito } & \multicolumn{2}{c}{ Ajuste VTF } & \multicolumn{2}{c}{ Constantes WLF } \\
\hline HEC & {$[\mathbf{N C O} /[\mathbf{O H}]$} & $\mathbf{A}\left(\mathbf{S c m}^{-\mathbf{1}} \mathbf{K}^{\mathbf{- 1 / 2}}\right)$ & $\mathbf{E a}\left(\mathbf{k J m o l} \mathbf{~}^{\mathbf{1}}\right)$ & $\mathbf{C}_{\mathbf{1}}(\mathbf{T g})$ & $\left.\mathbf{C}_{\mathbf{2}}(\mathbf{T g}) \mathbf{K}\right)$ \\
\hline QP09H & 0,4 & 1875 & 19,2 & 21 & 34 \\
& 0,6 & 1530 & 18,0 & 17,8 & 44 \\
& 0,8 & 1454 & 18,4 & 14,9 & 71 \\
\hline QP4400 & 0,4 & 17,5 & 15,6 & 18 & 38 \\
& 0,6 & 387 & 16,7 & 17,3 & 40 \\
& 0,8 & 354 & 18,2 & 33 & 24 \\
\hline QP30MH & 0,4 & 573 & 18,4 & 21 & 40 \\
& 0,6 & 426 & 17,9 & 15,7 & 25 \\
& 0,8 & 369 & 16,7 & 16,7 & 60 \\
\hline QP300H & 0,6 & 435 & 18,3 & 28 & 18,4 \\
\hline
\end{tabular}

Valores semelhantes de energia de ativação foram obtidos para eletrólitos à base de POE/Desmodur $\mathrm{R}$ dopados com bis(trifluorometano sulfonimida) ${ }^{14}$ a

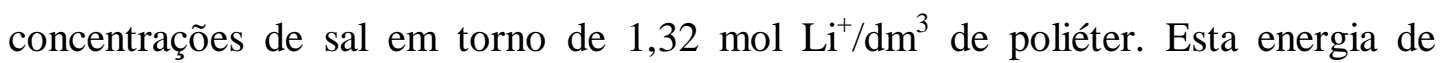
ativação pode ser interpretada como a energia requerida para criar um volume adequado para a mobilidade iônica durante o fenômeno de condução ${ }^{14}$. É então esperado que, para altas concentrações de sal este valor seja também mais elevado, pois a mobilidade da cadeia polimérica é menor. Os desvios dos valores obtidos para as constantes WLF em relação aos desvios ditos universais não são expressivos, quando comparados com os valores já obtidos para materiais similares ${ }^{10,11}$. Esta 
flutuação sugere que as redes preparadas não atingiram estrutura tridimensional perfeita, como já descrito na seção 2.3.4.1.

Considerando que a variação na concentração de sal nos eletrólitos sólidos poliméricos não é significativa, podemos avaliar a influência dos parâmetros estruturais da HEC, no caso, grau de substituição molar (MS) e da proporção de entrecruzamento (representada pela razão $[\mathrm{NCO}] /[\mathrm{OH}]$ ). Com o auxílio da figura 3.7 podemos observar os seguintes comportamentos:

1) Observando os valores de $\log \sigma$ para um dado valor de MS, percebe-se que a condutividade é maior para eletrólitos com razão $[\mathrm{NCO}] /[\mathrm{OH}]$ igual a 0,6 e para valores de MS iguais a 1,2 e 1,4. Na amostra com menor MS, a condutividade tem seu valor mais baixo para a mesma proporção de isocianato.

2) Para uma mesma proporção de entrecruzamento, os valores de condutividade são maiores para as amostras com MS igual a 1,2. Nas proporções 0,4 e 0,8 as condutividades são menores para maior MS, fenômeno inverso ao observado para proporção igual a 0,6 . 


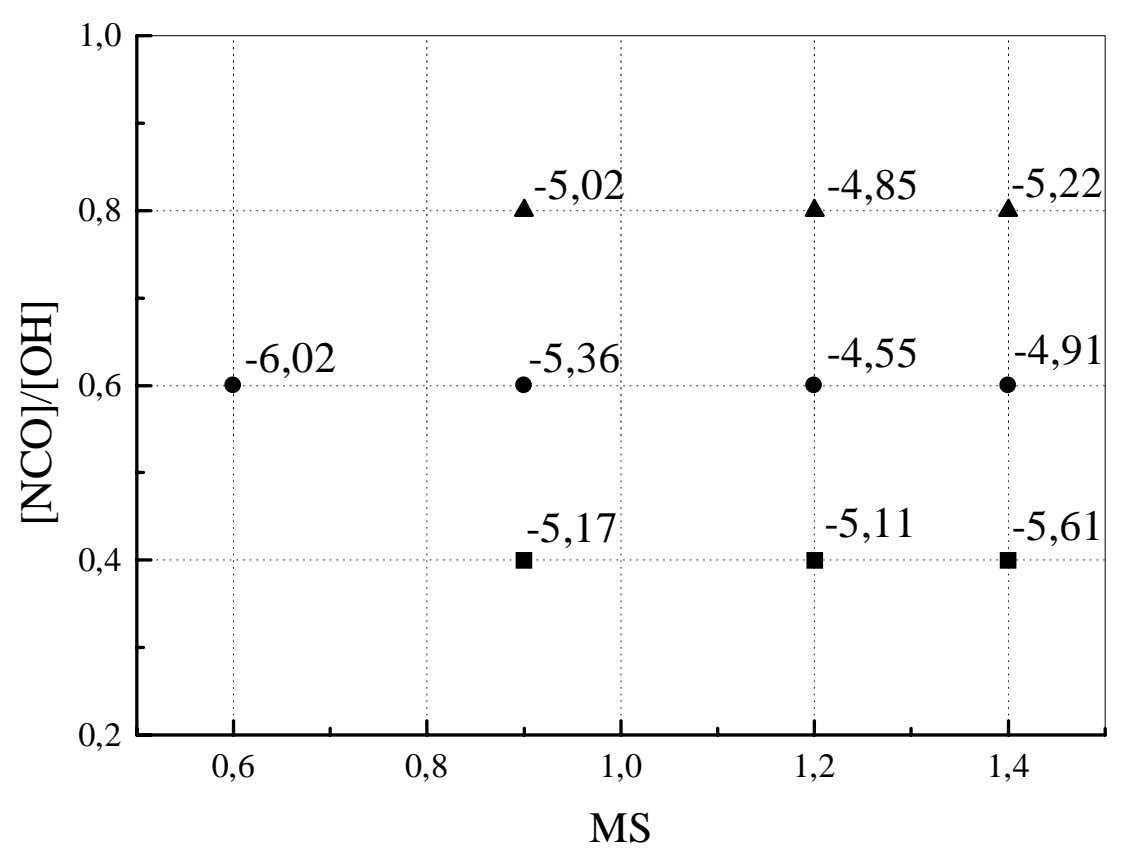

Figura 3. 7: Estudo da influência de MS da hidroxietil celulose e da razão $[\mathrm{NCO}] /[\mathrm{OH}]$ nos valores de logaritmo de condutividade a $60^{\circ} \mathrm{C}$ para os eletrólitos sólidos poliméricos sintetizados com DPOE2

Conclui-se que a interpretação dos resultados de condutividade em função dos parâmetros estruturais da HEC e da razão de entrecruzamento não é direta. A influência da presença do polissacarídeo não é muito pronunciada. Portanto, pode ser inferido que a adição de HEC nesta nova formulação de sistema com poli(óxido de etileno) não tem contribuição significativa no fenômeno de condução. A maior condutividade observada nestes sistemas a temperatura de $60^{\circ} \mathrm{C}$ foi igual a $2,82 \times 10^{-}$ ${ }^{5} \mathrm{~S} / \mathrm{cm}$ para a amostra QP09H/DPOE2 à razão $[\mathrm{NCO}] /[\mathrm{OH}]=0,6$. 
3.4.1.2-Polilóxido de propileno)

\section{Diisocianato de poli(óxido de propileno)}

Na figura 3.8 são apresentados os diagramas do tipo Arrhenius para os filmes de hidroxietil celulose entrecruzada com diisocianato de poli(óxido de propileno). Os pontos representam os resultados experimentais e a linha, o ajuste segundo a equação VTF. Mais uma vez observa-se que os resultados experimentais estão em boa concordância com o ajuste, indicando que a condutividade nestes sistemas é auxiliada pela movimentação dos segmentos poliméricos. Os dados obtidos a partir dos ajustes VTF e WLF são apresentados na tabela 3.2.

Tabela 3. 2: Parâmetros obtidos a partir do ajuste VTF e WLF dos resultados experimentais de condutividade para filmes de HEC/DPOP2 dopados com $\mathrm{LiClO}_{4}$

\begin{tabular}{|c|c|c|c|c|c|}
\hline \multicolumn{2}{|c|}{ Eletrólito } & \multicolumn{2}{|c|}{ Ajuste VTF } & \multicolumn{2}{|c|}{ Constantes WLF } \\
\hline HEC & {$[\mathrm{NCO}] /[\mathrm{OH}]$} & $\mathrm{A}\left(\mathrm{Scm}^{-1} \mathrm{~K}^{-1 / 2}\right)$ & Ea $\left(\mathrm{kJmol}^{-1}\right)$ & $\mathrm{C}_{1}(\mathrm{Tg})$ & $\mathrm{C}_{2}(\mathrm{Tg})(\mathrm{K})$ \\
\hline \multirow[t]{3}{*}{ QP09H } & 0,4 & 133 & 19,4 & 21,9 & 74 \\
\hline & 0,6 & 4879 & 25,0 & 29 & 28 \\
\hline & 0,8 & $1,25 \times 10^{5}$ & 19,5 & 14,3 & 54 \\
\hline \multirow[t]{3}{*}{ QP4400 } & 0,4 & 2,367 & 15,9 & 21 & 92 \\
\hline & 0,6 & 157 & 19,1 & 19,8 & 81 \\
\hline & 0,8 & 123 & 16,6 & 16,6 & 43 \\
\hline \multirow[t]{3}{*}{ QP30MH } & 0,4 & 230 & 15,1 & 14 & 41 \\
\hline & 0,6 & 145 & 15,1 & 16,3 & 44 \\
\hline & 0,8 & $8,54 \times 10^{8}$ & 29,5 & $*$ & $*$ \\
\hline QP300H & 0,6 & 37,8 & 12,7 & 15,3 & 41 \\
\hline
\end{tabular}

*não foi possível determinar 


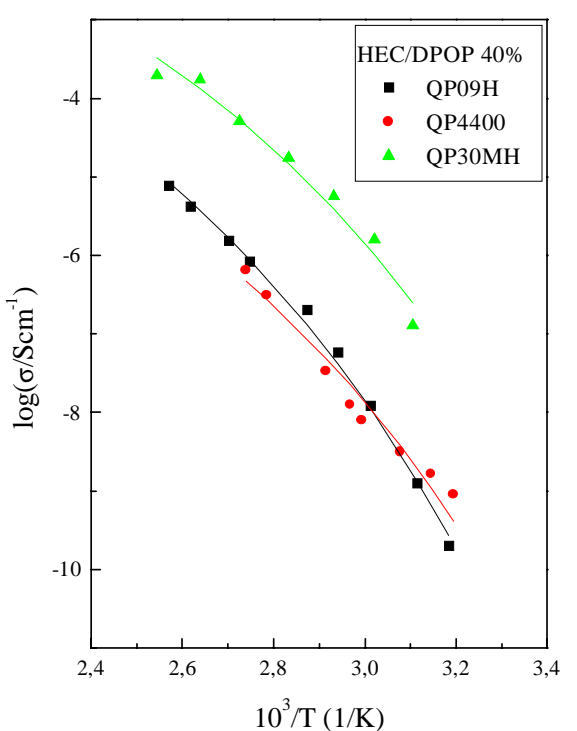

(a)

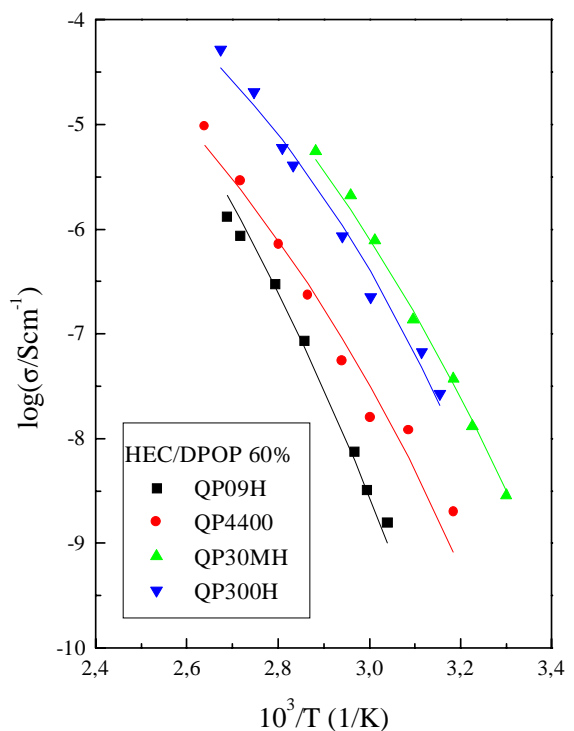

(b)

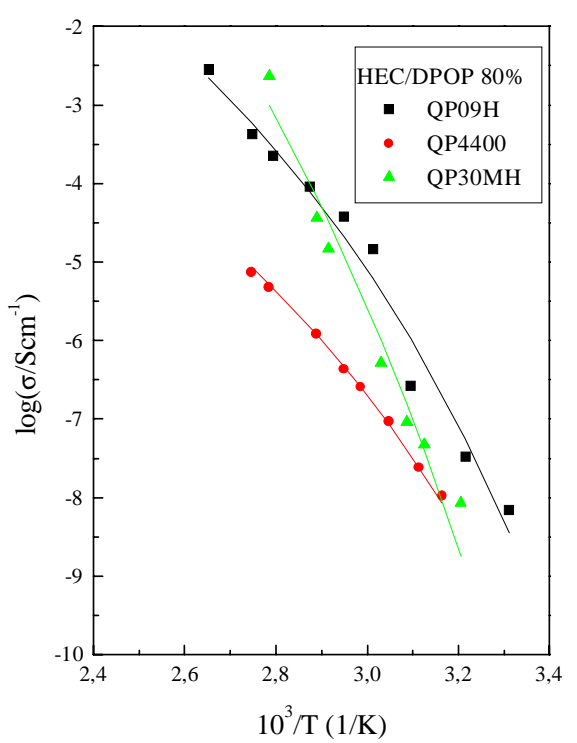

(c)

Figura 3. 8: Diagramas de logaritmo de condutividade em função do inverso de temperatura para filmes de hidroxietil celulose entrecruzada com poli(óxido de propileno) a várias razões de entrecruzamento

Os valores de energia de ativação dos sistemas contendo poli(óxido de propileno) são da mesma magnitude (entre 15 e $19 \mathrm{kJmol}^{-1}$ ) que para os com 
poli(óxido de etileno) salvo duas exceções: QP09H/DPOP2 $[\mathrm{NCO}] /[\mathrm{OH}]=0,6 \mathrm{e}$ $\mathrm{QP} 30 \mathrm{MH} / \mathrm{DPOP} 2[\mathrm{NCO}] /[\mathrm{OH}]=0,8$. No entanto os altos valores de energia de ativação não estão associados às condutividades mais baixas, mas podem estar associados a mecanismos diferentes de condução. Isto pode ser proposto se observarmos que nos diagramas da figura 3.8 os resultados das amostras em questão apresentam decréscimo mais expressivo da condutividade com a diminuição da temperatura em comparação com as outras amostras.

Os valores das constantes WLF encontram-se dentro do esperado para este tipo de sistema. A apreciação mais detalhada dos resultados de condutividade pode ser feita observando-se a figura 3.9, onde podem ser observados os valores de logaritmo de condutividade a $60^{\circ} \mathrm{C}$ para os eletrólitos sintetizados.

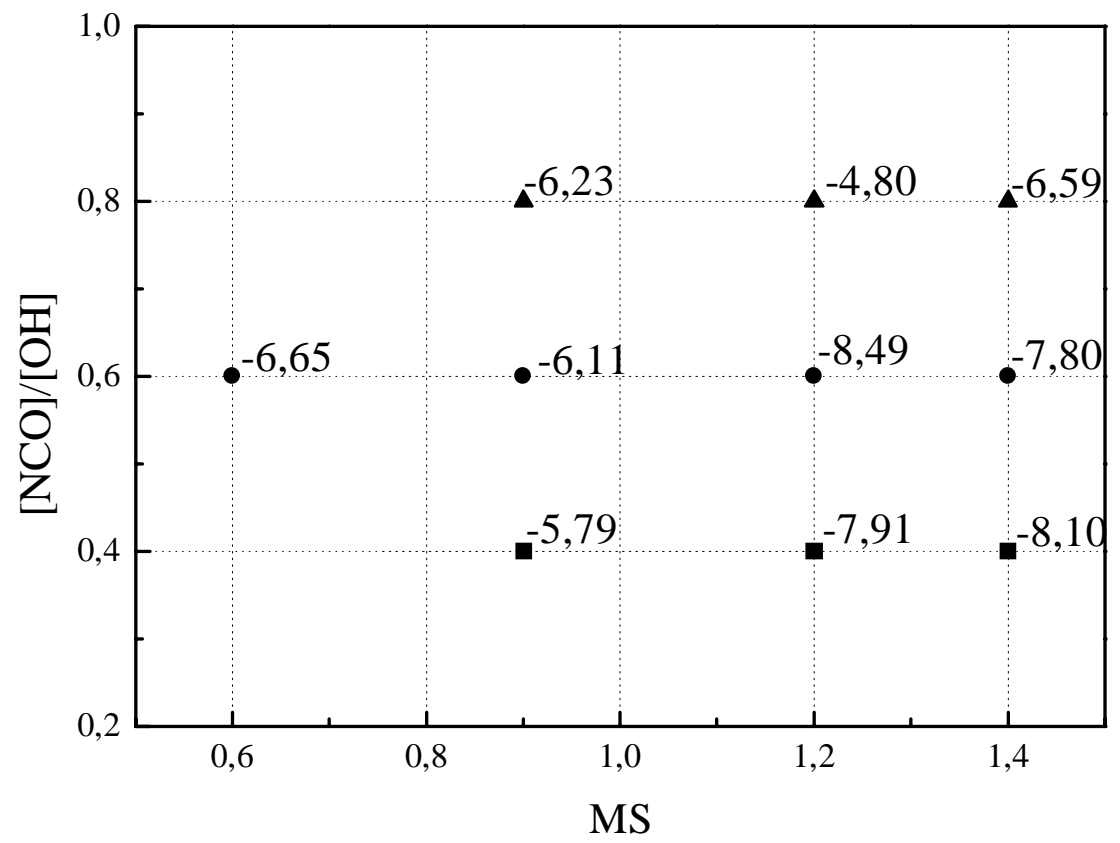

Figura 3. 9: Estudo da influência de MS da hidroxietil celulose e da razão $[\mathrm{NCO}] /[\mathrm{OH}]$ nos valores de logaritmo de condutividade a $60^{\circ} \mathrm{C}$ para os eletrólitos sólidos poliméricos sintetizados com DPOP2 
Em termos gerais a condutividade para os eletrólitos sintetizados a partir do entrecruzamento de HEC com DPOP2 é menor que para HEC com DPOE2. Este fato pode ser explicado pela diminuição da mobilidade das cadeias poliméricas quando o isocianato utilizado para o entrecruzamento apresenta grupo lateral. Podemos também inferir que a diminuição da condutividade está relacionada com o aumento da temperatura de transição vítrea dos filmes.

Os valores de condutividade apresentam maior variação em torno da média $\left(1,41 \times 10^{-7} \mathrm{Scm}^{-1}\right.$ a $\left.60^{\circ} \mathrm{C}\right)$ o que pode indicar sua maior dependência frente ao MS ou porcentagem de entrecruzamento. A partir da figura 3.9 podemos concluir que para determinado MS (igual a 1,2 e 1,4) ocorre um aumento da condutividade no sentido de maiores razões $[\mathrm{NCO}] /[\mathrm{OH}]$ e para $\mathrm{MS}=0,9$ no sentido contrário. Analisando os resultados para concentrações fixas de NCO não se observa tendência aparente, salvo para porcentagem de entrecruzamento igual a $40 \%$, onde a condutividade aumenta com o decréscimo de MS.

Diferente dos sistemas com poli(óxido de etileno), os eletrólitos sólidos com HEC e poli(óxido de propileno) além de apresentarem menores valores de condutividade são, aparentemente, mais influenciados pela presença do polissacarídeo. Esta influência é maior se considerarmos a razão de entrecruzamento do que o MS da HEC. A maior condutividade observada a $60^{\circ} \mathrm{C}$ é 1,47 x $10^{-5} \mathrm{Scm}^{-1}$ para QP09H/DPOP2 [NCO]/[OH] $=0,8$.

\section{Monoisocianato de poli(óxido de etileno)}

Na figura 3.10 estão apresentados os diagramas do tipo Arrhenius para os eletrólitos sólidos poliméricos a base de hidroxietil celulose enxertada com 
monoisocianato de poli(óxido de propileno). Como para as outras amostras, os pontos representam os resultados experimentais e a curva, o ajuste segundo a equação VTF. Os parâmetros VTF e WLF determinados para estes filmes encontram-se na tabela 3.3. Analisando os valores de energia de ativação observamos que estes se encontram na mesma ordem dos anteriores, salvo para os filmes com HEC QP30MH com razões de enxertia iguais a 0,4 e 0,6. Assim como o observado para eletrólitos à base de HEC entrecruzada com DPOP, estes maiores valores de energia de ativação estão associados a comportamento diferenciado das curvas de condutividade em função da temperatura. A condução diminui mais acentuadamente com a diminuição da temperatura para estas amostras que para as outras. Segundo os dados da tabela 2.7, a amostra de hidroxietil celulose QP30MH apresenta maior grau de polimerização. Este parâmetro pode estar contribuindo com esta diferença de comportamento quando os eletrólitos sólidos poliméricos são sintetizados com poli(óxido de propileno).

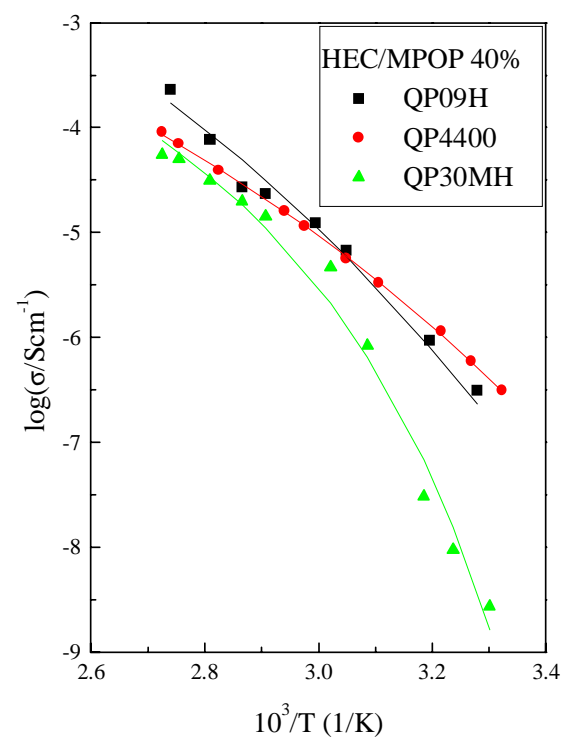

(a)

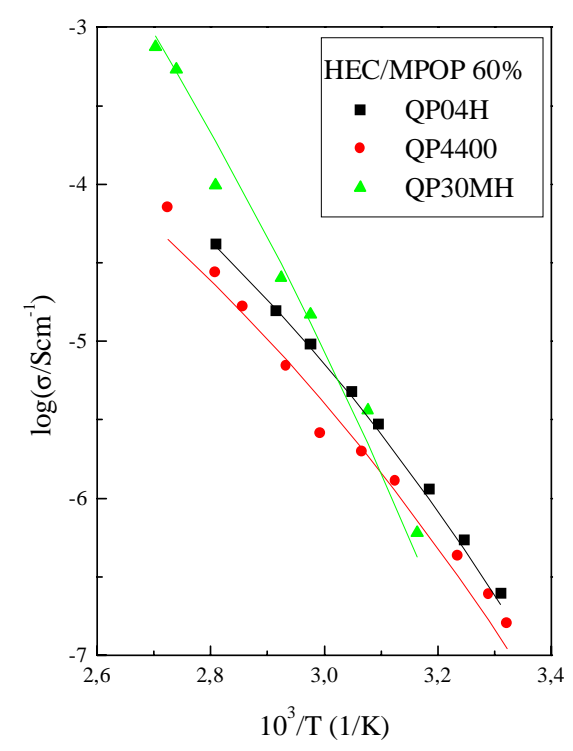

(b) 


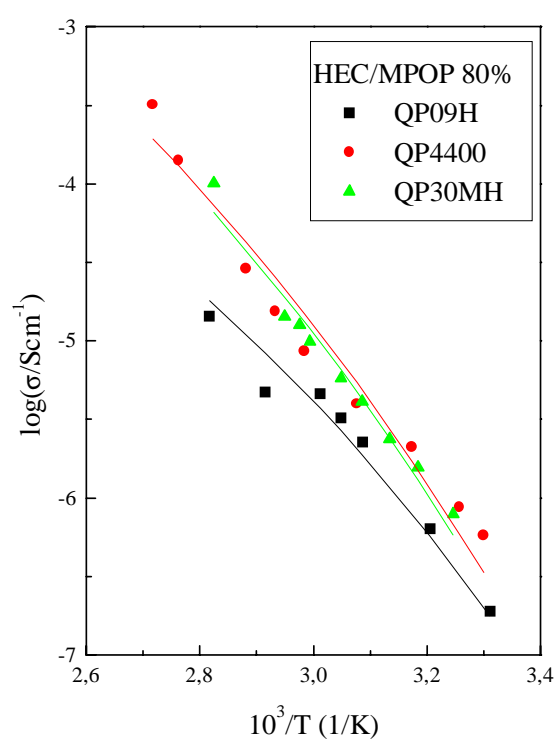

(c)

Figura 3. 10: Diagramas de logaritmo de condutividade em função do inverso da temperatura para filmes de hidroxietil celulose enxertada com monoisocianato de poli(óxido de propileno) a várias razões de enxertia

Tabela 3. 3: Parâmetros obtidos a partir do ajuste VTF e WLF dos resultados experimentais de condutividade para filmes de HEC/MPOP1 dopados com $\mathrm{LiClO}_{4}$

\begin{tabular}{cccccc}
\hline \multicolumn{2}{c}{ Eletrólito } & \multicolumn{2}{c}{ Ajuste VTF } & \multicolumn{2}{c}{ Constantes WLF } \\
\hline HEC & {$[\mathbf{N C O}] /[\mathbf{O H}]$} & $\mathbf{A}\left(\mathbf{S c m}^{-1} \mathbf{K}^{-1 / 2}\right)$ & $\mathbf{E a}\left(\mathbf{k J m o l} \mathbf{~}^{-1}\right)$ & $\mathbf{C}_{\mathbf{1}}(\mathbf{T g})$ & $\mathbf{C}_{\mathbf{2}}(\mathbf{T g})(\mathbf{K})$ \\
\hline QP09H & 0,4 & 329 & 16,6 & 8,7 & 72 \\
& 0,6 & 51,3 & 15,6 & 17 & 43 \\
& 0,8 & 2,621 & 12,7 & 16 & 39 \\
\hline QP4400 & 0,4 & 27,7 & 14,4 & 13,7 & 80 \\
& 0,6 & 37,7 & 16,4 & 15 & 107 \\
& 0,8 & 382 & 18,6 & 13,1 & 133 \\
\hline QP30MH & 0,4 & $4,88 \times 10^{6}$ & 34,4 & 82 & 21 \\
& 0,6 & $9,59 \times 10^{5}$ & 29,3 & 24,2 & 145 \\
& 0,8 & 494 & 18,7 & 17,8 & 53 \\
\hline
\end{tabular}

A análise mais detalhada dos valores de condutividade obtidos para estas amostras pode ser feito com auxílio da figura 3.11, onde estão representados os valores de $\sigma$ em função do grau de substituição molar e da concentração de enxertia na temperatura de $60^{\circ} \mathrm{C}$. 


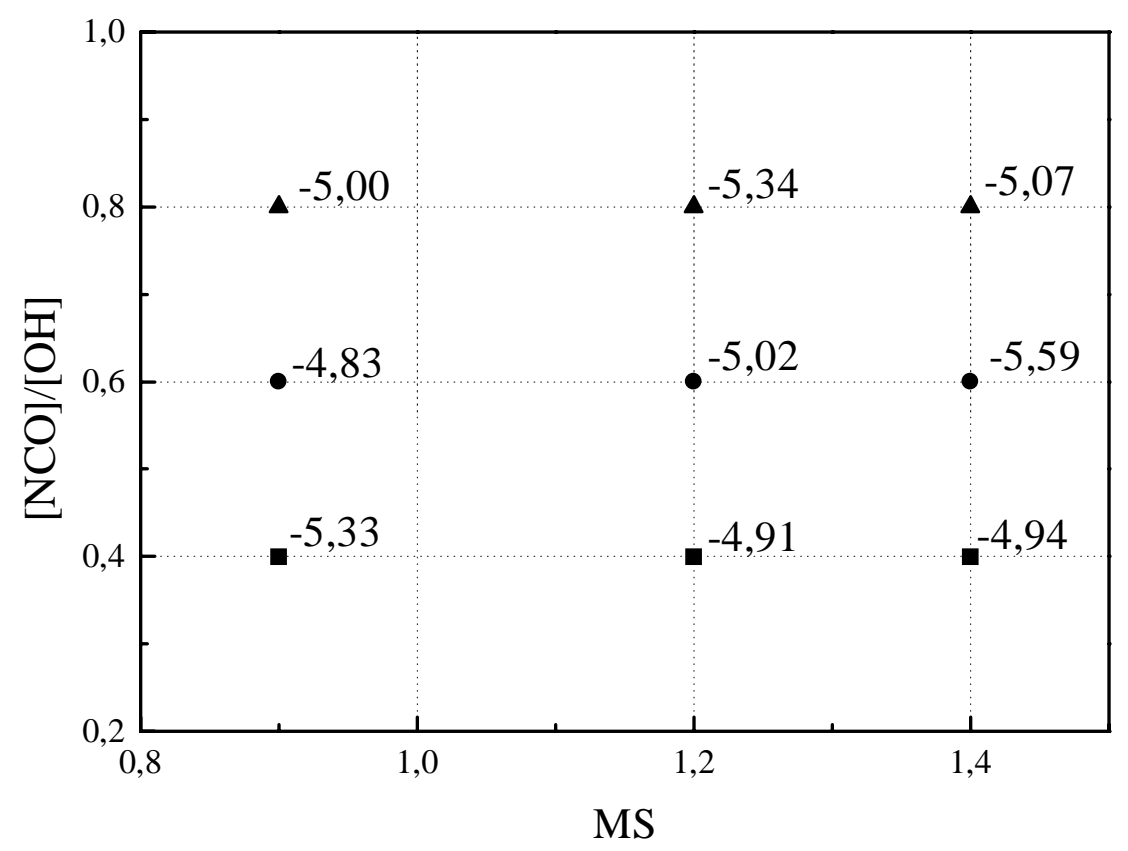

Figura 3. 11: Estudo da influência de MS da hidroxietil celulose e da razão $[\mathrm{NCO}] /[\mathrm{OH}]$ nos valores de logaritmo de condutividade a $60^{\circ} \mathrm{C}$ para os eletrólitos sólidos poliméricos sintetizados com MPOP1

Observamos na figura 3.11 que os resultados de logaritmo de condutividade a $60^{\circ} \mathrm{C}$ são mais homogêneos em torno da média igual a 5,11. Isto equivale a dizer que a condutividade das amostras de hidroxietil celulose enxertadas com monoisocianato de poli(óxido de propileno) são muito similares. Portanto, nem os parâmetros estruturais da HEC nem a concentração de poliéter parecem influenciar no resultado de condução quando a HEC é enxertada com poli(óxido de propileno). O maior valor encontrado a $60^{\circ} \mathrm{C}$ é igual a $1,48 \times 10^{-5} \mathrm{Scm}^{-1}$ para amostra QP30MH/MPOP1 $[\mathrm{NCO}] /[\mathrm{OH}]=0,4$; percebe-se que este valor é muito parecido com os valores de condutividade obtidos para as amostras entrecruzadas com poli(óxido de etileno) na mesma temperatura.

Analisando os resultados obtidos para todos os eletrólitos à base de hidroxietil celulose e poliéter podemos fazer algumas observações. Ao comparar os valores de 
condutividade para os sistemas entrecruzados (com DPOE e DPOP), percebemos que a condução é maior para os sistemas com poli(óxido de etileno). Devido ao fato da condutividade estar associada à movimentação dos segmentos poliméricos, obtêm-se valores maiores para sistemas com maior mobilidade, ou seja, naquele com menor ramificação. Nos sistemas com DPOE a condutividade parece ser independente dos parâmetros estruturais do polissacarídeo ou da razão de entrecruzamento, enquanto que nos sistemas com DPOP, os resultados indicam que a proporção $[\mathrm{NCO}] /[\mathrm{OH}]$ é importante.

A diferença de comportamento entre o sistema entrecruzado e o enxertado pode ser observada ao comparar os resultados de condutividade para os sistemas com DPOP e MPOP. Os eletrólitos sólidos obtidos com a enxertia da HEC apresentam maior condutividade que os entrecruzados. Este fato e a observação de que os parâmetros estruturais do polissacarídeo ou a relação $[\mathrm{NCO}] /[\mathrm{OH}]$ não influenciarem no resultado de condução podem ser relacionados ao maior número de graus de liberdade associado ao sistema enxertado. É interessante observar também que, nos sistemas com poli(óxido de propileno), a amostra de HEC com maior grau de polimerização apresenta comportamento diferenciado da curva de logaritmo de condutividade em função da temperatura.

3.4.2 - Eletrólitos sólidos poliméricos à base de fidroxipropil celulose enxertada com poliéteres

Na figura 3.12 estão apresentados os diagramas do tipo Arrhenius para os eletrólitos sólidos poliméricos preparados a partir de hidroxipropil celulose enxeratada com poliéteres; e na tabela 3.4 os resultados dos ajustes VTF e WLF. 


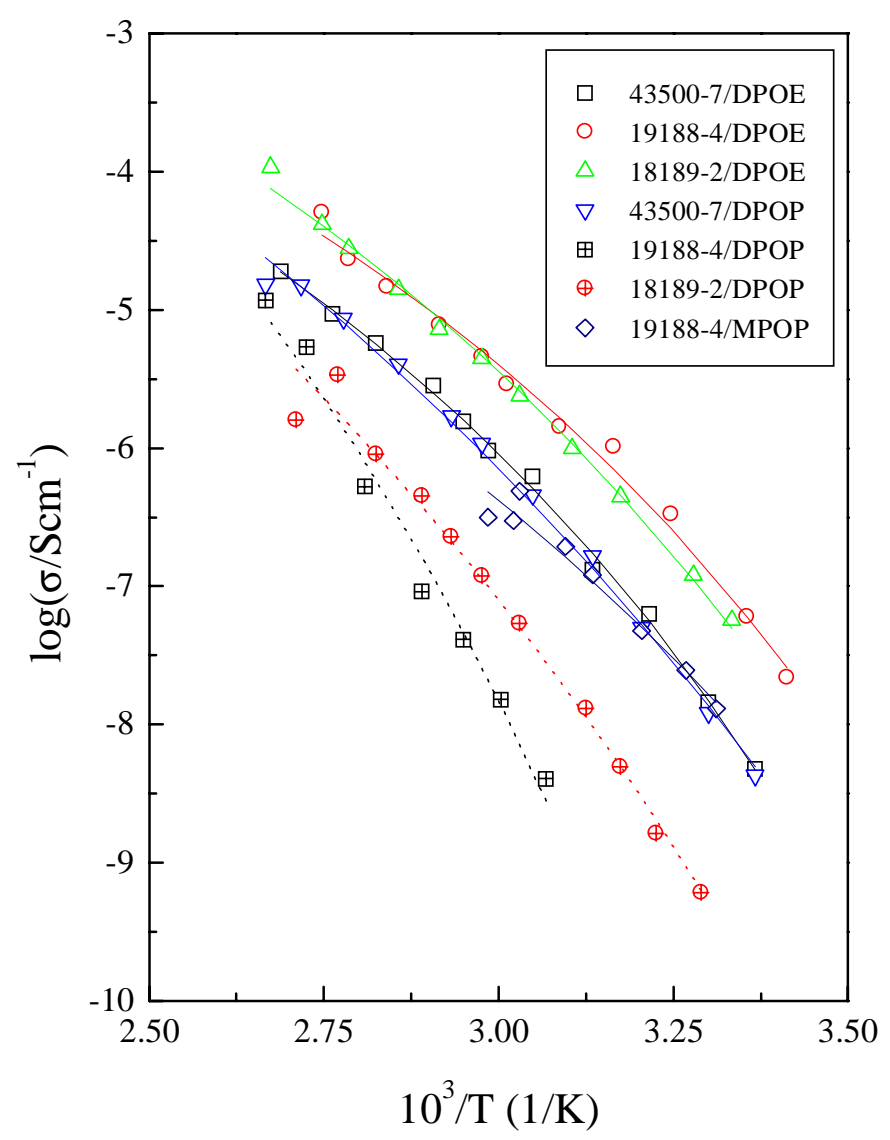

Figura 3. 12: Diagrama do tipo Arrhenius para os eletrólitos sólidos poliméricos com matriz de hidroxipropil celulose enxertada com poliéteres

Analisando-se a figura 3.12 percebe-se que para as amostras com massas molares mais altas $(19,188-4$ e 19,189-2) a condutividade é maior para os filmes entrecruzados com poli(óxido de etileno). Os parâmetros estruturais (MS e DS) não influenciam no resultado de condução iônica, nem a pequena diferença na concentração de sal (quando se considera para cálculo apenas a relação entre número de moles de oxigênios ou volume de poliéter e número de moles de cátions $\mathrm{Li}^{+}$). Este fato é demonstrado pela sobreposição das curvas de condutividade no diagrama do tipo Arrhenius. 
Para estas mesmas amostras de HPC entrecruzadas com poli(óxido de propileno) a condutividade é maior para polissacarídeo com maior massa molar, indicando a possível contribuição da cadeia de polissacarídeo no fenômeno de condução quando se utiliza DPOP na formação do filme. Para a amostra de hidroxipropil celulose com menor massa molar $(43,500-7)$ os resultados de condutividade das amostras entrecruzadas com poli(óxido de etileno) e poli(óxido de propileno) são semelhantes. Pode-se inferir que para esta amostra o tipo de diisocianato utilizado para a formação do eletrólito sólido não influencia nas propriedades de condução.

Alguns filmes de HPC enxertados com monoisocianato de poli(óxido de etileno) assemelhavam-se a géis muito viscosos e quando submetidos a temperaturas maiores de $40^{\circ} \mathrm{C}$ eram liqüefeitos. Desta forma foi possível a determinação da condutividade de apenas um dos filmes sintetizados, pois este era um sólido bastante flexível. Comparando o resultado de condutividade para este sistema e os resultados para a mesma HPC entrecruzada com DPOE ou DPOP, observa-se que obtém-se um resultado intermediário. A condutividade com poli(óxido de etileno) é maior quando com parado com o resultado de filme com DPOP, devido à maior flexibilidade da cadeia polimérica do POE. Comparando os resultados de DPOP e MPOP para a mesma amostra de HPC, observamos que, quando é utilizado isocianato monofuncional a condutividade é maior, indicando que o maior número de graus de liberdade do sistema, resultado da presença de uma extremidade livre na cadeia de poliéter. Este também pode ser a explicação da obtenção de géis muito viscosos para a maioria dos filmes sintetizados com HPC e MPOP. 
Tabela 3. 4: Resultados do ajuste VTF e constantes WLF para filmes de hidroxipropil celulose enxertados com poliéter

\begin{tabular}{ccccc}
\hline \multirow{2}{*}{ Eletrólito } & \multicolumn{2}{c}{ Ajuste VTF } & \multicolumn{2}{c}{ Constantes WLF } \\
\cline { 2 - 5 } & $\mathbf{A}\left(\mathbf{S c m}^{-\mathbf{1}} \mathbf{K}^{\mathbf{- 1 / 2}}\right)$ & $\mathbf{E a}\left(\mathbf{k J m o l}^{\mathbf{- 1}}\right)$ & $\mathbf{C}_{\mathbf{1}} \mathbf{( T g )}$ & $\mathbf{C}_{\mathbf{2}} \mathbf{( T g )}(\mathbf{K})$ \\
\hline 43,500-7/DPOE & 7,77 & 13,6 & 16,6 & 104 \\
43,500-7/DPOP & 14,5 & 15,1 & 15,4 & 48 \\
19,188-4/DPOE & 9,77 & 13,1 & 31,2 & 15 \\
19,188-4/DPOP & 8350 & 22,8 & 21,9 & 26 \\
19,188-4/MPOP & 10,8 & 19,0 & 25,1 & 40 \\
19,189-2/DPOE & 51,5 & 18,6 & 16,8 & 44 \\
19,189-2/DPOP & 6,70 & 14,6 & 17,2 & 128 \\
\hline
\end{tabular}

Os resultados de energia de ativação obtidos através do ajuste VTF apresentados na tabela 3.4 são valores semelhantes aos obtidos para as amostras de hidroxietil celulose. No entanto os valores do fator pré-exponencial $(A)$ são bem menores. A constante $A$ é usualmente associada ao número de transportadores de carga $^{14,15}$ mas não é encontrada literatura nenhuma descrição do seu comportamento em função da temperatura, concentração de sal, tipo de eletrólito, ou mesmo condutividade. Os valores das constantes WLF obtidas para os sistemas com HPC encontram-se dentro do esperado ${ }^{10,11}$ e são bastante similares aos encontrados para os sistemas com HEC. O melhor resultado de condutividade obtido a $60^{\circ} \mathrm{C}$ foi $3,16 \mathrm{x}$ $10^{-6} \mathrm{Scm}^{-1}$ para os filmes de HPC 19,189-2 e 19,188-4 entrecruzados com diisocianato de poli(óxido de etileno).

\section{5 - Conclusões do capitulo}

Os resultados de condutividade discutidos neste capítulo permitem concluir que os sitemas de polissacarídeos enxertados ou entrecruzados com poliéteres podem ser aplicados como eletrólitos sólidos poliméricos. O ajuste segundo a equação VTF 
mostra que nestes sistemas a condutividade é promovida com auxílio dos movimentos dos segmentos poliméricos. Apesar da elevada concentração de sal nos sistemas contendo hidroxietil celulose como matriz, podemos observar que a condutividade aparentemente não é influenciada pelos parâmetros estruturais do polissacarídeo. Este fenômeno parece encontrar-se mais relacionado ao tipo de poliéter enxertado na cadeia de HEC, sendo obtidos valores de condução maiores para redes com poli(óxido de etileno) e menores para redes com poli(óxido de propileno). Este resultado pode ser devido à estrutura do POP ser mais rígida e portanto, a contribuição dos movimentos moleculares na condução é menor. O melhor resultado de condutividade para os sistemas contendo $\mathrm{HEC}$ a $60^{\circ} \mathrm{C}$ é $2,82 \mathrm{x}$ $10^{-5} \mathrm{Scm}^{-1}$ para eletrólito sólido à base de HEC QP09H entrecruzada com poli(óxido de propileno) à razão $[\mathrm{NCO}] /[\mathrm{OH}]=0,6$.

Os sistemas contendo hidroxipropil celulose como matriz apresentam valores de condutividade que aparentemente também não estão relacionados com os parâmetros estruturais do polissacarídeo, mas com o tipo de poliéter agregado à cadeia; salvo para a amostra de HPC com massa molar igual a $80000 \mathrm{~g} / \mathrm{mol}$. Os resultados de condutividade para esta amostra independem do isocianato utilizado na síntese do filme. A maioria das amostras de HPC enxertada com monoisocianato de poli(óxido de propileno) não fornecem eletrólitos sólidos poliméricos, mas géis poliméricos cujo estudo deve ser diferenciado ao realizado para as demais amostras. O melhor resultado de condutividade a $60^{\circ} \mathrm{C}$ obtido foi $3,16 \times 10^{-6} \mathrm{Scm}^{-1}$ para os filmes de HPC 19,189-2 e 19,188-4 entrecruzados com diisocianato de poli(óxido de etileno). 
3.6 - Referências bibliográficas

${ }^{1}$ ALBINSSON, I.; MELLANDER, B. E. Ion association effects and ionic conductivity in polymer electrolytes. Solid State Ionics v. 60, p. 63-66, 1993.

${ }^{2}$ GIROTTO, E. M.; DE PAOLI, M. A. Transporte de massa em polímeros intrinsecamente condutores: Importância, técnicas e modelos teóricos. Química Nova, v.22, n.3, p. 358-368, 1999.

${ }^{3}$ VINCENT, C. A. Polymer electrolytes. Progress in Solid State Chemistry, v. 17, p. 145-261, 1987.

${ }^{4}$ LeNEST, Jean-François. Etude fondamentale des relations entre la structure de reseaux macromoleculaire et leur propriete de conduction ionique. Grenoble, 1985. 284p. Tese (Doutorado) - Ecole Française de Papeterie et des Industries Graphiques, Institut National Polytechnique.

${ }^{5}$ DÉPORTES, C. Cours d'electrochimie des solides. Grenoble, LIES, 1980. /Apostila/

${ }^{6}$ RATNER, M. A. Aspects on theoretical treatment of polymer solid electrolytes: transport theory and models. In: POLYMER Electrolytes Reviews. London, Elsevier Applied Science, 1987, p. 173-236

${ }^{7}$ LeNEST, J. F.; CHERADAME, H.; GANDINI, A. A mechanism of ionic conduction in cross-linked polyethers. Solid State Ionics, n.28-30, p. 1032-1037, 1988.

${ }^{8}$ LeNEST, J. F.; GANDINI, A. Crosslinked polyether electrolytes with alkali-metal salts for solid-state batteries: relationship between structure and ionic conductivity. In: INTERNATIONAL SYMPOSIUM ON POLYMER ELECTROLYTES, 2., Siena, 1989. Proceedings. Londres, Elsevier, 1989. p. $129-141$.

${ }^{9}$ BRUCE, P. G. Electrical measurements on polymer electrolytes. In: POLYMER electrolytes reviews, London, Elsevier Applied Science, 1987. p. 237-274.

${ }^{10}$ LeNEST, J. -F.; GANDINI, A.; CHERADAME, H. Crosslinked polyethers as media for ionic conduction. British Polymer Journal, n.20, p. 253-268, 1988.

${ }^{11}$ SCHOENENBERGER, C.; LeNEST, J. -F.; GANDINI, A. Polymer electrolytes based on modified polysaccharides. 2.Polyether-modified cellulosics. Electrochimica Acta, v.40, n.13/14, p. 2281-2284, 1995.

${ }^{12}$ ARMAND, M. Current state of PEO-based electrolyte. In: POLYMER electrolytes reviews. London, Elsevier Applied Science, 1987, p.1-22. 
${ }^{13}$ GAZOTTI, W. A.; SPINACÉ, M. A. S.; GIROTTO, E. M.; DE PAOLI, M. A. Polymer electrolytes based on ethylene oxide-epichlorohydrin copolymers.

Solid State Ionics, v. 130, n. 3-4, p. 281-291, 2000.

${ }^{14}$ CARVALHO, L. M.; GUÉGAN, P.; CHERADAME, H.; GOMES A. S. Variation of the mesh size of PEO-based networks filled with TFSILi: from an Arrhenius to WLF type conductivity behavior. European Polymer Journal, n. 36, p. 401-409, 2000.

${ }^{15}$ NG, S. T. C.; FORSYTH, M. MacFARLANE, R.; GARCIA, M.; SMITH, M. E.; STRANGE, J. Composition effects in polyurethane-based solid polymer electrolytes. Polymer, v. 39, n. 25, p. 6261-6268, 1998. 


\section{CAPÍTULO 4 - ENS AIOS COM IS OCI ANATOS}

COMERCI AIS

\section{$4.1-$ Introdução}

As reações da celulose e derivados com vários tipos de isocianatos é bastante conhecida na literatura ${ }^{1,2,3,4}$. Algumas destas reações têm como objetivo a modificação superficial das fibras de celulose com o objetivo de conferir ao polissacarídeo a compatibilidade necessária para aplicação como reforço em materiais compósitos poliméricos ${ }^{2,3}$. Outra finalidade deste tipo de modificação é a proteção da superfície da madeira, promovido pelo recobrimento com material adequado, de agentes externos. Outros consideram a possibilidade de solubilização da celulose modificada, o que torna possível uma série de caracterizações $^{4,5}$. A escolha do isocianato adequado depende das características finais esperadas para o material.

Nesta seção estudaremos as propriedades de filmes de hidroxietilcelulose enxertada com fenilisocianato e hexametileno diisocianato, isocianatos mais conhecidos para a modificação de fibras de celulose, com o objetivo de verificar a eventual contribuição da cadeia celulósica na condução iônica, uma vez que os isocianatos utilizados na formação dos filmes não são do tipo poliéter. 


\section{2-Materiais}

Foram utilizados os isocianatos comerciais hexametileno diisocianato (HDI Bayer) e fenilisocianato ( $\mathrm{PhNCO}$ - Aldrich) como recebidos. Foram utilizados também KBr (Riedel-de-Haën) em análises de infravermelho, clorofórmio deuterado (Aldrich) para ressonância magnética nuclear, dimetilacetamida (Aldrich) como solvente para síntese dos filmes e dibutil dilaurato de estanho como catalisador (Aldrich).

4.3 - Métodos

Infravermelho: Os isocianatos foram caracterizados utilizando-se técnica de FTIR colocando-se uma gota da amostra sobre pastilha de $\mathrm{KBr}$. As análises foram realizadas em aparelho BOMEM modelo MB-102. Para amostra de hidroxietil celulose entrecruzada com HDI, esta análise foi realizada a partir de pastilhas de KBr:amostra na proporção 150:1.

Ressonância magnética nuclear: Por serem isocianatos comerciais os experimentos de espectroscopia de RMN foram realizados com a finalidade de verificar a possível presença de impurezas. Os espectros de RMN de carbono e hidrogênio dos isocianatos foram feitos em aparelho BRUCKER AC50 E AC200 respectivamente, em temperatura ambiente, utilizando-se como solvente $\mathrm{CDCl}_{3}$.

Síntese das redes: As redes de hidroxietilcelulose enxertada com isocianatos comerciais foi realizada seguindo procedimento descrito na seção2.3.3.1. 
Espectroscopia no ultravioleta: Os filmes obtidos foram submetidos a análise no ultravioleta (UV-vis) em aparelho HITASHI U-3501.

Análise de difração de raios-X: Os filmes de HEC obtidos após reação com os isocianatos foram submetidos a este tipo de análise em Difratômetro Universal de Raios-X URD-6, Carl Zeiss Jena, a potência $\mu=40 \mathrm{kV} / 20 \mathrm{~mA}$ e irradiação CuK $\alpha$ $\operatorname{com} \lambda=1.540 \AA$.

Calorimetria exploratória diferencial: Para determinação da temperatura de transição vítrea (Tg) dos filmes através de DSC (SHIMADZU DSC-50), foram realizadas duas corridas no intervalo de temperatura de -100 a $200^{\circ} \mathrm{C}$ sob fluxo de nitrogênio $(20 \mathrm{~mL} / \mathrm{min})$. A primeira corrida foi realizada a uma taxa de aquecimento de $20^{\circ} \mathrm{C} / \mathrm{min}$ e a segunda, utilizada na determinação de $\mathrm{Tg}, 10^{\circ} \mathrm{C} / \mathrm{min}$.

Condutividade: As medidas de impedância foram realizadas em potenciostato SCHLUMBERGER 1272 acoplado a um microcomputador, num intervalo de freqüência de $1 \mathrm{~Hz}$ a $10 \mathrm{MHz}$, sob vácuo para evitar a influência da umidade, em voltagem constante e igual a $0,5 \mathrm{~V}$. Todos os experimentos foram realizados utilizando-se a cela de medida apresentada na seção 3.3 (no laboratório de materiais poliméricos na EFPG - INPG, Grenoble - França) com amostras previamente secas sob vácuo a $60^{\circ} \mathrm{C}$ por duas horas.

4.4 - Resultados

O hexametileno diisocianato (HDI) tem a estrutura apresentada na figura 4.1. A esta estrutura correspondem o espectro no infravermelho da figura 4.2. As bandas de absorção mais características são apresentadas na tabela 4.1 e os deslocamentos 
químicos do espectro de ${ }^{1} \mathrm{H}-\mathrm{RMN}$ na tabela 4.2. É interessante notar a presença de bandas características a amidas, caracterizando a uréia formada durante o processo de fabricação do HDI.

$$
\mathrm{O}=\mathrm{C}=\mathrm{N}-\mathrm{CH}_{2}-\left(-\mathrm{CH}_{2}-\right)_{4} \mathrm{CH}_{2}-\mathrm{N}=\mathrm{C}=\mathrm{O}
$$

Figura 4. 1 : Modelo de estrutura do hexametileno diisocianato (HDI)

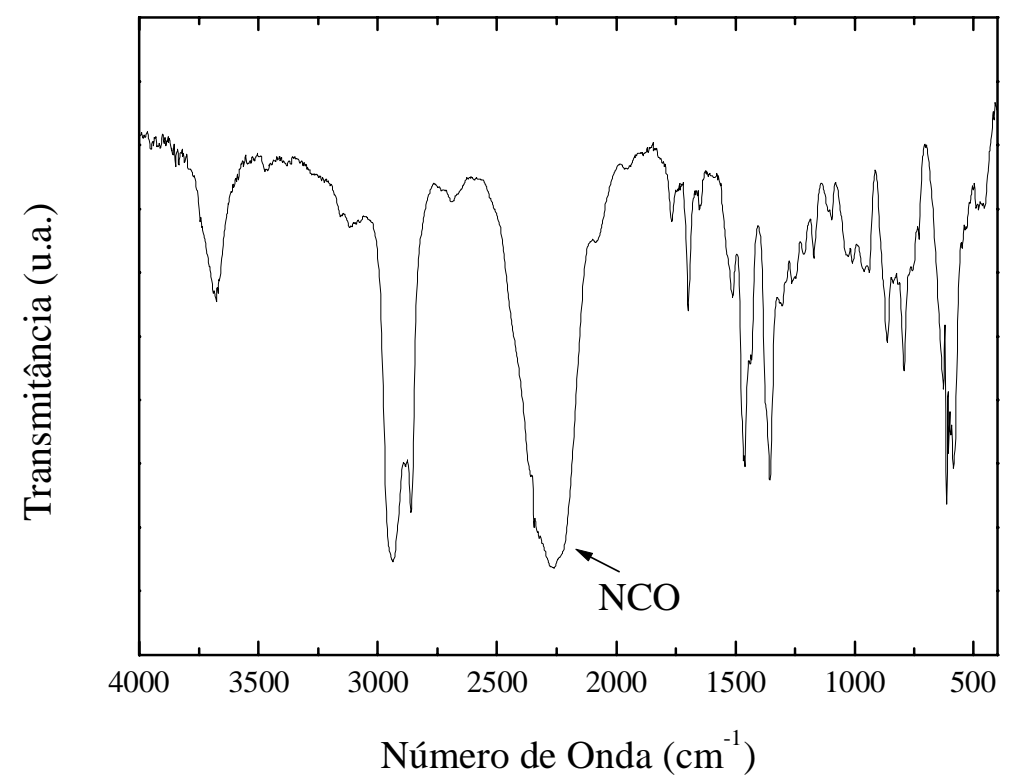

Figura 4. 2: Espectro no infravermelho de hexametileno diisocianato (HDI)

Tabela 4. 1: Principais bandas de absorção no infravermelho observadas para o hexametileno diisocianato (HDI)

\begin{tabular}{ll}
\hline Número de Onda $\left(\mathbf{c m}^{-1}\right)$ & \multicolumn{1}{c}{ Ligação } \\
\hline 3687 & Deformação axial simétrica e assimétrica de ligação NH \\
2936 e 2860 & Deformação axial de ligação CH alifático \\
2261 & Deformação axial da ligação dupla acumulada N=C=O \\
1767 & Deformação axial de ligação C=O de uréia \\
1697 e 1650 & Deformação angular de ligação NH (banda de amida II) \\
1465 e 1459 & Deformação angular simétrica de ligação CN \\
1354 & Deformação angular simétrica de ligação CH de grupo \\
& metileno \\
662 a 792 & Deformação angular simétrica fora do plano de ligação CH \\
627 a 584 & Deformação angular simétrica fora do plano de ligação NH \\
\hline
\end{tabular}


Tabela 4. 2: Deslocamentos químicos dos hidrogênios no espectro de ressonância magnética nuclear do hexametileno diisocianato (HDI)

\begin{tabular}{lcc}
\hline & $\mathrm{O}=\mathrm{C}=\mathrm{N}-\mathrm{CH}_{2}-\left(-\mathrm{CH}_{2}-\right)_{4} \mathrm{CH}_{2}-\mathrm{N}=\mathrm{C}=\mathrm{O}$ \\
\hline & Hidrogênio & Deslocamento (ppm) \\
\hline $\mathrm{H}$ & Triplete a 3.3 \\
$\mathrm{H}$ & Dublete múltiplo de 1.8 a 1.3 \\
\hline
\end{tabular}

$\mathrm{O}$ fenil isocianato tem estrutura apresentada na figura 4.3. $\mathrm{O}$ espectro no infravermelho é apresentado na figura 4.4 e as principais bandas de absorção observadas, listadas na tabela 4.3. Todos os espectros no infravermelho e de RMN obtidos para estes isocianatos encontram-se de acordo com os dados da literatura ${ }^{6,7}$.

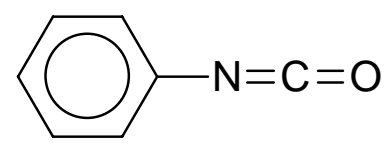

Figura 4. 3: Modelo de estrutura de fenil isocianato

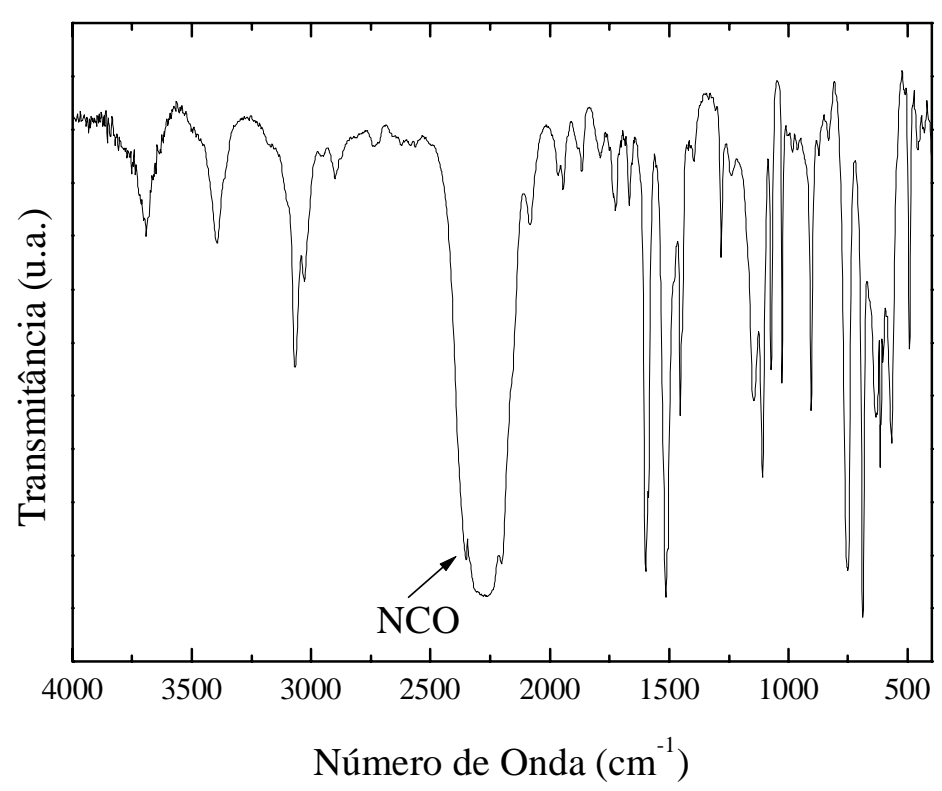

Figura 4. 4: Espectro no infravermelho de fenil isocianato 
Tabela 4. 3: Principais bandas de absorção observadas no espectro no infravermelho de fenil isocianato

\begin{tabular}{ll}
\hline \multicolumn{1}{c}{ Número de Onda $\left(\mathbf{c m}^{-1}\right)$} & \multicolumn{1}{c}{ Ligação } \\
\hline 3690 e 3390 & Harmônicas de $\mathrm{C}=\mathrm{O}$ de amida \\
3067 e 3028 & Deformação axial de ligação $\mathrm{CH}$ em aromáticos \\
2277 & Ligação acoplada $\mathrm{N}=\mathrm{C}=\mathrm{O}$ \\
1943,1865 e 1788 & Harmônicas de anel aromático \\
1725 e 1667 & $\mathrm{C}=\mathrm{O}$ de amida \\
1598 a 1453 & Deformação axial de ligação $\mathrm{C}=\mathrm{C}$ \\
\hline
\end{tabular}

Para a síntese dos filmes foram escolhidas apenas duas amostras de HEC, QP300H e QP15MH porque possuem o menor e maior DS respectivamente. As curvas de DSC para estes filmes, entrecruzados com HDI e derivatizados com PhNCO são apresentadas nas figuras 4.5 e 4.6 respectivamente, e os valores de $\mathrm{Tg}$ encontram-se na tabela 4.4 .

Podemos observar que, da mesma forma como o ocorrido para as redes entrecruzadas com DPOE e DPOP, a temperatura de transição vítrea dos materiais é função do tipo de isocianato utilizado. Era esperado que a $\mathrm{Tg}$ para materiais entrecruzados com HDI fosse menor que para os derivatizados com $\mathrm{PhNCO}$, pois a primeira molécula tem estrutura linear, tornando maior a desordem do sistema. No entanto, esta esperada diminuição de $\mathrm{Tg}$ é compensada com a presença de dois grupos reativos na estrutura, que pode reagir com dois segmentos de uma mesma cadeia ou com duas cadeias diferentes resultando em um aumento de Tg. A somatória dos dois fatores resulta no valor da temperatura de transição vítrea dos materiais próxima ao valor obtido com as redes sintetizadas com PhNCO. Mesmo com valores de Tg tão próximos a característica macroscópica dos filmes sintetizados com HDI é completamente diferente da dos sintetizados com PhNCO. Estes apresentam alguma flexibilidade à temperatura próxima a $30^{\circ} \mathrm{C}$, enquanto aqueles são bem rígidos, sendo muito difícil a sua retirada do molde. 
Tabela 4. 4: Valores de temperatura de transição vítrea (Tg) de filmes de hidroxietil celulose (HEC) graftizada com isocianatos comerciais (hexametileno diisocianato HDI- e fenil isocianato - PhNCO)

\begin{tabular}{llc}
\hline HEC & Isocianato & $\left.\mathbf{T g} \mathbf{(}^{\mathbf{0}} \mathbf{C}\right)$ \\
\hline QP300H & HDI & 40 \\
& PhNCO & 40 \\
\hline QP15MH & HDI & 42 \\
& PhNCO & 44 \\
\hline
\end{tabular}

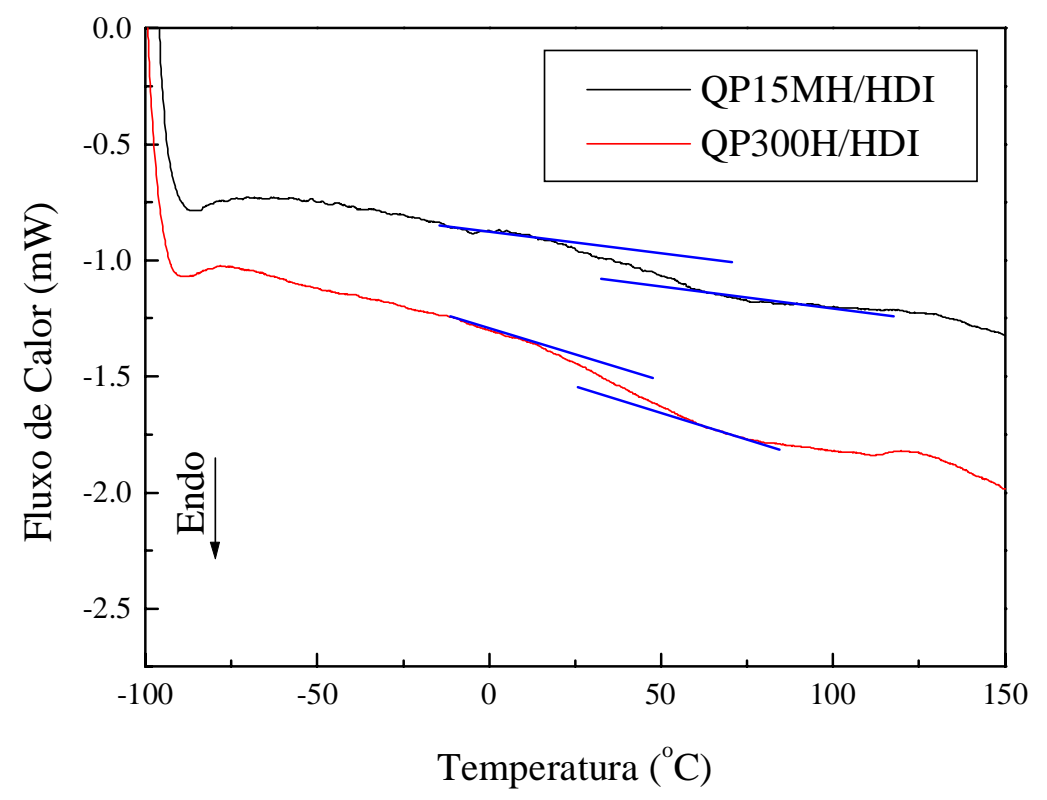

Figura 4. 5: Curva de calorimetria diferencial exploratória de redes de hidroxietil celulose (HEC) graftizadas com hexametileno diisocianato (HDI) 


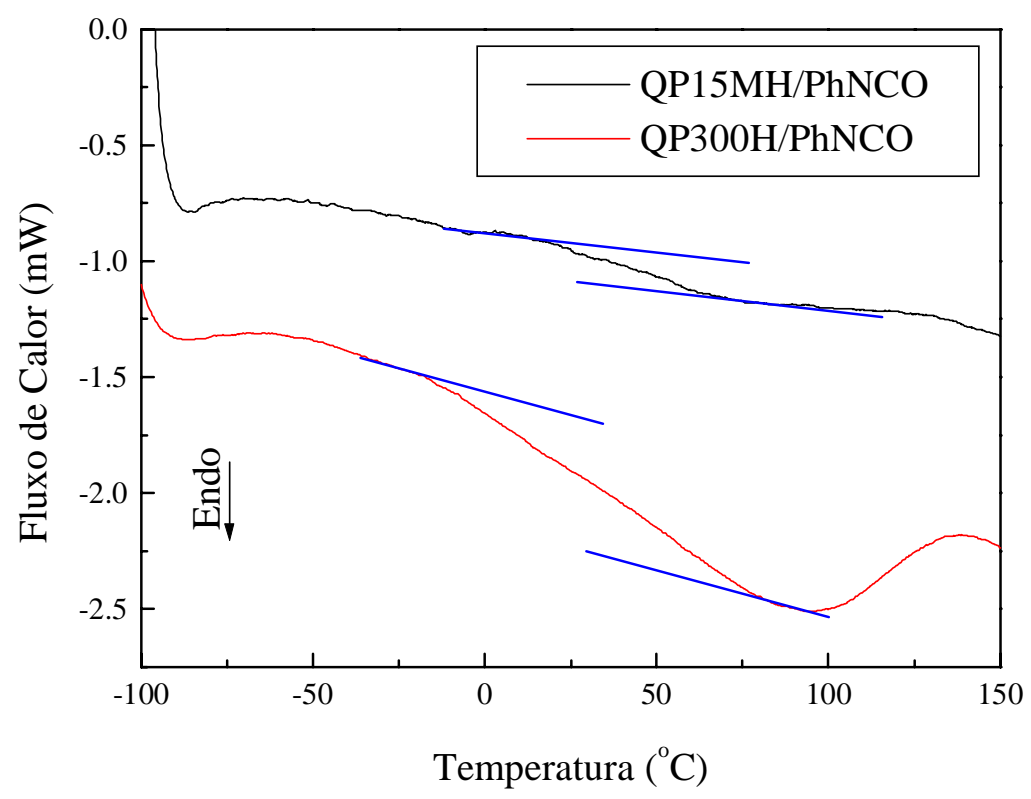

Figura 4. 6: Curva de calorimetria diferencial exploratória de redes de hidroxietil celulose (HEC) graftizadas com fenil isocianato (PhNCO)

A ausência de cristalinidade aparente das amostras pode ser caracterizada pela presença dos picos dos planos cristalográficos de celulose e seus derivados na região de $2 \theta$ próximo a $10^{\circ}$ (planos 101 e $10 \overline{1}$ ) e $20^{\circ}$ (plano 020 ), representado pelo difratograma da amostra QP300H entrecruzada com HDI apresentado na figura 4.7. No experimento de difração de raios-X para as amostras de HEC derivatizadas com PhNCO (figura 4.8) foi obtido resultado inesperado: foram observados picos indicando presença de produto cristalino. Pesquisando literatura existente ${ }^{8,9}$, concluise que estes picos são relativos ao dímero e ao trímero do fenil isocianato.

O espectro de UV-VIS para os filmes de $\mathrm{HEC} / \mathrm{PhNCO}$ (figura 4.9) são bem semelhantes, apresentando banda de absorção a 291 e 299 nm, característica ao grupo fenila. Não foi possível obter espectro parecido para as amostras de HEC/HDI porque foi difícil a confecção destes materiais na forma de filme. 


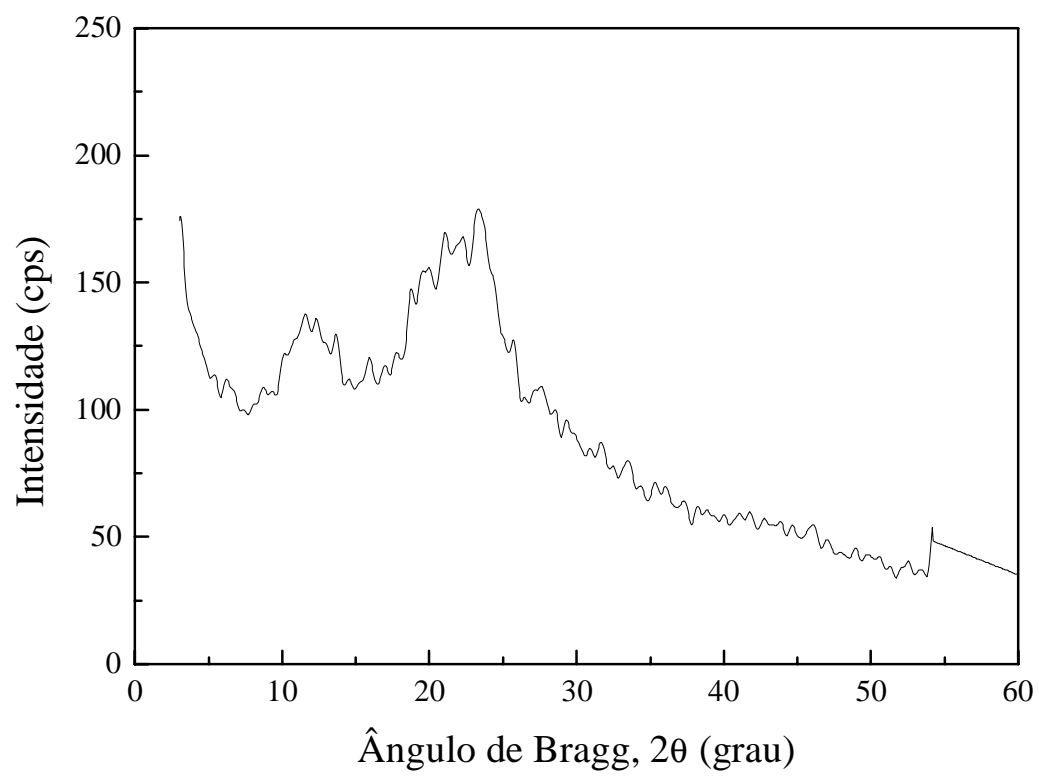

Figura 4. 7: Difratograma de raios-X de hidroxietil celulose QP300H graftizada com hexametileno diisocianato

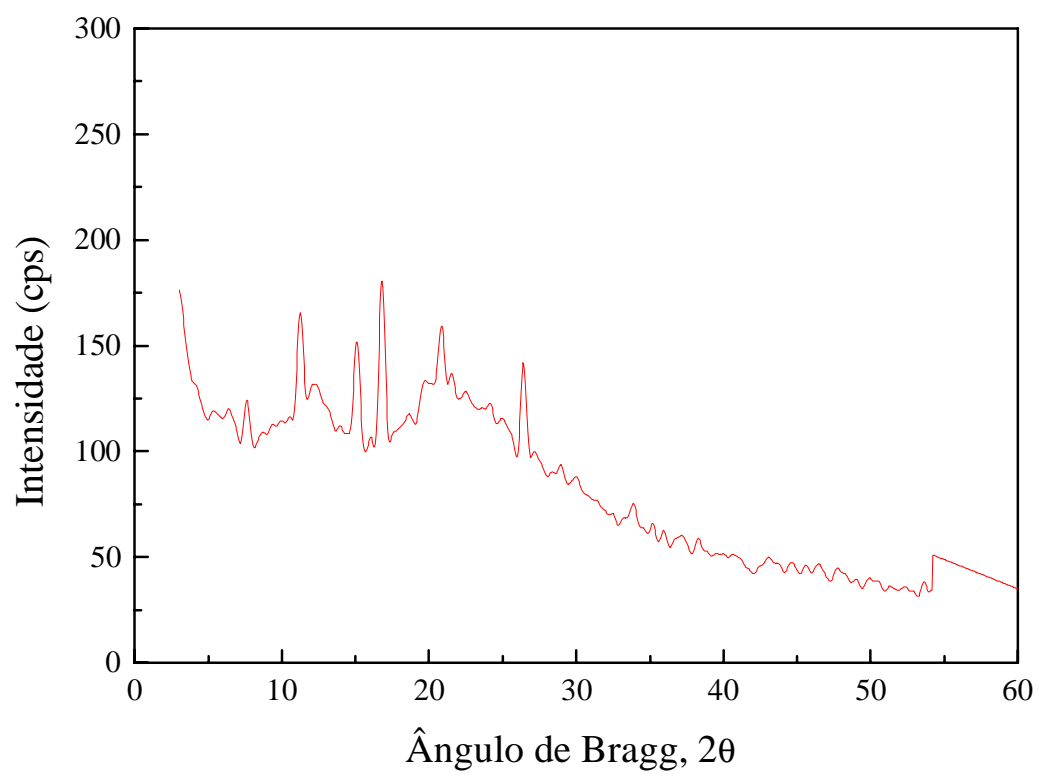

Figura 4. 8: Difratograma de raios-X de hidroxietil celulose QP300H graftizada com fenil isocianato 


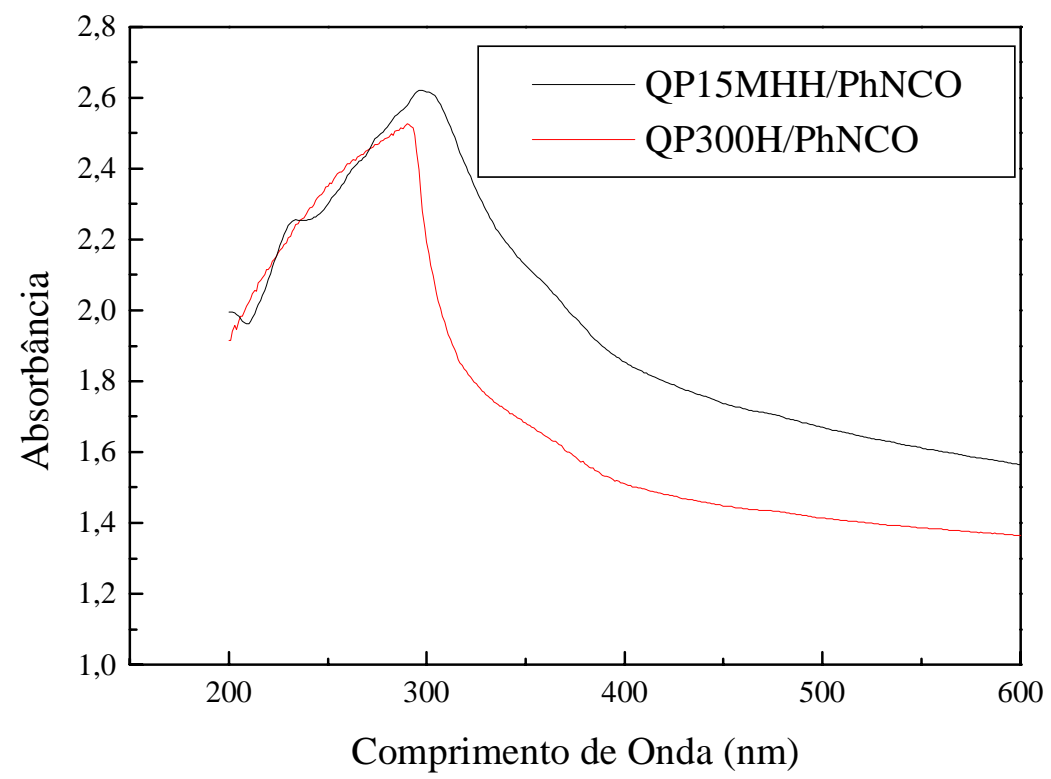

Figura 4. 9: Espectro no ultravioleta de redes de hidroxietil celulose graftizadas com fenil isocianato

A análise do espectro obtido na região do infravermelho (figura 4.10) auxilia na observação da ocorrência da reação. A banda de $\mathrm{OH}$ não encontra-se alargada como no espectro da HEC antes da reação, o que demonstra que as ligações de hidrogênio foram substituídas por outro tipo de ligação. Também foi observado um aumento de intensidade da banda de absorção de $\mathrm{CH}_{2}$, indicando a inserção destes grupos na cadeia do polissacarídeo através da reação. Podemos ainda observar banda relativa à absorção de ligação do tipo uretana a $1660 \mathrm{~cm}^{-1}$ para ambos os filmes com HDI. Não foi possível realizar este tipo de análise para filmes de HEC com fenilisocianato devido à grande espessura.

Para a síntese dos filmes dopados com sal, introduziu-se $\mathrm{LiClO}_{4}$ durante a etapa de síntese, da mesma forma como para os filmes de HEC enxertados com poliéter. A característica macroscópica destes filmes é a aparente não dissolução do sal na matriz, pois podem ser visualisados aglomerados salinos na superfície dos filmes opacos. Os filmes de hidroxietil celulose entrecruzada com HDI não 
apresentaram resultados de condutividade, não sendo obtido semicírculo no diagrama de impedância complexa. Pode-se extrapolar que, o polissacarídeo pode solvatar os cátions $\mathrm{Li}^{+}$em alguma extensão, mas neste caso não contribui para o fenômeno de condução iônica; este é assegurado na presença de cadeias que possuam grupos capazes de solvatar os cátions, mas que também apresentem mobilidade, como no caso dos poliéteres estudados no capítulo 3. Quando a cadeia agregada à HEC não possui nenhum grupo com poder de solvatação das espécies responsáveis pela condução e ainda, promove o entrecruzamento da cadeia de polissacarídeo resultando em menor mobilidade da cadeia, nenhum resultado de condutividade é obtido. Também não foi possível a determinação da Tg através de técnica de DSC; não foi observada nenhuma mudança de linha de base na curva de análise térmica.

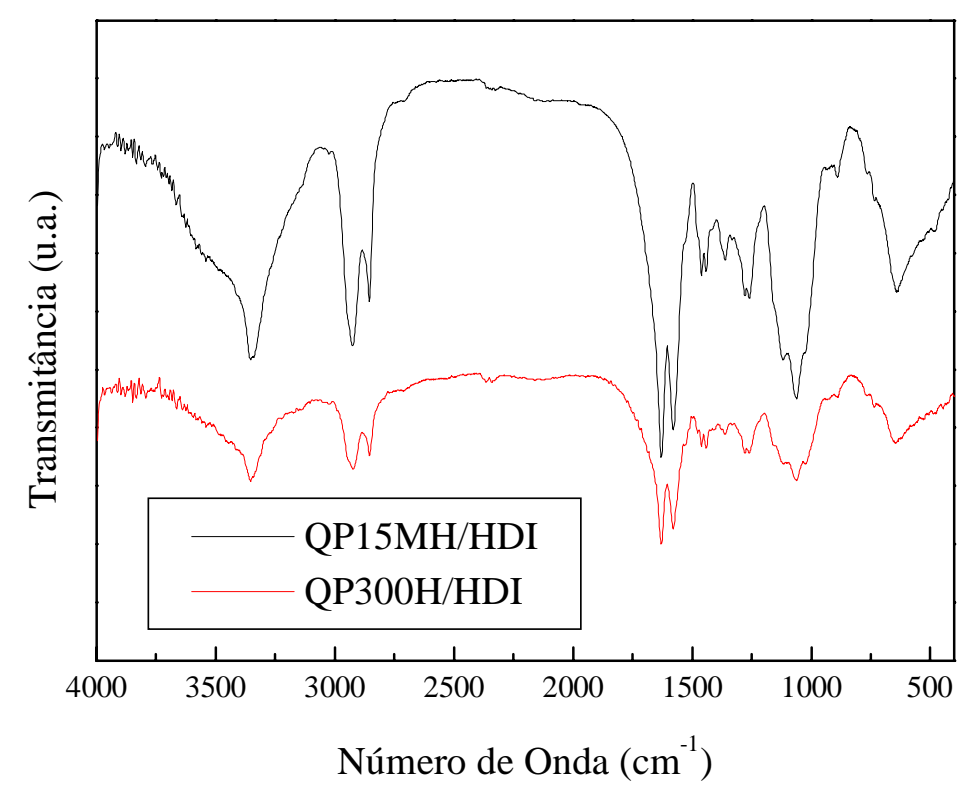

Figura 4. 10: Espectro no infravermelho de hidroxietil celulose grafitizada com hexametileno diisocianato

A medida de condutividade para os filmes de hidroxietil celulose derivatizada com fenilisocianato foi complicada, pois dependendo da parte do filme em que é 
colhida a amostra para ensaio, obtém-se resultados diferentes para a condução. Este fato contribui com a conclusão de que a dissolução do sal na matriz não foi adequada. Os melhores resultados obtidos para estes filmes são apresentados no diagrama do tipo Arrhenius da figura 4.11. A quantidade de sal introduzida na solução de síntese corresponde à razão $\mathrm{O} / \mathrm{Li}=12$ (todos os oxigênios provém da estrutura do polissacarídeo), mas a presente no pedaço de amostra utilizado no experimento pode ser diferenciada, não sendo possível a sua determinação. A condutividade aparente destas amostras pode ser explicada pela coordenação dos cátions $\mathrm{Li}^{+}$com os anéis aromáticos e a sua passagem de um sítio de solvatação a outro. A coordenação do cátion metálico com o anel aromático é possível porque estes possuem alta densidade de carga negativa capaz de atrair os cátions livres. A curvatura observada nos diagramas do tipo Arrhenius sugere que a condução é auxiliada pelos movimentos dos segmentos poliméricos (comportamento VTF). Podemos então inferir que, as macromoléculas de HEC além de solvatar os cátions $\mathrm{Li}^{+}$em alguma extensão, também promovem a condutividade através dos movimentos de suas cadeias. Na tabela 4.5 são apresentados os resultados dos ajustes VTF para as curvas da figura 4.11.

Tabela 4. 5: Resultados do ajuste VTF e constantes WLF para filmes de hidroxietil celulose entrecruzados com fenilisocianato e dopados com $\mathrm{LiClO}_{4}$

\begin{tabular}{|c|c|c|c|c|c|}
\hline \multirow[t]{2}{*}{ amostra } & \multirow[t]{2}{*}{$\operatorname{Tg}\left({ }^{\circ} \mathrm{C}\right)$} & \multicolumn{2}{|c|}{ Ajuste VTF } & \multicolumn{2}{|c|}{ Constantes WLF } \\
\hline & & $A\left(\operatorname{Scm}^{-1} K^{-1 / 2}\right)$ & $\Delta \mathrm{E}\left(\mathrm{kJmol}^{-1}\right)$ & $\mathrm{C}_{1}(\mathrm{Tg})$ & $\mathrm{C}_{2}(\mathrm{Tg})(\mathrm{K})$ \\
\hline QP300H & 57 & 0,586 & 9,42 & 7,9 & 116 \\
\hline QP15MH & 60 & 0,049 & 7,94 & 21 & 275 \\
\hline
\end{tabular}




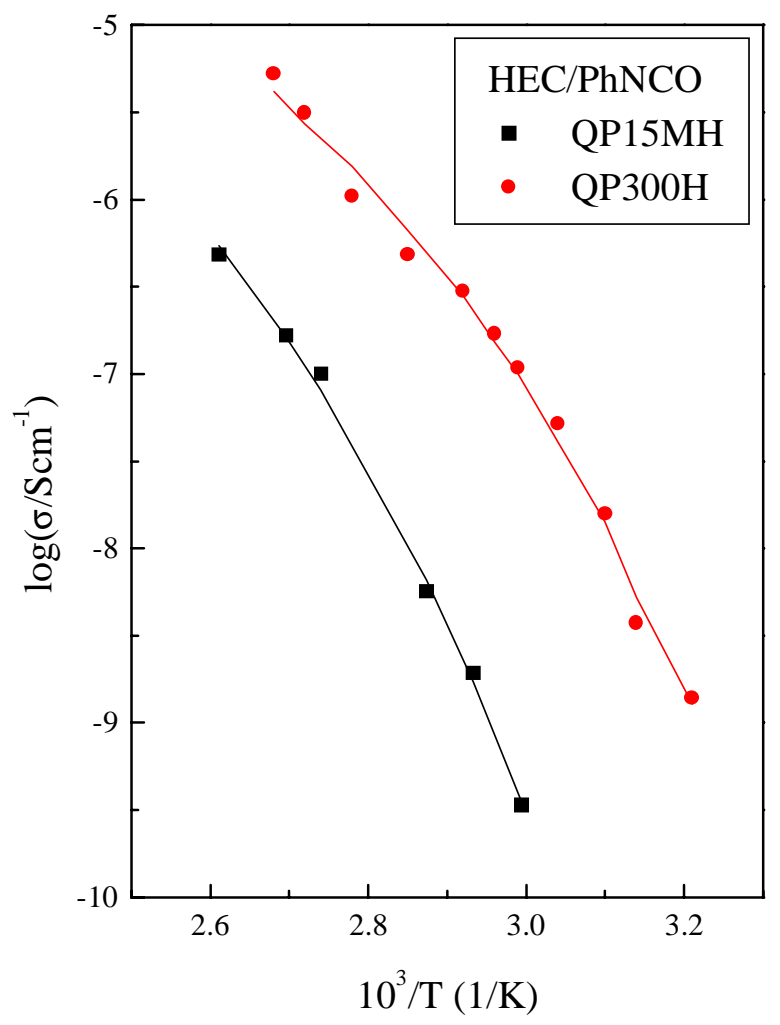

Figura 4. 11: Diagrama do tipo Arrhenius para condutividade das amostras de hidroxietil celulose QP300H e QP15MH derivatizadas com fenilisocianato

A comparação dos resultados de condutividade obtidos para os dois filmes de HEC com fenilisocianato, bem como com os demais filmes com diferentes poliéteres não é conveniente porque as características dos filmes com fenilisocianato não são confiáveis devido à concentração de sal na matriz polimérica não ser constante.

4.5 - Conclusões do capitulo

Neste capítulo foram apresentadas a síntese, caracterização e as propriedades de filmes de hidroxietilcelulose enxertada com hexametileno diisocianato e fenilisocianato. A caracterização dos filmes por análise térmica mostrou que a 
temperatura de transição vítrea do material é semelhante para os dois tipos de isocianato. A introdução de grupo linear de maior comprimento (promovido pela graftização com HDI) é compensada pelo entrecruzamento das cadeias de polissacarídeo resultando em $\mathrm{Tg}$ com valor próximo ao obtido quando a HEC é derivatizada com fenilisocianato. Estes filmes com HDI são aparentemente amorfos e no caso dos materiais com $\mathrm{PhNCO}$ a cristalinidade observada está provavelmente relacionada com a presença de dímeros e trímeros do isocianato. Os filmes com fenilisocianato também apresentam absorção no ultravioleta como resultado da presença dos grupos aromáticos.

A condução iônica é observada apenas para os filmes com PhNCO indicando que a cadeia de hidroxietilcelulose pode solvatar os cátions $\mathrm{Li}^{+}$em alguma extensão, mas quando as cadeias de polissacarídeo são entrecruzadas utilizando-se HDI, tornando os segmentos mais rígidos, elas não participam do fenômeno de condução. O resultado de condutividade obtido para os filmes com fenilisocianato não são confiáveis porque a distribuição de sal na matriz polimérica não é constante. Foram observados visualmente aglomerados salinos e, dependendo da parte do filme escolhido para análise foi obtido resultado diferente de condutividade. Para que fossem obtidos eletrólitos sólidos propostos neste capítulo seria necessário o melhoramento da síntese dos mesmos, principalmente o estudo da correta solubilização de sal neste tipo de matriz. 


\section{6 - Referências bibliográficas}

1. TOFFEY, A.; GALSSER, W. Cure characterization of polyurethanes with lignin and cellulose derivatives. Holzforschung, v. 51, p. 71-78, 1997.

2 TREJO-O'REILLY, J. A.; CAVAILLE, J. Y. GANDINI, A. The surface chemical modification of cellulosic fibres in view of their use in composite materials.

Cellulose, v. 4, p. 305-320, 1997

${ }^{3}$ BOTARO, V. R.; GANDINI, A. Chemical modification of the surface of cellulosic fibres. 2. Introduction of alkenyl moieties via condensation reactions involving isocyanate funcitons. Cellulose, v. 5, p. 65-78, 1998.

${ }^{4}$ DA ROZ, Alessandra Luzia. Preparação e caracterização de novos materiais a partir de polpa celulósica. São Carlos, 2000. 110p. Dissertação (Mestrado) Instituto de Química de São Carlos, Universidade de São Paulo.

${ }^{5}$ EVANS, R.; WEARNE, R. H.; WALLIS, A. F. A. Molecular weight distribuition of cellulose as its tricarbanilate by high performance size exclusion chromatography. Journal of Applied Polymer Science, v. 37, p. 3291-3303, 1989.

${ }^{6}$ POUCHERT, C. J. The Aldrich Library of FT-IR Spectra. Milwaukee, Aldrich Chemical, 1985. v. 2, p. 470,A.

${ }^{7}$ POUCHERT, C. J. The Aldrich library of NMR Spectra. Milwaukee, Aldrich Chemical, 1985. v. 2, p. 441,D.

${ }^{8}$ INTERNATIONAL Centre for Diffraction Data. Powder Diffraction File - PDF - 2 Database Sets 1-44. Pensilvania, ICDD, 1994. (CD - ROM). Ref 29-1844. 9 op. cit., Ref. 32-1827. 


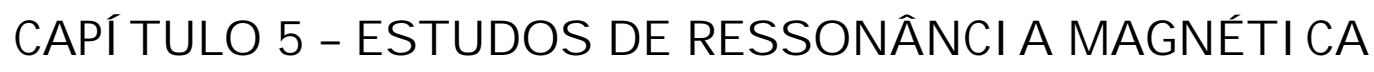
$\mathcal{N U C L E \mathcal { R }}$

$5.1-$ Introdução

Há alguns anos experimentos de ressonância magnética nuclear (RMN) têm sido utilizados para estudar a dinâmica de cadeias de polímeros e a mobilidade das cadeias de íons ${ }^{1,2}$. Os experimentos de RMN consistem basicamente em determinar a forma de linha do sinal detectado (que depende diretamente do tempo de relaxação transversal, $T_{2}$ ) e da taxa de relaxação spin-rede, $1 / T_{1}$.

Ao submeter uma amostra constituída de átomos, cujos núcleos possuem momentos magnéticos não nulos, à um campo magnético externo constante $\left(\vec{B}_{0}\right)$ é promovida a separação dos níveis de energia. A diferença de ocupação entre eles é responsável por uma magnetização resultante, $\vec{M}_{0}$, na direção do eixo $z$ (alinhada com o campo magnético). Nesta situação de equilíbrio, a componente longitudinal, $M_{z}$ tem valor igual à da magnetização, e as componentes transversais, $M_{x}$ e $M_{y}$ são iguais a zero. Quando nesta situação é aplicado um campo magnético oscilante, $\vec{B}_{1}$, o equilíbrio é desfeito. Cessando $\vec{B}_{1}$, os fenômenos de relaxação tendem a restaurar a magnetização à situação de equilíbrio. 
O tempo $T_{2}$ está relacionado às componentes $M_{x}$ e $M_{y}$ e por isso recebe o nome de tempo de relaxação transversal. Já $T_{1}$ está relacionado à componente $M_{z}$ e é denominado tempo de relaxação longitudinal. A recuperação total de $M_{z}$ está relacionada à relaxação de spins nucleares excitados por $\vec{B}_{1}$. Esta é acompanhada pela transferência de energia do sistema de spins para a rede. Portanto, $T_{1}$ também recebe o nome de relaxação spin-rede.

Devido ao fato dos processos de relaxação nuclear dependerem da existência de movimentos moleculares (responsáveis pela variação ao acaso dos campos magnéticos gerados ) é possível obter informações a respeito dos mesmos a partir das velocidades de relaxação medidas experimentalmente.

Para a medida da forma de linha, aplica-se um pulso de $\pi / 2$, e em seguida, o sistema experimenta a relaxação ${ }^{3}$. As equações de Bloch $^{4}$ prevêem uma banda de forma lorentziana, com uma largura a meia-altura que é

$$
\Delta v_{1 / 2}=\frac{1}{\pi T_{2}}
$$

Devido à não-homogeneidade do campo magnético nos vários pontos da amostra, pode haver desvios significativos da forma de linha prevista pela equação de Bloch. Em analogia à equação 24, define-se um tempo de relaxação efetivo, $T_{2} *$, dado por

$$
\Delta v_{1 / 2}=\frac{1}{\pi T_{2}^{*}}
$$


Nesta expressão, $T_{2} *$ inclui contribuições da largura natural e da não homogeneidade do campo magnético.

Para medida de $T_{1}$ utiliza-se geralmente o método de saturaçãorecuperação ${ }^{3,4,5}$, onde se aplica uma seqüência de pulsos de $\pi / 2$. O intervalo entre estes pulsos é de geralmente $4 \mu$ s. O objetivo é destruir toda a magnetização existente em qualquer direção, sendo criada uma situação de saturação ${ }^{6}$. Em seguida, o sistema experimenta a relaxação durante um tempo $\tau$, após o qual um novo pulso de $\pi / 2$ é dado. Em seguida o sistema experimenta novamente a relaxação durante o tempo $T a$. Esta seqüência é repetida várias vezes de $\tau$ bem pequenos, onde a componente $M_{z}$ é quase nula, até $\tau$ suficientes para restabelecer a magnetização de equiíbrio. A partir da equação 26 determina-se o tempo de relaxação spin-rede, $T_{1}$.

$$
M_{Z}(t)=M_{0}\left[1-\exp \left(-\frac{1}{T_{1}}\right)\right]
$$

O estudo da taxa de relaxação spin-rede, $1 / T_{1}$, em função da temperatura permite determinar os mecanismos de condução do sistema em estudo e obter os parâmetros de energia de ativação e do fator de tempo de correlação ${ }^{3}$.

Desde a síntese dos primeiros eletrólitos sólidos poliméricos utiliza-se a técnica de RMN para o estudo da cristalinidade, coeficientes de difusão, mobilidade iônica e mobilidade das cadeias polimérica nestes sistemas ${ }^{7,8}$. Este interesse é devido à alta dependência das taxas de relaxação nuclear frente à dinâmica dos segmentos poliméricos. Medidas de tempos de relaxação em função da temperatura têm sido usadas para estudar a correlação entre os movimentos moleculares e a presença de espécies catiônicas $^{2,5,9}$. 
Com o objetivo de melhor estudar os fenômenos de condução e mobilidade das cadeias dos eletrólitos sólidos poliméricos com matriz de polissacarídeo enxertado com poliéter, foram realizados alguns ensaios de ressonância magnética nuclear.

Os experimentos de RMN foram realizados pelo doutorando Caio Eduardo de Campos Tambelli, sob orientação do Professor Doutor José Pedro Donoso Gonzales, no Instituto de Física de São Carlos - USP. Foram submetidas à análise as amostras de HEC QP300H, QP4400 e QP30MH entrecruzadas com diisocianato de poli(óxido de etileno) na proporção $[\mathrm{NCO}] /[\mathrm{OH}]=0,6$ e dopadas com $\mathrm{LiClO}_{4}$.

Medidas de largura de linha e tempos de relaxação spin-rede, $T_{l}$, de próton $\left({ }^{1} \mathrm{H}\right)$ foram realizadas em espectrômetro de RMN equipado com TECMAG NMR-kit, operando a $36 \mathrm{MHz}$ no intervalo de temperatura de 210 a $380 \mathrm{~K}$. Para medidas de $T_{1}$ de ${ }^{7} \mathrm{Li}$ o intervalo de temperatura estudado foi de 220 a $380 \mathrm{~K}$ utilizando equipamento Varian - 400MHz Inova NMR spectrometer operando a 155,4MHz. Para determinar os tempos de relaxação spin-rede utilizou-se método de saturação recuperação.

\section{3- Resultados}

Para estimar a mobilidade dos segmentos das cadeias poliméricas, dois filmes de hidroxietil celulose enxertada com poliéter foram submetidos a experimentos de RMN de próton. Na figura 5.1 é mostrada a dependência da largura de linha do 
espectro de ${ }^{1} \mathrm{H}$ para filme de HECQP300H entrecruzada com DPOE, com e sem sal. Os espectros consistem em uma única banda de absorção em todo o intervalo de temperatura investigado, diferente do encontrado para filmes de poli(óxido de etileno) puro ou na forma de eletrólito sólido. Os espectros destes materiais consistem, geralmente, de duas componentes associadas às fases amorfa e cristalina $^{10,11}$.

$\mathrm{Na}$ presença de um campo magnético pode-se imaginar que os núcleos comportam-se como micro-ímãs oscilando dentro da bobina. Cada momento de dipolo magnético gera um pequeno campo magnético que atuará nos momentos de dipolo magnético vizinho. O campo magnético dipolar depende não só destes momentos de dipolo magnético, mas também das distâncias internucleares e do campo magnético externo, $\vec{B}_{0}$. Na ausência de interação dipolar o núcleo interage apenas com $\vec{B}_{0}$ e o espectro resultante consiste em uma única linha centrada em freqüência que depende deste campo. Ao considerar a interação dipolar magnética, a frequiência de ressonância será dada em termos do campo magnético local, resultando em um desdobramento de linhas de ressonância ${ }^{3,6}$ correspondente às duas situações de spin, no caso de núcleos de hidrogênio. Para uma amostra sólida, o espectro apresenta uma forma alargada. E este fato é característico da interação dipolar.

Em temperaturas suficientemente baixas, todos os movimentos atômicos e moleculares estão "congelados" na escala de tempo de RMN. Este é denominado regime de rede rígida e as interações predominantes são as de dipolo magnético. É por isto que a largura de linha nestas temperaturas é maior.

$\mathrm{O}$ estreitamento de largura de linha causado pelos movimentos moleculares inicia quando a frequiência das flutuações dos campos magnéticos locais torna-se 
muito alta. Com o aumento da temperatura, a mobilidade das cadeias poliméricas aumenta, e neste estado, será observado apenas o valor médio das interações. Como conseqüência, tem-se o estreitamento da banda de absorção.

Observa-se na figura 5.1 o estreitamento rápido da largura de linha, a partir de $223 \mathrm{~K}$ e até $280 \mathrm{~K}$ para o filme HECQP300H/DPOE (253 e 300K para o respectivo eletrólito sólido), até o limite de $350 \mathrm{~K}$ a partir do qual permanece constante. Este estreitamento tem seu início em temperaturas próximas a Tg (223K para filme sem sal e 253K para o eletrólito sólido, em excelente concordância com os valores obtidos por técnica de DSC). Comportamento similar é observado em poliéteres e eletrólitos sólidos poliméricos ${ }^{10,12}$ onde o estreitamento da linha em temperatura igual a Tg é atribuído ao início dos movimentos dos segmentos das cadeias poliméricas. Este fato evidencia que as transições de linha estão diretamente associadas à dinâmica polimérica. O deslocamento observado para o início do estreitamento da linha para temperaturas mais altas no filme HECQP300H/DPOE dopado com $\mathrm{LiClO}_{4}$ reflete a redução da mobilidade das cadeias quando o sal é dissolvido no sistema. O entrecruzamento iônico promovido pela solvatação dos cátions $\mathrm{Li}^{+}$pelos oxigênios presentes na estrutura do filme resulta na redução da mobilidade dos segmentos das cadeias poliméricas. 


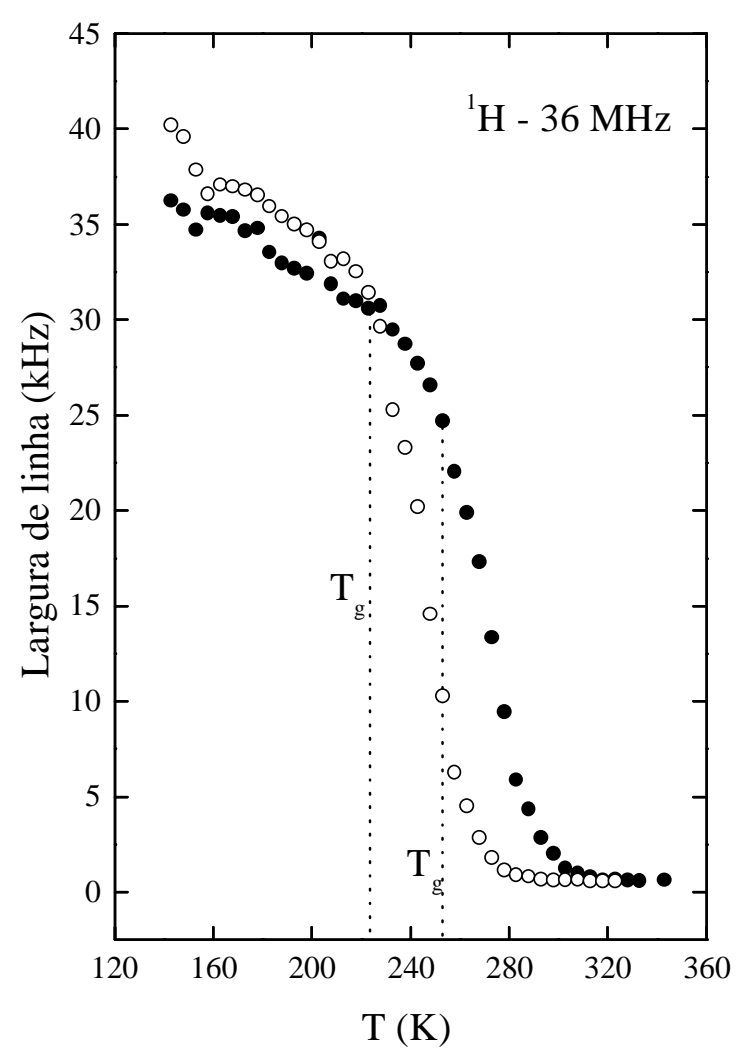

Figura 5. 1: Dependência da largura de linha de ${ }^{1} \mathrm{H}-\mathrm{RMN}$ com a temperatura para filmes de HECQP300H/DPOE (O) e HECQP300H/DPOE/LiClO 4 (๑).

Na figura 5.2 encontra-se representada a dependência com a temperatura da taxa de relaxação spin-rede, $1 / T_{1}$, dos filmes HEC QP300H/DPOE e HEC QP300H/DPOP. É observado um único máximo de relaxação para os dois filmes. Acima de $230 \mathrm{~K}, 1 / T_{1}$ aumenta com o aumento da temperatura até o valor máximo em aproximadamente 300K para HEC QP300H/DPOE e 330K para a amostra QP300H/DPOP. O principal mecanismo de relaxação de próton nestes sistema é a flutuação das interações dipolo causada pelos movimentos moleculares. O máximo corresponde a flutuações da ordem da freqüência de Larmor. Para uma mesma freqüência de Larmor, a mobilidade relativa dos núcleos pode ser comparada analisando as posições dos máximos de relaxação. A ocorrência deste em temperaturas mais elevadas indica núcleos menos móveis ${ }^{7,11}$. Como mostrado na 
figura 5.2, o deslocamento do máximo indica que o filme entrecruzado com poli(óxido de propileno) tem mobilidade de cadeia polimérica menor que o com poli(óxido de etileno). Portanto, o filme com maior mobilidade é o sintetizado através do entrecruzamento de HEC QP300H com diisocianato de poli(óxido de etileno).

Assumindo um processo termicamente ativado, a taxa de relaxação spin-rede depende da temperatura e pode ser representada pelo tempo de correlação na expressão de Arrhenius ou na função Vogel-Tamman-Fulcher. A energia de ativação do processo pode então ser calculada a partir da parte linear das curvas da figura 5.2. Para o filme de HEC QP300H/DPOE obteve-se $E \approx 0,23 \mathrm{eV}$, o que é ligeiramente menor que a energia de ativação reportada para a componente amorfa de poli(óxido de etileno) puro $(E \approx 0,29 \mathrm{eV})^{10}$. A mobilidade das cadeias destes filmes pode ser comparada estimando-se o valor de tempo de correlação, $\tau_{c}$, que é calculado a partir da equação $\omega_{0} \tau_{\mathrm{c}} \approx 1$, onde $\omega_{0}$ é a freqüência de Larmor na temperatura do máximo de $1 / \mathrm{T}_{1}$. Foi obtido para a matriz contendo polissacarídeo o valor de $\tau_{\mathrm{c}} \approx 4,0 \times 10^{-9} \mathrm{~s}$. Este valor é de uma ordem de grandeza menor que o encontrado para filmes de poli(óxido de etileno) puro e na mesma temperatura ${ }^{10}$, indicando maior mobilidade das cadeias poliméricas nos filmes contendo polissacarídeo. 


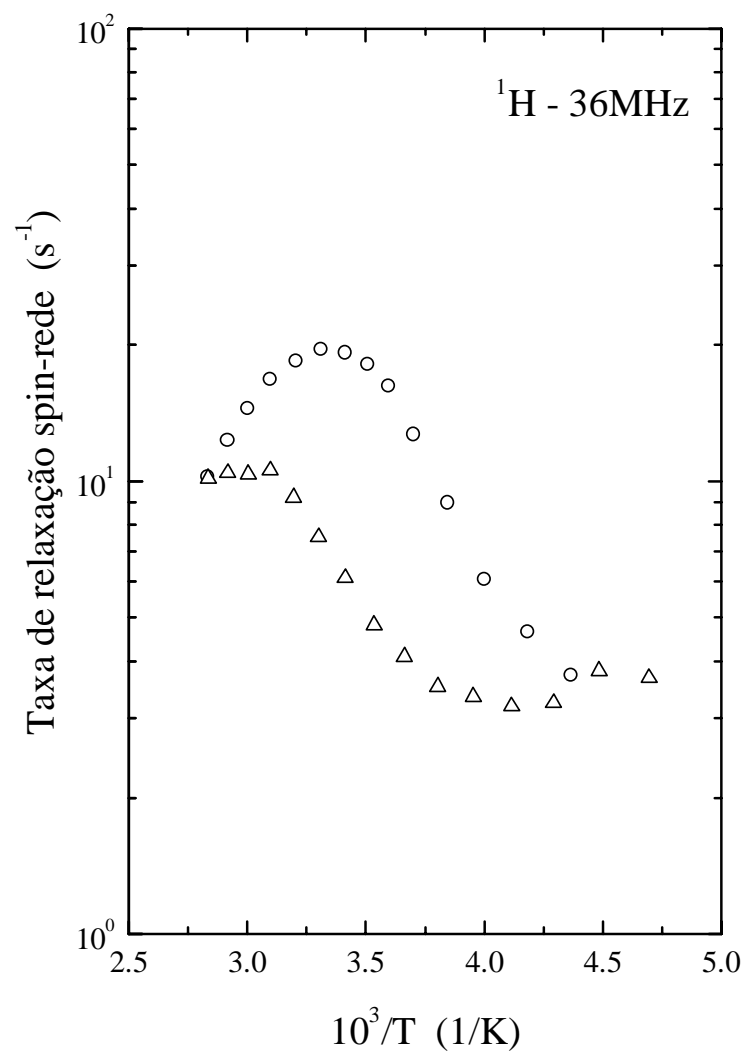

Figura 5. 2: Dependência da taxa de relaxação de próton, $1 / T_{1}$, com a temperatura dos filmes HEC QP300H/DPOE (O); HECQP300H/DPOP $(\Delta)$

A comparação das taxas de relaxação spin-rede de próton para diferentes eletrólitos sólidos poliméricos com matriz de polissacarídeo pode ser observada na figura 5.3. A recuperação de magnetização no equilíbrio nestes sistemas é exponencial e descrita por um único valor de $1 / T_{1}$, em concordância com a observação de uma única banda de absorção em todo o intervalo de temperatura investigado. Funções não exponenciais para a taxa de relaxação de próton são encontradas em sistemas de poli(óxido de etileno) semicristalinos, onde diferentes componentes de relaxação correspondem a núcleos de hidrogênio nas fases amorfa e cristalina $^{13,14,15}$. Os dados da figura 5.3 mostram um único máximo da taxa de relaxação para as três amostras investigadas. Em temperaturas acima de $250 \mathrm{~K}, 1 / T_{1}$ aumenta com o aumento de temperatura até um valor máximo de aproximadamente 
343K para o eletrólito sólido com HECQP30MH/DPOE e 330K para as outras duas amostras. O mecanismo responsável pela relaxação de próton nestes sistemas é a flutuação de interações dipolo resultante dos movimentos das cadeias de poli(óxido de etileno) e hidroxietil celulose, ou seja, da modulação das distâncias H-H entre os prótons das cadeias poliméricas e da modulação da distância H-Li entre os prótons e os cátions $\mathrm{Li}^{+}$.

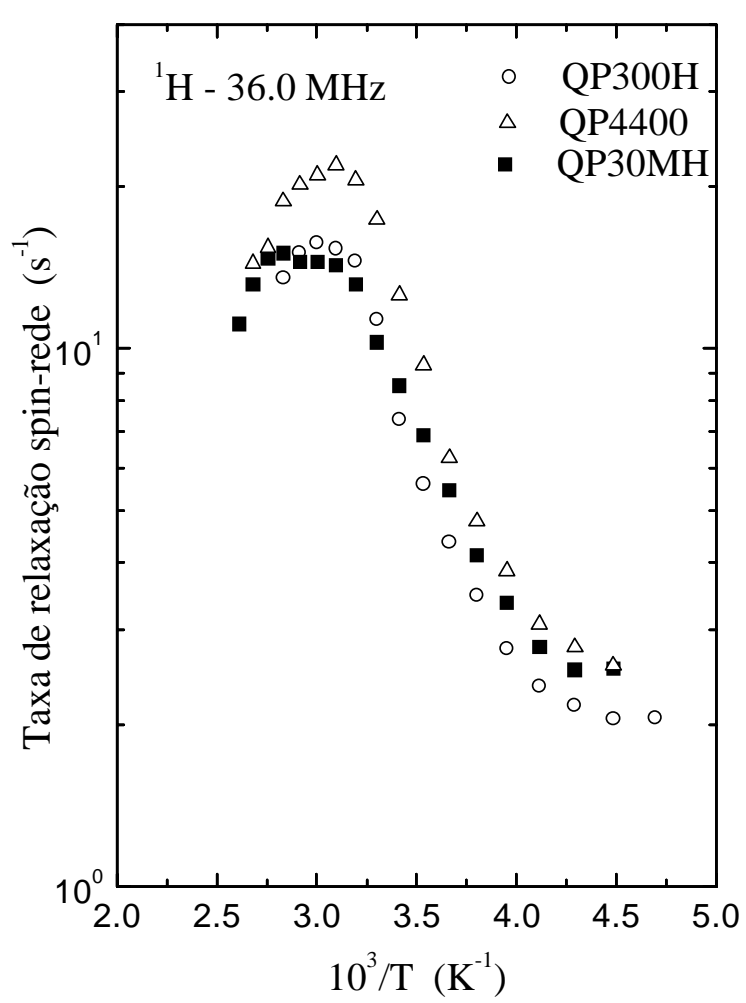

Figura 5. 3: Dependência com a temperatura da taxa de relaxação spin-rede, $1 / T_{1}$, de eletrólitos sólidos poliméricos com matriz de hidroxietil celulose entrecruzada com diisocianato de poli(óxido de etileno) dopados com $\mathrm{LiClO}_{4}$

Os valores de energia de ativação calculados a partir da parte linear das curvas da figura 5.3 e da equação de Arrhenius são iguais a $0,23 \mathrm{eV}$ para a amostra com HECQP300H e 0,17 eV para as amostras com HECQP4400 e QP30MH. Estes resultados são similares aos encontrados na literatura para eletrólitos sólidos 
poliméricos à base de poli(óxido de etileno) e perclorato de lítio $\left(\mathrm{PEO}_{8}: \mathrm{LiClO}_{4}\right)^{6,10,16}$.

Na tabela 5.1 são apresentados os parâmetros obtidos a partir dos dados de taxa de relaxação spin-rede para as três amostras investigadas.

Tabela 5. 1: Parâmetros obtidos a partir de experimentos de RMN de ${ }^{1} \mathrm{H} \mathrm{e}{ }^{7} \mathrm{Li}$ dos eletrólitos sólidos poliméricos com matriz de hidroxietil celulose graftizada com diisocianato de poli(óxido de etileno) e dopadas com $\mathrm{LiClO}_{4} . \Delta H_{r e s}$ é a largura de linha residual de ${ }^{7} \mathrm{Li}$ após o desacoplamento de próton; $T_{\max }$ é a temperatura no máximo de taxa de relaxação e $E_{a}$ é a energia de ativação para o movimento responsável pela relaxação

\begin{tabular}{|c|c|c|c|}
\hline & QP300H/DPOE & QP4400/DPOE & QP30MH/DPOE \\
\hline \multicolumn{4}{|l|}{ experimentos ${ }^{1} \mathrm{H}$ : } \\
\hline${ }^{1} \mathrm{H}$ "Rigid lattice" & $\mathrm{T}<200 \mathrm{~K}$ & - & - \\
\hline$T_{\max }$ & $330 \pm 5 \mathrm{~K}$ & $328 \pm 3 \mathrm{~K}$ & $343 \pm 5 \mathrm{~K}$ \\
\hline$\left(T_{1}\right)_{\max }$ & $67 \mathrm{~ms}$ & $46 \mathrm{~ms}$ & $67 \mathrm{~ms}$ \\
\hline$E_{A}$ & $0.23 \pm 0.02 \mathrm{eV}$ & $0.22 \pm 0.02 \mathrm{eV}$ & $0.17 \pm 0.02 \mathrm{eV}$ \\
\hline$\tau_{o}$ & $8 \times 10^{-13} \mathrm{~s}$ & $1.0 \pm 0.2 \times 10^{-12} \mathrm{~s}$ & $8.4 \times 10^{-12} \mathrm{~s}$ \\
\hline \multicolumn{4}{|l|}{ experimentos ${ }^{7} \mathrm{Li}$ : } \\
\hline${ }^{7} \mathrm{Li} \Delta H_{\mathrm{RL}}$ (central) & $7.2 \mathrm{KHz}$ & $8.3 \mathrm{KHz}$ & $7.3 \mathrm{KHz}$ \\
\hline $\begin{array}{l}{ }^{7} \mathrm{Li} \Delta H_{\mathrm{RL}} \text { (linha de } \\
\text { base) }\end{array}$ & $\sim 40 \mathrm{KHz}$ & $\sim 41 \mathrm{KHz}$ & $\sim 43 \mathrm{KHz}$ \\
\hline$\Delta H_{\mathrm{res}}$ & $1.5 \mathrm{KHz}$ & $1.5 \mathrm{KHz}$ & $1.55 \mathrm{KHz}$ \\
\hline$T_{\max }$ & $\sim 364 \mathrm{~K}$ & $>380 \mathrm{~K}$ & $\sim 378 \mathrm{~K}$ \\
\hline$\left(T_{1}\right)_{\max }$ & $\sim 350 \mathrm{~ms}$ & $\sim 300 \mathrm{~ms}$ & $\sim 300 \mathrm{~ms}$ \\
\hline$E_{A}$ & $0.24 \pm 0.01 \mathrm{eV}$ & $0.24 \pm 0.01 \mathrm{eV}$ & $0.23 \pm 0.01 \mathrm{eV}$ \\
\hline$\tau_{o}$ & $3 \times 10^{-13} \mathrm{~s}$ & - & $5.0 \times 10^{-13} \mathrm{~s}$ \\
\hline$v_{Q}=e^{2} q Q / h$ & $\sim 22 \mathrm{KHz}$ & - & - \\
\hline
\end{tabular}


$\mathrm{Na}$ figura 5.4 encontra-se apresentado o espectro de ${ }^{7} \mathrm{Li}$ para a amostra QP30MH/DPOE/LiClO 4 a 183K (obtido a temperatura abaixo da Tg, 241K). O espectro é caracterizado por uma linha larga e de baixa intensidade $(\Delta H \approx 40 \mathrm{kHz})$ e uma linha fina central $(\Delta H \approx 7 \mathrm{kHz})$, onde $\Delta H$ é a largura de linha na metade do máximo. A forma de linha do espectro de RMN de um sistema de spin $\mathrm{I}=3 / 2 \mathrm{em}$ uma sólida pode ser explicado através da interação de quadrupolos. Núcleos com spin I >1/2, possuem também quadrupolos elétricos, isto é, comportam-se como uma distribuição não esférica de carga elétrica. A interação do quadrupolo com o ambiente eletrônico envolvente diminui, em geral, o tempo de vida dos estados magnéticos de spin nuclear. Esta diminuição implica em uma maior incerteza nos valores de energia destes estados, resultando em bandas largas nos espectros de $\mathrm{RMN}^{6}$. O espectro apresentado na figura 5.4 possui uma componente central alargada devido à transição $1 / 2 \leftrightarrow-1 / 2$ e um dublete resultado das transições $3 / 2$ $\leftrightarrow 1 / 2$ e $-1 / 2 \leftrightarrow-3 / 2$. Os eletrólitos sólidos poliméricos são sistemas desordenados e por isso é esperada a presença de satélites quadrupolares, resultado de todas as distribuições possíveis do gradiente de campo elétrico. Espectros similares são reportados para alguns sistemas do mesmo tipo ${ }^{14,17,18}$.

A proporção da área da ressonância central em relação à área da base do pico de ressonância corresponde a aproximadamente $42 \%$, em concordância com o valor teórico de $40 \%$ esperado para espectro de núcleo com $I=3 / 2$ com interação quadrupolar ${ }^{19}$. 


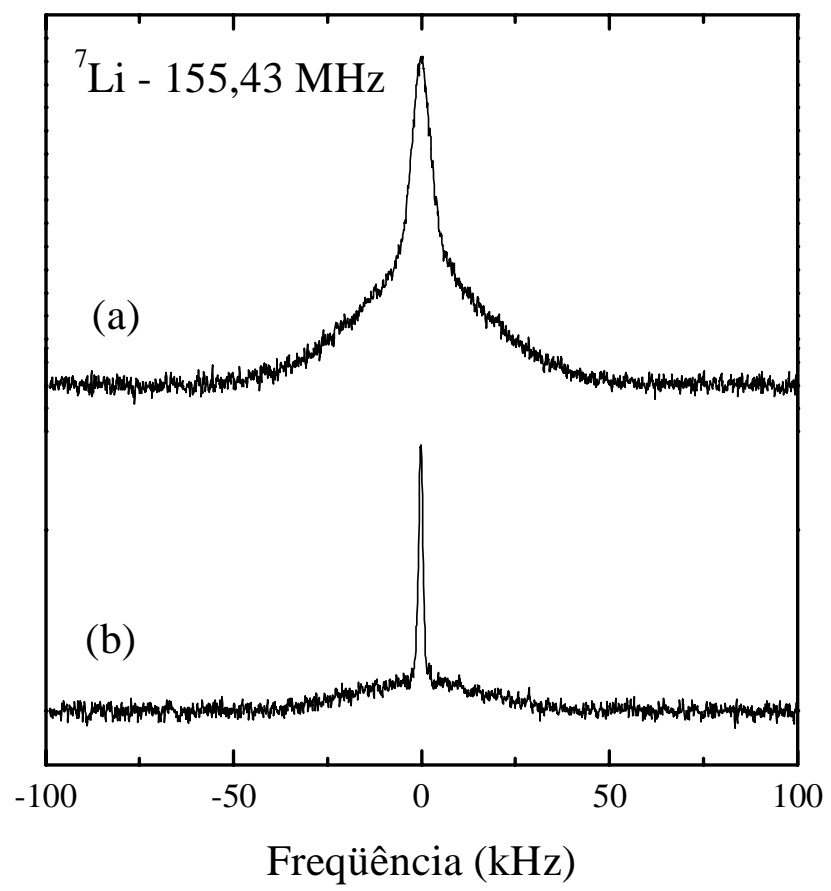

Figura 5. 4: Espectro de ${ }^{7} \mathrm{Li}-\mathrm{RMN}$ de amostra HEC/QP30MH/DPOE/LiClO 4 obtida a partir da transformada de Fourrier do sinal FID a 183K. (a) Espectro de ${ }^{7} \mathrm{Li}$ RMN (b) Espectro de ${ }^{7} \mathrm{Li}-\left\{{ }^{1} \mathrm{H}\right\}$ desacoplado

A linha associada à transição $1 / 2 \leftrightarrow-1 / 2$ não sofre alargamento devido ao acoplamento quadrupolar ${ }^{18,19}$, mas há outras fontes que podem influir como os acoplamentos dipolares dos núcleos adjacentes. Além do alargamento da linha central por interações dipolares homonucleares, há contribuições heteronucleares das espécies protônicas (POE e HEC) e acoplamento com cloro e oxigênio das espécies $\mathrm{ClO}_{4}^{-}$. Dados os pequenos fatores giromagnéticos e/ou a abundância natural de ${ }^{13} \mathrm{C}$, ${ }^{35} \mathrm{Cl}$ e ${ }^{17} \mathrm{O}$, podemos concluir que as interações ${ }^{7} \mathrm{Li}-{ }^{7} \mathrm{Li}$ e ${ }^{7} \mathrm{Li}-{ }^{1} \mathrm{H}$ são as principais responsáveis pelo alargamento de largura de linha no espectro de ressonância de lítio. Para estudar a importância destas interações realiza-se experimento de desacoplamento. Ou seja, os núcleos de hidrogênio são saturados através de pulso de radiofrequiência impedindo que o mecanismo de relaxação do lítio envolva acoplamento com hidrogênio. A figura 5.4(b) mostra o espectro de ${ }^{7}$ Li desacoplado a 
180K para a amostra QP30MH/DPOE/LiClO 4 . A redução de largura de linha de 7,16 para $1,45 \mathrm{kHz}$ indica a forte interação entre os ${ }^{7} \mathrm{Li}$ e os prótons da matriz polimérica (DPOE e HEC). Como a largura de linha central corresponde somente à interação entre os núcleos de lítio, a distância média entre estes átomos pode ser calculada ${ }^{12,19}$, através da expressão $\left(r=\sqrt[3]{3 \gamma \hbar / 2 \Delta B_{0}}\right)$, obtendo-se como resultado $\sim 3,4 \AA$. Este valor é da mesma ordem da distância entre dois átomos de oxigênio consecutivos na cadeia de poli(óxido de etileno) $(\sim 3 \AA)^{20}$. Resultados similares foram observados para as amostras com HEC QP300H e QP4400.

A figura 5.5 mostra a dependência da taxa de relaxação spin-rede de ${ }^{7} \mathrm{Li}$ para os eletrólitos sólidos poliméricos com matriz de polissacarídeo/poliéter. Em temperaturas superiores a $220 \mathrm{~K}, 1 / T_{1}$ aumenta com o aumento da temperatura até o valor máximo de $\sim 3 \mathrm{~s}^{-1}$ a $\mathrm{T} \geq 360 \mathrm{~K}$ para as três amostras estudadas. A relaxação de ${ }^{7} \mathrm{Li}$ em sólidos iônicos é governada principalmente por dois mecanismos: (i) relaxação quadrupolar, $\left(T_{1}^{-1}\right)_{\mathrm{Q}}$. Este fenômeno é devido às interações entre momento quadrupolar nuclear e as flutuações do gradiente de campo elétrico no entorno. Este último é resultado da distribuição não homogênea de carga nos sítios onde se encontram os núcleos em estudo. (ii) a relaxação dipolar $\left(T_{1}^{-1}\right)_{\text {dip: }}$ :

$$
T_{1}^{-1}=\left(T_{l}^{-1}\right)_{d i p}+\left(T_{l}^{-1}\right)_{Q}
$$

A relaxação spin-rede é expressa como função da densidade espectral $J(\omega)$ que representa a densidade de flutuações do campo magnético na freqüência de Larmor:

$$
T_{1}^{-1}=C_{1}\left[J\left(\omega_{1}\right)+J\left(2 \omega_{1}\right)\right]+C_{2}\left[J\left(\omega_{1}-\omega_{s}\right)+3 J\left(\omega_{1}\right)+6 J\left(\omega_{1}+\omega_{s}\right)\right]
$$


O primeiro termo do lado direito da equação 38 descreve a interação entre spins iguais $I-I$ e o segundo termo entre spins diferentes $I-S$. A freqüência de Larmor $\omega_{l}$ refere-se aos núcleos com spin $I\left({ }^{7} \mathrm{Li}, \omega_{l}=155,4 \mathrm{MHz}\right)$ e $\omega_{s}$ refere-se ao núcleo de spin $S\left({ }^{1} \mathrm{H}, \omega_{s}=400 \mathrm{MHz}\right)$. As constantes $\mathrm{C}_{1}$ e $\mathrm{C}_{2}$ dependem da interação de spin responsável pela relaxação ${ }^{12,18}$. Para núcleo com spin igual a $1 / 2$ os valores destas constantes é uma medida das interações dipolo homo e heteronucleares determinadas pela estrutura geométrica e pelo número de interações dos núcleos. Para spin maior que $1 / 2$ a relaxação spin-rede é governada principalmente pelas interações quadrupolares e as constantes da equação 38 são proporcionais ao quadrado das constantes de acoplamento quadrupolar, $\mathrm{v}_{\mathrm{q}}$. Em uma análise preliminar, assume-se que um único tempo de correlação descreve o movimento aleatório de um núcleo em relação ao seu ambiente, como previsto no modelo de relaxação BloembergenPurcell-Pround (BPP), levando à equação do tipo Debye da para a função de densidade espectral ${ }^{19}$.

$$
J(\omega)=\tau_{c} /\left(1+\omega^{2} \tau_{c}^{2}\right)
$$

Um cálculo simples a partir dos dados aqui obtidos para relaxação indica que a interação quadrupolar é dominante no mecanismo de relaxação spin-rede de ${ }^{7} \mathrm{Li}$. Uma estimativa de taxa de relaxação dipolar spin-rede pode ser obtida usando o segundo momento da linha central $\left(M_{2}(\mathrm{Li}) \approx 0,15 \mathrm{G}^{2}\right)$ e os resultados de desacoplamento ${ }^{7} \mathrm{Li}-\left\{{ }^{1} \mathrm{H}\right\}$. A partir das equações 28 e 29 calcula-se $\left(T_{1}^{-1}\right)_{\text {dip }} \approx 1 \mathrm{~s}^{-1}$ no máximo da taxa de relaxação; este resultado é menor do que o valor experimental, 
$\left(T_{1}^{-1}\right)_{\max } \approx 3 \mathrm{~s}^{-1}$. De acordo com a equação 37 , a magnitude da relaxação quadrupolar spin-rede deve ser, portanto, $\left(T_{l}^{-1}\right)_{\mathrm{Q}} \approx 2 \mathrm{~s}^{-1}$.

O valor de $\left(T_{1}^{-1}\right)_{\mathrm{Q}}$ no máximo depende unicamente da força da interação quadrupolar descrita pelos pré-fatores na equação 38. Para um núcleo $I=3 / 2$,

$$
C_{q}=\left\{3 \pi^{2}(2 I+3) / 10 I^{2}(2 I+1)\right\} v_{q}^{2}=\left(2 \pi^{2} / 5\right) v_{q}^{2}
$$

Resultando na constante de acoplamento quadrupolar $v_{\mathrm{q}}=22 \mathrm{kHz}$, o que é da mesma magnitude dos valores encontrados na literatura para outros eletrólitos sólidos poliméricos $^{16,21}$.

Assumindo um processo termicamente ativado, que segue a equação de Arrhenius para tempos de correlação, a análise dos dados da figura 5.5 leva a energias de ativação da ordem de 0,24 eV para os eletrólitos sólidos com matriz de polissacarídeo/poliéter (tabela 5.1). Estes valores são coerentes com os encontrados na literatura $(0,2-0,3 \mathrm{eV})^{12,16}$ e com os valores obtidos a partir dos experimentos de condutividade (capítulo 3). Observa-se também que as curvas de relaxação da figura 5.5 são independentes da amostra, indicando que a energia de ativação para a movimentação dos cátions não é afetada pelo derivado de celulose utilizado na matriz polimérica. 


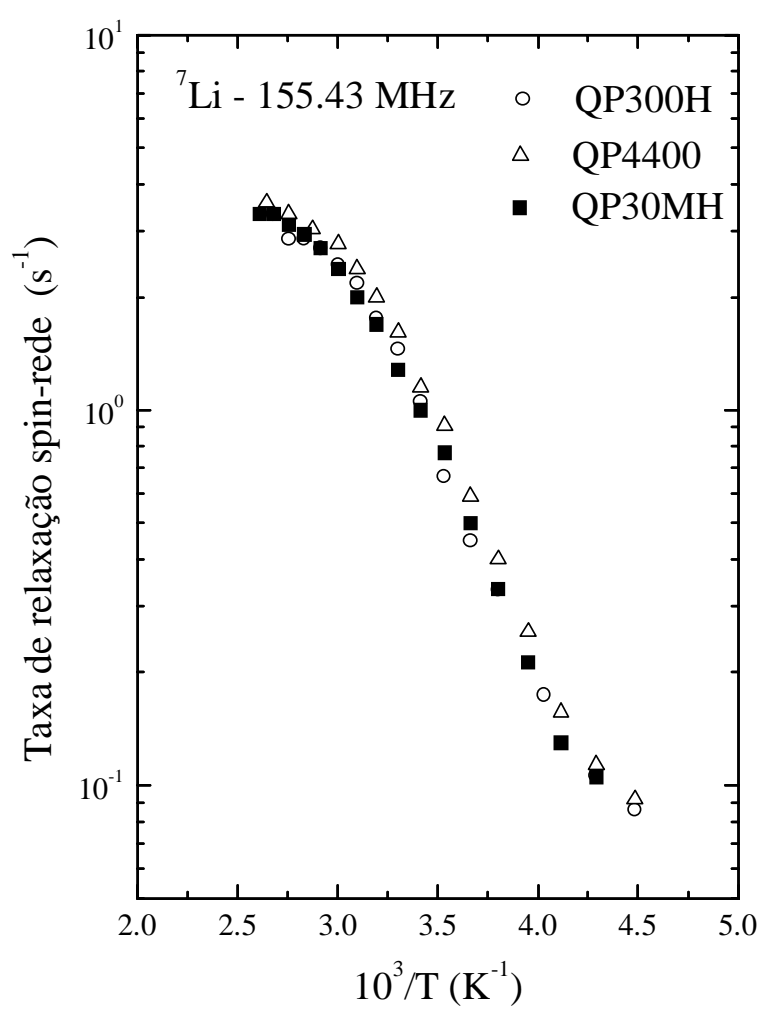

Figura 5. 5: Dependência com a temperatura de taxa de relaxação spin-rede de ${ }^{7} \mathrm{Li}$ para os filmes de HEC QP300H, QP4400, QP30MH entrecruzados com DPOE e dopados com $\mathrm{LiClO}_{4}$

Com o objetivo de comparar a mobilidade das cadeias poliméricas e dos cátions $\mathrm{Li}^{+}$no eletrólito sólido polimérico $\mathrm{HEC} / \mathrm{DPOE} / \mathrm{LiClO}_{4}$ com outros reportados na literatura, calculou-se o tempo de correlação, $\tau_{c}$, para os movimentos de lítio. Os valores de $\tau_{c}$ em função do inverso de temperatura para os eletrólitos sólidos estudados neste capítulo são apresentados na figura 5.6. As curvas das três amostras são quase coincidentes, no intervalo de temperatura estudado, os tempos de correlação de próton e lítio variam de duas ordens de grandeza.

Estes resultados podem ser comparados com os de outros eletrólitos sólidos

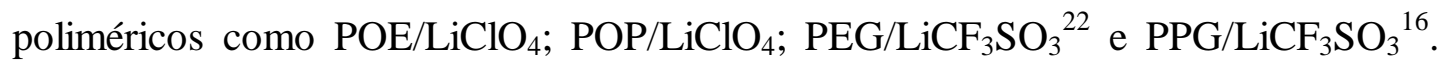
Observa-se na figura 5.6 que a dependência dos tempos de correlação de ${ }^{7} \mathrm{Li}$ e ${ }^{1} \mathrm{H}$ para os eletrólitos sintetizados neste trabalho são próximos aos resultados 
encontrados para o sistema $\mathrm{PEO} / \mathrm{LiClO}_{4}[\mathrm{O} / \mathrm{Li}]=8$ indicando que a mobilidade relativa do cátion $\mathrm{Li}^{+}$para os dois tipos de sistemas é da mesma ordem. $\mathrm{O}$ sistema $\mathrm{PEG}_{11} \mathrm{LiCF}_{3} \mathrm{SO}_{3}$ tem maior mobilidade de próton e lítio em temperaturas superiores à ambiente. Nos sistemas com POP e PPG são encontrados tempos de correlação superiores aos sistemas com poli(óxido de etileno) indicando que os sistemas com estrutura mais ramificada possuem menor mobilidade; fato este devido ao menor número de graus de liberdade dos segmentos das cadeias de poli(óxido de propileno).

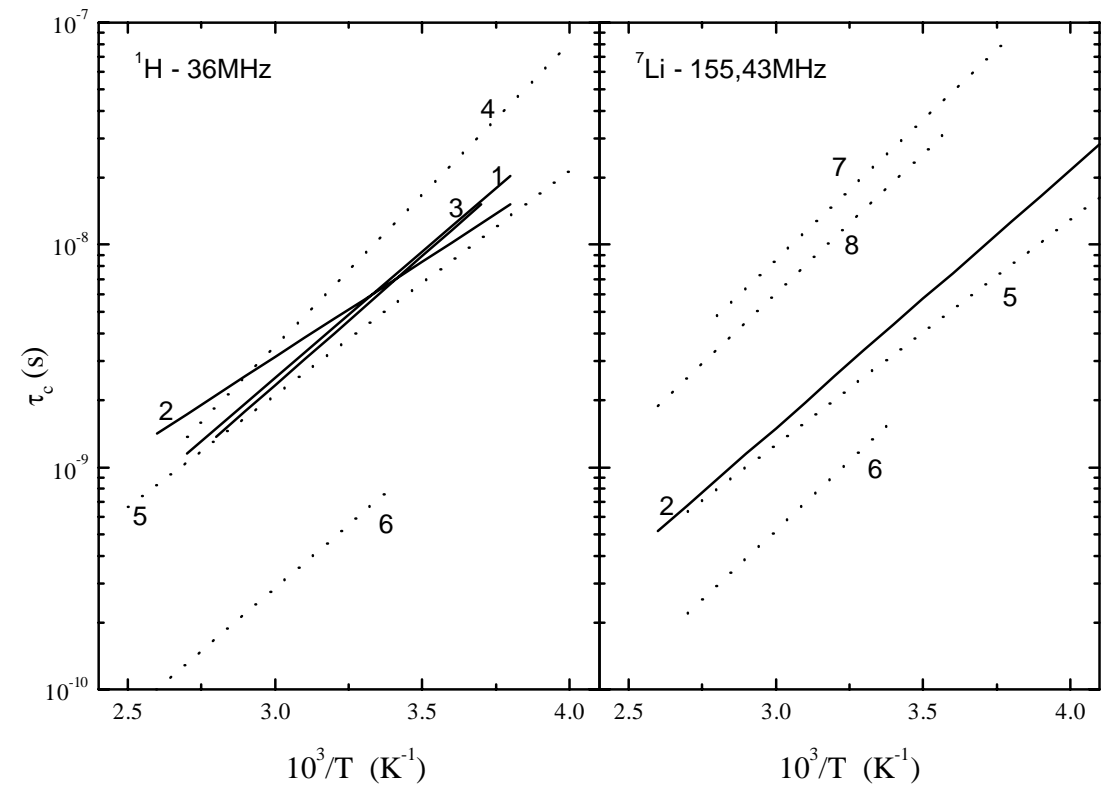

Figura 5. 6: Dependência com a temperatura dos tempos de correlação de ${ }^{7} \mathrm{Li}$ e ${ }^{1} \mathrm{H}$ calculados a partir dos parâmetros de mobilidade obtidos em experimentos de RMN, assumindo comportamento Arrhenius para $\tau_{c}$. As linhas cheias correspondem aos eletrólitos sólidos poliméricos com matriz de hidroxietil celulose entrecruzada com poli(óxido de etileno): (1) QP4400; (2) QP30MH; (3) QP300H. As curvas tracejadas correspondem aos dados da literatura: (4) $\mathrm{PPO}_{6} \mathrm{LiBF}_{4}{ }^{23}$; (5) $\mathrm{PEO}_{8} \mathrm{LiClO}_{4}$; (6) $\mathrm{PEG}_{10} \mathrm{LiCF}_{3} \mathrm{SO}_{3}{ }^{24}$; (7) $\mathrm{PPG}_{8} \mathrm{LiCF}_{3} \mathrm{SO}_{3}{ }^{14}$; (8) $\mathrm{PPO}_{8} \mathrm{LiClO}_{4}{ }^{23}$ 
5.4 - Conclusões do capítulo

Os experimentos de RMN dos filmes de hidroxietil celulose graftizada com poliéter mostram aspectos qualitativos associados a eletrólitos sólidos poliméricos; ou seja, observa-se a diminuição de largura de linha. Este estreitamento é associado aos movimentos dos segmentos poliméricos e tem seu início em temperatura igual à temperatura de transição vítrea do material. Foi observado também a existência de um único máximo para taxa de relaxação spin-rede em função de temperatura. Outra observação importante é a presença de uma única banda de absorção nos espectros de ${ }^{1} \mathrm{H}$ e ${ }^{7} \mathrm{Li}$ e decaimento exponencial da relaxação indicando que as amostras encontram-se no estado amorfo (como já observado nos experimentos de difração de raios-X; capítulo 2).

Quando comparamos os resultados obtidos para eletrólitos sólidos poliméricos com diferentes HEC na matriz percebe-se que a mobilidade do cátion é pouco ou quase nada afetada por esta diferenciação na estrutura. A dependência dos tempos de correlação de lítio e próton para estes sistemas é da mesma magnitude que para $\mathrm{POE}_{8} \mathrm{LiClO}_{4}$ indicando que os cátions e as cadeias poliméricas têm a mesma mobilidade que neste eletrólito sólido polimérico tradicional. 
5.5 - Referências bibliográficas

${ }^{1}$ LeNEST, J. F.; GANDINI, A.; CHERADAME, H. Crosslinked polyethers as media for ionic conduction. British Polymer Journal, v. 20, p. 253-268, 1988.

${ }^{2}$ WARD, I. M.; BODEN, N.; CRUICKSHANK, J.; LENG, S. A. NMR studies of ionic mobility and molecular mobility in polymer electrolytes. Electrochimica Acta, v. 40, n. 13-14, p. 2071-2076, 1995.

${ }^{3}$ TAMBELLI, Caio Eduardo Campos. Estudo por ressonância magnética nuclear do condutor protônico $\mathbf{H P b}_{\mathbf{2}} \mathbf{N b}_{\mathbf{3}} \mathbf{O}_{\mathbf{1 0}} \cdot \mathbf{n} \mathbf{H}_{\mathbf{2}} \mathbf{O}$. São Carlos, 1999. 110p.

Dissertação (Mestrado) - Instituto de Física de São Carlos, Universidade de São Paulo.

${ }^{4}$ GIL, V. S. M.; GERALDES, C. F. G. C. Ressonância magnética nuclear: fundamentos, métodos e aplicações. Lisboa, Fundação Calouste Gulbenkian, 1987. 1012p.

${ }^{5}$ NG. S. T. C.; FORSYTH, M.; MacFARLANE, D. R.; GARCIA, M.; SMITH, M. E.; STRANGE, J. H. Composition effects in polyether-urethane based solid polymer electrolytes. Polymer, v. 39, n. 25, p. 6261-6268, 1998.

${ }^{6}$ TAMBELLI, Cassio Campos. Ressonância magnética nuclear $\left({ }^{1} \mathbf{H} \mathbf{e}^{7} \mathbf{L i}\right) \mathbf{d o s}$ compósitos formados por POE: $\mathrm{LiClO}_{4}$ e aluminas. São Carlos, 2000. 167p. Dissertação (Mestrado) - Instituto de Física de São Carlos, Universidade de São Paulo.

${ }^{7}$ REGIANI, A. M.; TAMBELli, C. E.; PAWLICKA, A.; CURVELO, A. A. S.; GANDINI, A.; LeNEST, J. F.; DONOSO, J. P. DSC and solid state NMR characterization of hydroxyethylcellulose/polyether films. Polymer International, v. 49, 2000. /no prelo/.

${ }^{8}$ VINCENT, C. A. Polymer electrolytes. Progress in Solid State Chemistry, v. 17, p. 145-261, 1987.

${ }^{9}$ NG. S. T. C.; FORSYTH, M.; GARCIA, M.; MacFARLANE, D. R.; SMITH, M. E. A nuclear magnetic ressonance study of ${ }^{7} \mathrm{Li}$ dynamics in polyetherutrethane based solid polymer electrolytes. Electrochimica Acta, v. 43, n. 10-11, p. 1551-1556, 1998.

${ }^{10}$ JOHANSSON, A.; TEGENFELDT, J. Segmental mobility in complexes of $\mathrm{Pb}\left(\mathrm{CF}_{3} \mathrm{SO}_{3}\right)_{2}$ and poly(ethyelne oxide) studied by NMR spectroscopy. Journal of Chemical Physics, v. 104, n. 13, p. 5317-5325, 1996

${ }^{11}$ GORECKI, W.; DONOSO, J. P.; ARMAND, M. Nuclear magnetic resonance spectrocopy in solid polymer electrolytes. Brazilian Journal of Physics, v. 22, n. 3, p. 194-204, 1992 
${ }^{12}$ DONOSO, J. P.; BONAGAMBA, T.; PANEPUCCI, H.; OLIVEIRA, L.N.; GORECKI, W.; BERTHIER, C.; ARMAND, M. Nuclear magnetic relaxation study of poly(ethylene oxide) lithium salt based electrolytes. Journal of Chemical Physics, v. 98, n. 12, p. 10026-10036, 1993.

${ }^{13}$ GORECKI, W.; ANDREANI, R.; BERTHIER, C.; ARMAND, M.; MALI, M.; ROOS, J.; BRINCKMANN, D. NMR, DSC and conductivity study of a poly(ethylene oxide) complex electrolyte $-\mathrm{PEO}\left(\mathrm{LiClO}_{4}\right)_{\mathrm{x}}$. Solid State Ionics, v. 18 , n. 9 , p. 295-299, 1986.

${ }^{14}$ FRANCO, R. W. A.; DONOSO, J. P.; MAGON, C. J.; RODELLA, C. B.; FLORENTINO, A. O.; SAEKI, M. J.; PERNAULT, J. M.; OLIVEIRA, A. L. Eletric and magnetic properties of polymer electrolyte/carbon black composites Solid State Ionics, v. 115, p. 149-160, 1998.

${ }^{15}$ CHUNG, S. H.; JEFREY, K. R.; STEVENS, J. R. A Li-7 nuclear magnetic resonance study of $\mathrm{LiCF}_{3} \mathrm{SO}_{3}$ complexed in poly(propylene glycol). Journal of Chemical Physics, v. 94, n. 3, p. 1803-1811, 1991.

${ }^{16}$ STALLWORTH, P. E.; GREENBAUM, S.G.; CROCE, F.; SLANE, S.; SALAMON, M. Li-7 NMR and ionic conductivity studies of gel electrolytes based on poly(methyl cetacrulate). Electrochimica Acta, v. 40, n. 13-14, p. 2137-2141, 1995.

${ }^{17}$ PANERO, S.; SCROSATI, B. GREEBAUM, S. G. Ionic conductivity and Li-7 NMR study of poly(ethylene glycol) complexed with lithium salts. Electrochimica Acta, v. 37, n. 9, p. 1533-1538, 1992.

${ }^{18}$ BROWN, S. D.; GREEBAUM, S. G.; McLIN, M. G.; WINTERSGILL, M.C.; FONTANELLA, J. J. Complexed impedance, DSC, and Li-\& NMR studies of poly(propylene oxide) complexed with $\mathrm{LiN}\left(\mathrm{SO}_{2} \mathrm{CF}_{3}\right)_{2}$ and with $\mathrm{LiAsI}_{6}$. Solid State Ionics, v. 67, n. 3-4, p. 257-262, 1994.

${ }^{19}$ ABRAGAM, A. Principles of nuclear magnetism. Oxford, Oxford University Press, 1961. 599p.

${ }^{20}$ LAUENSTEIN, A.; TEGENFELDT, J. Ion coordination and chain mobility in $\mathrm{La}\left(\mathrm{CF}_{3} \mathrm{SO}_{3}\right)_{3} \mathrm{PEO}_{\mathrm{n}}$ studied with NMR spectroscopy. Journal of Physical Chemistry B, v. 101, n. 17, p. 3311-3317, 1997

${ }^{21}$ WONG, S.; VAIA, R.A.; GIANNELIS, E. P.; ZAX, D. B. Dynamics in poly(ethylene oxide)-based nanocomposites polymer electrolyte probed by solid state NMR. Solid State Ionics, v. 86, i. 8, p. 547-557, 1996.

22 JOHANSSON, A.; GOGOLL, A.; TEGENFELDT, J. Diffusion and ionic conductivity in $\mathrm{Li}\left(\mathrm{CF}_{3} \mathrm{SO}_{3}\right) \mathrm{PEG}_{10}$ and $\mathrm{LiN}\left(\mathrm{CF}_{3} \mathrm{SO}_{2}\right)_{2} \mathrm{PEG}_{10}$. Polymer, v. 37, n. 8, p. 1387-1393, 1996. 
${ }^{23}$ DONOSO, J. P.; BONAGAMBA, T. J.; FRARE, P. L.; MELlO, N. C.; MAGON, C. J.; PANEPUCCI, H. Nuclear magnetic relaxation study of poly(propylene oxide) complexed with lithium slat. Electrochimica Acta, v. 40, n. 13-14, p. 2361-2363, 1995.

${ }^{24}$ FORSYTH, M.; GARCIA, M.; MacFARLANE, D. R.; MEAKIN, P.; NG, S.; SMITH, S. E. NMR determination of ionic structure on plasticized polyetherurethane polymer electrolytes. Solid State Ionics, v. 85, n. 1-4, p. 209-218, 1996 


\section{CAPÍTULO 6 - CONCLUS Õ ES E PERS PECTI VAS}

Neste trabalho foram apresentadas a síntese e a caracterização de um novo tipo de eletrólito sólido polimérico. Estes materiais consistiram de filmes de hidroxietil celulose ou hidroxipropil celulose entrecruzadas com diisocianatos de poli(óxido de etileno) e poli(óxido de propileno) ou enxertadas com monoisocianato de poli(óxido de propileno). Estes isocianatos foram sintetizados a partir das respectivas aminas comerciais. A reação de enxertia de poliéter na cadeia de polissacarídeo foi confirmada pela presença de banda de ligação uretana a $1740 \mathrm{~cm}^{1}$ no espectro de infravermelho dos filmes, que foram também caracterizados através de técnicas de difração de raios-X, espectroscopia de ressonância magnética nuclear e análises térmicas. Esta última permitiu a determinação da temperatura de transição vítrea (Tg) dos materiais, sendo observado que este parâmetro é função do tipo de poliéter inserido na matriz de polissacarídeo e não dos parâmetros estruturais ou do tipo de derivado de celulose utilizado. A introdução de sal $\left(\mathrm{LiClO}_{4}\right)$ nos sistemas levou a um aumento da $\mathrm{Tg}$, resultante do entrecruzamento iônico promovido pela solvatação dos cátions $\mathrm{Li}^{+}$pelos oxigênios presentes na estrutura dos filmes. Este tipo de entrecruzamento também foi sugerido através da observação das curvas de análise termodinâmico mecânicas. 
Através dos resultados de condutividade avaliou-se a possível aplicação destes sistemas como eletrólitos sólidos poliméricos. O ajuste das curvas de logaritmo de condutividade em função do inverso da temperatura segundo a equação VTF mostra que a condução nestes sistemas é promovida com auxílio dos movimentos dos segmentos poliméricos. A condutividade não é, aparentemente, influenciada pelos parâmetros estruturais do polissacarídeo. Este fenômeno parece encontrar-se mais relacionado ao tipo de poliéter utilizado. O melhor resultado de condutividade para os sistemas aqui estudados foi $2,82 \times 10^{-5} \mathrm{Scm}^{-1}$.

Foram também estudados sistemas de hidroxietil celulose enxertada com hexametileno diisocianato (HDI) ou enxertada com fenilisocianato. A $\mathrm{Tg}$ dos materiais independe do isocianato e dos parâmetros estruturais do polissacarídeo. Foi observada condução iônica apenas para os filmes contendo fenil isocianato. Entretanto, este resultado não é confiável porque a distribuição do sal na matriz polimérica não é homogênea. Mas podemos inferir que, as cadeias de hidroxietil celulose podem solvatar os cátions $\mathrm{Li}^{+}$em alguma extensão obtendo-se como resposta a condução. Mas quando as cadeias de polissacarídeo são entrecruzadas utilizando-se HDI, os segmentos dos polissacarídeos ficam mais rígidos e portanto não observa-se resultado de condutividade.

Foi possível estudar a mobilidade da cadeia polimérica através de experimentos de ressonância magnética nuclear. A comparação dos resultados obtidos com os dados existentes na literatura para outros tipos de eletrólitos sólidos poliméricos permite inferir que a mobilidade do cátion é pouco ou quase nada afetada pela presença de polissacarídeo na estrutura do eletrólito sólido. As cadeias poliméricas dos sistemas aqui estudados têm a mesma mobilidade que no eletrólito sólido polimérico $\mathrm{POE}_{8} \mathrm{LiClO}_{4}$. 
Conclui-se que os materiais baseados em filmes de polissacarídeos enxertados com poliéteres podem ser aplicados como eletrólitos sólidos poliméricos. Entretanto, alguns estudos devem ainda serem aprofundados, como a reação da conversão de aminas em isocianatos; etapa fundamental na síntese dos filmes. O estudo de novos procedimentos de síntese pode ser realizado, a fim de garantir a obtenção de filmes tridimensionalmente perfeitos e reprodutíveis.

Com o intuito de eliminar esta etapa é interessante a oxidação prévia dos grupos hidroxila presentes na estrutura dos polissacarídeos a grupos aldeído ou cetona $^{1}$. Estes reagem diretamente com as aminas de poliéter.

Visando o aproveitamento da biomassa vegetal, fonte renovável de recursos, pode também ser realizada a síntese de um outro tipo de eletrólito a partir do amido. Alguns estudos estão em andamento ${ }^{2}$, onde é utilizado o mesmo procedimento de síntese aqui descrito, ou utilizando-se filmes de amido e plasticizante. A reação de oxidação do amido com formação de dialdeído de amido também pode ser utilizada, pois o produto de oxidação pode ser diretamente enxertado com a Jeffamine desejada.

\footnotetext{
${ }^{1}$ MACHADO, G. O. Projeto FAPESP n ${ }^{\circ}$ 00/00386-6 (Doutorado)

${ }^{2}$ DRAGUNSKI, D.C. Projeto FAPESP n ${ }^{\circ}$ 99/04334-1 (Doutorado)
} 